\title{
EFEITO DO FLÚOR SOBRE O ALUMÍNIO E O FÓSFORO EM UM PODZÓLICO VERMELHO-AMARELO E SUA ACUMÚLAÇÃO EM ALGUMAS ESPÉCIES VEGETAIS
}

\author{
FERNANDO CÉZAR SARAIVA DO AMARAL \\ Engenheiro Agrônomo
}

Orientador: Prof. Dr. JOSÉ CARLOS CHITOLINA

Tese apresentada à Escola Superior de Agricultura "Luiz de Queiroz", Universidade de São Paulo, para obtenção do título de Doutor em Agronomia, Área de Concentração: Solos e Nutrição de Plantas.

PIR A C I C A B A

Estado de São Paulo - Brasil

Novembro - 1997 
Dados Internacionais de Catalogação na Publicação (CIP) DIVISĀo DE BIBLIOTECA E DOCUMENTAÇĀO - Campus "Luiz de Queiroz"/USP

Amaral, Fernando Cézar Saraiva do

Efeito do flúor sobre o alumínio e o fósforo em um podzólico vermelho-amarelo e sua acumulaçăo em algumas espécies vegetais / Fernando Cézar Saraiva do Amaral. - Piracicaba, 1998.

$118 \mathrm{p}$.

Tese (doutorado) - - Escola Superior de Agricultura Luiz de Queiroz, 1998.

Bibliografia.

1. Aluminio 2. Análise quimica 3. Fluor 4. Fósforo 5. Quimica de solo 6. Planta cultivada 7. Podzólico vermelho-amarelo 8 . Solo 1 . Título

CDD 631.41 


\section{EFEITO DO FLÚOR SOBRE O ALUMÍNIO E O FÓSFORO EM}

UM PODZÓLICO VERMELHO-AMARELO E SUA

ACUMULAÇÃO EM ALGUMAS ESPÉCIES VEGETAIS

FERNANDO CÉZAR SARAIVA DO AMARAL

Aprovada em: 18 de dezembro de 1997

Comissão julgadora:

Prof. Dr. JOSÉ CARLOS CHITOLINA

ESALQ/USP

Prof. Dr. LUIS IGNÁCIO PROCHNOW

ESALQ/USP

Dr. OTÁVIO ANTONIO DE CAMARGO

IAC

Dr. EDMILSON JOSÉ AMBROZANO

IAC

Prof. Dr. JOÃO CARLOS DE ANDRADE

IQ/UNICAMP

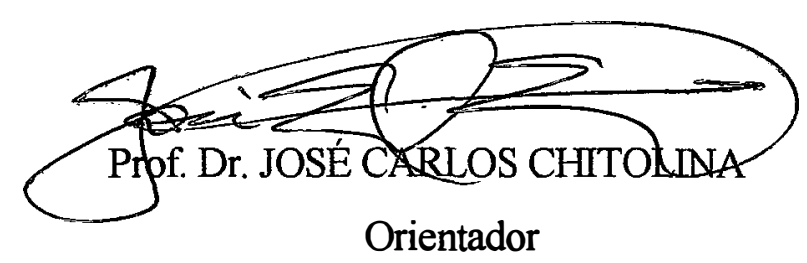




\section{AGRADECIMENTOS}

A Empresa Brasileira de Pesquisa Agropecuária - EMBRAPA, pela liberação que possibilitou a realização deste trabalho.

Ao Instituto Agronômico de Campinas - IAC, pela possibilidade de realização do experimento de campo.

Ao Conselho Nacional de Desenvolvimento Científico e Tecnológico - CNPq, pela concessão da bolsa de estudo para a realização do curso.

A Fundação de Amparo à Pesquisa do Estado de São Paulo - FAPESP, pelo custeio dos experimentos.

Ao Prof. Dr. José Carlos Chitolina, pela orientação e amizade.

A Gertrudes C. B. Fornazier e ao Carlos Rubini Júnior, pelo apoio nas análises químicas.

A Sílvia Cristina Vettorazzo, pelo auxílio no desenvolvimento deste trabalho.

A minha filha Luiza, pelo estímulo maior. 


\section{SUMÁRIO}

Página

RESUMO

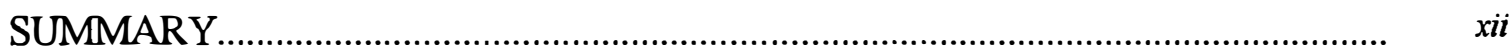

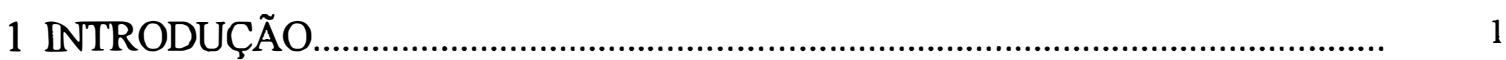

2 REVISÃO DE LITERATURA..................................................................................

2.1 Ocorrência do flúor..............................................................................................

2.2 Solubilidade do flúor ................................................................................... 5

2.3 Interação entre flúor e alumínio........................................................................ 7

2.4 Adsorção e dessorção do flúor.................................................................................. 11

2.5 Mobilidade do flúor no solo................................................................................... 15

2.6 O flúor como melhorador de solo........................................................................ 17

2.7 O flúor nos seres vivos........................................................................................

2.7.1 O flúor nas plantas.....................................................................................

2.7.2 O flúor nos animais...............................................................................

3 MATERIAL E MÉTODOS .......................................................................................

3.1 Experimento de campo..............................................................................

3.1.1 Caracterização do solo.......................................................................... 32

3.1.2 Tratamentos aplicados no solo................................................................

3.1.3 Condução do experimento e obtenção de amostras de planta e solo......... 35

3.1.4 Análise química de solo............................................................................ 36

3.1.5 Análise química de plantas..................................................................... 36

3.2 Experimento em casa de vegetação....................................................................... 37

3.2.1 Caracterização do solo........................................................................... 37

3.2.2 Tratamentos aplicados no solo.................................................................. 38

3.2.3 Condução do experimento e obtenção de amostras de planta, solo e solução percolada.

3.2.4 Análise química da solução percolada......................................................... 40

3.2.5 Análise química de plantas e solo........................................................... 40

3.3 Especiação iônica........................................................................................... 40 


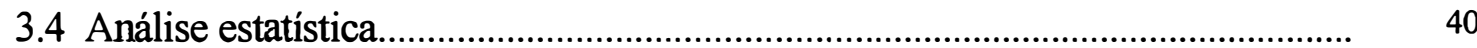

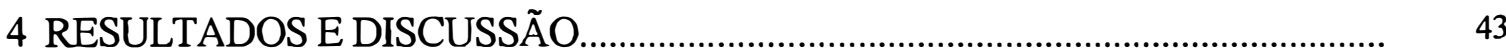

4.1 Efeito da aplicação de fluoreto de sódio nos atributos químicos do solo e na produção e nutrição de sorgo e crotalária.

4.1.1 Alterações químicas do solo

4.1.1.1 $\mathrm{pH}$ do solo................................................................................ 44

4.1.1.2 Matéria orgânica do solo............................................................. 47

4.1.1.3 Alumínio trocável.................................................................. 50

4.1.1.4 Cálcio, magnésio e potássio trocáveis.......................................... 52

4.1.1.5 Sódio trocável..................................................................... 53

4.1.1.6 Fósforo lábil..............................................................................

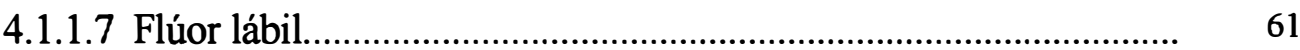

4.1.1.8 Outros atributos químicos do solo.................................................

4.1.2 Produção de matéria seca e nutrição de sorgo e crotalária......................... 70

4.1.2.1 Sorgo.................................................................................................

4.1.2.2 Crotalária.......................................................................... 74

4.2 Efeito da aplicação de carbonato de cálcio e fluoreto de cálcio no solo e nas plantas, em casa de vegetação.

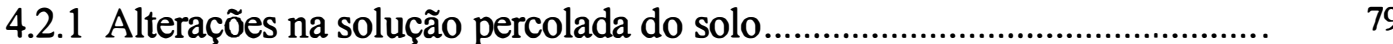

4.2.1.1 pH da solução.............................................................................

4.2.1.2 Alumínio em solução...................................................................... 80

4.2.1.3 Cálcio, potássio, magnésio e sódio em solução........................... 80

4.2.1.4 Nitrogênio em solução..................................................................... 84

4.2.1.5 Fósforo e flúor em solução........................................................... 85

4.2.1.6 Ferro em solução.............................................................................. 87

4.2.2 Especiação iônica e atividades das espécies químicas na solução percolada.

4.2.2.1 Especiação iônica na solução percolada ......................................... 88

4.2.2.2 Atividades das espécies iônicas na solução percolada................. 89 
Página

4.2.2.2.1 Tratamento com fluoreto de cálcio................................. 89

4.2.2.2.2 Tratamento com carbonato de cálcio............................. 97

4.2.2.2.3 Testemunha.............................................................. 98

4.2.3 Alterações químicas do solo.............................................................. 99

4.2.4 Produção de matéria seca e concentração de $\mathrm{F}$ em diferentes culturas.

101

5 CONCLUSÕES.

105

REFERÊNCIAS BIBLIOGRÁFICAS................................................................... 106 


\title{
EFEITO DO FLÚOR SOBRE O ALUMÍNIO E O FÓSFORO EM UM PODZÓLICO VERMELHO-AMARELO E SUA ACUMULAÇÃO EM ALGUMAS ESPÉCIES VEGETAIS
}

\author{
Autor: FERNANDO CÉZAR SARAIVA DO AMARAL \\ Orientador: Prof. Dr. JOSÉ CARLOS CHITOLINA
}

\section{RESUMO}

Este estudo, desenvolvido em condições de campo e casa de vegetação em Piracicaba (SP),objetivou avaliar o efeito da aplicação de doses de fluoreto $\left(\mathrm{NaF}_{\mathrm{a}} \mathrm{CaF}_{2}\right)$ num podzólico vermelho-amarelo ácido sobre parâmetros de fertilidade do solo, na solubilidade de F no solo e sua absorção em cinco culturas: crotalária (Crotalaria juncea L), feijão (Phaseolus vulgaris L.), milho (Zea mays L.), soja (Glycine max L.) e sorgo (Sorghum vulgare L.). Os resultados mostraram que aplicações de $\mathrm{NaF}$ (condições de campo) e $\mathrm{CaF}_{2}$ (condições de casa de vegetação) aumentaram significativamente o $\mathrm{pH}$ do solo e a concentração de $\mathrm{F}$ e diminuíram a concentração de Al no solo. Após seis meses da aplicação de $\mathrm{NaF}$, a tendência de aumento da concentração de $\mathrm{P}$ foi associada com o aumento do $\mathrm{pH}$ do solo. A solubilidade do $\mathrm{F}$ no solo quando ligado ao $\mathrm{Na}$ foi superior à do $\mathrm{Ca}$. $\mathrm{A}$ especiação iônica em diferentes soluções percoladas do solo mostrou que aproximadamente $99 \%$ do Al estava complexado com $\mathrm{F}$. A acumulação de $\mathrm{F}$ nas folhas da crotalária foi superior àquela do sorgo, mesmo sendo a concentração de $\mathrm{F}$ no solo maior na última cultura. A concentração máxima de $\mathrm{F}$ nas folhas não excedeu o nível crítico aceitável para animais (30-40 $\mathrm{mg} \mathrm{kg}^{-1}$ de $\mathrm{F}$ na matéria seca), mesmo para uma aplicação máxima de 3762 $\mathrm{kg} \mathrm{ha}^{-1}$ de F no solo. Nas folhas de crotalária, aumentando a concentração de F aumentou a concentração de $\mathrm{Al}$, mas nas folhas de sorgo, não houve relação significativa entre ambos elementos. As produções de sorgo e crotalária não foram significativamente diminuídas até a dose $2772 \mathrm{~kg} \mathrm{ha}^{-1}$ de $\mathrm{NaF}$. Nos tratamentos que receberam $\mathrm{CaF}_{2}\left(2185\right.$ e $\left.4370 \mathrm{~kg} \mathrm{ha}^{-1}\right)$, a produção de matéria seca de todas as culturas (feijão, soja, crotalária e milho) foi superior à da testemunha (solo não tratado). 


\title{
EFFECT OF FLUORINE ON ALUMINUM AND PHOSPHORUS IN
} AN ULTISOL AND ITS ACCUMULATION IN SEVERAL PLANTS

\author{
Author: FERNANDO CÉZAR SARAIVA DO AMARAL \\ Adviser: Prof. Dr. JOSÉ CARLOS CHITOLINA
}

\section{SUMMARY}

This study were carried out under field and greenhouse conditions to evaluate the effect of rate application of fluorine $\left(\mathrm{NaF}\right.$ and $\left.\mathrm{CaF}_{2}\right)$ in an ultisol on soil fertility parameters, F solubility in soil and F absorption to five crops: sunn-hemp (Crotalaria juncea $\mathrm{L}$ ), phaseolus bean (Phaseolus vulgaris L.), maize (Zea mays L.), soybean (Glycine max L.) and sorghum (Sorghum vulgare L.) in Piracicaba, State of São Paulo, Brazil. Results showed that $\mathrm{NaF}$ (field conditions) and $\mathrm{CaF}_{2}$ (greenhouse conditions) applications increased significantly soil $\mathrm{pH}$ and $\mathrm{F}$ concentration and reduced $\mathrm{Al}$ concentration. At six months of $\mathrm{NaF}$ application, the tendency to increase $\mathrm{P}$ concentration was associated with soil $\mathrm{pH}$ increase. Fluorine solubility in soil when bond to $\mathrm{Na}$ was higher than $\mathrm{Ca}$. The ionic speciation in several soil percolated solutions showed that approximately $99 \%$ of $\mathrm{Al}$ were complexed with $F$. The concentration of $F$ in leaves of sunn-hemp was higher than the sorghum, although the soil $\mathrm{F}$ concentration was higher for the latter crop. The maximum $\mathrm{F}$ concentration in leaves did not exceed the tolerable level for animals (30-40 $\left.\mathrm{mg} \mathrm{kg}^{-1} \mathrm{~F}\right)$, even when an application rate of $\mathrm{NaF}$ in soil was $3,762 \mathrm{~kg} \mathrm{ha}^{-1}$. In the sunn-hemp leaves, increasing $\mathrm{F}$ concentration increased $\mathrm{Al}$ concentration, but in the sorghum leaves, it was not found significant relation between both elements. Sorghum and sunn-hemp yields was not significantly reduced until a rate $2,772 \mathrm{~kg} \mathrm{NaF} \mathrm{ha}^{-1}$ soil. In the treatments that received $\mathrm{CaF}_{2}\left(2,185\right.$ and $4,370 \mathrm{~kg} \mathrm{ha}^{-1}$ soil), the dry matter yield of all crops (phaseolus bean, soybean, sunn-hemp and maize) was higher than in the control (untreated soil). 


\section{INTRODUÇÃO}

O alumínio é o elemento metálico mais abundante na crosta terrestre e sua fase sólida, bem como suas reações em solução, são de enorme interesse para as diversas áreas do conhecimento. No caso específico da Ciência do Solo, seu estudo ganha importância por ser o elemento de maior fitotoxicidade em condições naturais de solos tropicais ácidos. $\mathrm{O}$ excesso de alumínio, associado ou não à baixa disponibilidade de fósforo, constituem-se em dois dos principais impedimentos para o aumento da produtividade agrícola nestes solos.

O flúor é o elemento que apresenta maior reatividade entre todos os nãometálicos, reagindo com inúmeras substâncias orgânicas e inorgânicas e formando com o alumínio compostos de alta estabilidade. Sua ocorrência natural em solos, principalmente nos ácidos e/ou intemperizados, é muito baixa, assim como é pequena a participação deste elemento, como impureza, na maior parte dos fertilizantes fosfatados e condicionadores do solo normalmente utilizados. Maiores concentrações encontram-se em algumas formações minerais e em diversos rejeitos industriais, manifestando-se muitas vezes como um sério problema ambiental.

Diversos trabalhos sobre a determinação do fósforo no solo, principalmente em solos ácidos, têm demonstrado que extratores contendo flúor, que conseguem complexar o alumínio ligado ao fósforo, fornecem estimativas da disponibilidade do fósforo fortemente correlacionadas com a concentração absorvida pelas plantas. A explicação dessa troca de ligantes, está no fato do flúor formar compostos muito estáveis com o alumínio, complexando-o e diminuindo, conseqüentemente, o efeito de sua toxicidade para as plantas.

O problema da contaminação do solo, plantas e animais com metais pesados, bem como por elementos não-metálicos, como o flúor, pelo lançamento de poluentes 
industriais na atmosfera, rios ou diretamente nos solos, provoca grande preocupação. A acumulação de flúor nas camadas superficiais do solo tem merecido destaque, principalmente nas regiões de clima temperado, ressaltando-se os estudos sobre as mudanças das propriedades químicas dos materiais orgânicos do solo, a atividade de macro e microrganismos e a ciclagem de nutrientes. Por outro lado, nos solos tropicais, a dinâmica do flúor e seus possíveis efeitos benéficos como melhorador das condições edafológicas, tanto em superfície quanto em subsuperfície, além da acumulação nas plantas cultivadas não vêm recebendo a atenção que a potencialidade do tema desperta.

Este trabalho objetiva caracterizar o efeito do flúor sobre o alumínio fitotóxico em um solo ácido, a ocorrência de bioacumulação por algumas espécies vegetais cultivadas, assim como sua influência na disponibilidade de fósforo do solo, principalmente àquele ligado ao alumínio. 


\section{REVISÃO DE LITERATURA}

\subsection{Ocorrência do flúor}

Embora constituindo somente $0,065 \%$ da crosta terrestre, o flúor $(\mathrm{F})$ pode ser considerado um elemento ubíquo, distribuindo-se desde vulcões e suas emanações, passando por diferentes rochas, oceanos, lagos, rios e outras formas de água natural. Além disso, o F está presente nos ossos, dentes e sangue dos mamíferos e em todas as partes das plantas.

Segundo Adriano (1986), os valores médios de $\mathrm{F}$ total $\left(\mathrm{mg} \mathrm{kg}^{-1}\right)$ encontrados nas rochas são: basalto, 360; andesito, 210; riolito, 480; fonolito, 930; gabro e diabásio, 420; granito e granodiorito, 810; rochas básicas, 1000; calcários, 220; dolomita, 260; arenito, 180; sedimentos oceânicos, 730; minerais silicatados, 650 e solos variando de 200 a 300. Os principais minerais contendo $\mathrm{F}$ são a fluorita $\left(\mathrm{CaF}_{2}\right)$, fluorapatita $\left[\mathrm{Ca}_{5}\left(\mathrm{PO}_{4}\right)_{3} \mathrm{~F}\right]$ e criolita $\left(\mathrm{Na}_{3} \mathrm{AlF}_{6}\right)$. O F está sempre presente em plantas, solos e

fertilizantes fosfatados, com concentrações respectivas da ordem de $3 \times 10^{\circ}, 3 \times 10^{2}$ e $3 \times 10^{4} \mathrm{mg} \mathrm{kg}^{-1}$ (Larsen \& Widdowson, 1971).

As principais atividades industriais que utilizam ou produzem como resíduo o F são fertilizantes, metalurgia, vidro, esmalte, porcelana, higiene, limpeza, teflon, processamento de urânio, gás refrigerante, aerossol, inseticida esterilizante, fluoretação de água (combate da cárie dental) e ainda, em menor quantidade, na combustão do carvão, bem como na catálise de algumas reações orgânicas como a produção de dodecilbenzeno (Haag, 1985). As taxas de emissões gasosas e sólidas contendo F são semelhantes, sendo a metalurgia, entre os ramos industriais, a que produz a maior quantidade de emissões. Os sólidos principais são $\mathrm{NaF}, \mathrm{AlF}_{3}$ e $\mathrm{CaF}_{2}$, enquanto os gasosos são $\mathrm{HF}, \mathrm{CF}_{4}$ e $\mathrm{SiF}_{4}$. O HF é o mais abundante dentre todas as emissões (Ilkun \& Motruk, 1976). 
As reservas brasileiras de fluorita (indicada + inferida) são de $7.337 .000 \mathrm{t}$ com uma concentração média ponderada de $50,2 \% \mathrm{de}^{-\mathrm{CaF}_{2}}$, estando localizadas em ordem decrescente nos Estados: Paraná, Santa Catarina, Rio de Janeiro e Bahia. A exploração corresponde a aproximadamente 3,3\% da reserva, na seguinte ordem: Santa Catarina, Paraná e Rio de Janeiro. A reserva brasileira corresponde a $11,3 \%$ da reserva mundial sendo a participação na produção de apenas 2,0\%. Comparativamente, as reservas de calcário (indicada + inferida) são de $39.622 .597 .000 \mathrm{t}$, estando concentradas, decrescentemente, nos estados do Mato Grosso do Sul, Minas Gerais e Paraná. A produção corresponde a $0,1 \%$ da reserva, sendo os maiores produtores Minas Gerais, São Paulo e Paraná. A produção de fertilizantes no Brasil, expressa em toneladas, está ao redor de 1.710 .430 de nitrogenados, 4.601 .688 de fosfatados e 373.553 de potássicos. A participação no valor da produção mineral bruta é de 3,68 \% para o calcário, 0,18 \% para a fluorita e 2,20\% para os fosfatos naturais (Anuário Estatístico do Brasil, 1997). Portanto, comparativamente, o $\mathrm{F}$ da fluorita tem uma participação quase marginal, inferior ao $\mathrm{F}$ contido na fluorapatita.

Segundo Noemmik (1953), as concentrações de F variam amplamente no mesmo pedon, mas aumentam, com freqüência, em profundidade (sendo maior próximo do regolito). A concentração de $\mathrm{F}$ natural cresce em profundidade no solo e somente $5 \mathrm{a}$ $10 \%$ do $\mathrm{F}$ total encontra-se na solução do solo. Sob condições naturais, esta concentração raramente ultrapassa $1 \mathrm{mg} \mathrm{L}^{-1}$, no entanto, em solos de regiões altamente poluídas, pode atingir $10 \mathrm{mg} \mathrm{L}^{-1}$.

No entanto, Gilpin \& Johnson (1980), trabalhando com diversos solos da Pennsylvania (EUA), encontraram valores médios, em $\mathrm{mg} \mathrm{kg}^{-1}$, de $377,0,4$ e 21,7, respectivamente para $\mathrm{F}$ total, solúvel e fracamente adsorvido (resina), considerado lábil. Esses resultados discordam dos resultados obtidos por Noemmik (1953), sendo essa discrepância devido à diferenças nas metodologias de determinação empregada entre esses autores.

Para solos do Canadá, Schuppli (1985) encontrou concentrações de F total variando entre 90 e $1000 \mathrm{mg} \mathrm{kg}^{-1}$, sendo a média no horizonte superficial de $146 \mathrm{mg} \mathrm{kg}^{-1}$. 
Grewal \& Dahiya (1992) estudaram a variação espacial do concentração de F solúvel em água em diferentes zonas agroclimáticas do Estado de Haryana, Índia. Esses autores encontraram os seguintes valores de $\mathrm{F}$, em $\mathrm{mg} \mathrm{kg}^{-1}$ : na região quente e árida: 4,42; na região quente e seca: 4,60; na região quente e semi-seca: 4,23; na região quente e sub-úmida: 2,47 e na região quente e úmida: 2,12; sendo o valor médio de 4,19 para todo o Estado. Esta distribuição das concentrações de $\mathrm{F}$ foi relacionada, principalmente, com o $\mathrm{pH}$ do solo, ou seja, inversamente relacionada com o fator de intemperização.

A disponibilidade de $\mathrm{F}$ não se relaciona obrigatoriamente com seu conteúdo total no solo. Há diversos fatores que controlam sua disponibilidade para as plantas, entre estes: $\mathrm{pH}$, tipo de solo e quantidade de argila, concentrações de $\mathrm{Ca}$ e $\mathrm{P}$ no solo (Brewer, 1965; Mengel \& Kirkby, 1982). Em solos ácidos, mesmo quando os níveis de $\mathrm{F}$ solúveis são elevados, este não é prontamente absorvível pelas raizes das plantas.

A entrada de F no solo, seja como impureza dos principais adubos fosfatados ou do fosfogesso (média de 0,5 a $1,5 \%$ de F), seja pelo uso direto da fluorapatita como fosfato natural ( 3,0 a 4,0 \%), corrobora a abrangência deste elemento em todo o sistema agrícola. Além desta utilização involuntária, segundo Luther et al. (1995), grandes quantidades de fosfogesso, oriundas da produção de adubos fosfatados, estão sendo acumuladas, já que os principais países produtores são temerosos de uma possivel contaminação do lençol freático pelo $\mathrm{F}$, se este produto for utilizado na agricultura.

\subsection{Solubilidade do flúor}

Elrashidi \& Lindsay (1985) desenvolveram modelos de predição da solubilidade de minerais fluoretados e compararam com medições da solubilidade do F realizadas em 109 solos dos Estados do Colorado, Novo México e Tennessee (EUA). Os resultados experimentais indicaram que $\mathrm{o} \mathrm{AlF}_{3}$ pode ser a fase sólida controladora da solubilidade do $\mathrm{F}$ em solos fortemente ácidos $(\mathrm{pH}<5,0), \mathrm{CaF}_{2}$ (fluorita) em solos levemente ácidos $(5,0<\mathrm{pH}<6,6)$ e $\mathrm{KMg}_{3} \mathrm{AlSi}_{3} \mathrm{O}_{10} \mathrm{~F}_{2}$ (fluorflogopita) em solos neutros e alcalinos ( $\mathrm{pH}>6,6)$. Embora a fluorapatita, sozinha ou combinada com hidroxiapatita, teoricamente, possa também diminuir a solubilidade do $\mathrm{F}$, sua participação é inferior 
aquelas três espécies. Trabalhos posteriores desses mesmos autores (Elrashidi \& Lindsay, 1986a,b), analisando reações de equilíbrio e constantes de estabilidade para os minerais fluoretados e espécies em solução, confirmaram os resultados apresentados anteriormente. $\mathrm{O} \mathrm{AlF}$, provavelmente, precipita-se em solos fortemente ácidos com

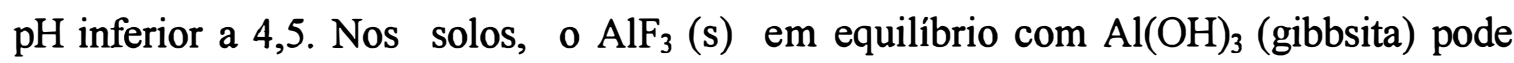
manter a concentração de $\mathrm{F}$ abaixo de $10^{-4} \mathrm{~mol} \mathrm{~L}^{-1}$ em solução, enquanto que a fluorita parece ser mais estável em solos ligeiramente ácidos e quase neutros. $\mathrm{O}$ mineral fluorflogopita é, provavelmente, estável em solos alcalinos e tem sua solubilidade afetada pelas atividades do $\mathrm{H}_{4} \mathrm{SiO}_{4}, \mathrm{Al}, \mathrm{K}, \mathrm{Mg}$ e pelo $\mathrm{pH}$. Termodinamicamente, a fluorapatita é instável em solos ácidos sendo, porém, a forma mineral de $\mathrm{F}$ mais estável em solos alcalinos e calcários. Os complexos de $\mathrm{F}$ com $\mathrm{Al}\left(\mathrm{AlF}^{2+}, \mathrm{AlF}_{2}^{+}\right.$e $\left.\mathrm{AlF}_{3}\right)$ e com $\mathrm{Fe}\left(\mathrm{FeF}^{2+}, \mathrm{FeF}_{2}{ }^{+}\right.$e $\left.\mathrm{FeF}_{3}\right)$ são as espécies principais em solos com $\mathrm{pH}$ abaixo de 6,0. Ainda segundo estes autores, acima deste $\mathrm{pH}$, o $\mathrm{F}^{-}$passa a ser a espécie dominante na solução do solo. Complexos de $\mathrm{F}^{-}$com $\mathrm{Si}$ e $\mathrm{Pb}$ assim como as espécies $\mathrm{KF}, \mathrm{NaF}, \mathrm{CuF}^{+}, \mathrm{ZnF}_{2}$ e $\mathrm{HF}_{2}^{-}$não são importantes na maior parte dos solos cultivados.

Moore \& Ritchie (1988), trabalhando com o programa de computador QELIOS, constataram que a concentração do Al livre na solução permaneceu aproximadamente constante, e posteriormente, decresceu quanto mais $F$ foi adicionado ao solo, mesmo que o $\mathrm{Al}$ solúvel total tenha aumentado. $\mathrm{O} \mathrm{AlF}^{2+}$ foi o principal complexo formado para relações $\mathrm{Al} / \mathrm{F}>1$, ao passo que $\mathrm{AlF}_{2}^{+}$representou mais que $50 \%$ do $\mathrm{F}$ complexado para a relação $\mathrm{Al} / \mathrm{F}<1$. Os complexos $\mathrm{Fe}-\mathrm{F}$ tiveram menor importância e não reduziram significativamente a quantidade de $\mathrm{F}^{-}$disponível para complexar com Al, discordando dos trabalhos de Elrashidi \& Lindsay (1985, 1986a,b).

Wenzel \& Blum (1992a), avaliando solos (luvissolo e regossolo) contaminados com $\mathrm{F}$ liberado em regiões de metalúrgicas, concluíram que a solubilidade do $\mathrm{F}$ total foi mínima em $\mathrm{pH}$ 6,0-6,5. A maior solubilidade em condições de maior acidez foi explicada pela formação de complexos catiônicos $\mathrm{AlF}^{2+}$ e $\mathrm{AlF}_{2}{ }^{+}$, enquanto o aumento da solubilidade do $\mathrm{F}$ em $\mathrm{pH}>6,5$ deveu-se à dessorção do $\mathrm{F}^{-}$induzida pela repulsão das superfícies carregadas negativamente. Desse modo, concluíram que o risco de contaminação para a cadeia alimentar e o lençol freático é baixo em solos pouco ácidos, 
mas aumenta em condições fortemente ácidas tanto quanto em condições alcalinas.

Segundo Gilpin \& Johnson (1980), o F é relativamente imóvel no solo, e em sua maior parte está combinado com espécies químicas que não são prontamente solúveis ou trocáveis. Os solos intemperizados possuem tendência de fixar $\mathrm{F}$, sendo esta uma propriedade desejável se os solos em questão fossem usados para o tratamento de rejeitos com elevada concentração de F solúvel.

A calagem diminui a mobilidade do $\mathrm{F}$, provavelmente pela elevação do $\mathrm{pH} \mathrm{e}$ formação de fluorita (Sizov et al., 1992; Rutherford et al., 1994).

Solos que receberam aplicações contínuas e prolongadas de fosfogesso em regiões temperadas, como o norte e centro da Europa e algumas regiões da Rússia, têm apresentado elevadas concentrações de F, com conseqüente acúmulo em vegetais e mesmo contaminação do lençol freático. Na região de Belarus (Rússia), Baranovskii et al. (1992), estudando o efeito de aplicações prolongadas de fertilizantes fosfatados em solos ricos em matéria orgânica cultivados com forrageiras, verificaram que o $\mathrm{P}$ acumulou-se na camada arável e o F na camada turfosa, enquanto nas forrageiras, a acumulação de $\mathrm{F}$ foi maior do que aquela considerada tóxica para a dieta animal (30-40 $\left.\mathrm{mg} \mathrm{kg}^{-1}\right)$.

\subsection{Interação entre flúor e alumínio}

Uma boa solução extratora deve solubilizar apenas a porção disponível do elemento analisado e, portanto, facilitar sua determinação, o que na prática, é extremamente difícil. No caso dos estudos para formulação de soluções extratoras para P, o ânion na solução extratora deve ser bastante reativo, ser estável em solução neutra, não oferecer complicações em determinações colorimétricas subseqüentes do fosfato e ser facilmente disponível para troca. Nesses estudos, o $F$ foi a escolha óbvia (Dickman \& Bray, 1941). O método de determinação de fósforo Bray \& Kurtz (1945) tem sido amplamente usado como um índice do $\mathrm{P}$ disponível do solo. $\mathrm{O} \mathrm{NH}_{4} \mathrm{~F}$ dissolve fosfatos de $\mathrm{Al}$ e $\mathrm{Fe}$ em solução ácida sendo portanto satisfatório para uso em solos ácidos (Olsen \& Sommers, 1982).

Chang \& Jackson (1957) desenvolveram um método para separar o P ligado ao 
Al, Fe e Ca empregando o HF como extrator. Segundo Parfitt (1978), esse método não teve muita aceitação por envolver outros processos para liberação de outros cátions ligados ao $\mathrm{P}$ e além disso, apresentar resultados falhos. No entanto, serviu para atestar a possibilidade de recuperação pelas plantas do $\mathrm{P}$ ligado principalmente ao $\mathrm{Al}$ usando o $\mathrm{F}$ como trocador.

Tandon (1969) verificou que o HF foi eficiente na extração de $\mathrm{P}$ e $\mathrm{Al}$ em diferentes solos que receberam ou não adubação fosfatada e concluiu que a velocidade da reação era elevada e linear nos primeiros minutos, sendo esta velocidade inversamente proporcional ao teor de argila.

Gilkes \& Hughes (1994) utilizaram o valor de $\mathrm{pH}$ em NaF para estimar, sob condições de campo, a adsorção de $\mathrm{P}$ pelos compostos de $\mathrm{Al}$ orgânico e inorgânico amorfos, já que esta fração do solo libera elevada quantidade de $\mathrm{OH}^{-}$em solução de $\mathrm{NaF}$.

Gardiner et al. (1987), estudando a especiação iônica em soluções do solo, concluíram que em amostras superficiais, a maior parte do $\mathrm{Al}$ estava ligado a fração orgânica, enquanto em amostras de 15 e $35 \mathrm{~cm}$ de profundidade mais do que $90 \%$ do $\mathrm{Al}$ participava de espécies com baixa massa molar.

Anderson \& Bertsch (1988) verificaram que na presença de $F^{-}$e outros ligantes competidores (como oxalato e acetato) pelo $\mathrm{Al}$, houve uma aceleração na formação do complexo $\mathrm{AlF}^{2+}$. Esta constatação é aparentemente contraditória ante a esperada competitividade dos ligantes pelo Al. Segundo esses autores, esta constatação pode influir nos modelos de especiação baseados em reações cinéticas.

A espécie química do $\mathrm{Al}$ considerada mais fitotóxica é a hexahidratada $\mathrm{Al}\left(\mathrm{OH}_{2}{ }^{0,5+}\right)_{6}$ ou simplificadamente grafada $\mathrm{Al}^{3+}$. Segundo Alva et al. (1988), a determinação das concentrações de espécies de $\mathrm{Al}$ realmente fitotóxicas, tem sido um sério obstáculo na predição da toxicidade do $\mathrm{Al}$, tanto em solução nutritiva quanto na solução do solo. Diversos ânions, como $\mathrm{OH}^{-}, \mathrm{H}_{2} \mathrm{PO}_{4}{ }^{-}, \mathrm{SO}_{4}{ }^{2-}, \mathrm{F}^{-}$e ligantes orgânicos entre outros, presentes na solução do solo, podem complexar, polimerizar ou precipitar $\mathrm{Al}$, diminuindo consideravelmente a fração fitotóxica remanescente na solução. Desta forma, a concentração de $\mathrm{Al}$ total, sem dúvida, não reflete a fitoxicidade do $\mathrm{Al}$ na 
solução quando esses ânions estão presentes. Nesse trabalho, os autores estudaram os efeitos de concentrações variáveis de $\mathrm{F}$ na medição de Al fitotóxico, empregando dois métodos colorimétricos: o aluminon e 8-hidroxiquinolina, concluindo pela superioridade do último, pois esse sofreu menos interferência do Al complexado.

Nos últimos anos, têm ocorrido um crescente aumento no número de trabalhos sobre o uso do eletrodo seletivo de F como um método indireto para a determinação de Al (Hodges, 1987; Garotti et al., 1992; Miyazawa et al, 1992a,b; Munns et al., 1992), devido à grande estabilidade dos complexos Al-F e ainda, por este método ser simples, rápido, preciso e facilmente adaptável para determinações de rotina. Entretanto, em situações de alta concentração de ácidos orgânicos, algumas espécies tóxicas de $\mathrm{Al}$ determinadas pelo eletrodo seletivo de $\mathrm{F}$ podem ser superestimadas, mas se a relação $\mathrm{Al} / \mathrm{F}$ for baixa, mesmo na presença destes ligantes orgânicos, os resultados ainda são comparáveis aos calculados teoricamente (Hodges, 1987; Miyazawa et al., 1992b). Munns et al. (1992), estudando a determinação da atividade do $\mathrm{Al}^{3+}$ pela medição do $\mathrm{F}$ em soluções de solos ácidos, concluíram que o eletrodo seletivo superestimou o $\mathrm{Al}$ quando o pH aumentou e a concentração de Al diminuiu. Garotti et al. (1992), estudando treze solos diferentes do Estado de São Paulo, concluíram que as determinações do $\mathrm{Al}$ empregando o eletrodo seletivo de $\mathrm{F}$, foram semelhantes àquelas obtidas pelo plasma (ICP-AES), principalmente em amostras de solo com elevada concentração de $\mathrm{Al}$.

A melhoria do ambiente radicular tem sido observada com a adição de íons tais como $\mathrm{F}^{-}$e $\mathrm{SO}_{4}{ }^{2-}$, os quais formam complexos com o $\mathrm{Al}$ reduzindo efetivamente a atividade das espécies fitotóxicas deste elemento na solução do solo. $\mathrm{O} \mathrm{F}^{-}$forma uma série de complexos estáveis com o $\mathrm{Al}$ de fórmula geral $\left[\mathrm{AlF}_{\mathrm{n}}\left(\mathrm{H}_{2} \mathrm{O}\right)_{6-\mathrm{n}}\right]^{(3-\mathrm{n})+}$, onde $\mathrm{n}$ varia de $1 \mathrm{a} 6$, enquanto $\mathrm{o}_{\mathrm{SO}_{4}}{ }^{2-}$ forma complexos instáveis de forma $\left[\mathrm{Al}\left(\mathrm{SO}_{4}\right)_{\mathrm{n}}\left(\mathrm{H}_{2} \mathrm{O}\right)_{6-2 \mathrm{n}}\right]^{(3-2 \mathrm{n})}$, com $\mathrm{n}$ variando de $1 \mathrm{a} 2$.

A diferença no comportamento do $\mathrm{F}^{-}$e $\mathrm{SO}_{4}{ }^{2-}$ em relação ao $\mathrm{Al}$ foi bem caracterizada por Gibson et al. (1992) ao comparar o efeito destes ânions na adsorção de $\mathrm{Al}$ por um oxissolo. A adição de $\mathrm{SO}_{4}{ }^{2-}$ aumentou a adsorção do $\mathrm{Al}$, provavelmente, devido à geração de cargas negativas de superfície. Ao contrário, o $\mathrm{F}^{-}$diminuiu a 
adsorção pela reação direta com o $\mathrm{Al}$, formando complexos $\mathrm{Al}-\mathrm{F}$. Do $\mathrm{F}^{-}$adicionado ao solo pouco ficou em solução na forma não complexada $(<0,02 \%)$ ou não complexada a $\mathrm{Al}$, constatando-se que cerca de $74 \%$ ficou adsorvido e $25 \%$ permaneceu em solução complexado com o Al. Evidentemente, esta proporção vai depender da mineralogia do solo, como uma função dos sítios para adsorção do $\mathrm{F}^{-} \mathrm{e}$ da magnitude do $\mathrm{Al} \mathrm{em}$ solução, sendo que, quanto maior for sua concentração, maior será a formação de complexos Al-F. Os complexos formados são muito estáveis, decompondo-se somente em condiç̧ões fortemente ácidas ou alcalinas, sofrendo pouca ação de outros ligantes (entre outros $\mathrm{Cl}^{-}, \mathrm{NO}_{3}^{-}, \mathrm{SO}_{4}{ }^{2-}, \mathrm{OH}^{-}, \mathrm{H}_{2} \mathrm{PO}_{4}^{-}$). Segundo os referidos autores, o $\mathrm{F}^{-}$ adicionado aumentou o $\mathrm{Al}$ em solução, mas diminuiu sua fitotoxicidade. $\mathrm{O}$ aumento do $\mathrm{Al}$ em solução, complexado, contribuiu para aumentar sua solubilidade e promover sua lixivição, diminuindo sua concentração na zona radicular.

Sumner (1993) destacou que o fosfogesso, contendo 2,3\% de $\mathrm{F}^{-}$aplicado na superfície em colunas de solo, resultou em maior lixiviação do Al, sendo este removido provavelmente como complexo solúvel Al-F.

Alvarez et al. (1992) estudaram a relação entre o material originário dos solos ácidos da região da Galícia (Espanha) com as espécies tóxicas de $\mathrm{Al}$ concluindo que os solos derivados de granito apresentaram as maiores concentrações de $\mathrm{Al}$ em solução, estando a maior parte na forma monomérica ligada a radicais orgânicos e ao $\mathrm{F}^{-}$.

A magnitude da interação entre $\mathrm{Al}$ e $\mathrm{F}$ também foi constatada em outros trabalhos empregando diversos materiais, entre estes Barraco et al. (1990), que estudaram a utilização de diversos materiais contendo $\mathrm{Fe}, \mathrm{Si}, \mathrm{Al}$ e $\mathrm{Mg}$, reagindo com os íons: $\mathrm{Cl}^{-}, \mathrm{F}^{-}$e $\mathrm{SO}_{4}{ }^{2-}$, objetivando diminuir a corrosão nas colunas de aço em processos industriais de produção de fertilizantes, verificaram que o $\mathrm{Si}$ e $\mathrm{Al}$ foram muito mais reativos com o $\mathrm{F}^{-}$do que foi $\mathrm{o} \mathrm{Mg}$.

Algumas variedades de cana-de-acúcar cultivadas em solo com alta porcentagem de saturação por $\mathrm{Al}$ também podem apresentar alta concentração de $\mathrm{Al}$ no caldo, sendo este elemento limitante na atuação da levedura. Como o pH do caldo não pode ser elevado para neutralizar o $\mathrm{Al}$, pois inibiria a fermentação, 
Basso $^{1}$ et al. encontraram marcante atenuação da toxicidade do $\mathrm{Al}$ quando quantidade correspondente de $\mathrm{F}$ foi adicionada ao meio de cultura $(\mathrm{pH}<4,0)$. No entanto, quando o $\mathrm{Al}$ ou o $\mathrm{F}$ estavam presentes isoladamente, ambos mostraram-se limitantes do crescimento da levedura.

\subsection{Adsorção e dessorção do flúor}

A adsorção específica em solos de carga variável, por mecanismos de troca de ligantes, ocorre pela reação química do ânion com a superfície dos óxidos hidratados, substituindo a hidroxila superficial. Enquanto $\mathrm{NO}_{3}{ }^{-}$e $\mathrm{Cl}^{-}$não participam desse tipo de adsorção, os ânions fosfato e $\mathrm{F}^{-}$são fortemente adsorvidos nas superfícies dos óxidos. $\mathrm{O} \mathrm{SO}_{4}{ }^{2-}$ apresenta grau de adsorção intermediário, com dependência da composição de outros íons na solução do solo e da natureza dos materiais constituintes da matriz do solo.

A adsorção do $\mathrm{F}^{-}$acompanhada pela liberação de $\mathrm{OH}^{-}$, foi bem descrita pela equação de Langmuir. Gibbsita, halloysita e caulinita adsorvem mais $\mathrm{F}^{-}$que goethita, montmorilonita e vermiculita (Bower \& Hatcher, 1967). Segundo Yuan \& Fiskell (1959), o $\mathrm{F}^{-}$não só deslocou o $\mathrm{Al}$ ligado aos diversos fosfatos, como aquele constituinte da gibbsita, por mecanismo de troca de ligantes. Para Parfitt (1978), o $\mathrm{F}^{-}$reagiu com goethita pelo mesmo mecanismo, com conseqüente liberação de hidroxila.

$\mathrm{A}$ afinidade de alguns ânions com a superfície de óxidos de $\mathrm{Fe}$ ou $\mathrm{Al}$ hidratados foi descrita por Parfitt (1980), como sendo a seguinte: fosfato > molibdato > fluoreto $>$ sulfato $>$ cloreto $>$ nitrato. Por outro lado, Saeki \& Matsumoto (1993), estudando andossolos no Japão, verificaram que a energia de ligação do $\mathrm{F}^{-}$(afinidade com o $\mathrm{Al}$ ) superava a dos ânions fosfato e este a dos ânions selenito, sendo seu mecanismo de adsorção diferente dos outros ânions.

${ }^{1}$ BASSO, L.C.; AMARAL, F.C.S.; CHITOLINA, J.C. Uso do flúor na redução da toxicidade do aluminio em leveduras. (Em redação) 
Segundo Sposito (1989), o fluoreto é fortemente protonado em $\mathrm{pH}<3,2$. Sua adsorção é crescente até o $\mathrm{pH}$ 3,5-4,0 e rapidamente decresce a partir do valor 4,0. O borato, outro ligante monoprótico, tem adsorção completamente diferenciada, sendo crescente até $\mathrm{pH}$ 9,0-9,5 e depois decrescente. Os ligantes polipróticos, como fosfato e arseniato, têm adsorção intermediária entre o comportamento de fluoreto e borato, a adsorção é máxima e praticamente constante entre $\mathrm{pH}$ 3,0-5,5, caindo rapidamente a partir do valor 5,5.

Flühler et al. (1982) trabalharam com colunas de areias quartzosas e concluíram que o comportamento dos ânions $\mathrm{F}^{-}$e $\mathrm{Cl}^{-}$foi praticamente similar, indicando que o primeiro não interage significativamente com a superfície do quartzo. Os mesmos autores constataram ainda que, em elevadas concentrações de $\mathrm{F}^{*}$, as hidroxilas dos bordos cristalinos dos minerais de argila foram substituídas com liberação simultânea de $\mathrm{Al} \mathrm{e} \mathrm{Fe,} \mathrm{mas} \mathrm{esta} \mathrm{substituição} \mathrm{somente} \mathrm{ocorreu} \mathrm{como} \mathrm{uma} \mathrm{fração} \mathrm{relativamente} \mathrm{pequena}$ de toda a adsorção. Esses autores afirmaram que o freqüente conceito de que a isoterma de adsorção é linear, pode conduzir à erros na predição das trocas do flúor. Baseados nestes resultados, os autores concluíram que os modelos de transporte do $\mathrm{F}$ podiam conter uma taxa dependente de um sumidouro ("sink") não linear.

O Canadá é um dos maiores produtores de $\mathrm{Al}$ e por conseqüência, um dos países que mais lança $\mathrm{F}$ na atmosfera, sendo de aproximadamente $2600 \mathrm{t}^{-1}$ ano ${ }^{-1}$ somente na província de Quebec. Simard \& Lafrance (1996), estudando a adsorção e dessorção do $\mathrm{F}$ em diversos solos circundantes de metalúrgicas desse país, verificaram que os solos ácidos, com maiores concentrações de $\mathrm{Fe}, \mathrm{Al}$ (trocável ou "amorfo") e matéria orgânica, adsorviam $\mathrm{F}^{-}$mais intensamente. Estes solos, segundo esses autores, deveriam ser priorizados na localização de novas plantas industriais, pois o $\mathrm{F}$ lixiviado para $\mathrm{o}$ lençol freático seria bem menor. Verificaram também, que a adsorção foi maior nos horizontes A e B do que no horizonte $\mathrm{C}$.

Peek \& Volk (1986), trabalhando com adsorção e dessorção de $\mathrm{F}^{-}$em solos, verificaram que a capacidade de adsorção máxima de $\mathrm{F}^{-}$em gibbsita recém-precipitada (baixo grau de cristalização), foi cerca de duzentas e quarenta vezes superior ao valor retido pela gibbsita cristalina. Esse valor sugere que os oxi-hidróxidos de $\mathrm{Al}$ amorfos 
podem representar a maior quantidade de sítios de adsorção de $\mathrm{F}^{*}$ nos solos. Quanto à estabilidade dessas reações, Hingston et al. (1974) sugeriram a irreversibilidade da adsorção de $\mathrm{F}^{-}$em solos com alta concentração de $\mathrm{Al}$ amorfo, sendo esse mecanismo de adsorção nos solos, mais complexo que a simples reação de troca de ligantes monodentados. Ao mesmo tempo, o $\mathrm{F}^{-}$remanescente na solução, mostrou forte afinidade pelo $\mathrm{Al}$, sendo capaz de competir com os sítios de troca de cátions e desta forma complexá-lo. Assim sendo, um extrator de eletrólito fraco $\left(\mathrm{CaCl}_{2}\right.$, por exemplo) e também o índice $\mathrm{pH}$ não são bons indicadores para predizerem as ligações $\mathrm{Al}-\mathrm{F}$ na solução do solo (Moore \& Ritchie, 1988).

Independentemente do fenômeno ser motivado por uma simples reação de adsorção ou até mesmo uma desestruturação do mineral, diversos trabalhos (Perrot et al., 1976; Moore \& Ritchie, 1988) têm mostrado que as reações envolvendo F" resultam em liberação de $\mathrm{OH}^{\circ}$, o que provoca elevação do $\mathrm{pH}$, e que alofanas, argilas não cristalinas de solos, assim como géis e aluminossilicatos sintéticos, liberam muito mais $\mathrm{OH}^{-}$que os minerais cristalinos do solo. A quantidade de $\mathrm{OH}^{-}$liberada é fortemente relacionada com a quantidade de alumina, tanto para os solos bem drenados quanto para solos mal drenados, os quais apresentam maior quantidade de minerais de cristalização indefinida.

Estas informações abriram a possibilidade de utilização da liberação de $\mathrm{OH}^{-}$ pelo $\mathrm{F}^{-}$, como um teste de campo para a presença de alofanas, dando margem ao desenvolvimento de um método laboratorial onde a liberação do primeiro ânion poderia ser empregada como um indicador da quantidade de material desordenado (baixo grau de cristalização) em subsuperfície. A troca de ligantes pode também ser usada como um método para estimar o número de sítios de troca. $\mathrm{O}$ fosfato tem sido usado com este objetivo, uma vez que ele é fortemente adsorvido, substituindo em larga proporção as hidroxilas reativas, e freqüentemente tem um máximo de adsorção bem definido. A adsorção de $\mathrm{F}^{-}$com a conseqüente determinação do $\mathrm{OH}^{-}$liberado nesse processo, tem sido usada, em base quantitativa, como um método para estimar a reatividade dos oxihidróxidos no solo, indicando a possibilidade de empregar este método na identificação de sítios específicos (Parfitt, 1978). 
Segundo Morshina \& Fanaskova (1985), a adsorção foi o processo principal que controlou o comportamento do $\mathrm{F}$ em baixas concentrações no solo. A quantidade adsorvida foi governada pelo $\mathrm{pH}$, diminuindo com sua elevação. Em altas concentrações, a adsorção do $\mathrm{F}^{-}$diminuiu, mas a desintegração de componentes sólidos do solo intensificou-se, como manifestado pela mobilização de metais e substâncias orgânicas. A extensão de sua ação nos componentes sólidos dependeu de diversos fatores, entre estes sua concentração, composição e tipo de solo. O NaF apresentou-se como o mais eficiente no processo de desintegração destes componentes.

Farrah et al. (1985) investigaram a capacidade de componentes individuais do solo em adsorver $\mathrm{F}^{-}$a partir de soluções diluídas de $\mathrm{F}$ (1-12 $\left.\mathrm{mg} \mathrm{L}^{-1}\right)$, em diferentes valores de $\mathrm{pH}$, não encontrando adsorção significativa quando usaram substratos como calcita, em pH variando de 6 a 9, hidróxido de manganês (IV), pirolusita, sílica, em pH de 3 a 8 . A quantidade de $\mathrm{F}^{-}$removida aumentou com a diminuição do $\mathrm{pH}$ ou com a adição de $\mathrm{CaCO}_{3}(\mathrm{~s})$, pela formação de $\mathrm{CaF}_{2}(\mathrm{~s})$.

Barrow (1986) estudou um modelo mecanístico para descrever a adsorção e a dessorção dos ânions $\mathrm{F}^{-}$e molibdato, avaliando os efeitos da temperatura, do tempo de incubação e da concentração na solução. O modelo assume algumas condições de contorno tais como a existência de adsorção inicial entre os ânions e as cargas de superfície, as superfícies não são uniformes em suas propriedades e a adsorção inicial é seguida de uma difusão sólida. Verificou-se que o aumento da temperatura aumentou a retenção do $\mathrm{F}^{-}$diminuindo, portanto, a sua concentração na solução. $\mathrm{O}$ modelo mostrou que a dessorção é lenta devido, principalmente, à necessidade de reverter a difusão sólida.

Barrow \& Ellis (1986), estudando os efeitos do pH sobre a adsorção do $\mathrm{F}^{-}$, constataram que numa mesma concentração de $\mathrm{F}$ total em solução, sua retenção foi maior em pH 5,5 e reduziu-se em valores de $\mathrm{pH}$ menores ou maiores. A diminuição da retenção em valores de $\mathrm{pH}$ abaixo de 5,5 deveu-se à provável formação dos complexos Al-F em solução. Desse modo, apenas uma pequena proporção do $\mathrm{F}$ total em solução estava presente como fluoreto. Numa mesma concentração de $F$, sua retenção diminuiu com o aumento do $\mathrm{pH}$. Esta diminuição foi atribuída à geração de cargas 
negativas nos sítios de carga variável.

Farrah \& Pickering (1986) observaram que a quantidade de $\mathrm{F}^{-}$retida pelos oxihidróxidos de Fe em suspensão relacionou-se com a concentração de $\mathrm{F}\left(2-100 \mathrm{mg} \mathrm{L}^{-1}\right)$, o valor de $\mathrm{pH}$ e a forma estrutural dos óxidos de $\mathrm{Fe}$. A menor adsorção ocorreu em $\mathrm{pH}>7$ e aumentou em valores menores. Para a faixa de $\mathrm{pH}$ compreendida entre 4,5 e 6,0, a quantidade de $\mathrm{F}^{-}$adsorvida variou com a concentração de acordo com a isoterma de Langmuir. Por outro lado, para menores valores de $\mathrm{pH}$, seu efeito foi contrabalançado pela dissolução dos sólidos. Neste caso, cada concentração estudada exibiu um pH (entre 3,5 e 4,5) onde a adsorção foi máxima. A dissolução dos sólidos foi acompanhada pela formacão de complexos solúveis entre Fe e F. Em meio ácido, a quantidade de $\mathrm{F}$ retida seguiu a ordem: hidróxidos de $\mathrm{Fe}>>$ goethita $>$ limonita $>>$ hematita. Em condições naturais, a interação e a retenção do $\mathrm{F}^{-}$, devem ser mais pronunciadas em meio ácido, contendo hidróxidos recém precipitados.

Peek \& Volk (1986), examinando os efeitos do F sobre as concentrações de $\mathrm{Al}, \mathrm{Fe}, \mathrm{P}, \mathrm{C}$ orgânico e a quantidade de hidroxila do solo, por meio de soluções com $\mathrm{NaF}$ variando de 1,1 a $2,5 \mathrm{mmol} \mathrm{L}^{-1}$, concluíram que as concentrações destes componentes na solução aumentaram com o aumento da concentração de F. O Al ocorreu em solução quase que inteiramente na forma de complexo com $\mathrm{F}$ e $\mathrm{C}$ orgânico, enquanto o $\mathrm{Fe}$ foi complexado quase completamente pelo $\mathrm{OH}^{-}$e pelo $\mathrm{C}$ orgânico. Com $\mathrm{Al}$ presente, aproximadamente $72 \%$ do $\mathrm{F}$ em solução formou complexos com este elemento e na sua ausência o F permaneceu na forma não complexada.

Estes conhecimentos assumem elevada importância, quando se considera o fato de as espécies $\mathrm{Al}-\mathrm{OH}$ e $\mathrm{Al}$ hexahidratado serem as mais importantes no equilíbrio ácido-base em muitos solos ocorrentes em clima tropical (Singh, 1982).

\subsection{Mobilidade do flúor no solo}

Há poucos estudos referentes à movimentação do $\mathrm{F}$ no solo. Os fatores que influenciam a retenção ou a liberação de espécies solúveis de $\mathrm{F}$ em solos foram revisadas por Pickering (1985). Para esse autor, sua mobilidade depende do tipo de solo, valor de $\mathrm{pH}$ e concentrações de $\mathrm{F}$, com a retenção sendo favorecida em sedimentos 
ácidos contendo argila e hidróxidos de Al pouco estruturados.

MacIntire et al. (1955), conduzindo experimentos durante seis anos em lisímetros com $\mathrm{KF}$ e $\mathrm{CaF}_{2}$, concluíram que o $\mathrm{F}$ apresenta baixa mobilidade sendo acentuada a sua retenção nos lisímetros.

Ilkun \& Motruk (1976), trabalhando em chemozém, verificou que compostos fluoretados acumularam-se predominantemente nos primeiros $5-10 \mathrm{~cm}$ do solo e a lixiviação do $\mathrm{F}$ foi acompanhada de cátions, como $\mathrm{K}$ e $\mathrm{Na}$, enquanto que $\mathrm{o} \mathrm{Ca}$ permaneceu praticamente imóvel.

Gilpin \& Johnson (1980) constataram que as concentrações totais do F em solos variaram amplamente com o tipo de material originário, série e grande grupo de solo, relacionando-se diretamente com o valor de $\mathrm{pH}$. O F extraído com resina cresceu com o aumento do $\mathrm{pH}$, sendo este comportamento similar às frações que contêm $\mathrm{P}$ lábil, não havendo uma explicação adequada para tal fenômeno.

Flühler et al. (1982), corroborando com os autores citados anteriormente, também obtiveram resultados similares quanto a grande correspondência entre $o$ movimento de substâncias de alta reatividade (como as que contêm F) e a associação cumulativa dos vários processos e propriedades do solo. Trabalhando com diferentes sais $\left(\mathrm{NaF}, \mathrm{KF}\right.$ e $\left.\mathrm{Na}_{5} \mathrm{Al}_{3} \mathrm{~F}_{14}\right)$, os autores verificaram que as curvas de adsorção foram similares, entretanto, of ligado ao $\mathrm{Na}$ apresentou maior mobilidade que o $\mathrm{F}$ ligado a outros cátions. Para os diferentes tipos de solo, foram obtidos resultados de adsorção quatro vezes menores num solo de origem calcária, em relação à um solo ácido.

Murray (1983), estudando a retenção em solos arenosos, constatou que o horizonte $\mathrm{B}$ e, em menor proporção o horizonte $\mathrm{A}$, foram os responsáveis pela maior parte da retenção do F. Com o decorrer do tempo, a quantidade de $\mathrm{F}$ lixiviada diminuiu, podendo ser explicado pelo aumento do número de ligações entre este elemento e os diversos componentes do solo.

Hua (1991), estudou a tolerância de seis tipos de solo a diversos poluentes $(\mathrm{Cu}$, $\mathrm{Pb}, \mathrm{Cd}$ e F) na Rússia e na China, concluindo que solos com forte poder tampão para metais pesados não o eram para $\mathrm{F}$. Esses solos tinham $\mathrm{pH}$ próximo a 7,0, eram ricos em matéria orgânica, com elevada CTC e alto teor de carbonatos além de apresentarem 
textura argilosa. Por outro lado, os solos ácidos, ricos em óxidos de $\mathrm{Fe}$ e $\mathrm{Al}$, apresentaram forte poder tampão para $\mathrm{F}$ mas fraco para metais pesados. Resultados semelhantes chegaram Lo \& Lo (1991) que trabalhando com alguns solos da China, verificaram que os solos com maiores concentrações de $\mathrm{Fe}$ e Al solúveis formaram complexos estáveis com flúor.

$\mathrm{Na}$ Áustria, Wenzel \& Blum (1992b), estudando seis luvissolos sob floresta que receberam deposições aéreas ricas em $\mathrm{F}$, devido suas proximidades com uma indústria processadora de $\mathrm{Al}$, corroborando os trabalhos citados anteriormente, também obtiveram resultados semelhantes quanto à troca de ligantes da hidroxila de óxidos de $\mathrm{Al}$ de baixa cristalização, com conseqüente lixiviação do $\mathrm{Al}$ e elevação do $\mathrm{pH}$.

Luther et al. (1995) trabalharam com dois solos argilosos montmoriloníticos, um calcário e outro não calcário, da província de Alberta, no Canadá, para avaliar a possível contaminação do lençol freático com $\mathrm{F}$, proveniente da lixiviação de grandes depósitos de fosfogesso. No Canadá e em outros países, existe legislação que limita a quantidade de $\mathrm{F}$ presente em águas naturais em $1,5 \mathrm{mg} \mathrm{L}^{-1}$. Os autores concluíram que, quando fosfogesso foi misturado ao solo, o enriquecimento de $\mathrm{F}$ na solução percolada do horizonte calcário foi bem maior $\left(22 \mathrm{mg} \mathrm{L}^{-1}\right)$ que naquele não calcário $\left(11 \mathrm{mg} \mathrm{L}^{-1}\right)$. $\mathrm{O}$ valor lixiviado na coluna composta apenas de fosfogesso atingiu $31 \mathrm{mg} \mathrm{L}^{-1}$. Além disso, a fração caulinita componente destes solos, tendeu a adsorver mais $\mathrm{F}$ do que a montmorilonita, levando os autores a concluírem que, a menor concentração final do $\mathrm{F}$ lixiviado, quando encontrasse os aqǘferos subterrâneos, seria tão reduzida, não constituíndo, portanto, em problema ambiental. Entretanto, esses autores não fizeram qualquer comentário, a respeito da utilização futura dos amplos depósitos de fosfogesso.

\subsection{O flúor como melhorador de solo}

Pode-se entender como melhorador de solo todo componente fisico, químico ou biológico que, melhore as relações edafológicas. Wright (1989) exemplificou como melhoradores do solo a resteva, estercos e resíduos municipais e industriais, de natureza orgânica e inorgânica, como tendo potencial para minorar a toxicidade do $\mathrm{Al}$ no solo, devendo merecer estudos mais aprofundados. 
De acordo com Geoghegan \& Sprent (1996), mais de 40\% das terras aráveis são afetadas pela toxicidade do Al. Estimativas sobre a área atingida pela acidez de subsuperfície são inconsistentes mas, conservadoramente, acredita-se que supere um bilhão de hectares (Orvedal \& Ackerson, 1972), uma extensão considerável, uma vez que todo o território brasileiro não supera 852 milhões de hectares.

De modo geral, em solos com valores de $\mathrm{pH}$ inferiores a 5,0, o $\mathrm{Al}$ trocável pode ser considerado o principal fator limitante da produção agrícola (Tan, 1993). Tratamentos para a diminuição da concentração da espécie $\mathrm{Al}^{3+}$ incluem tanto a elevação do $\mathrm{pH}$ como a adição de ligantes complexantes como fosfatos, sulfatos, fluoretos e orgânicos solúveis. Entretanto, a elevação acentuada do $\mathrm{pH}$ pode trazer sérias conseqüências. Uma delas é a fixação de $\mathrm{P}$ pelo $\mathrm{Ca}$ constituindo-se em um sério problema nos solos de regiões áridas ou mesmo em solos de regiões úmidas, como no sudeste dos Estados Unidos, que receberam calagens pesadas. Sob tais condições, a aplicação de fertilizantes fosfatados não mostrou a resposta esperada no crescimento das plantas. A fixação do $\mathrm{P}$ não pode ser evitada completamente, mas pode ser reduzida pela adição de íons competidores pelos sítios de fixação. Ânions orgânicos e silicatos foram reconhecidos pela eficiência na redução da fixação de $P$.

Segundo Hodges (1987), o Al tóxico pode ser entendido como a soma das espécies: $\mathrm{Al}^{3+}, \mathrm{Al}(\mathrm{OH})^{2+}, \mathrm{Al}(\mathrm{OH})_{2}{ }^{+}$e $\mathrm{Al}(\mathrm{OH})_{4}^{-}$presentes na amostra de solo. A toxicidade dos complexos $\mathrm{Al}_{-} \mathrm{SO}_{4}$ e $\mathrm{Al}$ polimérico não foi detectada. Resultados semelhantes foram obtidos por Pavan \& Bingham (1982) e Kinraide \& Parker (1987), mostrando que o $\mathrm{AlSO}_{4}{ }^{+}$não foi fitotóxico, ou ainda segundo os últimos autores, foi no mínimo, dez vezes menos tóxico que o $\mathrm{Al}^{3+}$.

Para Whitten \& Ritchie (1991), o Al complexado com ligantes como fluoreto, sulfato, citrato e oxalato, não é considerado fitotóxico. Dentre os ligantes orgânicos, citrato e oxalato parecem ser os mais efetivos redutores da toxicidade do $\mathrm{Al}$ em solução, com participação destacada em pH < 4,0 (Kerven et al., 1995).

Parker et al. (1988), estudando a especiação do Al e a fitotoxicidade em soluções diluídas em que o único ligante foi $\mathrm{OH}^{-}$, concluíram que todas as frações poli e mononucleares de $\mathrm{Al}$ foram fitotóxicas. Apesar do $\mathrm{Al}^{3+}$ ser a espécie com maior 
participação no estresse provocado pelo $\mathrm{Al}$, as outras formas também contribuíram, necessitando-se rever a prática comum de excluir a fração polinuclear da estimativa do Al fitotóxico.

Foy (1992), numa revisão sobre os fatores químicos do solo que limitam o desenvolvimento radicular, mostrou diversas participações do $F$ na diminuição da fitotoxicidade do $\mathrm{Al}$ e ressaltou a importância de se desenvolver pesquisas referentes à atuação do $\mathrm{Si}$ e do $\mathrm{F}$ como potenciais redutores da toxicidade do $\mathrm{Al}$ em subsuperfície de solos ácidos.

A principal entrada de $\mathrm{F}$ no sistema agrícola, segundo Adriano (1986), é através da aplicação de superfosfatos. No entanto, o efeito do $\mathrm{F}$ presente nestes adubos para as plantas é geralmente insignificante, já que sua concentração é pequena. Além disso, o $\mathrm{F}$ também é uma impureza presente no gesso agrícola, também chamado de fosfogesso por ser oriundo da fabricação do ácido fosfórico, mas o efeito desse elemento geralmente é desprezado nos estudos de aplicação desse subproduto. A concentração de F no gesso agrícola geralmente varia entre 0,7 e 1,5\% (Paolinelli et al., 1986; Beresin et al., 1991). Por outro lado, o F pode ser importante para a complexação do $\mathrm{Al}$ do solo, conforme constatado por Oates \& Caldwell (1985). Esses autores verificaram que o gesso agrícola foi mais eficiente em diminuir o $\mathrm{Al}$ do solo do que o gesso proveniente de minerações, devido à presença do $\mathrm{F}$ e conseqüente formação $\mathrm{e}$ lixiviação de complexos Al-F no solo.

Cameron et al. (1986) verificaram que o ânion $\mathrm{F}^{-}$formou complexos com $\mathrm{Al}$ muito rapidamente diminuindo sua toxicidade, sendo desta forma mais efetivo que o $\mathrm{SO}_{4}{ }^{2-}$. Em iguais concentrações, mais do que $90 \%$ do $\mathrm{F}^{-}$presente complexou com $\mathrm{Al}$, enquanto que menos de $0,5 \%$ do $\mathrm{SO}_{4}{ }^{2-}$ foi por ele complexado. Esses autores concluíram que a capacidade destes dois ânions na redução da toxicidade do $\mathrm{Al}$ dependerá de suas concentrações na solução do solo. Como em condições naturais a concentração média do F na solução do solo é baixa, essa espécie somente terá importância na diminuição da toxicidade do $\mathrm{Al}$ se este tiver igualmente baixa concentração. Desta forma, o $\mathrm{Al}$ complexado com $\mathrm{F}^{-}$ou $\mathrm{SO}_{4}{ }^{2-}$ tem sua toxicidade diminuída, assim como quando complexado com outros ânions, como silicatos, molibdatos, hidroxilas, fosfatos e ácidos 
orgânicos (Giongo et al., 1997). A capacidade desintoxicante dessas espécies químicas pode ser uma das razões do porquê das determinações do $\mathrm{Al}$ trocável, usando agentes complexantes, não serem sempre satisfatórias na distinção entre valor tóxico e não tóxico do $\mathrm{Al}$ do solo. A fitotoxicidade das espécies $\mathrm{Al}-\mathrm{F}$ é consideravelmente mais baixa que as espécies $\mathrm{Al}^{3+}$ ou $\mathrm{Al}-\mathrm{OH}$. $\mathrm{Na}$ mesma faixa de $\mathrm{pH}, \mathrm{o} \mathrm{F}^{-}$é um ligante mais forte que $\mathrm{OH}$, assim sendo, os complexos Al-F apresentam relativamente maior estabilidade (Alva et al., 1988).

Raij (1988) ressaltou que os complexos de $\mathrm{Al}$ com $\mathrm{F}^{-}$são muito estáveis, ao contrário dos formados com $\mathrm{SO}_{4}{ }^{2-}$. Provavelmente, em solos ácidos, a fase sólida que controla a solubilidade do $\mathrm{F}_{\text {seja }} \mathrm{AlF}_{3}$, enquanto que em solos pouco ácidos, essa solubilidade seja controlada por $\mathrm{CaF}_{2}$. Assim, pode-se esperar que o $\mathrm{F}$ do gesso agrícola, que nesse produto vem ligado ao $\mathrm{Ca}$, ligue-se ao $\mathrm{Al}$ em solos ácidos formando complexos solúveis e lixiviáveis no solo. No entanto, a baixa concentração de F presente no gesso agrícola pode restringir a sua atuação sobre o Al do solo.

Moore \& Ritchie (1988) constataram que o $\mathrm{F}$ formou complexos solúveis com $\mathrm{Al}$ em solos, mesmo quando mais que $90 \%$ do $\mathrm{F}$ total do solo estava adsorvido, contribuindo para decrescer a concentração de formas de Al fitotóxicas. Além disso, houve elevação do $\mathrm{pH}$ e do $\mathrm{Al}$ solúvel total, os quais estavam contrastantes com a variação do $\mathrm{Al}$ solúvel total e com o pH na ausência de $\mathrm{F}$.

Amaral \& Chitolina ${ }^{1}$ também encontraram aumento de $\mathrm{pH}$ e diminuição do Al tóxico, bem como aumento de $\mathrm{P}$ lábil em quatro solos ácidos, tanto em tratamentos com $\mathrm{NaF}$ quanto com $\mathrm{CaF}_{2}$.

Gibson et al. (1992), trabalhando com coluna de solo constituída de um torrox, caulinítico e ilítico com baixa concentração de $\mathrm{Al}$ trocável $\left(0,08 \mathrm{cmol}_{\mathrm{c}} \mathrm{kg}^{-1}\right)$, concluíram que os ânions $\mathrm{F}^{-}$e $\mathrm{SO}_{4}{ }^{2-}$ possuíam capacidades contrastantes de complexar $\mathrm{Al}$.

${ }^{1}$ AMARAL, F.C.S.; CHITOLINA, J.C. Influência do flúor na concentração do alumínio trocável e no fósforo lábil em solos ácidos de diferentes texturas. (Em redação) 
Enquanto o primeiro pôde mobilizá-lo para a subsuperfície, o segundo retardou seu movimento. Bond et al. (1995), trabalhando em condições similares, concluíram que nem $\mathrm{F}^{-}$nem $\mathrm{SO}_{4}{ }^{2-}$ tiveram a capacidade de lixiviar $\mathrm{Al}$ em profundidade, apesar do $\mathrm{F}^{-}$ formar complexos muito mais estáveis com $\mathrm{Al}$, e elevar $\mathrm{o} \mathrm{pH}$ mais que o $\mathrm{SO}_{4}{ }^{2-}$, devido à liberação de $\mathrm{OH}$, quando da formação de minerais Al-F, por um mecanismo denominado autocalagem.

Singh (1982), estudando os efeitos de $\mathrm{Cl}^{-}$e $\mathrm{SO}_{4}{ }^{2-}$ nas características químicas de alguns solos ácidos, concluiu que o $\mathrm{pH}$ e o grau de saturação por bases de amostras de solo equilibradas em solução de $\mathrm{CaSO}_{4}$ foram maiores que os obtidos para amostras com $\mathrm{CaCl}_{2}$. Com relação ao $\mathrm{Al}$, mesmo nas amostras equilibradas com $\mathrm{CaSO}_{4}$ onde a concentração de $\mathrm{Al}$ total foi maior, o $\mathrm{Al}^{3+}$ foi muito menor: $93,4 \%$ e $36,0 \%$ do $\mathrm{Al}$ estavam na forma de $\mathrm{Al}^{3+}$, respectivamente nas suspensões de $\mathrm{CaCl}_{2} \mathrm{e} \mathrm{CaSO}_{4}$. Ainda nas suspensões de $\mathrm{CaSO}_{4}$ 60,0\% do $\mathrm{Al}$ apresentaram-se na forma de $\mathrm{AlSO}_{4}{ }^{+}$, que não é tão efetivo quanto o $\mathrm{Al}^{3+}$ na competição com os cátions básicos pelos sítios de troca. Além disso, o $\mathrm{AlSO}_{4}{ }^{+}$foi mais facilmente lixiviável no perfil do solo, diminuindo, portanto, sua concentração no volume de solo ocupado pelo sistema radicular.

Os efeitos benéficos do gesso agrícola na atenuação da toxicidade do $\mathrm{Al}$, pelo menos parcialmente, por pareamento do $\mathrm{Al}$ com $\mathrm{F}^{-}$e $\mathrm{SO}_{4}{ }^{2-}$ foram encontrados em vários trabalhos (Souza \& Ritchey, 1986; Alva \& Sumner, 1988; O'Brien \& Sumner, 1988; Alva et al., 1989; Keerthisinghe et al., 1991a; Carvalho, 1994).

Em solução nutritiva contendo $0,04 \mathrm{mmol} \mathrm{L}^{-1}$ de $\mathrm{Al}$, a adição de $\mathrm{CaSO}_{4} \cdot 2 \mathrm{H}_{2} \mathrm{O}\left(2,07 \mathrm{~g} \mathrm{~L}^{-1}\right)$ diminuiu a atividade do $\mathrm{Al}^{3+}$ de 0,036 para $0,011 \mathrm{mmol} \mathrm{L}^{-1} \mathrm{e}$ aumentou a atividade do $\mathrm{AlSO}_{4}{ }^{+}$de 0,033 para $0,080 \mathrm{mmol} \mathrm{L}{ }^{-1}$, promovendo um aumento de quatro vezes no tamanho das raízes de soja (Alva \& Sumner, 1988). Quando o solo foi tratado com $5 \mathrm{t} \mathrm{ha}^{-1}$ de gesso agrícola, $99 \%$ e $0,6 \%$ do Al total contido no lixiviado do solo ficaram complexados com $\mathrm{F}^{-}$e $\mathrm{SO}_{4}{ }^{2-}$, respectivamente, restando somente $0,3 \%$ na forma de $\mathrm{Al}^{3+}$ (Alva et al., 1989).

Em experimentos com colunas de solo, O'Brien \& Sumner (1988) encontraram diminuição da acidez subsuperfície após a aplicação de fosfogesso em superfície, pela diminuição das concentrações de $\mathrm{Al}$ e aumento de $\mathrm{Ca}$ trocáveis, sugerindo que o 
fenômeno pode ter ocorrido pela precipitação do Al tóxico, formando a alunita $\left[\mathrm{KAl}_{3}\left(\mathrm{SO}_{4}\right)(\mathrm{OH})_{6}\right]$.

Keerthisinghe et al. (1991a) estudaram sob condições de casa de vegetação, o efeito da aplicação de gesso agrícola, $\mathrm{CaSO}_{4}$ e $\mathrm{CaF}_{2}$ para diminuir a acidez de subsuperfície em solos com pastagem. Os autores verificaram que nenhum dos tratamentos alterou o valor de $\mathrm{pH}$ do solo, tanto em superfície como em subsuperfície. Com o aumento das doses de $\mathrm{F}^{*}$, houve um aumento nas quantidades de $\mathrm{F}^{-}$ligado ao $\mathrm{Al}$. $\mathrm{O}$ efeito melhorador do $\mathrm{F}^{-}$foi atribuído à formação de complexos não fitotóxicos entre $\mathrm{Al}$ e $\mathrm{F}$ nas camadas subsuperficiais.

Carvalho (1994), comparando $\mathrm{CaSO}_{4}$ (p.a.), $\mathrm{CaCO}_{3}$ (p.a.) e gesso agrícola na melhoria do ambiente radicular em amostras de subsolo ácido, concluiu que os três materiais estimularam o desenvolvimento radicular do milho, tendo o tratamento com gesso apresentado o resultado mais expressivo, 194\%, tanto pela elevação da concentração de $\mathrm{Ca}$ quanto pela diminuição da toxicidade do $\mathrm{Al}$ no substrato. Ainda que o gesso apresentasse menos que $1 \%$ de $\mathrm{F}$, a especiação iônica mostrou que este elemento foi responsável por $90 \%$ da complexação do $\mathrm{Al}$ quando a relação $\mathrm{Al} / \mathrm{F}<1$.

Bissani et al. (1997), avaliaram a capacidade do calcário e do gesso agrícola na correção do $\mathrm{Al}$ tóxico quando aplicados superficialmente, concluindo que ambos foram efetivos tanto em superfície quanto em subsuperfície, tendo o gesso propiciado maior lixiviação de $\mathrm{Al}, \mathrm{Ca}$ e $\mathrm{Mg}$ do que o calcário.

Mishra (1980) pesquisando o uso do gesso agrícola na recuperação de solos sódicos, verificou que quantidades superiores a $32 \mathrm{t} \mathrm{ha}^{-1}$ de gesso agrícola poderiam ser usadas na recuperação de solos sódicos, sem problemas, apesar da elevada concentração de F.

Beresin et al. (1991), estudaram o uso de gesso agrícola com $1,5 \%$ de $\mathrm{F}$, com o objetivo de diminuir a saturação por $\mathrm{Na}$ em solos sódicos da Rússia cultivados com cevada e aveia. Verificaram que nos solos pesquisados a concentração de $F$ aumentou com a elevação do nível do lençol freático e da alcalinidade, não se constatando uma relação direta entre a concentração de $\mathrm{F}$ no solo e na planta. 
Segundo diversos autores (Saha et al., 1981; Gaponyuk \& Reut, 1983; Kremlenkova \& Gaponyuk, 1984), o NaF pode afetar a distribuição de ácidos húmicos e seus derivados, pelo aumento de suas solubilidades, assim sendo, pode ser empregado em solos para diminuir o acúmulo de material orgânico. De um modo geral, o $\mathrm{F}^{-}$reduz a liberação de $\mathrm{N}-\mathrm{NH}_{3}$ dos carboidratos da matéria orgânica em decomposição. Esse efeito pode ser devido à sua atuação direta sobre as enzimas que atuam no processo de decomposição da matéria orgânica.

David \& Driscoll (1984), mostraram um predomínio de complexos de $\mathrm{F}^{-} \mathrm{e}$ substâncias orgânicas na especiação do Al presente na solução de um espodossolo do Estado de Nova York (EUA). A avaliação dos efeitos do Al no completo desenvolvimento da planta deveria levar em consideração os complexos orgânicos e inorgânicos formados, tanto das formas hexahidratadas como daquelas ligadas a hidróxidos. Resultados semelhantes foram obtidos por Ritchie et al. (1988) e Ritchie (1995), ressaltando a importância dos ácidos húmicos e do $\mathrm{F}^{-}$complexarem o $\mathrm{Al}$ quanto mais baixo for o $\mathrm{pH}$ do solo.

\subsection{O flúor nos seres vivos}

\subsubsection{O flúor nas plantas}

$\mathrm{O} F$ não é essencial para as plantas, mas, especula-se, que o seja para os animais (Adriano \& Doner, 1982; Adriano, 1986; Allaway, 1986). Sua absorção, particularmente pela via foliar, durante períodos prolongados e com excessivas doses pode provocar sintomas de toxicidade em plantas, produzindo necrose marginal nas folhas e redução do crescimento. Entretanto, esses sintomas não são específicos para a toxicidade do F (Weinsten, 1971). Muitas enzimas podem ser inibidas pelo F, entre estas a enolase, fosfoglucomutase, desidrogenase succínica, fosfatases e hexoquinases. A distribuição e a concentração do F na célula podem determinar tanto o tipo quanto o grau de efeito a ser produzido (Weinstein, 1977).

Embora o F seja reconhecidamente importante na área de Toxicologia Ambiental, sua determinação quantitativa na vegetação ainda é problemática. De acordo com Cooke et al. (1976), essa determinação é, provavelmente, uma das mais difíceis 
na Química Analítica. Atualmente, os métodos mais utilizados para a determinação de F nas plantas são o potenciométrico da AOAC - Association of Official Analytical Chemists (Cunniff, 1995) e os métodos de fusão alcalina, seguido pela determinação com eletrodo seletivo (McQuaker \& Gurney, 1977; Keerthisinghe et al., 1991b). Contudo, diversos trabalhos têm relatado que esses métodos apresentam erros na determinação de F (Shortland, 1988; Keerthisinghe et al., 1991b). O método da AOAC, segundo Cunniff (1995), não é apropriado para: (1) amostras de plantas que contenham menos que $10 \mathrm{mg} \mathrm{kg}^{-1}$ de $\mathrm{F}$, pois sua faixa de leitura varia entre 10 e $2000 \mathrm{mg} \mathrm{kg}^{-1}$; (2) amostras que tenham sido expostas a concentrações elevadas de $\mathrm{Al}$ ou outros agentes complexantes de F; (3) não é recomendável para $\mathrm{F}$ inorgânico insolúvel ou F em combinações orgânicas. Alguns dos problemas apresentados na literatura (Heede et al., 1975; McQuaker \& Gurney,1977; Shortland, 1988; Keerthisinghe et al., 1991b) relacionam-se com métodos que provocam perdas de $\mathrm{F}$ por volatilização durante a digestão com temperaturas altas $\left(400-600^{\circ} \mathrm{C}\right)$, contaminações e mineralização incompleta da amostra.

As plantas geralmente acumulam pequenas quantidades de $\mathrm{F}$, variando fundamentalmente com a espécie vegetal e seu estádio de crescimento. Plantas crescidas em solos ou em outros meios (por exemplo, solução nutritiva) com a mesma concentração de $\mathrm{F}$ podem apresentar diferenças na concentração desse elemento nas folhas ou em outra parte aérea analisada, mostrando a existência de capacidades distintas de absorção de F pelas raízes e/ ou transporte e distribuição dentro da planta. Nas plantas crescidas em ambientes normais (sem adição de qualquer fonte de F), a concentração média de $\mathrm{F}$ encontrada nas folhas varia de traços a $<10 \mathrm{mg} \mathrm{kg}^{-1}$ (Davison et al., 1983; Adriano, 1986). Segundo Lu \& Zhao (1992), a concentração de F aumenta nos órgãos mais velhos. Nos alimentos de origem vegetal, segundo Dabeka \& McKenzie (1995), a concentração natural de $\mathrm{F}$ é bastante variável, podendo atingir $1020 \mathrm{mg} \mathrm{kg}^{-1}$ nos grãos de trigo e $4970 \mathrm{mg} \mathrm{kg}^{-1}$ no chá inglês. De modo geral, acreditase que o $\mathrm{F}$ possa ser tóxico quando presente em qualquer composto orgânico, principalmente aqueles participantes do ciclo de Krebs (Meyer \& O’Hagan, 1992), enquanto na forma inorgânica, mesmo em altas concentrações, provavelmente não seja 
tóxico. No caso de algumas espécies da família Theaceae (Camellia-Thea), que são reconhecidamente uma das principais plantas acumuladoras de $\mathrm{F}$ e $\mathrm{Al}$, têm sido encontradas concentrações de $\mathrm{F}$ superiores a $4000 \mathrm{mg} \mathrm{kg}^{-1}$, sem problemas de toxicidade.

A biodisponibilidade do $\mathrm{F}$ para as plantas é relativamente pequena. A absorção pelas raízes do $\mathrm{F}^{-}$na solução do solo ou solução nutritiva ocorre passivamente, sendo aparentemente de fácil absorção (Treshow, 1971). Peters \& Shorthouse (1964), trabalhando com plântulas de gramíneas em solução nutritiva, não encontraram níveis de absorção apreciável de $\mathrm{F}$ para concentrações superiores a $19 \mathrm{mg} \mathrm{L}^{-1}$. Não houve formação de compostos orgânicos fluoretados nas plantas mesmo nas concentrações próximas a $140 \mathrm{mg} \mathrm{L}^{-1}$ de $\mathrm{F}$ em solução.

Böszörményi \& Cseh (1961), verificaram que a ordem de absorção de ânions durante um período de $24 \mathrm{~h}$ foi a seguinte: $\mathrm{Br}^{-}>\mathrm{Cl}^{-}>\mathrm{I}^{-}>\mathrm{F}^{-}$, tanto nas raízes como na parte aérea de plantas de trigo.

Venkateswarlu et al. (1965), avaliando as diferenças na absorção de $\mathrm{Cl}^{-}$e $\mathrm{F}^{-}$ por raízes de cevada, constataram que, em baixas concentrações $\left(0,01\right.$ e $\left.0,1 \mathrm{mmol} \mathrm{L}^{-1}\right)$, a absorção de $\mathrm{Cl}^{-}$pelas raízes foi cerca de cem vezes superior àquela do $\mathrm{F}^{-}$. Por outro lado, aumentando-se a concentração do halogênio $\left(1,0 \mathrm{mmol} \mathrm{L}^{-1}\right), \mathrm{o} \mathrm{Cl}^{-}$foi absorvido vinte e cinco vezes mais do que $\mathrm{F}^{-}$.

No Canadá, Sheppard \& Evenden (1992), avaliando a resposta de alguns vegetais (milho doce, repolho e beterraba) a quatro halogênios, verificaram que a adsorção no solo foi na seguinte ordem: $\mathrm{F}^{-}>\mathrm{I}^{-}>\mathrm{Br}^{-}>\mathrm{Cl}^{-}$. Por outro lado, as concentrações nas plantas foram geralmente no sentido inverso, $\mathrm{Cl}^{-}>\mathrm{Br}^{-}>\mathrm{F}^{-}>\mathrm{I}^{-}$. Houve evidência de interação competitiva entre os halogênios testados e ânions do solo, como sulfato e fosfato. A competição reduziu a toxicidade do I e afetou a concentração de $\mathrm{P}, \mathrm{S}$ e dos halogênios no tecido vegetal.

De acordo com Takmaz-Nisancioglu \& Davison (1988), o $\mathrm{F}^{-}$não é prontamente absorvido quando fornecido como $\mathrm{NaF}$, devido à exclusão do $\mathrm{F}^{-}$pelos sítios de absorção de mesma polarização encontrados na raiz. Quando o $\mathrm{F}^{-}$é fornecido como $\mathrm{AlF}_{3}$, sua absorção na forma catiônica é facilitada pela diminuição da exclusão de 
Donnan e portanto, maior acúmulo no apoplasto. Nesse trabalho, a absorção de $\mathrm{F}^{-}$ ligado ao $\mathrm{Al}$, em relação ao ligado ao $\mathrm{Na}$, foi o dobro para raízes e o quádruplo para as primeiras folhas de feijão. Por outro lado, MacLean et al. (1992) constataram que plantas em solução contendo Al-F absorveram menos $\mathrm{F}$ que aquelas cultivadas na ausência de Al.

Geoghegan \& Sprent (1996), analisando diversas espécies nativas do cerrado brasileiro consideradas acumuladoras de $\mathrm{Al}$, incluindo algumas leguminosas noduladoras, encontraram concentrações de $\mathrm{Al}$ significativamente elevadas e discrepantes, com um máximo de $16390 \mathrm{mg} \mathrm{kg}^{-1}$ em Chamaecrista repens. Esses autores acreditam que esta acumulação não seja propriamente devido à alta tolerância do tecido vegetal, mas devido à quelatação do $\mathrm{Al}$ na rizosfera por ácidos orgânicos, com o conseqüente transporte e deposição no apoplasto foliar. Esse mecanismo de acumulação de $\mathrm{Al}$ é, provavelmente, semelhante ao mecanismo de acumulação de $\mathrm{F}$, sugerido por Takmaz-Nisancioglu \& Davison (1988).

Os poluentes atmosféricos constituem-se na principal fonte de $\mathrm{F}$ que originam desordens nas plantas. $\mathrm{O} \mathrm{HF}$ é um dos maiores poluentes, com relação as injúrias foliares, superado pelo ozônio, dióxido de enxofre e outros oxidantes que não ozônio, por exemplo, óxidos de nitrogênio e pesticidas (Weinstein, 1977). Estudos comparativos com vários gases contendo $\mathrm{F}\left(\mathrm{HF}, \mathrm{F}_{2}, \mathrm{SiF}_{4} \mathrm{e}_{2} \mathrm{HiF}_{6}\right)$ têm revelado que eles são igualmente tóxicos e provocam sintomas semelhantes, consistindo geralmente de clorose e, posteriormente, necrose das bainhas foliares (Weinstein, 1977). A absorção foliar do F, que é dependente da concentração e do tempo de exposição (Malavolta, 1980), é similar à de outros poluentes gasosos, sendo absorvido através da cutícula quando depositado na superfície da folha. A clorose causada pelo $\mathrm{F}$ pode ser explicada pela aparente dissolução da estrutura dos cloroplastos (McNulty \& Newman, 1961).

Trabalhos com diferentes espécies vegetais (Treshow, 1971; Weinstein, 1977; Maftoun \& Sheibany, 1979; Mason, 1981) têm relatado a ocorrência de necroses e até mesmo abscisão foliar, causando reduções no crescimento e na produção vegetal como resultado da atmosfera enriquecida com HF ou de aplicações foliares com soluções contendo $\mathrm{F}$ e ainda, de irrigação com água com rica em F. Por outro lado, o efeito 
favorável do $\mathrm{F}$ (como por exemplo, aumento da produção de matéria seca e aumento do diâmetro da planta) ou, pelo menos, não prejudicial deste para o crescimento das plantas têm sido relatado para diferentes plantas, crescidas sob condições controladas com atmosfera enriquecida com $\mathrm{HF}$ ou que receberam aplicação foliar de fertilizantes contendo F (Hill et al., 1958; Treshow \& Harner, 1968; Doley, 1989; Sikora et al., 1992). Weinstein (1977) relatou que, plantas expostas a atmosfera enriquecida com HF, apresentaram diminuição na incidência de pragas (pulgão) e algumas doenças (principalmente fúngicas, como o míldio), levando inclusive, como ação indireta, à maior produção vegetal.

$\mathrm{Na}$ região de Cubatão (Vila Parisi), Estado de São Paulo, foram encontradas as maiores concentrações de $\mathrm{F}\left(8,9 \mathrm{mg} \mathrm{L}^{-1}\right)$ na água da chuva em todo o mundo, sendo esta concentração sensivelmente decrescente com o aumento da distância da fonte emissora. Apesar dessa elevada concentração, não se constatou qualquer caso de fluorose nas pessoas residentes nesta região (Haag, 1985).

Silva Filho (1988) verificou a existência de injúrias nas plantas desenvolvidas em áreas altamente poluídas de Cubatão, constatando que o $\mathrm{F}$ presente na atmosfera foi absorvido pelas folhas, acumulando-se nos bordos, e que a absorção pelas raízes do $\mathrm{F}$ do solo foi pequena e não contribuiu para essas injúrias. Klumpp et al. (1997), ainda na região de Cubatão, encontraram fitotoxicidade em diversos cultivares de gladíolo, reconhecidamente uma das melhores indicadoras da poluição atmosférica deste elemento, quando efluentes industriais enriqueceram continuamente a atmosfera com $\mathrm{HF}, \mathrm{NH}_{3}$ e compostos sulfurosos. Esses autores entretanto, não conseguiram distinguir o grau de injúria vegetal devido a cada poluente distintamente.

Arnesen (1997), trabalhando com solos próximos a metalúrgicas, os quais recebiam deposições atmosféricas de $\mathrm{F}$, verificou que a concentração de $\mathrm{F}$ na parte aérea das plantas cultivadas era proveniente de absorção via estômatos e não via solo. Em outro experimento com dois solos isentos de F, um franco-arenoso e outro arenoso, em que foram aplicadas diversas doses de $\mathrm{NaF}$ e cultivadas gramíneas e leguminosas, verificou-se que a absorção via solo não foi proporcional à concentração de $\mathrm{F}$ no solo, $\mathrm{e}$ ainda que a leguminosa absorveu mais que a gramínea, mas em concentrações abaixo do 
nível máximo tolerável na dieta animal de bovinos e caprinos $\left(40 \mathrm{mg} \mathrm{kg}^{-1}\right)$. Constatou-se ainda maior absorção de $\mathrm{Al}$, indicando redução da fitotoxicidade dos dois elementos. $\mathrm{O}$ autor não considera que houve efeito depressivo do $\mathrm{Na}$, apesar da condutividade elétrica superar 5,0 mS cm$~^{-1}$ quando foi aplicada a dose de $1768 \mathrm{mg}$ de NaF por quilograma de solo.

Treshow (1971) relatou que plantas que desenvolveram-se em solos de áreas contaminadas por $\mathrm{F}$, apresentaram concentrações de $\mathrm{F}$ quatro vezes superior que o normal, comparado com valores de vinte e duas a duzentas vezes naquelas que se desenvolveram em atmosfera enriquecida com F. O F aplicado na forma de $\mathrm{NaF}$, em doses elevadas no substrato, pode inibir tanto a germinação quanto o crescimento de espécies sensíveis. Por outro lado, em pequenas doses, o F pode estimular a germinação em algumas espécies tolerantes.

Alguns trabalhos (Leone et al., 1948; Daines et al., 1952; Brewer et al., 1958) realizados em condições controladas constataram que o $\mathrm{F}$ acumulou-se nas folhas, causando fitotoxicidade. Por outro lado, em condições de campo, Macintire (1949) aplicou 2,6 t ha ${ }^{-1}$ de $\mathrm{F}$ na forma de $\mathrm{CaF}_{2}$ e não encontrou elevação da concentração de $\mathrm{F}$ nas folhas. Estes resultados mostram que a fitotoxicidade encontrada em condições controladas não se aplica necessariamente em condições de campo. Além disso, de acordo com MacIntire (1949), alguns trabalhos feitos em condições controladas, têm empregado concentrações de F muito elevadas, raramente encontradas no campo.

Hansen et al. (1958) estudaram o efeito da aplicação de $\mathrm{NaF}$ e $\mathrm{Na}_{2} \mathrm{SiF}_{6}$ em quatro solos sobre a absorção de $\mathrm{F}$ em plantas de alfafa e nabo. Esses resultados de acumulação de $\mathrm{F}$ via solo nessas plantas foram comparados com a acumulação ocorrida nelas em regiões com elevada concentração de $\mathrm{F}$ na atmosfera. Esses autores concluíram que houve diminuição geral da produção quando a concentração de $\mathrm{F}$ na parte aérea foi superior ao nível crítico. Todavia, a absorção foi bem menor nos solos argilosos, calcariados, com maior concentração de matéria orgânica e tratados com $\mathrm{Na}_{2} \mathrm{SiF}_{6}$. Os resultados obtidos por Hansen et al. (1958) e por outros autores (Treshow, 1971; Weinstein,1977; Needham, 1983), demonstram que, em condições de campo, a contaminação ocorre via absorção direta da atmosfera e não indiretamente via solo. 
Allaway (1986) relatou que a adição de fonte fluoretada de baixa solubilidade em solos variando de moderadamente ácidos a moderadamente alcalinos, não aumentou a concentração de $\mathrm{F}$ nas plantas e portanto, não causando danos às mesmas. Segundo esse autor, quando o $\mathrm{F}$ está presente na forma orgânica seu risco é diminuído e limitado às formas solúveis e, mesmo assim, quando aplicado em solos fortemente ácidos. Portanto, qualquer prejuízo decorrente da aplicação no solo de $\mathrm{F}$ poderia ser substancialmente corrigido pela calagem.

Singh et al. (1979a), preocupados com o uso do gesso agrícola para a correção de solos sódicos em uma região da Índia, estudaram a interação entre F e $\mathrm{P}$, utilizando $\mathrm{NaF}$ e $\mathrm{KH}_{2} \mathrm{PO}_{4}$, em dois solos com diferentes níveis de saturação por $\mathrm{Na}$ (30 e 70\%), tendo o arroz como planta indicadora. Verificaram que o $\mathrm{F}$ diminuiu a produção, principalmente no nível de $70 \%$ de saturação por $\mathrm{Na}$, sendo que nesse tratamento ocorreu a maior absorção de $\mathrm{F}$ e Na. No entanto, os autores não apresentaram os valores de $\mathrm{pH}$ e nem isolaram o fator depressivo do $\mathrm{Na}$ no aumento dos níveis de saturação por $\mathrm{Na}$ de 30 para $70 \%$. Nas plantas de arroz, o $\mathrm{F}$ acumulou-se nas folhas, mas não nos grãos. Houve ainda diminuição da absorção do $\mathrm{F}$ quando o $\mathrm{P}$ estava em alta concentração. Posteriormente, Singh et al. (1979b), num experimento similar utilizando como planta indicadora o trigo, encontraram os mesmos resultados do experimento com arroz, evidenciando ainda a redução da absorção de $\mathrm{Cl}$ em elevadas concentrações de $\mathrm{P}$.

Beresin et al. (1991), num estudo onde o gesso agrícola foi aplicado para diminuir a saturação por $\mathrm{Na}$ em solos sódicos na Rússia, verificaram que as concentrações de $\mathrm{F}$ nas plantas de aveia e cevada foram baixas e independentes das práticas agrícolas e de melhoramento do solo. Em condições de cultivo, a concentração de $\mathrm{F}$ nas plantas crescidas em solos alcalinos de pradaria foi inferior a $10 \mathrm{mg} \mathrm{kg}^{-1}$. Em anos muito chuvosos, essa concentração nas plantas aumentou para $40 \mathrm{mg} \mathrm{kg}^{-1}$, enquanto que em anos secos, reduziu-se para $2 \mathrm{mg} \mathrm{kg}^{-1}$. Não houve associação significativa entre a concentração de $\mathrm{F}$ no solo e $\mathrm{F}$ nas plantas e também, não ocorreu acúmulo de $\mathrm{F}$ nos grãos de aveia e cevada. $\mathrm{O}$ acúmulo (passivo) de $\mathrm{F}$ nas plantas cultivadas em solos salinos pode ser atribuído à melhoria das condições de fertilidade $\mathrm{e}$ do aumento da porosidade do solo devido ao uso do gesso agrícola. 
McLaughlin et al. (1996), numa revisão sobre o impacto ambiental de diversos contaminantes presentes em adubos (média de $1,1 \mathrm{~kg} \mathrm{ha}^{-1} \mathrm{ano}^{-1}$ na Austrália), concluíram que o $\mathrm{F}$ apresentava risco ínfimo de acumular-se em concentrações tóxicas nas partes comestíveis das plantas cultivadas, mesmo em solos pesadamente adubados, já que sua biodisponibilidade era muito baixa.

\subsubsection{O flúor nos animais}

Os organismos vivos necessitam somente de pequenas quantidades de alguns elementos como Ti, F, Al, V, Co, Ni, Si, As, Se e I (Adriano, 1986; Asher 1991; Campen, 1991; Miller et al., 1991). Especula-se que esses elementos sejam importantes, uma vez que parecem participar de importantes eventos biocatalíticos, entretanto, a participação desses no desenvolvimento dos animais ainda não foi esclarecida.

A essencialidade do F para animais é ainda questionável, enquanto alguns trabalhos confirmam esta essencialidade outros a rejeitam. Segundo Shortland (1988) e Miller et al. (1991), as evidências da essencialidade são: (1) o F é sempre encontrado em dentes e ossos; (2) pequenas concentrações de F reduzem a incidência de cárie dental, pois o $\mathrm{F}$ inibe a solubilidade do esmalte, pela substituição de $\mathrm{OH}$ e formação de um composto de baixa solubilidade; (3) o F reduz a desmineralização de ossos (osteoporose) em indivíduos de idade avançada; (4) o F estimula o crescimento e a reprodução de ratos e camundongos; (5) o F favorece a absorção do Fe e assim sendo, protege $\mathrm{o}$ organismo contra anemia.

O F está presente na constituição do esqueleto de animais, formando fluorapatita, que aumenta sua rigidez. Em animais domésticos, não expostos a ambientes contaminados, a concentração de F no esqueleto seco e sem gordura é alto, entre $300 \mathrm{e}$ $600 \mathrm{mg} \mathrm{kg}^{-1}$, variando com a porção óssea, mas é baixo nos tecidos moles, exceto nos rins e placenta, devido às suas funções de purificação do sangue, onde as concentrações são elevadas. Cerca de $75 \%$ do $\mathrm{F}$ presente no sangue está no plasma, tanto na forma iônica quanto na molecular (Miller et al., 1991).

Sintomas de deficiência de $\mathrm{F}$ ainda não foram relatados. Por outro lado, o seu excesso provoca manchas nos dentes, osteofluorose e pode provocar a destruição de 
eritrócitos no sangue, afetando a ação de enzimas no processo respiratório. A ingestão contínua de quantidades excessivas de $\mathrm{F}$ pelos animais pode acarretar desordens como a fluorose, enquanto que niveis subótimos na dieta também pode ser perigoso. Portanto, a quantidade de $\mathrm{F}$ nas plantas é importante na nutrição animal (Adriano, 1986). O problema de toxicidade de $\mathrm{F}$ pode ocorrer, especialmente se for consumida água de origem subterrânea que tenha percolado em solos com grande quantidade de fluorapatita, ou se esta água for usada para irrigação, pois as plantas absorvem o $\mathrm{F}$ facilmente via foliar. Dentre os animais domésticos, os bovinos são considerados dos mais sensíveis ao excesso de $\mathrm{F}$, sendo a concentração máxima tolerada na dieta de bezerros, na forma de $\mathrm{NaF}$, de $40 \mathrm{mg} \mathrm{kg}^{-1}$ e de $100 \mathrm{mg} \mathrm{kg}^{-1}$ para garrotes, em curtos períodos (Miller et al., 1991).

Segundo Food and Nutrition Board (1989), as doses diárias recomendadas de F (em mg) na dieta humana, presentes na água e nos alimentos, variam em função da idade: 0,1 a 1,0 para crianças até 1 ano de idade; 0,5 a 2,5 para crianças e adolescentes e de 1,5 a 4,0 para adultos. As maiores fontes de $\mathrm{F}$ são peixes e outros alimentos marinhos.

A velocidade e o grau de absorção do $\mathrm{F}$ varia com a forma física e química do composto, sendo máxima quando solúvel, como por exemplo $\mathrm{NaF}$, diminuindo quando o mesmo está ligado ao $\mathrm{Ca}, \mathrm{Mg}, \mathrm{Al}$ ou com participação de $\mathrm{P}$ ou $\mathrm{S}$ no composto. Wright $\&$ Thompson (1978), verificaram que na dieta de ratos, aproximadamente $97 \%$ do $\mathrm{F}$ fornecido como $\mathrm{NaF}$ foi absorvido no trato digestivo, mas quando este foi na forma $\mathrm{AlF}_{3}$ (ligação difícil de ser rompida) somente $16 \%$ foi absorvido, provavelmente, devido à menor proporção de HF (tóxico) formado no meio extremamente ácido do estômago. Segundo Spencer \& Cramer (1988), substâncias contendo Al são muito eficientes na inibição da absorção intestinal do F. O F absorvido é rapidamente distribuído pelo corpo, especialmente nos tecidos duros, e o excesso é rapidamente eliminado. 


\section{MATERIAL E MÉTODOS}

\subsection{Experimento de campo}

\subsubsection{Caracterização do solo}

O experimento foi conduzido na Estação Experimental de Cana, em Piracicaba (SP), pertencente ao Instituto Agronômico de Campinas - IAC, entre novembro de 1995 e maio de 1997, num solo podzólico vermelho-amarelo endoálico, textura argilosa, relevo local suave ondulado e regional ondulado, fase floresta tropical subcaducifólia, material originário folhelho, apresentando 490, $150 \mathrm{e} 360 \mathrm{~g} \mathrm{~kg}^{-1}$, respectivamente de argila, silte $\mathrm{e}$ areia, pelo método do densímetro. A mineralogia da fração argila é dominada por caulinita, mica e vermiculita além de gibbsita, goethita e hematita, enquanto a fração silte é dominada por feldspato e pirofilita.

Amostras de solo foram coletadas nas profundidades de $0-5,5-10,10-20 \mathrm{e}$ 20-30 cm, secas ao ar, destorroadas, passadas em peneira de $2 \mathrm{~mm}$ de malha (TFSA) e homogeneizadas. Em seguida, procedeu-se à análise química de rotina fazendo-se a determinação de $\mathrm{pH}$ em $\mathrm{CaCl}_{2} \quad 0,01 \mathrm{~mol} \mathrm{~L}^{-1}$, matéria orgânica (MO) pelo método colorimétrico, $\mathrm{Ca}, \mathrm{Mg}$ e $\mathrm{K}$ trocáveis e $\mathrm{P}$ pelo método da resina trocadora de íons, $\mathrm{H}+\mathrm{Al}$ pelo método SMP e Al trocável extraído com $\mathrm{KCl} 1,0 \mathrm{~mol} \mathrm{~L}^{-1}$ e calculou-se os valores de capacidade de troca de cátions (CTC), porcentagem de saturação por bases (V\%) e porcentagem de saturação por $\mathrm{Al}(\mathrm{m} \%)$, de acordo com Raij et al. (1987). Além disso, determinou-se o Na conforme método proposto por Vettori (1969), utilizando-se porém como solução extratora $\mathrm{H}_{2} \mathrm{SO}_{4} \quad 2,5 \mathrm{mmol} \mathrm{L}^{-1}$, que também foi empregada na diluição da solução padrão de $\mathrm{Na}$, visando manter constante a concentração de sulfato nas amostras e padrões.

O flúor "lábil" do solo foi determinado conforme metodologia descrita por Larsen \& Widdowson (1971). Foram pesadas $16 \mathrm{~g}$ de terra, seca e peneirada, e 
adicionado $50 \mathrm{~mL}$ de solução de $\mathrm{CaCl}_{2} \quad 0,01 \mathrm{~mol} \mathrm{~L}^{-1}$, agitando-se durante $16 \mathrm{~h}$ à temperatura constante de $25^{\circ} \mathrm{C}$. Em seguida, essa amostra foi filtrada em papel Whatman $\mathrm{n}^{\circ} 40$. Tomou-se uma alíquota de $20 \mathrm{~mL}$ desse filtrado, transferiu-se para um béquer de polietileno de $50 \mathrm{~mL}$, adicionaram-se $20 \mathrm{~mL}$ da solução tampão TISAB IV (fixa em limites estreitos o $\mathrm{pH}$ e a força iônica na solução, além de diminuir drasticamente a ação de agentes complexantes como o $\mathrm{Al}$ ) e corrigiu-se o $\mathrm{pH}$ para 7,5 com $\mathrm{HCl} 1,0 \mathrm{~mol} \mathrm{~L}^{-1}$. A leitura foi feita sob agitação com eletrodo seletivo de $\mathrm{F}$ marca Mettler-Toledo, sendo comparada graficamente em papel semi-log com as concentrações padrões de $\mathrm{F}$ na abscissa e suas respectivas leituras na ordenada. As soluções padrões foram feitas com concentrações seqüenciais de $\mathrm{F}$, através da diluição da solução estoque (1000 $\mathrm{mg} \mathrm{L}^{-1}$ de $\mathrm{F}$ na solução). A solução estoque de $\mathrm{F}$ foi preparada dissolvendo-se $2,21 \mathrm{~g}$ de $\mathrm{NaF}$, previamente seco $\left(120^{\circ} \mathrm{C}\right.$ durante 2 horas), em água bidestilada e diluída para 1 litro.

O método de preparação da solução tampão TISAB IV é apresentado a seguir: (1) adicionam-se $84 \mathrm{~mL}$ de $\mathrm{HCl}$ concentrado 36-38\% (m/v), $242 \mathrm{~g}$ de Tris (hidroximetil) amino metano e $230 \mathrm{~g}$ de tartarato de sódio em $500 \mathrm{~mL}$ de água bidestilada; (2) agita-se para dissolver e deixa-se esfriar a temperatura ambiente; (3) transfere-se a solução para um balão volumétrico de $1,0 \mathrm{~L}$ e completa-se o volume com água bidestilada.

A Tabela 1 apresenta a caracterização química do solo antes da instalação do experimento, revelando o elevado grau de acidez e a baixa fertilidade do solo.

\subsubsection{Tratamentos aplicados no solo}

Vinte e uma parcelas foram estabelecidas em novembro de 1995, numa área que não utilizada nos últimos cinco anos. Cada parcela possuiu uma área de $2 \mathrm{~m}^{2}(1 \mathrm{~m}$ de largura x $2 \mathrm{~m}$ de comprimento). $\mathrm{O}$ experimento seguiu delineamento em blocos casualizados com três repetições.

As parcelas constaram de sete doses de fluoreto de sódio (p.a.) aplicadas a lanço, calculadas com base na neutralização teórica do $\mathrm{Al}$ trocável (formação de $\mathrm{AlF}_{3}$ ) na camada 0-30 $\mathrm{cm}$ de solo, que foram as seguintes $\left(\mathrm{kg} \mathrm{ha}^{-1}\right)$ : 0 (testemunha); 832 (equivalente a quantidade teórica para a neutralização de $30 \%$ do $\mathrm{Al}$ trocável); 1386 (para neutralizar 50\% 
do Al trocável); 1941 (para neutralizar 70\% do $\mathrm{Al}$ teórico); 2772 (100\%, isto é, para a neutralização total do Al trocável); 5544 (200\%, isto é, para a neutralização total do Al trocável e ainda, gerando um excesso de $\mathrm{F}^{-}$equivalente a 100\%) e $8316(300 \%$, isto é, para a neutralização total do $\mathrm{Al}$ trocável e com excesso de $200 \%$ de $\mathrm{F}^{-}$). Os tratamentos com as duas doses mais altas de $\mathrm{NaF}$ (5544 e $8316 \mathrm{~kg} \mathrm{ha}^{-1}$ ) foram empregados para avaliar a existência de problemas de toxicidade de $\mathrm{F}$ para as plantas.

$\mathrm{O} \mathrm{Na}^{+}$foi escolhido como cátion acompanhante do $\mathrm{F}^{-}$, entre outros motivos, para que fosse isolado ao máximo possível, o efeito benéfico indireto da nutrição vegetal, pois se fosse usado $\mathrm{Ca}^{2+}, \mathrm{Mg}^{2+}$ ou $\mathrm{K}^{+}$, poderia ocorrer uma interferência nos resultados, mascarando o eventual efeito benéfico do $\mathrm{F}^{-}$sobre o Al fitotóxico. Evidentemente, o outro lado da questão deve ser esperado, isto é, o efeito prejudicial do $\mathrm{Na}^{+}$, quando em quantidade elevada, sobre o ambiente agrícola.

Tabela 1. Análise química de solo antes da instalação do experimento.

\begin{tabular}{lccccc}
\hline Atributo & \multicolumn{5}{c}{ Camada de solo (cm) } \\
\cline { 2 - 6 } do solo & $\mathbf{0 - 5}$ & $\mathbf{5 - 1 0}$ & $\mathbf{1 0 - 2 0}$ & $\mathbf{2 0 - 3 0}$ & Média $^{(1)}$ \\
\hline $\mathrm{pH} \mathrm{em} \mathrm{CaCl}$ & & 3,7 & 3,9 & 3,8 & 3,9 \\
$\mathrm{MO}\left(\mathrm{g} \mathrm{dm}^{-3}\right)$ & 20,0 & 17,0 & 16,7 & 14,7 & 17,1 \\
$\mathrm{Al}\left(\mathrm{mmol}_{\mathrm{c}} \mathrm{dm}^{-3}\right)$ & 17,7 & 23,7 & 21,7 & 22,0 & 21,3 \\
$\mathrm{Ca}\left(\mathrm{mmol}_{\mathrm{c}} \mathrm{dm}^{-3}\right)$ & 18,0 & 15,0 & 17,3 & 14,0 & 16,1 \\
$\mathrm{Mg}\left(\mathrm{mmol}_{\mathrm{c}} \mathrm{dm}^{-3}\right)$ & 8,0 & 6,0 & 5,3 & 3,3 & 5,7 \\
$\mathrm{~K}\left(\mathrm{mmol}_{\mathrm{c}} \mathrm{dm}^{-3}\right)$ & 2,2 & 1,9 & 1,6 & 1,0 & 1,7 \\
$\mathrm{Na}\left(\mathrm{mmol}_{\mathrm{c}} \mathrm{dm}^{-3}\right)$ & 1,1 & 1,1 & 1,1 & 1,1 & 1,1 \\
$\mathrm{P}\left(\mathrm{mg} \mathrm{dm}^{-3}\right)$ & 8,0 & 6,3 & 5,0 & 3,0 & 5,6 \\
I $\left(\mathrm{mg} \mathrm{dm}^{-3}\right)$ & 0,3 & 0,4 & 0,6 & 0,6 & 0,5 \\
$\mathrm{H}+\mathrm{Al}\left(\mathrm{mmol}_{\mathrm{c}} \mathrm{dm}^{-3}\right)$ & 80,0 & 98,7 & 89,0 & 88,7 & 89,1 \\
$\mathrm{CTC}\left(\mathrm{mmol}_{\mathrm{c}} \mathrm{dm}^{-3}\right)$ & 108,3 & 121,7 & 113,0 & 105,3 & 112,1 \\
$\mathrm{~V} \%$ & 26 & 19 & 21 & 16 & 21 \\
$\mathrm{~m} \%$ & 39 & 51 & 48 & 56 & 48 \\
\hline
\end{tabular}

${ }^{(1)}$ valores médios nos primeiros $30 \mathrm{~cm}$ de profundidade do solo. 


\subsubsection{Condução do experimento e obtenção de amostras de planta e solo}

Foram utilizadas como plantas-testes uma gramínea, o sorgo (Sorghum vulgare L.), que é uma espécie relativamente tolerante a níveis tóxicos de $\mathrm{Al}$ na solução do solo (Malavolta et al., 1981) e uma leguminosa, a crotalária (Crolalaria juncea L.), objetivando uma rotação de tipo de sistema radicular, e com diferenças na necessidade nutricional e na susceptibilidade a elementos tóxicos. Noventa dias após a aplicação de doses de $\mathrm{NaF}$ no solo, realizou-se a semeadura (manual) do sorgo (fevereiro de 1996), com espaçamento de $70 \mathrm{~cm}$ entre linhas e de $30 \mathrm{~cm}$ entre covas, e depois em meados de novembro de 1996, foi semeado a crotalária, em quatro covas eqüidistantes por parcela, com cinco sementes por cova. Não houve qualquer adubação mineral para não se introduzir outras fontes de variação. Tomou-se cuidado para retornar o material orgânico proveniente dos desbastes e capinas nas respectivas parcelas.

O suprimento de água para as culturas foi feito pela precipitação pluvial, complementada com irrigação com água destilada. A Figura 1 apresenta, mês a mês, a lâmina total $(2596,7 \mathrm{~mm})$ incidente durante todo o experimento de campo. As lâminas mensais correspondem à precipitação pluvial + irrigação. A precipitação anual média nessa região é de 1262,2 mm com tempo de recorrência de oitenta anos.

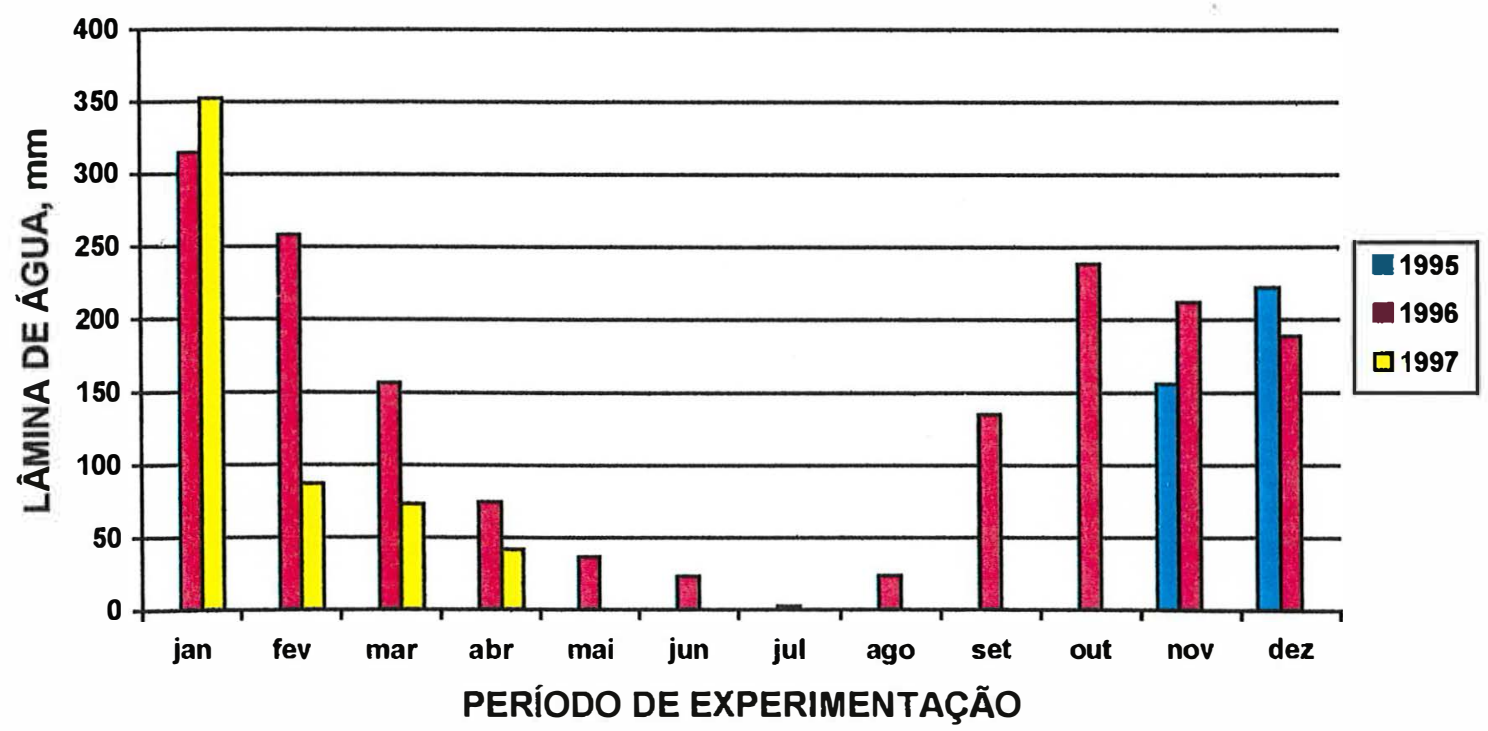

Figura 1. Lâmina total mensal durante o período de experimentação. 
Em abril de 1996, no início do perfilhamento do sorgo (aproximadamente três meses após o plantio), foram coletadas amostras de folhas $\left(3^{\mathrm{a}}\right.$ e $4^{\mathrm{a}}$ a partir da ponta) para análise química. Posteriormente, todas as panículas foram coletadas para determinação da produção de matéria seca de grãos. Com relação a crotalária, as amostras de folhas obtidas no terço médio da planta foram coletadas no início da floração, que ocorreu três meses após o plantio (meados de fevereiro de 1997) e, depois de quarenta e cinco dias (no final de abril de 1997), foram coletadas as vagens, para quantificar a produção de matéria seca de vagens.

Decorridos seis e dezoito meses da aplicação de doses de $\mathrm{NaF}$, respectivamente em maio de 1996 (após a colheita do sorgo) e maio de 1997 (após a colheita da crotalária), foram efetuadas amostragem do solo em quatro profundidades (camada 0-5, 5-10, 10-20 e 20-30 cm), denominadas de subparcelas (experimento em parcelas subdivididas), com a finalidade de quantificar variações ocorridas em alguns atributos químicos do solo, em função de doses de $\mathrm{NaF}$ aplicadas e da camada amostrada.

\subsubsection{Análise química de solo}

As amostras de solo obtidas em diversas profundidades foram secas ao ar, destorroadas, passadas em peneira de $2 \mathrm{~mm}$ de malha (TFSA) e homogeneizadas. Essas amostras foram submetidas à análise química para os mesmos atributos e conforme os mesmos procedimentos descritos no ítem 3.1.1.

\subsubsection{Análise química de plantas}

As amostras de folhas foram secas em estufa, com circulação forçada de ar, a $60^{\circ} \mathrm{C}$, até massa constante, sendo posteriormente moídas em moinho do tipo Wiley. As análises para a determinação total das concentrações de macro (N, P, K, Ca, Mg e S) e micronutrientes $(\mathrm{B}, \mathrm{Cu}, \mathrm{Fe}, \mathrm{Mn}$ e $\mathrm{Zn}), \mathrm{Na}$ e $\mathrm{Al}$ foram realizadas conforme metodologia descrita por Malavolta et al. (1989). O N foi analisado por digestão sulfúrica e destilação, o B por digestão via seca e determinado por colorimetria, e os outros elementos por digestão nitroperclórica, sendo o $\mathrm{P}$ determinado por colorimetria, $\mathrm{K}$ por fotometria de chama de emissão, e os demais por espectrofotometria de absorção 
atômica. O F nas plantas foi extraído pelo método da água quente, com base em Cury ${ }^{1}$. Pesou-se $1,0 \mathrm{~g}$ de amostra de cada parte das plantas, transferiu-se para béquer de $250 \mathrm{~mL}$, adicionaram-se $50 \mathrm{~mL}$ de água bidestilada e aqueceu-se a $100^{\circ} \mathrm{C}$ durante 5 minutos, cobrindo-se com vidro de relógio. Após esfriar, procedeu-se a filtragem através de papel de filtro, lavando-se o papel de filtro com água bidestilada. Tomou-se uma alíquota de $20 \mathrm{~mL}$ desse filtrado, transferiu-se para um béquer de polietileno de $50 \mathrm{~mL}$, adicionaram-se $20 \mathrm{~mL}$ da solução tampão TISAB IV, e corrigiu-se o $\mathrm{pH}$ para 7,5 com $\mathrm{HCl} 1,0 \mathrm{~mol} \mathrm{~L}^{-1}$. A leitura foi feita com eletrodo seletivo de $\mathrm{F}$, conforme descrito no ítem 3.1.1.

\subsection{Experimento em casa de vegetação}

\subsubsection{Caracterização do solo}

Para o experimento conduzido sob casa de vegetação foram coletadas amostras da camada 20-40 cm de um podzólico vermelho-amarelo, localizado na Estação Experimental de Cana do IAC, em Piracicaba (SP). Este solo foi semelhante ao utilizado no experimento de campo, situando-se nas proximidades e na mesma posição na paisagem, porém, sob floresta e com concentração de $\mathrm{Al}$ mais elevada em profundidade. As amostras de solo foram secas, destorroadas, peneiradas e analisadas quimicamente conforme descrito no ítem 3.1.1.

A caracterização química do solo coletado revelou $\mathrm{pH}$ em $\mathrm{CaCl}_{2}: 3,5$; MO: $20 \mathrm{~g} \mathrm{dm}^{-3}$; $\mathrm{Al}: 28 \mathrm{mmol}_{\mathrm{c}} \mathrm{dm}^{-3}$; $\mathrm{Ca}, \mathrm{Mg}$ e K trocáveis: $2,0,7,0$ e 1,0 $\mathrm{mmol}_{\mathrm{c}} \mathrm{dm}^{-3}$, respectivamente; $\mathrm{Na}: 1,3 \mathrm{mmol}_{\mathrm{c}} \mathrm{dm}^{-3} ; \mathrm{P}: 3 \mathrm{mg} \mathrm{dm}^{-3}$; F: $0,4 \mathrm{mg} \mathrm{dm}^{-3} ; \mathrm{H}+\mathrm{Al}: 121 \mathrm{mmol}_{\mathrm{c}}$ $\mathrm{dm}^{-3}$; CTC: $131 \mathrm{mmol}_{\mathrm{c}} \mathrm{dm}^{-3}$; V: $8 \%$ e m: $74 \%$.

${ }^{1}$ CURY, J.A. (UNICAMP. Faculdade de Odontologia de Piracicaba). Comunicação pessoal, 1995. 


\subsubsection{Tratamentos aplicados no solo}

Cinco amostras de quatro litros de solo, previamente seco e peneirado (TFSA), foram submetidas aos seguintes tratamentos com aplicação de fontes (p.a.) e doses: $\mathrm{CaCO}_{3}$ (dose 1): $1400 \mathrm{mg} \mathrm{dm}^{-3}$ (equivalente a $2800 \mathrm{~kg} \mathrm{ha}^{-1}$ a $20 \mathrm{~cm}$ de profundidade); $\mathrm{CaCO}_{3}$ (dose 2): $2800 \mathrm{mg} \mathrm{dm}^{-3}$ (equivalente a $5600 \mathrm{~kg} \mathrm{ha}^{-1}$ a $20 \mathrm{~cm}$ de profundidade); $\mathrm{CaF}_{2}$ (dose 1): $1092,5 \mathrm{mg} \mathrm{dm}^{-3}$ (equivalente a $2185 \mathrm{~kg} \mathrm{ha}^{-1}$ a $20 \mathrm{~cm}$ de profundidade); $\mathrm{CaF}_{2}$ (dose 2): $2185 \mathrm{mg} \mathrm{dm}^{-3}$ (equivalente a $4370 \mathrm{~kg} \mathrm{ha}^{-1}$ a $20 \mathrm{~cm}$ de profundidade) e uma amostra não recebeu nem $\mathrm{CaCO}_{3}$ e nem $\mathrm{CaF}_{2}$ (testemunha). A dose 1 foi equivalente à quantidade teórica necessária para a neutralização do Al trocável (formação do par $\mathrm{AlF}_{3}$ ), sendo a dose 2 o dobro da dose 1 . A dose de $\mathrm{CaCO}_{3}$ foi definida com base na equivalência de cargas em relação ao $\mathrm{CaF}_{2}$. Em seguida, essas amostras foram acondicionadas em vasos plásticos. O experimento seguiu delineamento em blocos casualizados, sendo cinco tratamentos de solo e quatro repetições, totalizando-se vinte parcelas.

É importante ressaltar que, nesse experimento sob casa de vegetação, não houve restrição de usar o $\mathrm{Ca}^{2+}$ como cátion acompanhante do $\mathrm{CO}_{3}{ }^{2-}$ e do $\mathrm{F}$, já que o efeito benéfico, indireto, desse cátion como nutriente para as plantas poderia ser quantificado.

\subsubsection{Condução do experimento e obtenção de amostras de planta, solo e solução percolada}

Para avaliar os efeitos da aplicação no solo de $\mathrm{CaF}_{2}$, em relação ao $\mathrm{CaCO}_{3}$, sobre a produção vegetal, utilizou-se seqüencialmente quatro culturas: feijão (Phaseolus vulgaris L.), soja (Glycine max L.), crotalária (Crotalaria juncea L.) e milho (Zea mays L.). No início do experimento, portanto no início do processo de incubação do solo, realizou-se a semeadura de feijão, deixando-se após a germinação duas plantas por vaso. Após a colheita de feijão, foi semeado a soja, deixando-se após a germinação quatro plantas. Como fator de produção de feijão e soja, utilizou-se a quantidade de matéria seca de vagens produzida durante o ciclo de ambas culturas (90 dias). Em seguida da colheita da soja, procedeu-se a semeadura de crotalária, deixando-se após a 
germinação quatro plantas por vaso. Por último, foi semeado o milho, deixando-se após a germinação quatro plantas por vaso. Para crotalária e milho, empregou-se como fator de produção a quantidade de matéria seca da parte aérea, que foi coletada cerca de $1 \mathrm{~cm}$ acima do solo, após 75 dias e 60 dias, respectivamente. $O$ teor de água do solo foi mantido em aproximadamente $70 \%$ da porosidade total.

Para a avaliação da dinâmica dos cátions e ânions na solução do solo, em função da aplicação de $\mathrm{CaCO}_{3}$ e $\mathrm{CaF}_{2}$, o solo dos vasos foi saturado em diferentes épocas, sendo efetuadas amostragens da solução percolada. Como cada vaso tinha $4 \mathrm{~L}$ de solo e um volume total de poros (VP) de aproximadamente $40 \%$, estimou-se que 1 VP foi igual a 1,6 L. Foram seis épocas de amostragem da solução percolada: no início do experimento (após $0,1 \mathrm{~L}$ percolados, que corresponde a aproximadamente $0,1 \mathrm{VP}$ ), após a colheita de feijão (percolados um total de $0,8 \mathrm{~L}$ desde o início do experimento, que corresponde a $50 \%$ do volume total de poros ou 0,5 VP), após a colheita da soja (1,6 L percolados no total ou 1,0 VP), após a colheita da crotalária $(3,2 \mathrm{~L}$ percolados no total ou 2,0 VP), após a colheita do milho (4,8 L percolados no total ou 3,0 VP) e após percolados um total de $6,4 \mathrm{~L}$, correspondente a 4,0 VP. Portanto, a dinâmica de cátions e ânions em solução foi avaliada em uma intensidade de lixiviação de aproximadamente quatro volumes de poros.

No final do experimento, foram efetuadas amostragens do solo de todos os vasos.

\subsubsection{Análise química da solução percolada}

Em cada amostra de solução percolada $(100 \mathrm{~mL}$ por vaso e por época de amostragem) foram feitas determinações de $\mathrm{pH}, \mathrm{N}-\mathrm{NO}_{3}, \mathrm{P}, \mathrm{K}, \mathrm{Ca}, \mathrm{Mg}, \mathrm{Al}, \mathrm{Na}$ e $\mathrm{F}$. Na solução percolada 3,0 VP, determinou-se também o Fe, enquanto na solução 4,0 VP mediu-se somente o $\mathrm{pH}$. A determinação de $\mathrm{N}$ em soluções percoladas foi feita segundo metodologia descrita por Alcarde \& Chitolina (1991). O P foi determinado por colorimetria, $\mathrm{K}$ e $\mathrm{Na}$ por fotometria de chama de emissão, $\mathrm{Ca}, \mathrm{Mg}$ e $\mathrm{Fe}$ por espectrofotometria de absorção atômica, em chama ar/acetileno, e Al também por espectrofotometria de absorção atômica, mas em chama ar/óxido nitroso. Para o F, 
tomou-se uma alíquota de $20 \mathrm{~mL}$ da amostra de solução percolada, transferiu-se para um béquer de polietileno de $50 \mathrm{~mL}$, adicionaram-se $20 \mathrm{~mL}$ da solução tampão TISAB IV e corrigiu-se o $\mathrm{pH}$ para 7,5 com $\mathrm{HCl} 1,0 \mathrm{~mol} \mathrm{~L}^{-1}$. A leitura foi feita com eletrodo seletivo de F, conforme descrito no ítem 3.1.1.

\subsubsection{Análise química de plantas e solo}

As amostras de vagens de soja e da parte aérea da crotalária e do milho, secas e moídas, foram analisadas quimicamente para a determinação de $\mathrm{F}$, empregando-se a mesma metodologia utilizada no ensaio de campo (ítem 3.1.5).

As amostras de solo, coletadas no final do experimento, foram secas, destorroadas e peneiradas e em seguida, submetidas às análises químicas de rotina, $\mathrm{Na} e$ F, como descrito no experimento de campo (ítem 3.1.1).

\subsection{Especiação iônica}

Utilizou-se o programa GEOCHEM-PC (Parker et al., 1995) para calcular a especiação iônica em todas as soluções percoladas.

\subsection{Análise estatística}

No experimento conduzido no campo para avaliar atributos químicos do solo, cujas parcelas foram distribuídas em blocos casualizados e com três repetições, empregou-se dois esquemas de análise da variância. Primeiramente, em cada uma das duas épocas de amostragem do solo (seis meses e dezoito meses), o experimento foi analisado em parcelas subdivididas (denominado de modelo parcial), sendo as parcelas, as sete doses de $\mathrm{NaF}$ e as subparcelas, as quatro camadas de solo (Tabela 2). Por último, realizou-se uma análise geral do experimento (denominado de modelo geral) em parcelas subdivididas, no qual as parcelas foram constituídas de sete doses de $\mathrm{NaF}$, as subparcelas foram quatro camadas de solo e as sub-subparcelas foram duas épocas de amostragem de solo (maio de 96 e maio de 97) (Tabela 3). Com relação ao sorgo e a crotalária cultivadas no campo, os resultados das variáveis estudadas (produção e concentração de elementos nas folhas, grãos e vagens) foram submetidos à análise da 
variância, de acordo com o delineamento em blocos casualizados, sendo os tratamentos constituídos das sete doses de $\mathrm{NaF}$ e com três repetições.

Tabela 2. Esquema da análise da variância para alguns atributos químicos do solo, obtidos no experimento em parcelas subdivididas realizado em condições de campo, em função das sete doses de fluoreto de sódio e das quatro camadas de solo, em cada época de amostragem do solo (modelo parcial).

\begin{tabular}{lc}
\hline Causa da variação & Graus de liberdade \\
\hline Blocos $(\mathrm{Bl})$ & 2 \\
Tratamentos doses de NaF (Dose) & 6 \\
Resíduo (a) & 12 \\
\hline (Parcelas) & $\frac{(20)}{3}$ \\
\hline Tratamentos camadas do solo (Camada) & 18 \\
Interação Dose x Camada & 42 \\
Resíduo (b) & 83 \\
\hline Total corrigido & \\
\hline
\end{tabular}

Tabela 3. Esquema da análise da variância para alguns atributos químicos do solo, obtidos no experimento em parcelas subdivididas realizado em condições de campo, em função de sete doses de fluoreto de sódio, quatro camadas de solo e duas épocas de amostragem do solo (modelo geral).

\begin{tabular}{lc}
\hline Causa da variação & Graus de liberdade \\
\hline Blocos $(\mathrm{Bl})$ & 2 \\
Tratamentos doses de NaF (Dose) & 6 \\
Resíduo (a) & 12 \\
\hline (Parcelas) & $\frac{(20)}{3}$ \\
\hline Tratamentos camadas do solo (Camada) & 18 \\
Interação Dose x Camada & 42 \\
Resíduo (b) & $(83)$ \\
\hline (Subparcelas) & 1 \\
\hline Tratamentos épocas de amostragem do solo (Época) & 6 \\
Interação Dose x Época & 3 \\
Interação Camada x Época & 18 \\
Interação Dose x Camada x Época & 56 \\
Resíduo (c) & 167 \\
\hline Total corrigido &
\end{tabular}


Com relação ao experimento desenvolvido sob condições de casa de vegetação para avaliar o efeito da aplicação de $\mathrm{CaF}_{2}$ e $\mathrm{CaCO}_{3}$ na composição química da solução percolada do solo, utilizou-se delineamento em blocos casualizados, cujo esquema foi parcelas subdivididas, sendo as parcelas os cinco tratamentos de solo e as subparcelas, as diferentes épocas de amostragem das soluções percoladas (cinco épocas para as concentrações de $\mathrm{Al}, \mathrm{Ca}, \mathrm{Mg}, \mathrm{K}, \mathrm{Na}, \mathrm{N}$ e $\mathrm{F}$, seis épocas para $\mathrm{pH}$ e quatro épocas para a concentração de P), com quatro repetições (Tabela 4). Os resultados das variáveis do solo (atributos químicos) e plantas (produção e concentração de $\mathrm{F}$ na parte aérea e vagens) e ainda, a concentração de Fe na solução percolada 3,0 VP foram analisados como delineamento em blocos casualizados, com cinco tratamentos e quatro repetições.

Para a realização das análises da variância (teste $F$ ), testes de comparação de médias (Tukey), análises de correlação (coeficientes de correlação de Pearson) e regressão linear, foram utilizados os procedimentos estatísticos do SAS (Statistical Analysis System Institute, 1996). Todos os resultados foram avaliados aos níveis de probabilidade de 5\% e 1\%, excetuando-se o teste de Tukey que foi avaliado somente ao nível de $5 \%$, enquanto as conclusões foram baseadas ao nível de $5 \%$ de probabilidade.

Tabela 4. Esquema da análise da variância para alguns atributos químicos da solução percolada do solo, obtido no experimento em parcelas subdivididas realizado sob condições de casa de vegetação, em função de cinco tratamentos do solo e diferentes épocas de amostragem da solução.

\begin{tabular}{|c|c|c|c|}
\hline \multirow[t]{2}{*}{ Causa da variação } & \multicolumn{3}{|c|}{ Graus de liberdade } \\
\hline & pH & $\mathrm{Al}, \mathrm{Ca}, \mathrm{Mg}, \mathrm{K}, \mathrm{Na}, \mathrm{N}$ e F & $\mathbf{P}$ \\
\hline Blocos (Bl) & 3 & 3 & 3 \\
\hline Trat. de adição de $\mathrm{CaCO}_{3}$ e $\mathrm{CaF}_{2}$ (Trat) & 4 & 4 & 4 \\
\hline Resíduo (a) & 12 & 12 & 12 \\
\hline (Parcelas) & (19) & (19) & (19) \\
\hline Trat. época amostragem sol. perc.(Época) & 5 & 4 & 3 \\
\hline Interação Trat x Época & 20 & 16 & 12 \\
\hline Resíduo (b) & 75 & 60 & 45 \\
\hline Total corrigido & 119 & 99 & 79 \\
\hline
\end{tabular}




\section{RESULTADOS E DISCUSSÃO}

4.1 Efeito da aplicação de fluoreto de sódio nos atributos químicos do solo e na produção e nutrição de sorgo e crotalária, em condições de campo

\subsubsection{Alterações químicas do solo}

Os resultados da análise da variância em cada época de amostragem do solo (modelos parciais: Tabela 2) e nas duas épocas de amostragem (modelo geral: Tabela 3) revelaram que para todos os atributos químicos do solo estudados ocorreu efeito significativo da camada de solo amostrada, enquanto que o efeito da dose de $\mathrm{NaF}$ aplicada foi significativo somente nas concentrações de $\mathrm{Na}$ e $\mathrm{F}$ e nos valores de $\mathrm{H}+\mathrm{Al}$ e CTC do solo. A ocorrência de interação significativa entre dose de $\mathrm{NaF}$ e camada de solo (dose x camada) dependeu do atributo químico estudado e também da época de amostragem do solo. Após seis meses de experimentação, essa interação foi significativa para os seguintes atributos do solo: valor de $\mathrm{pH}$, concentrações de $\mathrm{Al}, \mathrm{Ca}, \mathrm{K}, \mathrm{Na}$ e F, e valores de $\mathrm{V} \%$ e m\%. Por outro lado, após dezoito meses, essa interação dose x camada foi significativa somente nas concentrações de $\mathrm{Na}$ e F no solo. Já na análise geral dos resultados (modelo geral), a interação dose $\mathrm{x}$ camada foi significativa para todos os atributos estudados, com exceção da concentração de P e dos valores de CTC e MO do solo, sendo que a ausência de interação nestes últimos sugere que as modificações em função das doses de $\mathrm{NaF}$, foram proporcionalmente semelhantes, nas diferentes camadas de solo amostradas. A análise geral dos resultados mostrou interação significativa entre dose de $\mathrm{NaF}$ e época de amostragem (dose $\mathrm{x}$ época) no $\mathrm{pH}, \mathrm{MO}$, concentrações de $\mathrm{Al}$ e $\mathrm{Na}$, e valores de CTC e m\%. Essa interação não foi encontrada nas concentrações de $\mathrm{Ca}$, $\mathrm{Mg}, \mathrm{K}, \mathrm{P}$ e $\mathrm{F}$ e valores de $\mathrm{H}+\mathrm{Al}$ e $\mathrm{V} \%$. A ausência dessa interação sugere que as modificações nesses atributos químicos do solo, em função da dose de $\mathrm{NaF}$ aplicada, foram proporcionalmente semelhantes, nas duas épocas de amostragem do solo. 


\subsubsection{1 pH do solo}

Os valores de $\mathrm{pH}\left(\mathrm{em} \mathrm{CaCl}_{2}\right)$ do solo aumentaram com o aumento das doses de $\mathrm{NaF}$ aplicadas (Tabela 5), evidenciando o efeito positivo do $\mathrm{NaF}$ na melhoria do ambiente radicular. Após seis meses, verificou-se aumento significativo do valor de $\mathrm{pH}$ até $20 \mathrm{~cm}$ de profundidade do solo, em função da aplicação das duas doses mais altas de $\mathrm{NaF}$ (5544 e $8316 \mathrm{~kg} \mathrm{ha}^{-1}$ ), comparando-se com a testemunha. Por outro lado, após dezoito meses de experimentação, embora o aumento do $\mathrm{pH}$ perdurasse em todas as camadas estudadas, não houve diferença significativa entre doses de $\mathrm{NaF}$. $\mathrm{Na}$ análise geral do experimento (modelo geral, Tabela 6), verificou-se que os valores de $\mathrm{pH}$ do solo foram significativamente afetados pela dose de $\mathrm{NaF}$ aplicada, pela camada de solo estudada, pelas interações entre dose e camada, entre dose e época de amostragem e também entre camada e época de amostragem do solo.

Os valores médios de $\mathrm{pH}$ diminuíram significativamente com o aumento da profundidade do solo, independentemente da dose de $\mathrm{NaF}$ aplicada e da época de amostragem (Tabela 5). Não houve efeito significativo nos valores de $\mathrm{pH}(0-30 \mathrm{~cm})$ em função da época de amostragem do solo (Tabela 5), já que, em média, esses mantiveram-se praticamente iguais, em torno de 4,5, sendo superior ao encontrado no início do experimento $(3,9)$ (Tabela 1$)$.

Nos primeiros $30 \mathrm{~cm}$ de profundidade média do solo, o valor de $\mathrm{pH}$ mostrou-se diretamente proporcional à dose de $\mathrm{NaF}$ aplicada, às concentrações de $\mathrm{Na}$ e $\mathrm{F}$ e também, inversamente proporcional aos valores de $\mathrm{H}+\mathrm{Al}$ e CTC, tanto após seis meses comó após dezoito meses (Tabela 6). Além disso, após seis meses da aplicação de $\mathrm{NaF}$, o pH do solo mostrou-se diretamente proporcional à concentração de $\mathrm{P}$ e também, após dezoito meses, mostrou-se inversamente proporcional ao conteúdo de $\mathrm{MO}$, à concentração de $\mathrm{Al}$ e ao valor de $\mathrm{m} \%$.

$\mathrm{O}$ valor de $\mathrm{pH}$ aumentou linearmente em função da dose de $\mathrm{NaF}$ e das concentrações de $\mathrm{Na}$ e F no solo, tanto após seis meses como após dezoito meses de experimentação (Tabela 7). Esse aumento do $\mathrm{pH}$ do solo deveu-se tanto ao caráter básico do sal $\mathrm{NaF}$ quanto pela liberação de $\mathrm{OH}^{-}$dos óxidos e hidróxidos de $\mathrm{Fe}$ e $\mathrm{Al}$ (principalmente os de baixo grau de cristalização) e também da superfície dos minerais 
Tabela 5. Influência de doses de fluoreto de sódio no $\mathrm{pH}$ em $\mathrm{CaCl}_{2}$, após seis e dezoito meses da aplicação, em quatro camadas de um podzólico vermelho-amarelo, em Piracicaba, SP.

\begin{tabular}{|c|c|c|c|c|c|}
\hline \multirow{2}{*}{$\begin{array}{l}\text { Dose de NaF } \\
\left(\mathrm{kg} \mathrm{ha}^{-1}\right)\end{array}$} & \multicolumn{5}{|c|}{ Camada de solo $(\mathrm{cm})$} \\
\hline & $0-5$ & $5-10$ & $10-20$ & $20-30$ & Média \\
\hline \multicolumn{6}{|c|}{ Após seis meses da aplicação ${ }^{(1)}$} \\
\hline $\mathbf{0}$ & $4,43 \mathrm{Ab}$ & $4,00 \mathrm{Bc}$ & $3,87 \mathrm{Bc}$ & $3,90 \mathrm{Ba}$ & $4,05 c$ \\
\hline 832 & $4,70 \mathrm{Ab}$ & $4,27 \mathrm{Bc}$ & $3,96 \mathrm{Cbc}$ & $3,93 \mathrm{Ca}$ & $4,22 \mathrm{c}$ \\
\hline 1386 & $4,73 \mathrm{Ab}$ & $4,30 \mathrm{ABbc}$ & $4,00 \mathrm{Bbc}$ & $3,90 \mathrm{Ba}$ & $4,23 \mathrm{c}$ \\
\hline 1941 & $4,83 \mathrm{Ab}$ & 4,57ABabc & 4,37Babc & $4,23 \mathrm{Ba}$ & 4,50abc \\
\hline 2772 & $4,77 \mathrm{Ab}$ & 4,53Aabc & $4,30 \mathrm{ABabc}$ & $4,00 \mathrm{Ba}$ & $4,40 \mathrm{bc}$ \\
\hline 5544 & $5,80 \mathrm{Aa}$ & $5,20 \mathrm{Bab}$ & 4,73Bab & $4,23 \mathrm{Ca}$ & $4,99 \mathrm{ab}$ \\
\hline 8316 & 5,57Aa & $5,43 \mathrm{Aa}$ & $4,87 \mathrm{Ba}$ & $4,37 \mathrm{Ca}$ & $5,06 a$ \\
\hline Média & $4,98 \mathrm{~A}$ & $4,61 \mathrm{~B}$ & $4,30 \mathrm{C}$ & $4,08 \mathrm{D}$ & 4,49 \\
\hline$F($ dose) & $0,05 * *$ & \multicolumn{4}{|c|}{$\mathrm{F}($ camada $)=139,65 * * \quad \mathrm{~F}($ dose $\mathrm{x}$ camada $)=4,36 * *$} \\
\hline
\end{tabular}

Após dezoito meses da aplicação ${ }^{(2)}$

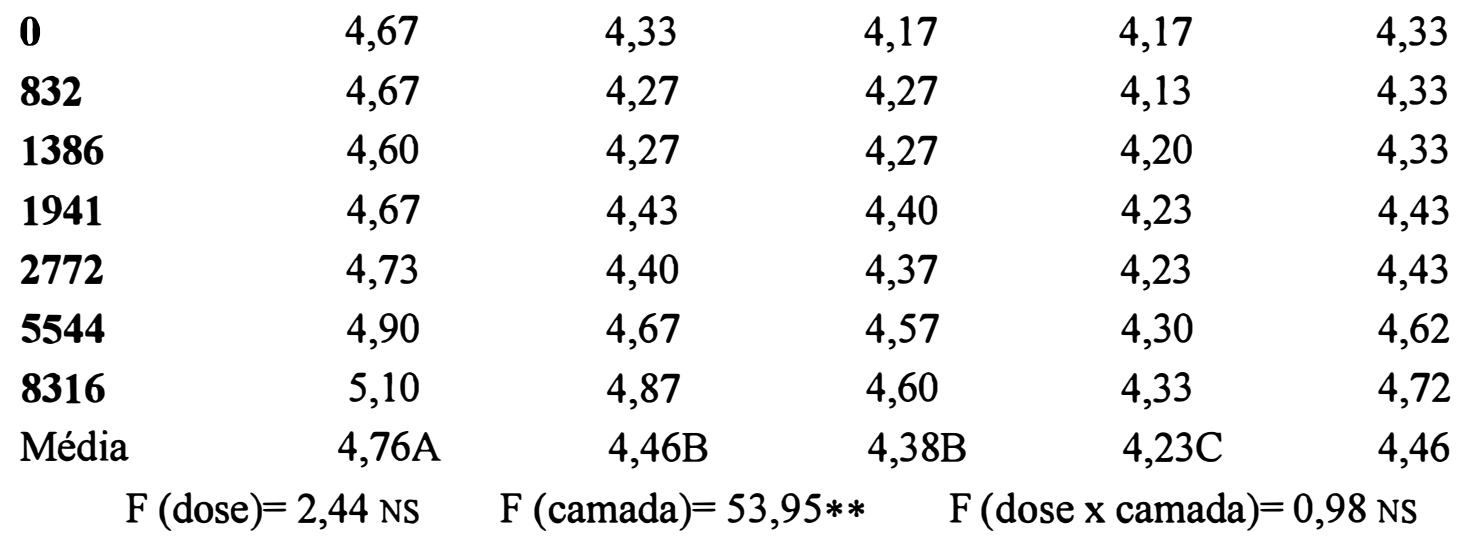

\section{Nas duas épocas de amostragem}

$$
\mathrm{F}(\text { dose })=6,96 * * \quad \mathrm{~F}(\text { camada })=175,03 * * \quad \mathrm{~F}(\text { época })=1,81 \mathrm{NS}
$$

$\mathrm{F}($ dose $\mathrm{x}$ camada $)=3,81 * * \quad \mathrm{~F}($ dose $\mathrm{x}$ época $)=12,10 * * \quad \mathrm{~F}($ camada $\mathrm{x}$ época $)=10,84 * *$

$\mathrm{F}($ dose $\mathrm{x}$ camada $\mathrm{x}$ época $)=1,31 \mathrm{NS}$

\footnotetext{
${ }^{(1)}$ Após cultivo de sorgo, em maio de 1996. ${ }^{(2)}$ Após cultivo de crotalária, em maio de 1997.

Números seguidos pela mesma letra, maiúscula na linha e minúscula na coluna, não diferem entre si ao nivel de $5 \%$ de probabilidade pelo teste de Tukey.

**, * significativo pelo teste $\mathrm{F}$ ao nível de $1 \%$ e $5 \%$ de probabilidade, respectivamente. NS não significativo.
} 


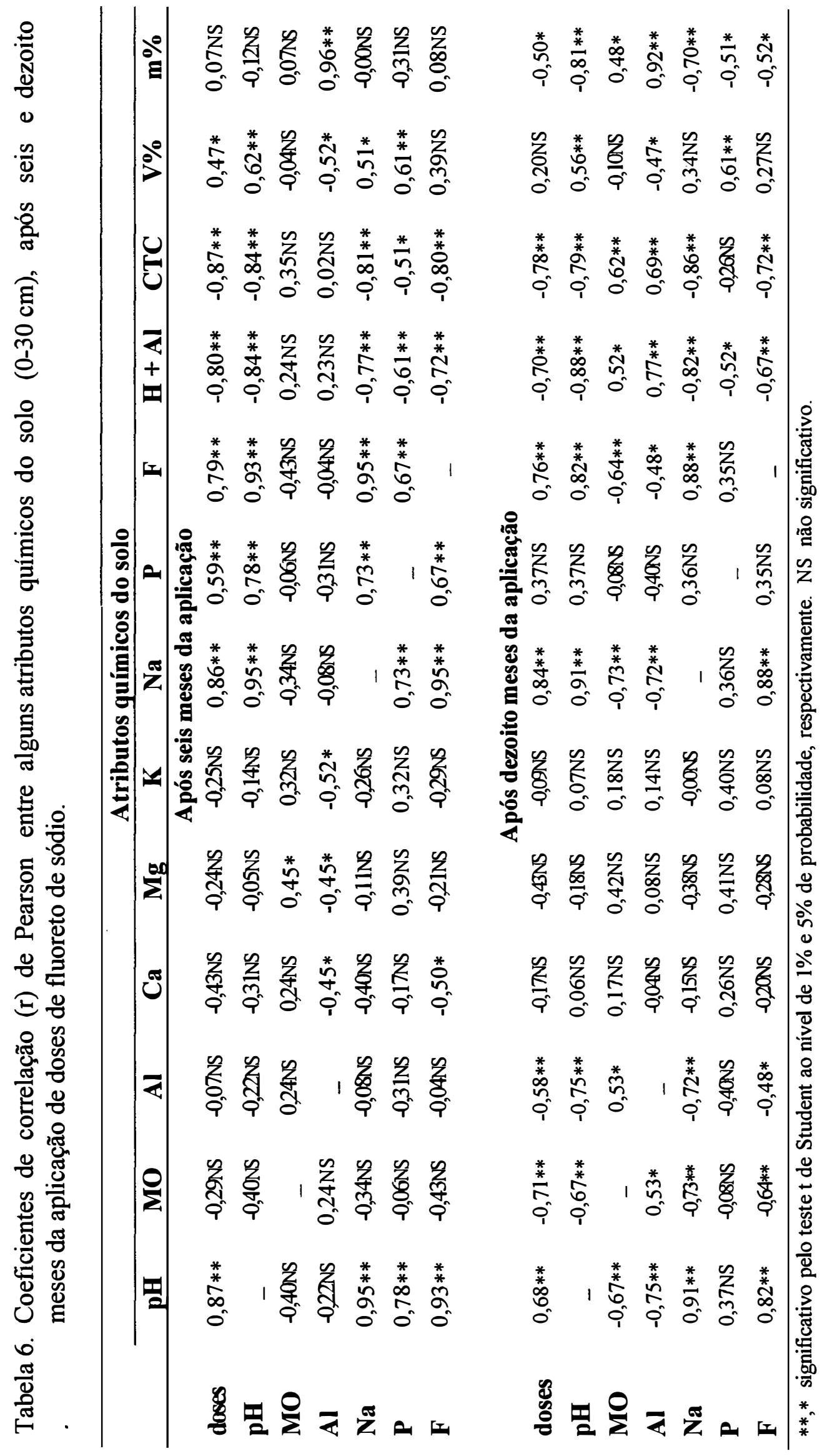


de argila devido à adsorção do F* (Dickman \& Bray, 1941; Parfitt, 1978; Flühler et al., 1982; Peek \& Volk, 1986; Hsu, 1989). Como o efeito principal do pH do solo é indireto, com a diminuição da acidez do solo pela aplicação de $\mathrm{NaF}$, houve no início do experimento aumento na disponibilidade de $\mathrm{P}$ e com o decorrer do tempo, houve diminuição do Al trocável do solo (Kiehl, 1979; Malavolta, 1980).

Tabela 7. Equações de regressão linear dos valores de $\mathrm{pH}$ do solo em função de doses de fluoreto de sódio $\left(\mathrm{kg} \mathrm{ha}^{-1}\right)$ ou das concentrações de sódio $\left(\mathrm{mmol}_{\mathrm{c}} \mathrm{dm}^{-3}\right) \mathrm{e}$ flúor $\left(\mathrm{mg} \mathrm{dm}^{-3}\right)$ no solo, após seis e dezoito meses da aplicação.

\begin{tabular}{lc}
\hline Equação de regressão & \multicolumn{1}{c}{$\mathbf{R}^{\mathbf{2}}$} \\
\hline & \multicolumn{1}{c}{ Após seis meses da aplicação } \\
1) $\mathrm{pH}$ solo $=4,1181+0,0001 \times$ dose NaF & $0,76 * *$ \\
2) $\mathrm{pH}$ solo $=4,2131+0,0042 \times \mathrm{F}$ solo & $0,87 * *$ \\
3) $\mathrm{pH}$ solo $=4,0890+0,0468 \times \mathrm{Na}$ solo & $0,91 * *$ \\
& Após dezoito meses da aplicação \\
1) $\mathrm{pH}$ solo $=4,3099+0,0001 \times$ dose NaF & $0,47 * *$ \\
2) $\mathrm{pH}$ solo $=4,3342+0,0021 \times$ F solo & $0,66 * *$ \\
3) $\mathrm{pH}$ solo $=4,2366+0,0400 \times$ Na solo & $0,83 * *$ \\
\hline
\end{tabular}

** Significativo ao nível de $1 \%$ de probabilidade pelo teste $\mathrm{F}$.

\subsubsection{Matéria orgânica do solo}

O conteúdo de MO não foi significativamente afetado pela aplicação de doses de $\mathrm{NaF}$ (Tabela 8). Valores mais baixos de $\mathrm{MO}$ foram encontrados nos tratamentos com as duas doses mais altas (5544 e $8316 \mathrm{~kg} \mathrm{ha}^{-1}$ ), mas esses foram semelhantes aos conteúdos iniciais (Tabela 1). Esses resultados deveram-se tanto à menor entrada de materiais orgânicos como também pela maior perda desses materiais por erosão nessas parcelas, já que o acúmulo de $\mathrm{Na}$ no solo promoveu a deterioração da estrutura e, conseqüentemente, das propriedades de infiltração de água e porosidade do solo (Raij, 1991), e assim, diminuiu a produção vegetal nos tratamentos com as duas doses mais altas de $\mathrm{NaF}$, fato que será discutido posteriormente. 
Não houve interação significativa entre dose de $\mathrm{NaF}$ aplicada e camada de solo no conteúdo de MO, após seis e após dezoito meses de experimentação (Tabela 8).

Pela análise geral do experimento (modelo geral), verificou-se ainda, a existência de interação significativa entre dose de $\mathrm{NaF}$ e época de amostragem no conteúdo de MO do solo (Tabela 8). Após seis meses de experimentação, o conteúdo de MO na camada 0-30 cm não foi relacionado com a dose de $\mathrm{NaF}$ aplicada e nem com os outros atributos químicos estudados, exceto a concentração de $\mathrm{Mg}$ (Tabela 6), porém na camada $0-5 \mathrm{~cm}$, o conteúdo de $\mathrm{MO}$ mostrou-se inversamente proporcional ao $\mathrm{pH}$ $(\mathrm{r}=-0,47 *)$ e à concentração de $\mathrm{F}$ no solo $(\mathrm{r}=-0,47 *)$. Por outro lado, após dezoito meses, o conteúdo de MO do solo $(0-30 \mathrm{~cm})$ mostrou-se inversamente proporcional à dose de $\mathrm{NaF}$ aplicada, ao $\mathrm{pH}$ e às concentrações de $\mathrm{Na}$ e $\mathrm{F}$ no solo (Tabela 6). Este fato contraditório relacionou-se, principalmente, com a cultura utilizada nos dois períodos de avaliação e não, somente, com o efeito negativo das altas concentrações de $\mathrm{Na}$, como descrito anteriormente, e de F no solo. De acordo com diversos trabalhos (Saha et al., 1981; Gaponyuk \& Reut, 1983; Kremlenkova \& Gaponyuk, 1984), o NaF têm sido empregado para diminuir o acúmulo de material orgânico em chernozém, devido ao seu efeito na redistribuição dos ácidos húmicos e seus derivados.

Entre seis meses e dezoito meses de experimentação, os valores médios de MO do solo diminuíram significativamente (Tabela 8), mas mesmo assim, foram superiores aos encontrados na época da instalação (Tabela 1). Essa diferença no conteúdo de MO entre as duas épocas de amostragem deveu-se, principalmente, às menores quantidades de entrada de materiais orgânicos no solo pela cultura da crotalária, em relação ao sorgo, já que esta última produz muito mais biomassa (raiz e parte aérea) podendo contribuir para um maior acréscimo de $\mathrm{MO}$ do solo e também, pode estar relacionado com o aumento da taxa de mineralização de materiais orgânicos provenientes da crotalária, pois esta cultura apresenta capacidade de fixação biológica de nitrogênio, podendo dar origem à materiais com relação $\mathrm{C} / \mathrm{N}$ mais baixa do que os do sorgo.

$\mathrm{Na}$ amostragem de solo efetuada após seis meses, como já era esperado, o conteúdo de $\mathrm{MO}$ do solo mostrou-se diretamente proporcional à concentração de $\mathrm{Mg}$ no solo, devendo-se à reconhecida capacidade da $\mathrm{MO}$ em formar quelatos com cátions 
Tabela 8. Influência de doses de fluoreto de sódio no conteúdo de matéria orgânica $\left(\mathrm{g} \mathrm{dm}^{-3}\right)$, após seis e dezoito meses da aplicação, em quatro camadas de um podzólico vermelho-amarelo, em Piracicaba, SP.

\begin{tabular}{|c|c|c|c|c|c|}
\hline \multirow{2}{*}{$\begin{array}{l}\text { Dose.de NaF } \\
\left(\mathrm{kg} \mathrm{ha}^{-1}\right)\end{array}$} & \multicolumn{5}{|c|}{ Camada de solo $(\mathrm{cm})$} \\
\hline & $0-5$ & $5-10$ & $10-20$ & $20-30$ & Média \\
\hline \multicolumn{6}{|c|}{ Após seis meses da aplicação ${ }^{(1)}$} \\
\hline $\mathbf{0}$ & 28,3 & 20,3 & 20,0 & 18,7 & 21,8 \\
\hline 832 & 25,0 & 22,3 & 18,0 & 18,0 & 20,8 \\
\hline 1386 & 25,0 & 18,0 & 16,0 & 16,7 & 18,9 \\
\hline 1941 & 24,7 & 17,7 & 16,7 & 16,3 & 18,8 \\
\hline 2772 & 28,0 & 22,7 & 19,3 & 19,0 & 22,3 \\
\hline 5544 & 21,0 & 17,7 & 17,3 & 16,7 & 18,2 \\
\hline 8316 & 23,0 & 19,7 & 19,0 & 17,0 & 19,7 \\
\hline Média & $25,0 \mathrm{~A}$ & $19,8 \mathrm{~B}$ & $18,1 \mathrm{BC}$ & $17,5 \mathrm{C}$ & 20,1 \\
\hline \multicolumn{2}{|c|}{$\mathrm{F}($ dose $)=2,57 \mathrm{NS}$} & $\operatorname{mada})=$ & \multicolumn{3}{|c|}{$\mathrm{F}($ dose $\mathrm{x}$ camada $)=0,90 \mathrm{NS}$} \\
\hline
\end{tabular}

Após dezoito meses da aplicação ${ }^{(2)}$

$\begin{array}{llllll}\mathbf{0} & 23,0 & 19,7 & 17,7 & 15,0 & 18,8 \\ \mathbf{8 3 2} & 23,0 & 19,3 & 16,3 & 15,7 & 18,6 \\ \mathbf{1 3 8 6} & 25,7 & 19,0 & 15,7 & 15,3 & 18,9 \\ \mathbf{1 9 4 1} & 25,7 & 18,7 & 17,3 & 15,0 & 19,2 \\ \mathbf{2 7 7 2} & 24,7 & 16,7 & 15,7 & 14,3 & 17,8 \\ \mathbf{5 5 4 4} & 22,0 & 16,7 & 15,7 & 14,3 & 17,2 \\ \mathbf{8 3 1 6} & 19,3 & 15,0 & 14,7 & 14,0 & 15,8 \\ \text { Média } & 23,3 \mathrm{~A} & 17,9 \mathrm{~B} & 16,1 \mathrm{C} & 14,8 \mathrm{C} & 18,0\end{array}$

$\mathrm{F}($ dose $)=2,66 \mathrm{NS} \quad \mathrm{F}($ camada $)=93,86 * * \quad \mathrm{~F}($ dose $\mathrm{x}$ camada $)=1,16 \mathrm{NS}$

Nas duas épocas de amostragem

$$
\mathrm{F}(\text { dose })=2,97 \mathrm{NS} \quad \mathrm{F}(\text { camada })=118,09 * * \quad \mathrm{~F}(\text { época })=35,27 * *
$$

$\mathrm{F}($ dose $\mathrm{x}$ camada $)=1,27 \mathrm{NS} \quad \mathrm{F}($ dose $\mathrm{x}$ época $)=4,26 * * \quad \mathrm{~F}($ camada $\mathrm{x}$ época $)=0,48 \mathrm{NS}$

$\mathrm{F}($ dose $\mathrm{x}$ camada $\mathrm{x}$ época $)=0,47 \mathrm{NS}$

(1) Após cultivo de sorgo, em maio de 1996. ${ }^{(2)}$ Após cultivo de crotalária, em maio de 1997.

Números seguidos pela mesma letra maiúscula na linha não diferem entre si ao nível de $5 \%$ de probabilidade pelo teste de Tukey.

**, * significativo pelo teste $\mathrm{F}$ ao nível de $1 \%$ e $5 \%$ de probabilidade, respectivamente. NS não significativo. 
reconhecidos como nutrientes das plantas, como o $\mathrm{Mg}$ (Kiehl, 1979; Malavolta, 1980). Por outro lado, na amostragem feita aos dezoito meses, o conteúdo de MO mostrou-se diretamente proporcional à concentração de $\mathrm{Al}$ e aos valores de $\mathrm{CTC}, \mathrm{H}+\mathrm{Al}$ e m\%, devendo-se ao fato que em solos ácidos, a MO contém grandes quantidades de $\mathrm{Al}$ (Mendonça, 1995), além de diversos nutrientes (Kiehl,1979; Malavolta, 1980).

Como já era esperado, o conteúdo de MO diminuiu significativamente com o aumento da profundidade do solo, independentemente da dose de $\mathrm{NaF}$ aplicada e da época de amostragem do solo (Tabela 8).

\subsubsection{Alumínio trocável}

As alterações na concentração de $\mathrm{Al}$ trocável, em função das doses de $\mathrm{NaF}$ aplicadas e das camadas de solo amostradas, encontram-se na Tabela 9. $\mathrm{Na}$ amostragem do solo efetuada após seis meses, verificou-se a ocorrência de efeitos significativos de dose de $\mathrm{NaF}$, da camada amostrada e da interação entre dose e camada na concentração de Al, mas após dezoito meses, só foi encontrado efeito da camada de solo amostrada. A análise geral dos resultados (modelo geral) também mostrou interação significativa entre doses de $\mathrm{NaF}$ e época de amostragem do solo na concentração de $\mathrm{Al}$.

Após seis meses, as menores concentrações de Al trocável até $20 \mathrm{~cm}$ de profundidade do solo foram encontradas com a aplicação de $1941 \mathrm{~kg} \mathrm{ha}^{-1}$ de $\mathrm{NaF}$ (essa dose foi calculada para neutralizar $70 \%$ do Al trocável nos primeiros $30 \mathrm{~cm}$ de profundidade do solo). Em relação à testemunha, a diminuição da concentração de $\mathrm{Al}$ no solo com a aplicação de $1941 \mathrm{~kg} \mathrm{ha}^{-1}$ de $\mathrm{NaF}$ foi de $63 \%$ na camada $0-5 \mathrm{~cm}$ e de $49 \%$ na camada 5-10 cm (Tabela 9). Segundo diversos trabalhos (Miyazawa et al.,1993; Mendonça, 1995), a solubilidade do $\mathrm{Al}$ em solos ácidos é controlada pelo $\mathrm{pH}$ e pela complexação organometálica. Por outro lado, na amostragem efetuada nesse período nos tratamentos com as doses mais altas de $\mathrm{NaF}$ ( $\left.\geq 2772 \mathrm{~kg} \mathrm{ha}^{-1}\right)$, verificou-se sensível aumento na concentração de $\mathrm{Al}$, possivelmente, devido à destruição de hidróxidos de $\mathrm{Al}$ pelo $\mathrm{F}^{-}$, conduzindo ao aumento desse cátion nos primeiros $10 \mathrm{~cm}$ do solo. Hsu (1989) evidenciou que o $\mathrm{F}^{*}$, além de remover $\mathrm{o}^{-}$das arestas das ligações dos polímeros, também pode romper as ligações interiores $\mathrm{Al}-\mathrm{OH}-\mathrm{Al}$ do polímero, resultando na 
Tabela 9. Influência de doses de fluoreto de sódio na concentração de alumínio trocável $\left(\mathrm{mmol}_{\mathrm{c}} \mathrm{dm}^{-3}\right)$, após seis e dezoito meses da aplicação, em quatro camadas de um podzólico vermelho-amarelo, em Piracicaba, SP.

\begin{tabular}{|c|c|c|c|c|c|}
\hline \multirow{2}{*}{$\begin{array}{l}\text { Dose de NaF } \\
\left(\mathrm{kg} \mathrm{ha}^{-1}\right)\end{array}$} & \multicolumn{5}{|c|}{ Camada de solo (cm) } \\
\hline & $0-5$ & 5-10 & $10-20$ & 20-30 & Média \\
\hline \multicolumn{6}{|c|}{ Após seis meses da aplicação ${ }^{(I)}$} \\
\hline $\mathbf{0}$ & $9,0 \mathrm{Aa}$ & 9,7Aa & $15,0 \mathrm{Aab}$ & $18,3 \mathrm{Aab}$ & $13,0 \mathrm{a}$ \\
\hline 832 & 7,3Aa & 7,3Aa & $10,7 \mathrm{Aab}$ & $14,7 \mathrm{Aab}$ & $10,0 \mathrm{ab}$ \\
\hline 1386 & $6,3 \mathrm{Ba}$ & $13,0 \mathrm{ABa}$ & $17,0 \mathrm{Aa}$ & $21,0 \mathrm{Aa}$ & $14,3 \mathrm{a}$ \\
\hline 1941 & 3,3Aa & $5,0 \mathrm{Aa}$ & $9,3 \mathrm{Aab}$ & 8,7Aab & $6,6 \mathrm{~b}$ \\
\hline 2772 & $10,7 \mathrm{Aa}$ & $13,0 \mathrm{Aa}$ & $11,0 \mathrm{Aab}$ & $16,0 \mathrm{Aab}$ & $12,7 \mathrm{a}$ \\
\hline 5544 & $16,3 \mathrm{Aa}$ & $12,0 \mathrm{ABa}$ & 7,7Bb & $7,3 \mathrm{Bb}$ & $10,8 \mathrm{ab}$ \\
\hline 8316 & $12,0 \mathrm{Aa}$ & $11,3 \mathrm{Aa}$ & $10,7 \mathrm{Aab}$ & $11,0 \mathrm{Aab}$ & $11,3 \mathrm{ab}$ \\
\hline Média & $9,3 \mathrm{~B}$ & $10,2 \mathrm{~B}$ & $11,6 \mathrm{AB}$ & $13,9 \mathrm{~A}$ & 11,2 \\
\hline \multicolumn{2}{|c|}{$\mathrm{F}($ dose $)=4,52 *$} & (camada) $=5$ & $\mathrm{~F}(\mathrm{c}$ & (camada $)=$ & ** \\
\hline
\end{tabular}

Após dezoito meses da aplicação ${ }^{(2)}$

\begin{tabular}{lccccc}
$\mathbf{0}$ & 4,7 & 9,7 & 17,0 & 21,3 & 13,2 \\
$\mathbf{8 3 2}$ & 3,7 & 13,7 & 17,0 & 22,3 & 14,2 \\
$\mathbf{1 3 8 6}$ & 4,7 & 13,7 & 15,7 & 14,7 & 12,2 \\
$\mathbf{1 9 4 1}$ & 4,3 & 12,7 & 15,3 & 18,7 & 12,8 \\
$\mathbf{2 7 7 2}$ & 3,0 & 11,3 & 9,7 & 19,3 & 10,8 \\
$\mathbf{5 5 4 4}$ & 10,7 & 8,0 & 10,7 & 16,7 & 11,5 \\
$\mathbf{8 3 1 6}$ & 0,0 & 2,3 & 5,3 & 12,3 & 5,0 \\
Média & $4,4 \mathrm{C}$ & $10,2 \mathrm{C}$ & $13,0 \mathrm{~B}$ & $17,9 \mathrm{~A}$ & 11,4 \\
\multicolumn{4}{r}{$\mathrm{F}($ dose $)=1,64 \mathrm{NS}$} & $\mathrm{F}($ camada $)=45,78 * *$ & $\mathrm{~F}$ (dose x camada) $=1,60 \mathrm{NS}$
\end{tabular}

Nas duas épocas de amostragem

$$
\mathrm{F}(\text { dose })=2,13 \mathrm{NS} \quad \mathrm{F}(\text { camada })=51,18 * * \quad \mathrm{~F}(\text { época })=0,03 \mathrm{NS}
$$

$\mathrm{F}($ dose $\mathrm{x}$ camada $)=3,82 \mathrm{NS} \quad \mathrm{F}($ dose $\mathrm{x}$ época $)=4,33 * * \quad \mathrm{~F}($ camada $\mathrm{x}$ época $)=6,15 * *$

$\mathrm{F}($ dose $\mathrm{x}$ camada $\mathrm{x}$ época $)=0,69 \mathrm{NS}$

(I) Após cultivo de sorgo, em maio de 1996. ${ }^{(2)}$ Após cultivo de crotalária, em maio de 1997.

Números seguidos pela mesma letra, maiúscula na linha e minúscula na coluna, não diferem entre si ao nivel de $5 \%$ de probabilidade pelo teste de Tukey.

**, * significativo pelo teste $\mathrm{F}$ ao nível de $1 \%$ e $5 \%$ de probabilidade, respectivamente. NS não significativo. 
destruição da estrutura do mineral.

$\mathrm{Na}$ amostragem efetuada após dezoito meses, constatou-se a eliminação completa do $\mathrm{Al}$ trocável na camada $0-5 \mathrm{~cm}$ do solo com a aplicação de $8316 \mathrm{~kg} \mathrm{ha}^{-1}$ de $\mathrm{NaF}$, e ainda diminuição de $76 \%$ na camada $5-10 \mathrm{~cm}$, de $69 \%$ na camada $10-20 \mathrm{~cm}$ e de $42 \%$ na camada $20-30 \mathrm{~cm}$ (Tabela 9). Entretanto, nesse mesmo período, verificou-se marcante aumento do Al trocável na camada $0-5 \mathrm{~cm}$ com a aplicação de $5544 \mathrm{~kg} \mathrm{ha}^{-1}$ de $\mathrm{NaF}$, mas este tratamento não diferiu significativamente da testemunha.

Após seis meses, a concentração de $\mathrm{Al}$ na camada $10-20 \mathrm{~cm}$ de solo mostrou-se inversamente proporcional ao $\mathrm{pH}(\mathrm{r}=-0,47 *)$ e à concentração de $\mathrm{P}(\mathrm{r}=-0,44 *)$, enquanto na camada $20-30 \mathrm{~cm}$, também mostrou-se inversamente proporcional ao $\mathrm{pH}$ $(\mathrm{r}=-0,75 * *)$ e à concentração de $\mathrm{F}$ no solo $(\mathrm{r}=-0,44 *)$. Por outro lado, após dezoito meses, a concentração de $\mathrm{Al}$ nos primeiros $30 \mathrm{~cm}$ de profundidade do solo (Tabela 6) mostrou-se inversamente proporcional à dose de $\mathrm{NaF}$ aplicada, ao $\mathrm{pH}$, às concentrações de $\mathrm{Na}$ e $\mathrm{F}$ e diretamente proporcional ao conteúdo de $\mathrm{MO}$ do solo.

A sensível diminuição do $\mathrm{Al}$ trocável até $30 \mathrm{~cm}$ de profundidade do solo deveu-se ao aumento de pH (Lindsay, 1979) e a formação e lixiviação de complexos estáveis entre Al e F (Luther et al., 1986; Gibson et al., 1992; Simard \& Lafrance, 1996) e entre Al e MO (Ritchie, 1995). Em solos tropicais, o controle do Al trocável na camada superficial é, provavelmente, regido pelas macromoléculas constituintes da MO (Miyazawa et al., 1993; Mendonça, 1995).

A concentração média de $\mathrm{Al}$ aumentou significativamente com o aumento da profundidade do solo, independentemente da dose de $\mathrm{NaF}$ aplicada e da época de amostragem (Tabela 10). Por ser um solo raso, à medida que se aproxima do regolito, há maior frequência de minerais de mais fácil intemperização, que elevam a saturação por $\mathrm{Al}$ à medida que se intemperizam (Lindsay, 1979). Não houve efeito significativo da época de amostragem do solo sobre a concentração média de $\mathrm{Al}$ (Tabela 10).

\subsubsection{Cálcio, magnésio e potássio trocáveis}

As concentrações de $\mathrm{Ca}, \mathrm{Mg}$ e $\mathrm{K}$ trocáveis não foram significativamente influenciadas pela aplicação de doses de $\mathrm{NaF}$, mas foram pela camada de solo 
amostrada. Houve diminuição nas concentrações de $\mathrm{Ca}, \mathrm{Mg}$ e $\mathrm{K}$ com o aumento da profundidade do solo, independentemente da dose de $\mathrm{NaF}$ e da época de amostragem do solo (Tabelas 10, 11 e 12).

$\mathrm{Na}$ amostragem do solo efetuada após seis meses, encontrou-se interação significativa entre doses de $\mathrm{NaF}$ e camada de solo nas concentrações de Ca e K, mas essa interação não foi significativa para ambos após dezoito meses. A concentração de Ca na camada 0-5 cm do solo diminuiu significativamente nos tratamentos com as duas maiores doses (5544 e $\left.8316 \mathrm{~kg} \mathrm{ha}^{-1}\right)$, em relação à testemunha, após seis meses, enquanto após dezoito meses, estes não diferiram-se significativamente (Tabela 10).

Não houve associação significativa entre concentrações de $\mathrm{Ca}, \mathrm{Mg}$ e $\mathrm{K}$ no solo $(0-30 \mathrm{~cm})$ e doses de $\mathrm{NaF}, \mathrm{pH}$ e concentração de $\mathrm{Na}$, tanto nas amostragens efetuadas após seis meses como após dezoito meses (Tabela 6). Ainda, as concentrações de $\mathrm{Ca}, \mathrm{Mg}$ e $\mathrm{K}$ mostraram-se inversamente proporcionais à concentração de $\mathrm{Al}$, após seis meses. Além disso, após seis meses, a concentração de Ca no solo mostrou-se inversamente proporcional à concentração de $\mathrm{F}$ no solo, enquanto a concentração de $\mathrm{Mg}$ mostrou-se diretamente proporcional ao conteúdo de MO do solo.

A análise geral do experimento (modelo geral) mostrou que as variações das concentrações médias de $\mathrm{Ca}, \mathrm{Mg}$ e $\mathrm{K}$ do solo foram mais fortemente influenciadas pela camada de solo amostrada, do que pelos outros fatores estudados. Não houve efeito da época de amostragem na concentração média de $K$ (Tabela 12), mas houve para as concentrações médias de $\mathrm{Ca}$ e $\mathrm{Mg}$ (Tabelas 10 e 11), já que ambos diminuíram entre seis e dezoito meses, mas mantiveram-se semelhantes aos valores encontrados no início do experimento (Tabela 1).

\subsubsection{Sódio trocável}

Nos dois primeiros meses de experimentação (novembro de 1995 a janeiro de 1996), constatou-se a morte de alguns organismos do solo (minhocas e colêmbolas), reconhecidamente importantes no processo de decomposição da $\mathrm{MO}$ do solo, e problemas de germinação de sementes nas parcelas submetidas aos tratamentos com as duas doses mais altas de $\mathrm{NaF}\left(5544 \mathrm{e} 8316 \mathrm{~kg} \mathrm{ha}^{-1}\right)$. Este fato deveu-se ao efeito 
Tabela 10. Influência de doses de fluoreto de sódio na concentração de cálcio trocável $\left(\mathrm{mmol}_{\mathrm{c}} \mathrm{dm}^{-3}\right)$, após seis e dezoito meses da aplicação, em quatro camadas de um podzólico vermelho-amarelo, em Piracicaba, SP.

\begin{tabular}{|c|c|c|c|c|c|}
\hline \multirow{2}{*}{$\begin{array}{l}\text { Dose de NaF } \\
\left(\mathrm{kg} \mathrm{ha}^{-1}\right)\end{array}$} & \multicolumn{5}{|c|}{ Camada de solo (cm) } \\
\hline & $0-5$ & 5-10 & $10-20$ & $20-30$ & Média \\
\hline \multicolumn{6}{|c|}{ Após seis meses da aplicação $^{(1)}$} \\
\hline $\mathbf{0}$ & $24,7 \mathrm{Aa}$ & $15,7 \mathrm{Ba}$ & $15,0 \mathrm{Ba}$ & $15,0 \mathrm{Bab}$ & 17,6 \\
\hline 832 & 21,7Aab & $17,3 \mathrm{Ba}$ & $14,3 \mathrm{Ca}$ & $14,3 \mathrm{Cab}$ & 16,9 \\
\hline 1386 & $22,0 \mathrm{Aab}$ & $14,7 \mathrm{Ba}$ & $13,3 \mathrm{Ba}$ & $14,0 \mathrm{Bab}$ & 16,0 \\
\hline 1941 & $23,7 \mathrm{Aab}$ & $16,7 \mathrm{Ba}$ & $16,3 \mathrm{Ba}$ & $18,3 \mathrm{Ba}$ & 18,8 \\
\hline 2772 & $25,3 \mathrm{Aa}$ & $17,0 \mathrm{Ba}$ & $15,0 \mathrm{Ba}$ & $14,0 \mathrm{Bab}$ & 17,8 \\
\hline 5544 & $19,0 \mathrm{Ab}$ & $13,3 \mathrm{Ba}$ & $13,3 \mathrm{Ba}$ & $13,3 \mathrm{Bab}$ & 14,8 \\
\hline 8316 & $18,3 \mathrm{Ab}$ & $16,0 \mathrm{ABa}$ & $15,0 \mathrm{ABa}$ & $11,7 \mathrm{Bb}$ & 15,3 \\
\hline Média & $22,1 \mathrm{~A}$ & $15,8 \mathrm{~B}$ & $14,6 \mathrm{~B}$ & $14,4 \mathrm{~B}$ & 16,7 \\
\hline \multicolumn{2}{|c|}{$\mathrm{F}($ dose $)=1,67 \mathrm{NS}$} & camada $)=$ & *** & x camad & $00 *$ \\
\hline
\end{tabular}

Após dezoito meses da aplicação ${ }^{(2)}$

\begin{tabular}{lccccc}
$\mathbf{0}$ & 19,7 & 13,7 & 12,7 & 13,3 & 14,8 \\
$\mathbf{8 3 2}$ & 23,0 & 15,0 & 13,3 & 13,7 & 16,3 \\
$\mathbf{1 3 8 6}$ & 19,7 & 13,0 & 11,3 & 12,0 & 14,0 \\
$\mathbf{1 9 4 1}$ & 18,7 & 15,3 & 13,3 & 14,0 & 15,3 \\
$\mathbf{2 7 7 2}$ & 21,0 & 13,7 & 12,3 & 10,7 & 14,4 \\
$\mathbf{5 5 4 4}$ & 17,0 & 13,3 & 13,7 & 13,3 & 14,3 \\
$\mathbf{8 3 1 6}$ & 16,0 & 20,3 & 9,7 & 9,7 & 13,9 \\
Média & $19,3 \mathrm{~A}$ & $14,9 \mathrm{~B}$ & $12,3 \mathrm{~B}$ & $12,4 \mathrm{~B}$ & 14,7 \\
\multicolumn{4}{r}{$\mathrm{F}($ dose $)=0,26 \mathrm{NS}$} & $\mathrm{F}($ camada $)=19,39 * *$ & $\mathrm{~F}$ (dose x camada) $=1,21 \mathrm{NS}$
\end{tabular}

Nas duas épocas de amostragem

$\mathrm{F}($ dose $)=0,82 \mathrm{NS} \quad \mathrm{F}($ camada $)=74,62 * * \quad \mathrm{~F}($ época $)=15,21 * *$

$\mathrm{F}($ dose $\mathrm{x}$ camada $)=2,24 * \quad \mathrm{~F}($ dose $\mathrm{x}$ época $)=0,84 \mathrm{NS} \quad \mathrm{F}($ camada $\mathrm{x}$ época $)=0,61 \mathrm{NS}$ $\mathrm{F}($ dose $\mathrm{x}$ camada $\mathrm{x}$ época $)=0,47 \mathrm{NS}$

(1) Após cultivo de sorgo, em maio de 1996. ${ }^{(2)}$ Após cultivo de crotalária, em maio de 1997.

Números seguidos pela mesma letra, maiúscula na linha e minúscula na coluna, não diferem entre si ao nivel de $5 \%$ de probabilidade pelo teste de Tukey.

**, * significativo pelo teste $\mathrm{F}$ ao nivel de $1 \%$ e $5 \%$ de probabilidade, respectivamente. NS não significativo. 
Tabela 11. Influência de doses de fluoreto de sódio na concentração de magnésio trocável $\left(\mathrm{mmol}_{\mathrm{c}} \mathrm{dm}^{-3}\right)$, após seis e dezoito meses da aplicação, em quatro camadas de um podzólico vermelho-amarelo, em Piracicaba, SP.

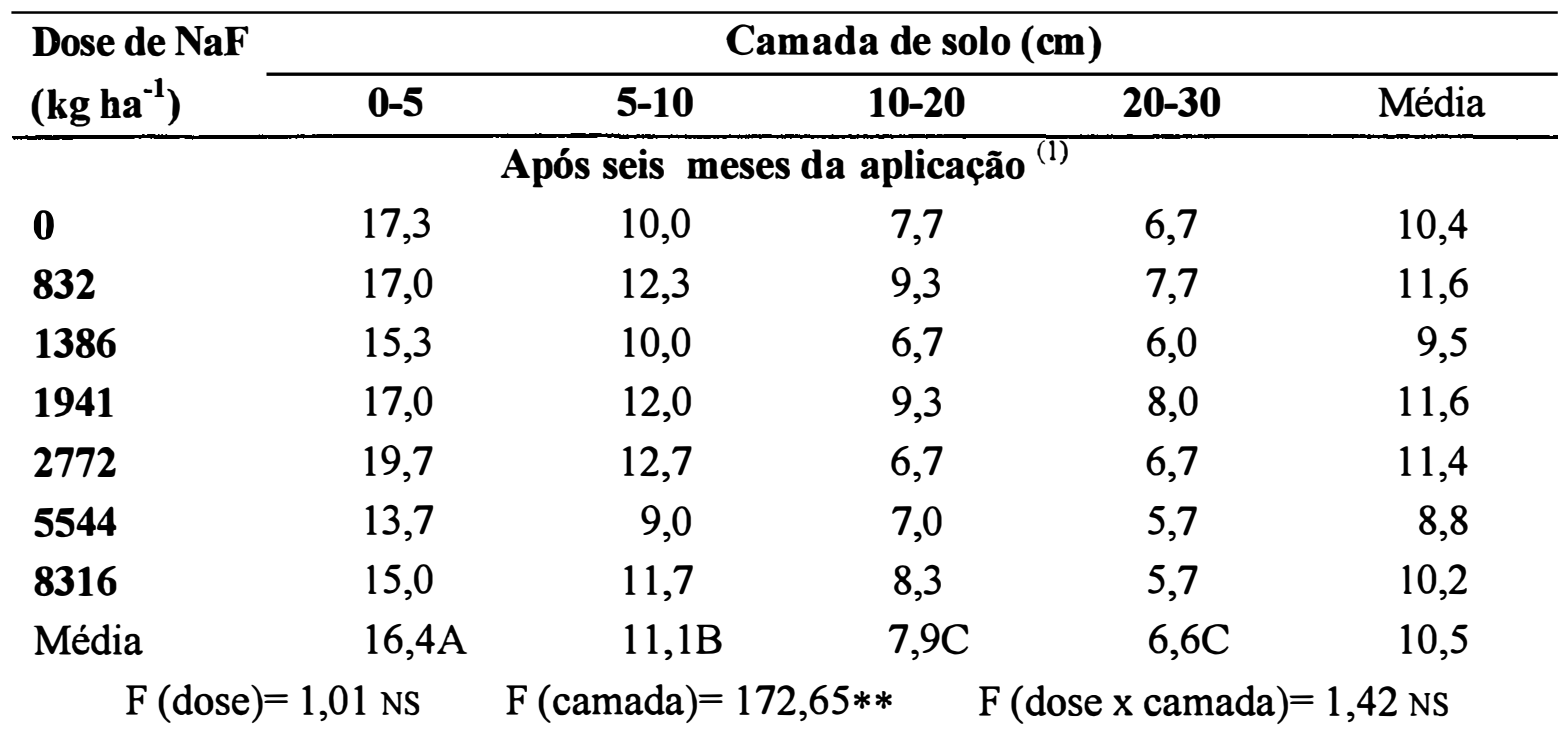

Após dezoito meses da aplicação ${ }^{(2)}$

\begin{tabular}{|c|c|c|c|c|}
\hline 0 & 12,7 & 7,7 & 5,7 & 4,3 \\
\hline 832 & 15,7 & 8,0 & 6,7 & 5,0 \\
\hline 1386 & 14,0 & 7,0 & 5,3 & 3,7 \\
\hline 1941 & 10,0 & 7,3 & 5,7 & 4,0 \\
\hline 2772 & 14,0 & 7,7 & 5,3 & 4,0 \\
\hline 5544 & 10,7 & 7,3 & 5,0 & 3,7 \\
\hline 8316 & 10,3 & 7,0 & 4,0 & 3,0 \\
\hline Média & $12,5 \mathrm{~A}$ & 7,4B & $5,4 \mathrm{C}$ & $4,0 \mathrm{D}$ \\
\hline
\end{tabular}

Nas duas épocas de amostragem

$\mathrm{F}($ dose $)=1,19 \mathrm{NS} \quad \mathrm{F}($ camada $)=342,54 * * \quad \mathrm{~F}($ época $)=118,03 * *$

$\mathrm{F}($ dose $\mathrm{x}$ camada $)=2,06 * \quad \mathrm{~F}($ dose $\mathrm{x}$ época $)=1,80 \mathrm{NS} \quad \mathrm{F}($ camada $\mathrm{x}$ época $)=1,54 \mathrm{NS}$

$\mathrm{F}($ dose $\mathrm{x}$ camada $\mathrm{x}$ época $)=0,52 \mathrm{NS}$

(1) Após cultivo de sorgo, em maio de 1996. ${ }^{(2)}$ Após cultivo de crotalária, em maio de 1997.

Números seguidos pela mesma letra maiúscula na linha não diferem entre si ao nível de $5 \%$ de probabilidade pelo teste de Tukey.

**, * significativo pelo teste $\mathrm{F}$ ao nível de $1 \%$ e $5 \%$ de probabilidade, respectivamente. NS não significativo. 
Tabela 12. Influência de doses de fluoreto de sódio na concentração de potássio trocável $\left(\mathrm{mmol}_{\mathrm{c}} \mathrm{dm}^{-3}\right)$, após seis e dezoito meses da aplicação, em quatro camadas de um podzólico vermelho-amarelo, em Piracicaba, SP.

\begin{tabular}{|c|c|c|c|c|c|}
\hline \multirow{2}{*}{$\begin{array}{l}\text { Dose de NaF } \\
\left(\mathrm{kg} \mathrm{ha}^{-1}\right)\end{array}$} & \multicolumn{5}{|c|}{ Camada de solo (cm) } \\
\hline & $0-5$ & $5-10$ & $10-20$ & $20-30$ & Média \\
\hline \multicolumn{6}{|c|}{ Após seis meses da aplicação ${ }^{(1)}$} \\
\hline 0 & 4,17Aab & $1,77 \mathrm{Ba}$ & $1,37 \mathrm{Ba}$ & $1,17 \mathrm{Ba}$ & 2,12 \\
\hline 832 & 4,53Aab & $2,30 \mathrm{Ba}$ & $1,63 \mathrm{Ba}$ & $1,30 \mathrm{Ba}$ & 2,44 \\
\hline 1386 & 3,53Aab & $1,57 \mathrm{Ba}$ & $1,17 \mathrm{Ba}$ & $1,23 \mathrm{Ba}$ & 1,88 \\
\hline 1941 & 4,13Aab & $2,97 \mathrm{Ba}$ & $2,27 \mathrm{BCa}$ & $1,87 \mathrm{Ca}$ & 2,81 \\
\hline 2772 & $5,00 \mathrm{Aa}$ & $1,87 \mathrm{Ba}$ & $1,23 \mathrm{Ba}$ & $1,17 \mathrm{Ba}$ & 2,32 \\
\hline 5544 & 3,30Aab & $1,97 \mathrm{Ba}$ & $1,20 \mathrm{Ba}$ & $1,23 \mathrm{Ba}$ & 1,93 \\
\hline 8316 & $2,73 \mathrm{Ab}$ & $1,93 \mathrm{ABa}$ & $1,70 \mathrm{ABa}$ & $1,23 \mathrm{Ba}$ & 1,90 \\
\hline Média & $3,91 \mathrm{~A}$ & $2,05 \mathrm{~B}$ & $1,51 \mathrm{C}$ & $1,31 \mathrm{C}$ & 2,20 \\
\hline
\end{tabular}

Após dezoito meses da aplicação ${ }^{(2)}$

$\begin{array}{llllll}\mathbf{0} & 4,87 & 1,93 & 1,73 & 1,37 & 2,48 \\ \mathbf{8 3 2} & 5,63 & 2,43 & 1,83 & 1,33 & 2,81 \\ \mathbf{1 3 8 6} & 4,20 & 1,53 & 1,23 & 1,37 & 2,08 \\ \mathbf{1 9 4 1} & 4,60 & 2,10 & 1,63 & 1,17 & 2,38 \\ \mathbf{2 7 7 2} & 5,50 & 1,70 & 1,17 & 0,87 & 2,31 \\ \mathbf{5 5 4 4} & 5,37 & 2,27 & 1,53 & 1,03 & 2,55 \\ \mathbf{8 3 1 6} & 4,73 & 2,30 & 1,10 & 0,90 & 2,55 \\ \text { Média } & 4,99 \mathrm{~A} & 2,04 \mathrm{~B} & 1,46 \mathrm{C} & 1,15 \mathrm{C} & 2,41\end{array}$

$\mathrm{F}($ dose $)=0,64 \mathrm{NS} \quad \mathrm{F}($ camada $)=145,30 * * \quad \mathrm{~F}($ dose $\mathrm{x}$ camada $)=0,69 \mathrm{NS}$

Nas duas épocas de amostragem

$\mathrm{F}($ dose $)=1,15 \mathrm{NS} \quad \mathrm{F}($ camada $)=278,94 * * \quad \mathrm{~F}($ época $)=3,23 \mathrm{NS}$

$\mathrm{F}($ dose $\mathrm{x}$ camada $)=1,92 * \quad \mathrm{~F}($ dose $\mathrm{x}$ época $)=1,21 \mathrm{NS} \quad \mathrm{F}($ camada $\mathrm{x}$ época $)=6,06 * *$

$\mathrm{F}($ dose $\mathrm{x}$ camada $\mathrm{x}$ época $)=0,39 \mathrm{NS}$

(7) Após cultivo de sorgo, em maio de $1996 .{ }^{(2)}$ Após cultivo de crotalária, em maio de 1997.

Números seguidos pela mesma letra, maiúscula na linha e minúscula na coluna, não diferem entre si ao nivel de $5 \%$ de probabilidade pelo teste de Tukey.

**, * significativo pelo teste $\mathrm{F}$ ao nivel de $1 \%$ e $5 \%$ de probabilidade, respectivamente. NS não significativo. 
deletério do $\mathrm{Na}$ sobre o ambiente, pois altas concentrações desse elemento podem resultar na desfloculação dos agregados do solo reduzindo a permeabilidade, especialmente em solos argilosos, inibindo o desenvolvimento de raizes de plantas.

Como esperado, a concentração de $\mathrm{Na}$ trocável no solo aumentou com o aumento da dose de $\mathrm{NaF}$ aplicada (Tabela 14). Houve aumento significativo na concentração de Na no solo entre a testemunha e as duas doses mais altas de $\mathrm{NaF}$ (5544 e $8316 \mathrm{~kg} \mathrm{ha}^{-1}$ ), tanto após seis meses como após dezoito meses. A concentração de $\mathrm{Na}$ foi significativamente diminuída com o aumento da profundidade do solo (Tabela 14) e com o decorrer do tempo de experimentação, particularmente nos primeiros $10 \mathrm{~cm}$ de solo (Tabela 13).

Decorridos dezoito meses da aplicação de NaF, nos tratamentos com as duas maiores doses (5544 e $8316 \mathrm{~kg} \mathrm{ha}^{-1}$ ) ainda foram encontradas concentrações elevadas de $\mathrm{Na}$ (aproximadamente dez vezes superior à da testemunha) nos primeiros $20 \mathrm{~cm}$ de profundidade do solo (Tabela 14), mesmo sendo o $\mathrm{Na}$ considerado um elemento de alta mobilidade no solo (Raij, 1991).

Houve efeito significativo da interação entre dose de $\mathrm{NaF}$ e camada de solo na variação da concentração média de Na no solo, tanto após seis como após dezoito meses (Tabela 13).

A concentração de $\mathrm{Na}$ no solo $(0-30 \mathrm{~cm})$ mostrou-se diretamente proporcional à dose de $\mathrm{NaF}$ aplicada, ao $\mathrm{pH}$ e à concentração de $\mathrm{F}$ no solo, e inversamente proporcional aos valores de $\mathrm{H}+\mathrm{Al}$ e CTC, tanto nas amostragens efetuadas após seis meses como após dezoito meses (Tabela 6). Após seis meses, a concentração de $\mathrm{Na}$ mostrou-se diretamente proporcional à concentração de $\mathrm{P}$ e ao valor de $\mathrm{V} \%$, enquanto após dezoito meses, a concentração de $\mathrm{Na}$ mostrou-se inversamente proporcional ao conteúdo de $\mathrm{MO}$ e à concentração de $\mathrm{Al}$ no solo. Com o aumento de $\mathrm{pH}$ do solo, em parte devido ao aumento da concentração de $\mathrm{Na}$ (já explicado no ítem 4.1.1.1), houve inicialmente aumento da disponibilidade de $\mathrm{P}$ e do valor de V\% e posteriormente, diminuição do $\mathrm{Al}$ e conseqüentemente, dos valores de $\mathrm{H}+\mathrm{Al}$ e $\mathrm{m} \%$, conforme apresentado por Malavolta (1980). 
Tabela 13. Influência de doses de fluoreto de sódio na concentração de sódio trocável $\left(\mathrm{mmol}_{\mathrm{c}} \mathrm{dm}^{-3}\right)$, após seis e dezoito meses da aplicação, em quatro camadas de um podzólico vermelho-amarelo, em Piracicaba, SP.

\begin{tabular}{|c|c|c|c|c|c|}
\hline \multirow{2}{*}{$\begin{array}{l}\text { Dose de NaF } \\
\left(\mathrm{kg} \mathrm{ha}^{-1}\right)\end{array}$} & \multicolumn{5}{|c|}{ Camada de solo (cm) } \\
\hline & $0-5$ & $5-10$ & $10-20$ & $20-30$ & Média \\
\hline \multicolumn{6}{|c|}{ Após seis meses da aplicação ${ }^{(1)}$} \\
\hline 0 & $1,7 \mathrm{Ab}$ & $1,4 \mathrm{Ac}$ & $1,3 \mathrm{Ab}$ & $1,2 \mathrm{Aa}$ & $1,4 c$ \\
\hline 832 & $2,4 \mathrm{Ab}$ & $2,9 \mathrm{Ac}$ & $2,4 \mathrm{Ab}$ & $2,0 \mathrm{Aa}$ & $2,4 \mathrm{c}$ \\
\hline 1386 & $6,0 \mathrm{Ab}$ & $7,4 \mathrm{Abc}$ & $2,9 \mathrm{Ab}$ & $2,3 \mathrm{Aa}$ & $4,7 \mathrm{c}$ \\
\hline 1941 & 7,7Ab & $8,8 \mathrm{Abc}$ & $7,2 \mathrm{Aab}$ & 3,9Aa & $6,9 b c$ \\
\hline 2772 & $8,1 \mathrm{Ab}$ & $8,4 \mathrm{Abc}$ & $6,5 \mathrm{Aab}$ & 2,9Aa & $6,5 \mathrm{bc}$ \\
\hline 5544 & $35,8 \mathrm{Aa}$ & 21,7Bab & $11,9 \mathrm{Cab}$ & $2,0 \mathrm{Da}$ & $17,9 \mathrm{ab}$ \\
\hline 8316 & $34,0 \mathrm{Aa}$ & $27,5 \mathrm{Aa}$ & $16,5 \mathrm{ABa}$ & $6,6 \mathrm{Ba}$ & $21,2 \mathrm{a}$ \\
\hline Média & $13,7 \mathrm{~A}$ & $11,2 \mathrm{~A}$ & $7,0 \mathrm{~B}$ & $3,0 \mathrm{C}$ & 8,7 \\
\hline \multicolumn{2}{|c|}{$F($ dose $)=8,42 * *$} & camada $)=4$ & \multicolumn{3}{|c|}{$F($ dose $x$ camada $)=9,66 * *$} \\
\hline
\end{tabular}

Após dezoito meses da aplicação ${ }^{(2)}$

$\begin{array}{lccccc}\mathbf{0} & 1,1 \mathrm{Ab} & 1,0 \mathrm{Ac} & 1,0 \mathrm{Ab} & 1,0 \mathrm{Ab} & 1,0 \mathrm{c} \\ \mathbf{8 3 2} & 1,6 \mathrm{Ab} & 1,4 \mathrm{Ac} & 1,4 \mathrm{Ac} & 1,8 \mathrm{Aab} & 1,5 \mathrm{c} \\ \mathbf{1 3 8 6} & 2,8 \mathrm{Ab} & 2,8 \mathrm{Abc} & 3,0 \mathrm{Ab} & 3,1 \mathrm{Aab} & 3,0 \mathrm{bc} \\ \mathbf{1 9 4 1} & 6,1 \mathrm{Aab} & 6,8 \mathrm{Aabc} & 6,1 \mathrm{Aab} & 4,1 \mathrm{Aab} & 5,8 \mathrm{abc} \\ \mathbf{2 7 7 2} & 5,5 \mathrm{Aab} & 5,7 \mathrm{Aabc} & 5,4 \mathrm{Aab} & 4,1 \mathrm{Aab} & 5,2 \mathrm{abc} \\ \mathbf{5 5 4 4} & 12,7 \mathrm{Aab} & 12,9 \mathrm{Aab} & 9,3 \mathrm{Aa} & 5,9 \mathrm{Aa} & 10,4 \mathrm{ab} \\ \mathbf{8 3 1 6} & 18,1 \mathrm{Aa} & 14,6 \mathrm{ABa} & 10,3 \mathrm{BCa} & 5,9 \mathrm{Ca} & 12,2 \mathrm{a} \\ \text { Média } & 6,8 \mathrm{~A} & 6,4 \mathrm{~A} & 5,3 \mathrm{AB} & 3,7 \mathrm{~B} & 5,6\end{array}$

$$
\mathrm{F}(\text { dose })=6,74 * * \quad \mathrm{~F}(\text { camada })=10,50 * * \quad \mathrm{~F}(\text { dose } \mathrm{x} \text { camada })=3,35 * *
$$

Nas duas épocas de amostragem

$$
\mathrm{F}(\text { dose })=9,73 * * \quad \mathrm{~F}(\text { camada })=42,34 * * \quad \mathrm{~F}(\text { época })=35,09 * *
$$

$\mathrm{F}($ dose $\mathrm{x}$ camada $)=10,02 * * \quad \mathrm{~F}($ dose $\mathrm{x}$ época $)=6,46 * * \quad \mathrm{~F}($ camada $\mathrm{x}$ época $)=9,99 * *$

$\mathrm{F}($ dose $\mathrm{x}$ camada $\mathrm{x}$ época $)=2,48 * *$

(1) Após cultivo de sorgo, em maio de 1996. ${ }^{(2)}$ Após cultivo de crotalária, em maio de 1997.

Números seguidos pela mesma letra, maiúscula na linha e minúscula na coluna, não diferem entre si ao nivel de $5 \%$ de probabilidade pelo teste de Tukey.

**, * significativo pelo teste $\mathrm{F}$ ao nivel de $1 \%$ e $5 \%$ de probabilidade, respectivamente. NS não significativo. 


\subsubsection{Fósforo lábil}

A concentração de $P$ no solo $(0-30 \mathrm{~cm})$ apresentou tendência de elevação com o aumento da dose de $\mathrm{NaF}$ aplicada (Tabela 14). Embora não tenha ocorrido efeito estatisticamente significativo de doses de $\mathrm{NaF}$ na concentração de $\mathrm{P}$ no solo, esse aumento é de grande importância em termos agronômicos, pois este um dos elementos que mais freqüentemente limitam a produção agrícola (Raij, 1991), particularmente em solos tropicais ácidos, como é o caso do solo estudado (Tabela 1). Em relação a testemunha, após seis meses da aplicação de $\mathrm{NaF}$, as doses 1941 e $8316 \mathrm{~kg} \mathrm{ha}^{-1}$ aumentaram as concentrações de $\mathrm{P}$ no solo $(0-30 \mathrm{~cm})$ em, respectivamente, $18 \%$ e $56 \%$ (equivalente à aplicação de 11 e $34 \mathrm{~kg} \mathrm{ha}^{-1}$ de $\mathrm{P}_{2} \mathrm{O}_{5}$ para uma profundidade de $30 \mathrm{~cm}$ ) e após dezoito meses, em $28 \%$ e $20 \%$ (equivalente à aplicação de 9,6 e $6,9 \mathrm{~kg} \mathrm{ha}^{-1}$ de $\mathrm{P}_{2} \mathrm{O}_{5}$ para uma profundidade de $30 \mathrm{~cm}$ ).

$\mathrm{Na}$ amostragem do solo efetuada após seis meses, a concentração de $\mathrm{P}$ no solo (0-30 cm) mostrou-se diretamente proporcional à dose de $\mathrm{NaF}$ aplicada, ao $\mathrm{pH}$, às concentrações de $\mathrm{Na}$ e $\mathrm{F}$ e ao valor de $\mathrm{V} \%$ (Tabela 6). Ainda nessa mesma época de amostragem do solo, a concentração de $P$ na camada 10-20 cm mostrou-se inversamente proporcional à concentração de $\mathrm{Al}(\mathrm{r}=-0,44 *)$. Por outro lado, após dezoito meses, a concentração de $\mathrm{P}$ na camada $10-20 \mathrm{~cm}$ do solo mostrou-se diretamente proporcional ao $\mathrm{pH}(\mathrm{r}=0,50 *)$ e à concentração de $\mathrm{Na}(\mathrm{r}=0,52 *)$ e inversamente proporcional ao valor de $\mathrm{H}+\mathrm{Al}(\mathrm{r}=-0,59 * *)$, enquanto na camada $20-30 \mathrm{~cm}$, a concentração de $\mathrm{P}$ mostrou-se diretamente proporcional à concentração de $\mathrm{F}(\mathrm{r}=0,54 *)$. O aumento da concentração de $\mathrm{P}$ deveu-se tanto pelo efeito direto do aumento do $\mathrm{pH}$, já que este é um dos principais fatores que afetam a disponibilidade desse elemento no solo (Kiehl, 1979; Sposito, 1989), quanto pelo aumento da concentração de $\mathrm{F}$, já que este último pode deslocar o fosfato adsorvido aos óxidos de $\mathrm{Fe}$ e $\mathrm{Al}$, formando complexos estáveis $\mathrm{Al}-\mathrm{F}$ (Dickman \& Bray, 1941; Parfitt, 1978). Com base nos diagramas de solubilidade de Lindsay (1979), nos solos com pH variando entre 4,4 e 5,8 e com relativamente baixa concentração de $\mathrm{Ca}$ e alta de $\mathrm{Al}$, há grande participação de $\mathrm{P}$ ligado ao $\mathrm{Al}$ (variscita). 
Tabela 14. Influência de doses de fluoreto de sódio na concentração de fósforo $\left(\mathrm{mg} \mathrm{dm}{ }^{-3}\right.$ ), após seis e dezoito meses da aplicação, em quatro camadas de um podzólico vermelho-amarelo, em Piracicaba, SP.

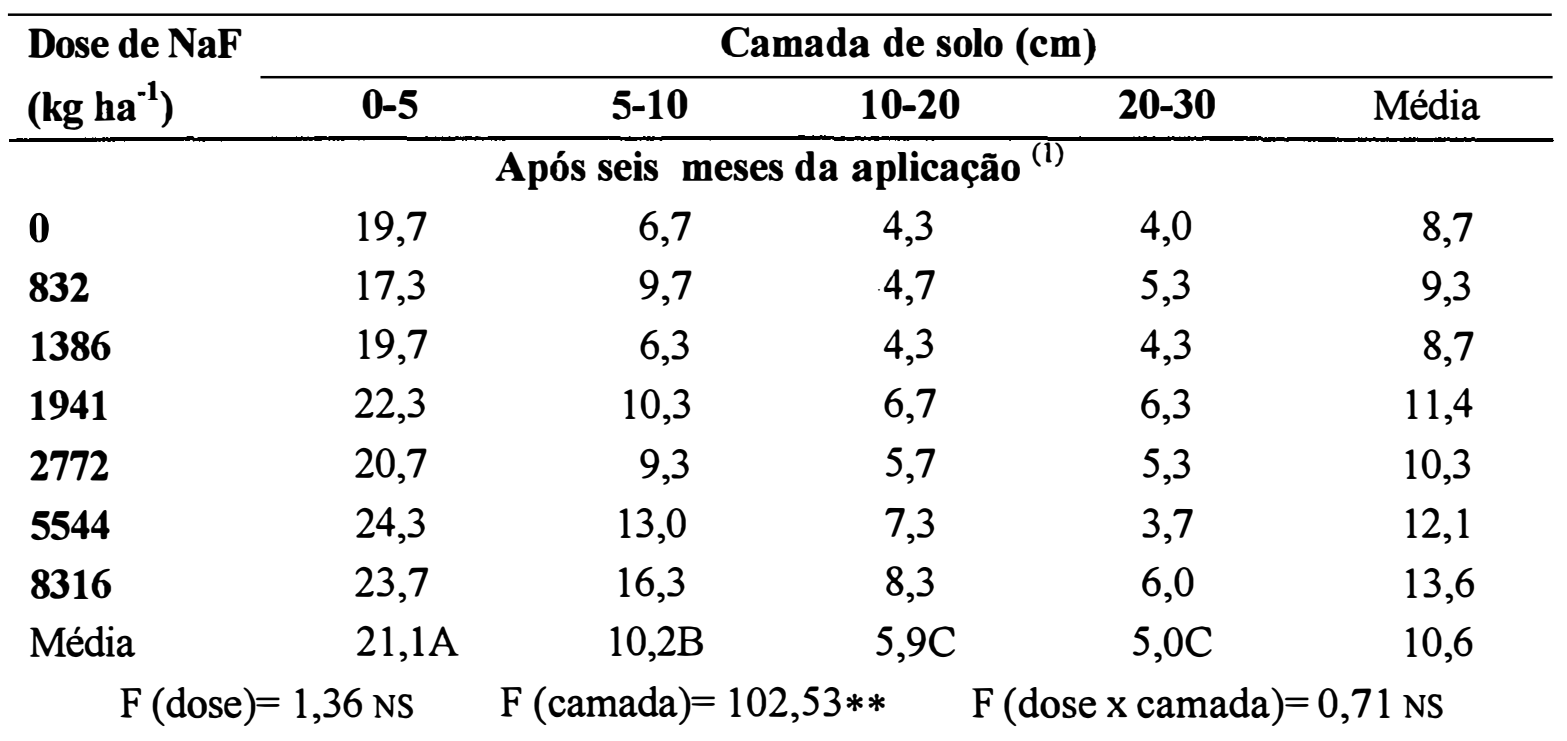

Após dezoito meses da aplicação ${ }^{(2)}$

\begin{tabular}{lrrrrr}
$\mathbf{0}$ & 9,0 & 4,7 & 3,3 & 3,0 & 5,0 \\
$\mathbf{8 3 2}$ & 9,7 & 4,3 & 3,3 & 3,0 & 5,3 \\
$\mathbf{1 3 8 6}$ & 10,7 & 4,3 & 2,7 & 3,0 & 5,2 \\
$\mathbf{1 9 4 1}$ & 9,0 & 5,3 & 4,3 & 3,3 & 5,5 \\
$\mathbf{2 7 7 2}$ & 13,3 & 5,3 & 4,0 & 3,0 & 6,4 \\
$\mathbf{5 5 4 4}$ & 11,0 & 5,3 & 4,3 & 4,3 & 6,3 \\
$\mathbf{8 3 1 6}$ & 11,3 & 5,7 & 4,0 & 3,0 & 6,0 \\
Média & $10,6 \mathrm{~A}$ & $5,1 \mathrm{~B}$ & $3,7 \mathrm{C}$ & $3,2 \mathrm{C}$ & 5,7 \\
\multicolumn{4}{r}{$\mathrm{F}($ dose $)=1,04 \mathrm{NS}$} & $\mathrm{F}($ camada $)=97,31 * *$ & $\mathrm{~F}($ dose $x$ camada $)=0,79 \mathrm{NS}$
\end{tabular}

Nas duas épocas de amostragem

$$
\mathrm{F}(\text { dose })=1,54 \mathrm{NS} \quad \mathrm{F}(\text { camada })=147,28 * * \quad \mathrm{~F}(\text { época })=137,00 * *
$$

$\mathrm{F}($ dose $\mathrm{x}$ camada $)=0,79 \mathrm{NS} \quad \mathrm{F}($ dose $\mathrm{x}$ época $)=1,97 \mathrm{NS} \quad \mathrm{F}($ camada $\mathrm{x}$ época $)=23,20 * *$

$\mathrm{F}($ dose $\mathrm{x}$ camada $\mathrm{x}$ época $)=0,66 \mathrm{NS}$

(1) Após cultivo de sorgo, em maio de $1996 .{ }^{(2)}$ Após cultivo de crotalária, em maio de 1997.

Números seguidos pela mesma letra maiúscula na linha não diferem entre si ao nível de $5 \%$ de probabilidade pelo teste de Tukey.

**, * significativo pelo teste $\mathrm{F}$ ao nível de $1 \%$ e $5 \%$ de probabilidade, respectivamente. NS não significativo. 
Assim, com a aplicação de doses de $\mathrm{NaF}$ e conseqüente aumento do $\mathrm{pH}$ do solo, houve troca de ligantes com formação de complexos Al-F e Al-OH, com aumento da disponibilidade de fósforo.

A concentração de $\mathrm{P}$ foi significativamente diminuída com o aumento da profundidade do solo, sendo que o valor médio encontrado na camada $0-5 \mathrm{~cm}$ foi quase $50 \%$ superior ao da camada 5-10 cm, tanto após seis como após dezoito meses (Tabela 14). Esses resultados concordam com aqueles obtidos por Kiehl (1979), que mostrou a predominância do P nos horizontes superficiais dos solos do Estado de São Paulo.

Entre seis meses e dezoito meses de experimentação, houve diminuição significativa na concentração média de $\mathrm{P}$ no solo $(0-30 \mathrm{~cm})$ (Tabela 14$)$, entretanto, a quantidade disponivel encontrada na última amostragem do solo foi semelhante àquela da instalação do experimento (Tabela 1).

\subsubsection{Flúor lábil}

A concentração média de $\mathrm{F}$ lábil no solo $(0-30 \mathrm{~cm})$ aumentou com o aumento da dose de $\mathrm{NaF}$, tanto após seis meses como após dezoito meses de experimentação (Tabela 15). Cabe ressaltar que na amostragem do solo feita após seis meses, a concentração de $\mathrm{F}$ encontrada na camada $0-5 \mathrm{~cm}$ variou entre 0,3 (valor mínimo) e $646,8 \mathrm{mg} \mathrm{dm}^{-3}$ (valor máximo), enquanto a média foi $173,6 \mathrm{mg} \mathrm{dm}^{-3}$. Verificou-se, nessa mesma camada do solo após dezoito meses, que a concentração de $\mathrm{F}$ variou entre $0,3 \mathrm{e}$ $467,4 \mathrm{mg} \mathrm{dm}^{-3}$ e a média foi $101,8 \mathrm{mg} \mathrm{dm}^{-3}$. Segundo Adriano (1986), as concentrações de $\mathrm{F}$ geralmente encontradas nos solos dos Estados Unidos variam entre $<100 \mathrm{mg} \mathrm{dm}^{-3}$ e $1000 \mathrm{mg} \mathrm{dm}^{-3}$ e média de $430 \mathrm{mg} \mathrm{dm}^{-3}$, enquanto em outros solos do mundo, o valor mediano relatado varia entre 200 e $300 \mathrm{mg} \mathrm{dm}^{-3}$.

As duas doses mais altas de $\mathrm{NaF}$ (5544 e $8316 \mathrm{~kg} \mathrm{ha}^{-1}$ ) aumentaram significativamente a concentração de $\mathrm{F}$ no solo $(0-30 \mathrm{~m} \mathrm{~cm})$, particularmente na camada 0-5 cm, tanto após seis meses como dezoito meses da aplicação (Tabela 15). A distribuição do $\mathrm{F}$ nos primeiros $30 \mathrm{~cm}$ de profundidade do solo evidenciou que, após seis meses da aplicação de doses de $\mathrm{NaF}$, houve acumulação de $\mathrm{F}$ predominantemente nos primeiros $10 \mathrm{~cm}$ do solo (Figura 2). 
Tabela 15. Influência de doses de fluoreto de sódio na concentração de flúor $\left(\mathrm{mg} \mathrm{dm}^{-3}\right)$, após seis e dezoito meses da aplicação, em quatro camadas de um podzólico vermelho-amarelo, em Piracicaba, SP.

\begin{tabular}{|c|c|c|c|c|c|}
\hline \multirow{2}{*}{$\begin{array}{l}\text { Dose de NaF } \\
\left(\mathrm{kg} \mathrm{ha}^{-1}\right)\end{array}$} & \multicolumn{5}{|c|}{ Camada de solo (cm) } \\
\hline & $0-5$ & 5-10 & $10-20$ & $20-30$ & Média \\
\hline \multicolumn{6}{|c|}{ Após seis meses da aplicação ${ }^{(1)}$} \\
\hline $\mathbf{0}$ & $1,0 \mathrm{Ab}$ & $0,8 \mathrm{Aa}$ & $0,8 \mathrm{Aa}$ & $0,7 \mathrm{Aa}$ & $0,8 \mathrm{c}$ \\
\hline 832 & $15,9 \mathrm{Ab}$ & $11,9 \mathrm{Aa}$ & $6,7 \mathrm{Aa}$ & 4,7Aa & $9,8 \mathrm{c}$ \\
\hline 1386 & $79,7 \mathrm{Ab}$ & 19,9Aa & $9,5 \mathrm{Aa}$ & $4,5 \mathrm{Aa}$ & $28,4 \mathrm{bc}$ \\
\hline 1941 & $45,9 \mathrm{Ab}$ & $34,1 \mathrm{Aa}$ & $23,2 \mathrm{Aa}$ & $15,1 \mathrm{Aa}$ & $29,6 \mathrm{bc}$ \\
\hline 2772 & $50,3 \mathrm{Ab}$ & $24,4 \mathrm{Ba}$ & $17,1 \mathrm{BCa}$ & $5,0 \mathrm{Ca}$ & $24,2 \mathrm{bc}$ \\
\hline 5544 & $607,1 \mathrm{Aa}$ & $200,6 \mathrm{ABa}$ & $26,2 \mathrm{Ba}$ & $3,1 \mathrm{Ba}$ & $209,3 a$ \\
\hline 8316 & $415,0 \mathrm{Aa}$ & $229,9 \mathrm{ABa}$ & $27,5 \mathrm{Ba}$ & $10,0 \mathrm{Ba}$ & $170,6 \mathrm{ab}$ \\
\hline Média & $173,6 \mathrm{~A}$ & $74,5 \mathrm{~B}$ & $15,9 \mathrm{BC}$ & $6,2 \mathrm{C}$ & 67,5 \\
\hline \multicolumn{2}{|c|}{$\mathrm{F}($ dose $)=8,19 * *$} & $($ camada $)=23$ & \multicolumn{3}{|c|}{$\mathrm{F}($ dose $\mathrm{x}$ camada $)=7,02 * *$} \\
\hline
\end{tabular}

Após dezoito meses da aplicação ${ }^{(2)}$

$\begin{array}{lccccc}\mathbf{0} & 0,7 \mathrm{Ab} & 0,8 \mathrm{Ab} & 1,0 \mathrm{Ab} & 0,8 \mathrm{Ab} & 0,8 \mathrm{c} \\ \mathbf{8 3 2} & 3,8 \mathrm{Ab} & 15,7 \mathrm{Ab} & 8,9 \mathrm{Ab} & 6,0 \mathrm{Aab} & 8,6 \mathrm{c} \\ \mathbf{1 3 8 6} & 36,2 \mathrm{Ab} & 34,1 \mathrm{Ab} & 21,6 \mathrm{ABb} & 11,1 \mathrm{Bab} & 25,8 \mathrm{bc} \\ \mathbf{1 9 4 1} & 31,8 \mathrm{Ab} & 37,4 \mathrm{Ab} & 31,9 \mathrm{Ab} & 14,0 \mathrm{Aab} & 28,8 \mathrm{bc} \\ \mathbf{2 7 7 2} & 34,5 \mathrm{Ab} & 28,9 \mathrm{Ab} & 15,0 \mathrm{Ab} & 8,3 \mathrm{Aab} & 21,7 \mathrm{bc} \\ \mathbf{5 5 4 4} & 325,3 \mathrm{Aa} & 260,9 \mathrm{Aa} & 147,5 \mathrm{ABa} & 38,1 \mathrm{Ba} & 193,0 \mathrm{a} \\ \mathbf{8 3 1 6} & 280,4 \mathrm{Aa} & 170,3 \mathrm{ABab} & 65,4 \mathrm{Bab} & 22,2 \mathrm{Bab} & 134,6 \mathrm{ab} \\ \text { Média } & 101,8 \mathrm{~A} & 78,3 \mathrm{AB} & 41,6 \mathrm{BC} & 14,4 \mathrm{C} & 59,0\end{array}$

$$
\mathrm{F}(\text { dose })=8,50 * * \quad \mathrm{~F}(\text { camada })=18,87 * * \quad \mathrm{~F}(\text { dose } \mathrm{x} \text { camada })=5,77 * *
$$

Nas duas épocas de amostragem

$$
\mathrm{F}(\text { dose })=8,70 * * \quad \mathrm{~F}(\text { camada })=27,82 * * \quad \mathrm{~F}(\text { época })=1,68 \mathrm{NS}
$$

$\mathrm{F}($ dose $\mathrm{x}$ camada $)=8,29 * * \quad \mathrm{~F}($ dose $\mathrm{x}$ época $)=0,60 \mathrm{NS} \quad \mathrm{F}($ camada $\mathrm{x}$ época $)=10,86 * *$

$\mathrm{F}($ dose $\mathrm{x}$ camada $\mathrm{x}$ época $)=3,68 * *$

(1) Após cultivo de sorgo, em maio de 1996. ${ }^{(2)}$ Após cultivo de crotalária, em maio de 1997.

Números seguidos pela mesma letra, maiúscula na linha e minúscula na coluna, não diferem entre si ao nível de $5 \%$ de probabilidade pelo teste de Tukey.

**, * significativo pelo teste $\mathrm{F}$ ao nível de $1 \%$ e $5 \%$ de probabilidade, respectivamente. NS não significativo. 

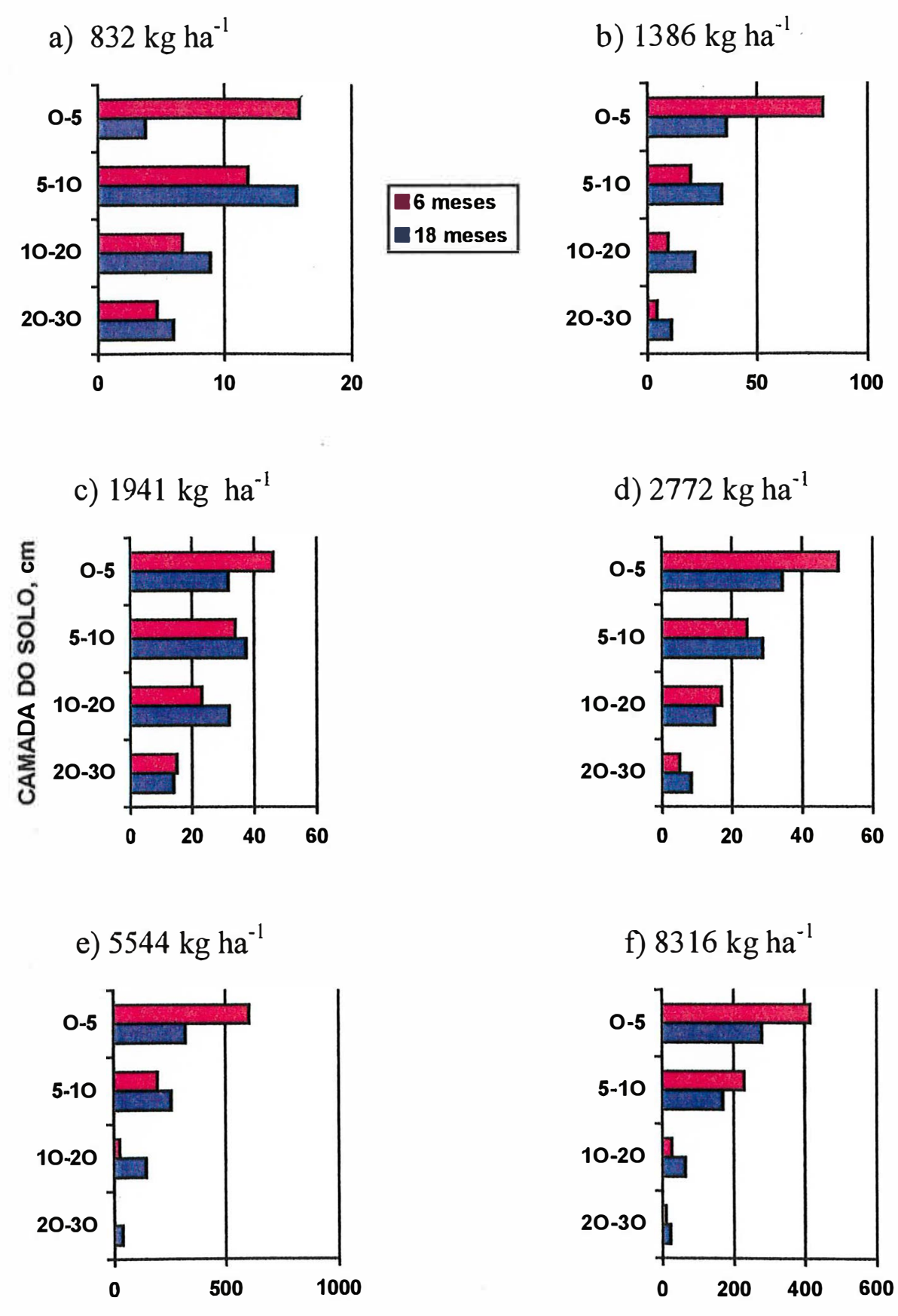

CONCENTRAÇÃO DE F NO SOLO, $\mathrm{mg} \mathrm{dm}^{-3}$

Figura 2. Distribuição do $\mathrm{F}$ em quatro camadas do solo, em função da dose de fluoreto de sódio aplicada e da época de amostragem. 
$\mathrm{Na}$ amostragem do solo efetuada após dezoito meses da aplicação de $\mathrm{NaF}$, encontrou-se aumento da concentração de $\mathrm{F}$ nos primeiros $20 \mathrm{~cm}$ do solo, mas as maiores concentrações ainda ocorreram na camada 0-5 cm (Tabela 15; Figura 2).

A concentração de $\mathrm{F}$ no solo foi inversamente proporcional ao contéudo de MO do solo, tanto após seis meses (na camada 0-5 cm: $\mathrm{r}=-0,47 *$ ) como após dezoito meses da aplicação de $\mathrm{NaF}$ (nas camadas $0-5 \mathrm{~cm}$ e $5-10 \mathrm{~cm}: \mathrm{r}=-0,48 *$ e $\mathrm{r}=-0,45 *$, respectivamente). Com o decorrer do tempo, é provável que o $\mathrm{F}$ acumule-se nas camadas subsuperficiais do solo, pois segundo Kabata-Pendias \& Pendias (1984), o F apresenta baixo grau de afinidade com a MO, portanto não se acumula nos horizontes mais superficiais na maioria dos solos. Pode-se inferir, pelo elevado grau de associação entre as concentrações de $\mathrm{F}$ e $\mathrm{Na}$ no solo $(0-30 \mathrm{~cm})$, tanto nas amostragens efetuadas após seis meses $(r=0,95 * *)$ como após dezoito meses $(r=0,88 * *)$ (Tabela 6), que uma grande parte do $\mathrm{F}^{-}$esteja sendo lixiviada no perfil na forma de $\mathrm{NaF}$. Segundo Flühler (1982), o $\mathrm{F}^{*}$ ligado ao $\mathrm{Na}$ apresenta maior solubilidade do que quando ligado à outros cátions, entre esses o cálcio. Resultados discordantes foram relatados por Gilpin \& Johnson (1980), sugerindo que o F seja relativamente imóvel (baixa solubilidade) no solo e em grande parte estaria combinado com espécies químicas que não são prontamente solúveis, e em solos intemperizados ocorreria tendência de fixação de $\mathrm{F}$.

A concentração de $\mathrm{F}$ no solo $(0-30 \mathrm{~cm})$ mostrou-se diretamente proporcional à dose de $\mathrm{NaF}$ aplicada, ao $\mathrm{pH}$, à concentração de $\mathrm{Na}$, e aos valores de $\mathrm{H}+\mathrm{Al}$ e $\mathrm{CTC}$, tanto na amostragem do solo efetuada após seis como após dezoito meses (Tabela 6). Após seis meses, na camada $0-5 \mathrm{~cm}$ do solo, a concentração de $\mathrm{F}$ mostrou-se diretamente proporcional à concentração de $\mathrm{Al}(\mathrm{r}=0,62 * *)$, devido à destruição de amorfos e MO do solo, enquanto na camada $20-30 \mathrm{~cm}$, foram inversamente proporcionais $(r=-0,44 *$ ). Por outro lado, após dezoito meses, a concentração de $\mathrm{F}$ mostrou-se inversamente proporcional à concentração de $\mathrm{Al}$, tanto na camada $5-10 \mathrm{~cm}$ $(\mathrm{r}=-0,57 *)$ como na camada $10-20 \mathrm{~cm}(\mathrm{r}=-0,52 *)$. Esses resultados mostram que uma parte do $\mathrm{F}^{-}$aplicado no solo está complexada com o $\mathrm{Al}(\mathrm{pH}$ do solo $=4,6-5,1)$, sendo lixiviado no perfil na forma de complexo Al-F, corroborando com diversos trabalhos (Adriano, 1986; Peek \& Volk (1986); Wenzel \& Blum, 1992a,b). Os resultados obtidos 
no presente trabalho confirmam que o $\mathrm{F}$ pode ser uma impureza útil em adubos fosfatados e gesso agrícola, devido à formação e lixiviação de complexos estáveis entre F e Al, como já relatado por diversos autores (Oates \& Caldwell, 1985; Raij, 1988; Carvalho, 1994).

\subsubsection{Outros atributos químicos do solo}

As variações nos valores de $\mathrm{H}+\mathrm{Al}, \mathrm{CTC}, \mathrm{V} \%$ e m\% em função da aplicação de doses de NaF no solo são apresentadas, respectivamente, nas Tabelas 16, 17, 18 e 19. Houve efeito significativo da aplicação de doses de $\mathrm{NaF}$ nos valores de $\mathrm{H}+\mathrm{Al}$ e CTC do solo, após seis meses e dezoito meses de experimentação. Os valores de $\mathrm{H}+\mathrm{Al}$ e CTC diminuíram-se com o aumento das doses de NaF. Entretanto, as diminuições variaram entre os tratamentos e as camadas de solo, sendo que na camada 10-20 cm, sempre foram significativas na camada $10-20 \mathrm{~cm}$ (Tabelas 16 e 17). Não houve efeito significativo de doses de $\mathrm{NaF}$ nos valores de $\mathrm{V} \%$, mas, como era esperado, houve efeito camada de solo estudada (Tabela 18). Com relação ao valor $\mathrm{m} \%$, houve efeito significativo de doses de $\mathrm{NaF}$ somente após seis meses de experimentação, sendo que em todas as camadas estudadas, os menores valores foram encontrados no tratamento com dose $1941 \mathrm{~kg} \mathrm{ha}^{-1}$ (Tabela 19), concordando com os resultados da concentração de Al no solo (Tabela 9).

Com o aumento da profundidade do solo, verificou-se aumento nos valores médios de $\mathrm{H}+\mathrm{Al}$, CTC e m\% e diminuição no valor de $\mathrm{V} \%$. No decorrer do período experimental, houve diminuição dos valores médios de $\mathrm{H}+\mathrm{Al}$ e CTC e aumento do valor de m\%, mas não houve variação significativa no valor de V\% (Tabelas 16 a 19).

Os valores de $\mathrm{H}+\mathrm{Al}$ e $\mathrm{m} \%$ foram diretamente proporcionais à concentração de $\mathrm{Al}$ no solo e inversamente proporcionais ao $\mathrm{pH}$, ao conteúdo de $\mathrm{MO}$ e à concentração de $\mathrm{P}$ no solo. A CTC do solo foi inversamente proporcional ao $\mathrm{pH}$. O valor de $\mathrm{V} \%$ foi inversamente proporcional à concentração de $\mathrm{Al}$, e diretamente proporcional ao $\mathrm{pH}$, ao conteúdo de $\mathrm{MO}$ e a concentração de $\mathrm{P}$ no solo. Como já relatado, as concentrações de $\mathrm{F}$

e $\mathrm{Na}$ no solo foram inversamente proporcionais aos valores de $\mathrm{H}+\mathrm{Al}$ e CTC e diretamente proporcional ao V\% (Tabela 6). 
Tabela 16. Influência de doses de fluoreto de sódio na acidez potencial $\left(\mathrm{H}+\mathrm{Al}, \mathrm{mmol}_{\mathrm{c}} \mathrm{dm}^{-3}\right)$, após seis e dezoito meses da aplicação, em quatro camadas de um podzólico vermelho-amarelo, em Piracicaba, SP.

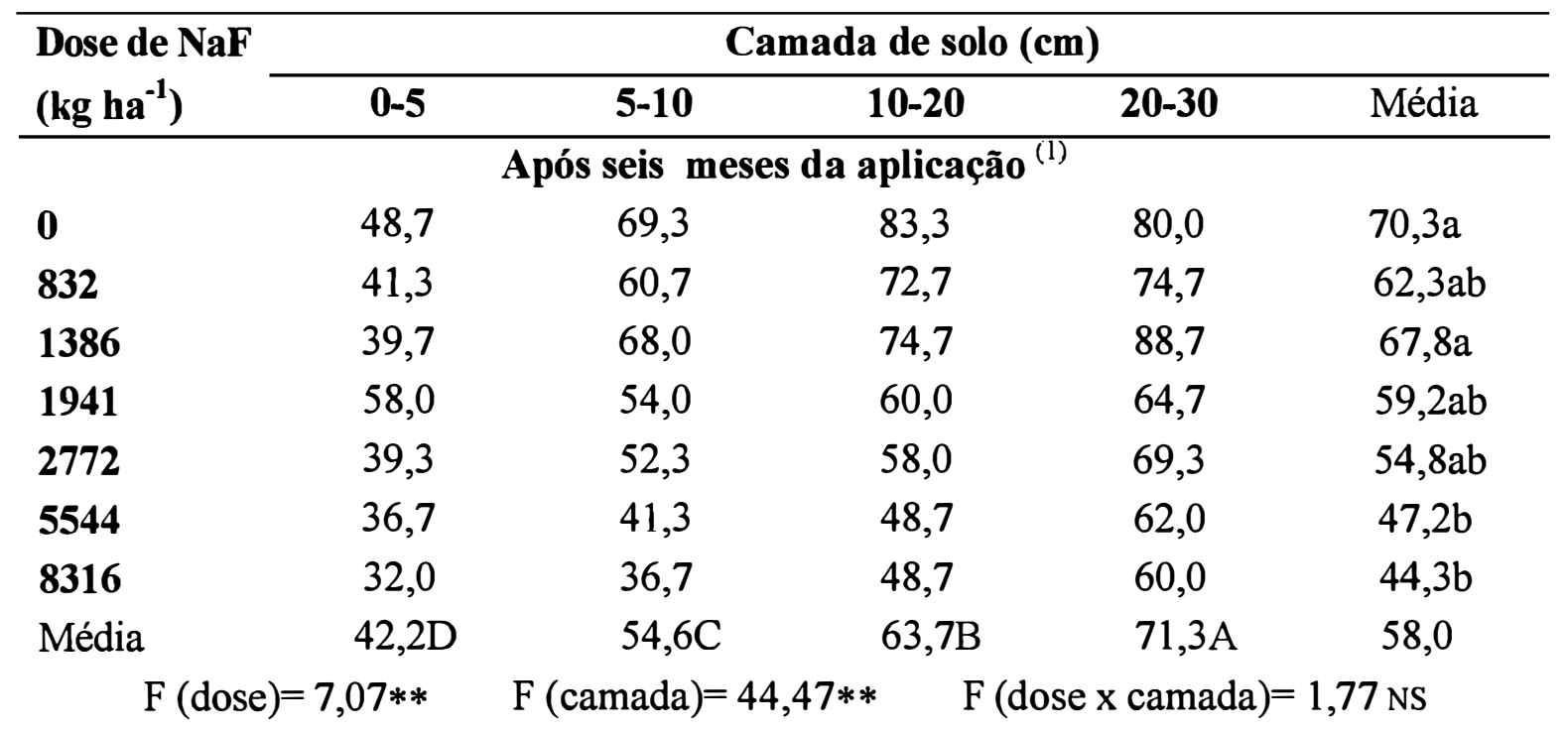

Após dezoito meses da aplicação ${ }^{(2)}$

$\begin{array}{llllll}\mathbf{0} & 37,7 & 52,3 & 62,7 & 58,0 & 52,7 \mathrm{a} \\ \mathbf{8 3 2} & 35,3 & 50,3 & 56,3 & 66,3 & 52,1 \mathrm{a} \\ \mathbf{1 3 8 6} & 39,3 & 52,3 & 56,0 & 62,0 & 52,4 \mathrm{a} \\ \mathbf{1 9 4 1} & 34,3 & 46,7 & 50,7 & 58,0 & 47,4 \mathrm{a} \\ \mathbf{2 7 7 2} & 34,3 & 43,7 & 50,7 & 60,0 & 47,2 \mathrm{a} \\ \mathbf{5 5 4 4} & 36,0 & 44,0 & 44,0 & 52,7 & 44,2 \mathrm{a} \\ \mathbf{8 3 1 6} & 30,0 & 35,3 & 40,7 & 52,3 & 39,6 \mathrm{a} \\ \text { Média } & 35,3 \mathrm{D} & 46,4 \mathrm{C} & 51,6 \mathrm{~B} & 58,5 \mathrm{~A} & 47,9\end{array}$

$\mathrm{F}($ dose $)=3,12 * \quad \mathrm{~F}($ camada $)=58,49 * * \quad \mathrm{~F}($ dose $\mathrm{x}$ camada $)=0,91 \mathrm{NS}$

Nas duas épocas de amostragem

$\mathrm{F}($ dose $)=6,38 * * \quad \mathrm{~F}($ camada $)=120,90 * * \quad \mathrm{~F}($ época $)=66,18 * *$

$\mathrm{F}($ dose $\mathrm{x}$ camada $)=2,68 * * \quad \mathrm{~F}($ dose $\mathrm{x}$ época $)=2,70 * \quad \mathrm{~F}($ camada $\mathrm{x}$ época $)=1,37 \mathrm{NS}$

$\mathrm{F}($ dose $\mathrm{x}$ camada $\mathrm{x}$ época $)=0,84 \mathrm{NS}$

(1) Após cultivo de sorgo, em maio de $1996 .{ }^{(2)}$ Após cultivo de crotalária, em maio de 1997.

Números seguidos pela mesma letra, maiúscula na linha e minúscula na coluna, não diferem entre si ao nivel de $5 \%$ de probabilidade pelo teste de Tukey.

**, * significativo pelo teste $\mathrm{F}$ ao nivel de $1 \%$ e $5 \%$ de probabilidade, respectivamente. NS não significativo. 
Tabela 17. Influência de doses de fluoreto de sódio na capacidade de troca de cátions $\left(\mathrm{CTC}, \mathrm{mmol}_{\mathrm{c}} \mathrm{dm}^{-3}\right)$, após seis e dezoito meses da aplicação, em quatro camadas de um podzólico vermelho-amarelo, em Piracicaba, SP.

\begin{tabular}{|c|c|c|c|c|c|}
\hline \multirow{2}{*}{$\begin{array}{l}\text { Dose de NaF } \\
\left(\mathrm{kg} \mathrm{ha}^{-1}\right)\end{array}$} & \multicolumn{5}{|c|}{ Camada de solo $(\mathrm{cm})$} \\
\hline & $0-5$ & $5-10$ & $10-20$ & $20-30$ & Média \\
\hline \multicolumn{6}{|c|}{ Após seis meses da aplicação ${ }^{(1)}$} \\
\hline $\mathbf{0}$ & 95,0 & 97,0 & 107,0 & 102,7 & $100,4 a$ \\
\hline 832 & 84,7 & 92,7 & 97,7 & 98,0 & $93,3 a$ \\
\hline 1386 & 80,7 & 94,3 & 95,7 & 109,7 & $95,1 \mathrm{a}$ \\
\hline 1941 & 103,0 & 86,0 & 89,3 & 93,0 & $92,8 \mathrm{a}$ \\
\hline 2772 & 89,3 & 84,0 & 81,0 & 91,0 & $86,3 \mathrm{ab}$ \\
\hline 5544 & 72,3 & 65,7 & 70,0 & 82,0 & $72,5 \mathrm{bc}$ \\
\hline 8316 & 68,0 & 66,0 & 73,7 & 78,3 & $71,5 \mathrm{c}$ \\
\hline Média & $84,7 \mathrm{~B}$ & $83,7 \mathrm{~B}$ & $87,8 \mathrm{AB}$ & $93,5 \mathrm{~A}$ & 87,4 \\
\hline \multicolumn{2}{|c|}{$\mathrm{F}($ dose $)=15,39 * *$} & camada) & $\mathrm{F}(\mathrm{do}$ & (amada $)=$ & NS \\
\hline
\end{tabular}

Após dezoito meses da aplicação ${ }^{(2)}$

$\begin{array}{llllll}\mathbf{0} & 75,0 & 76,0 & 82,7 & 77,0 & 77,7 \mathrm{a} \\ \mathbf{8 3 2} & 79,7 & 75,7 & 78,0 & 86,3 & 79,9 \mathrm{a} \\ \mathbf{1 3 8 6} & 77,3 & 73,7 & 74,0 & 79,0 & 76,0 \mathrm{ab} \\ \mathbf{1 9 4 1} & 67,7 & 71,7 & 71,3 & 77,3 & 72,0 \mathrm{ab} \\ \mathbf{2 7 7 2} & 74,7 & 66,7 & 69,3 & 75,7 & 71,6 \mathrm{ab} \\ \mathbf{5 5 4 4} & 69,0 & 66,7 & 64,3 & 70,7 & 67,7 \mathrm{ab} \\ \mathbf{8 3 1 6} & 60,7 & 64,7 & 55,3 & 66,0 & 61,7 \mathrm{~b} \\ \text { Média } & 72,0 \mathrm{AB} & 70,7 \mathrm{~B} & 70,7 \mathrm{~B} & 76,0 \mathrm{~A} & \mathbf{7 2 , 4}\end{array}$

$\mathrm{F}($ dose $)=4,15 * \quad \mathrm{~F}($ camada $)=3,55 * * \quad \mathrm{~F}($ dose $\mathrm{x}$ camada $)=0,82 \mathrm{NS}$

Nas duas épocas de amostragem

$\mathrm{F}($ dose $)=9,96 * * \quad \mathrm{~F}($ camada $)=11,54 * * \quad \mathrm{~F}($ época $)=133,57 * *$

$\mathrm{F}($ dose $\mathrm{x}$ camada $)=1,59 \mathrm{NS} \quad \mathrm{F}($ dose $\mathrm{x}$ época $)=3,42 * * \quad \mathrm{~F}($ camada $\mathrm{x}$ época $)=0,98 \mathrm{NS}$

$\mathrm{F}($ dose $\mathrm{x}$ camada $\mathrm{x}$ época $)=1,10 \mathrm{NS}$

(1) Após cultivo de sorgo, em maio de $1996 .{ }^{(2)}$ Após cultivo de crotalária, em maio de 1997.

Números seguidos pela mesma letra, maiúscula na linha e minúscula na coluna, não diferem entre si ao nivel de $5 \%$ de probabilidade pelo teste de Tukey.

**, * significativo pelo teste $\mathrm{F}$ ao nivel de $1 \%$ e $5 \%$ de probabilidade, respectivamente. NS não significativo. 
Tabela 16. Influência de doses de fluoreto de sódio na saturação por bases $(\mathrm{V}, \%)$, após seis e dezoito meses da aplicação, em quatro camadas de um podzólico vermelho-amarelo, em Piracicaba, SP.

\begin{tabular}{|c|c|c|c|c|c|}
\hline \multirow{2}{*}{$\begin{array}{l}\text { Dose de NaF } \\
\left(\mathrm{kg} \mathrm{ha}^{-1}\right)\end{array}$} & \multicolumn{5}{|c|}{ Camada de solo (cm) } \\
\hline & 0-5 & $5-10$ & $10-20$ & $20-30$ & Média \\
\hline \multicolumn{6}{|c|}{ Após seis meses da aplicação ${ }^{(1)}$} \\
\hline 0 & $49 \mathrm{Aa}$ & $29 \mathrm{Ba}$ & $22 \mathrm{Ba}$ & $22 \mathrm{Bab}$ & 31 \\
\hline 832 . & $52 \mathrm{Aa}$ & $35 \mathrm{Ba}$ & $26 \mathrm{Ca}$ & $24 \mathrm{Cab}$ & 34 \\
\hline 1386 & $51 \mathrm{Aa}$ & $29 \mathrm{Ba}$ & $22 \mathrm{Ba}$ & $19 \mathrm{Bb}$ & 30 \\
\hline 1941 & $47 \mathrm{Aa}$ & 37Aa & $33 \mathrm{Aa}$ & $31 \mathrm{Aa}$ & 37 \\
\hline 2772 & $56 \mathrm{Aa}$ & $38 \mathrm{Ba}$ & $29 \mathrm{BCa}$ & $24 \mathrm{Cab}$ & 37 \\
\hline 5544 & $49 \mathrm{Aa}$ & $37 \mathrm{Ba}$ & $31 \mathrm{BCa}$ & $25 \mathrm{Cab}$ & 35 \\
\hline 8316 & $53 \mathrm{Aa}$ & $44 \mathrm{Aa}$ & $34 \mathrm{Ba}$ & $24 \mathrm{Cab}$ & 39 \\
\hline Média & $51 \mathrm{~A}$ & $36 \mathrm{~B}$ & $28 \mathrm{C}$ & $24 \mathrm{D}$ & 35 \\
\hline
\end{tabular}

Após dezoito meses da aplicação ${ }^{(2)}$

\begin{tabular}{lrcccr}
$\mathbf{0}$ & 49 & 31 & 24 & 25 & 32 \\
$\mathbf{8 3 2}$ & 55 & 34 & 28 & 24 & 35 \\
$\mathbf{1 3 8 6}$ & 49 & 29 & 24 & 22 & 31 \\
$\mathbf{1 9 4 1}$ & 49 & 36 & 29 & 25 & 35 \\
$\mathbf{2 7 7 2}$ & 54 & 34 & 27 & 21 & 34 \\
$\mathbf{5 5 4 4}$ & 48 & 34 & 32 & 26 & 35 \\
$\mathbf{8 3 1 6}$ & 51 & 43 & 27 & 21 & 35 \\
Média & $51 \mathrm{~A}$ & $34 \mathrm{~B}$ & $27 \mathrm{C}$ & $23 \mathrm{C}$ & 34 \\
\multicolumn{4}{r}{$\mathrm{F}($ dose $)=0,52 \mathrm{NS}$} & $\mathrm{F}($ camada $)=121,96 * *$ & $\mathrm{~F}($ dose $\times$ camada $)=1,15$ NS
\end{tabular}

Nas duas épocas de amostragem

$$
\mathrm{F}(\text { dose })=1,63 \mathrm{NS} \quad \mathrm{F}(\text { camada })=333,05 * * \quad \mathrm{~F}(\text { época })=0,55 \mathrm{NS}
$$

$\mathrm{F}($ dose $\mathrm{x}$ camada $)=3,01 * * \quad \mathrm{~F}($ dose $\mathrm{x}$ época $)=0,68 \mathrm{NS} \quad \mathrm{F}($ camada $\mathrm{x}$ época $)=0,05$ NS $\mathrm{F}($ dose $\mathrm{x}$ camada $\mathrm{x}$ época $)=0,23 \mathrm{NS}$

(7) Após cultivo de sorgo, em maio de 1996. ${ }^{(2)}$ Após cultivo de crotalária, em maio de 1997.

Números seguidos pela mesma letra, maiúscula na linha e minúscula na coluna, não diferem entre si ao nível de $5 \%$ de probabilidade pelo teste de Tukey.

**, ${ }^{*}$ significativo pelo teste $\mathrm{F}$ ao nivel de $1 \%$ e $5 \%$ de probabilidade, respectivamente. NS não significativo. 
Tabela 19. Influência de doses de fluoreto de sódio na saturação por alumínio (m, \%), após seis e dezoito meses da aplicação, em quatro camadas de um podzólico vermelho-amarelo, em Piracicaba, SP.

\begin{tabular}{|c|c|c|c|c|c|}
\hline \multirow{2}{*}{$\begin{array}{l}\text { Dose de NaF } \\
\left(\mathrm{kg} \mathrm{ha}^{-1}\right)\end{array}$} & \multicolumn{5}{|c|}{ Camada de solo (cm) } \\
\hline & $0-5$ & $5-10$ & $10-20$ & $20-30$ & Média \\
\hline \multicolumn{6}{|c|}{ Após seis meses da aplicação ${ }^{(1)}$} \\
\hline $\mathbf{0}$ & $15 \mathrm{Bab}$ & $25 \mathrm{ABa}$ & 39Aab & $45 \mathrm{Aa}$ & $31 \mathrm{ab}$ \\
\hline 832 & $14 \mathrm{Cab}$ & $19 \mathrm{BCa}$ & $30 \mathrm{ABab}$ & $38 \mathrm{Aa}$ & $25 \mathrm{ab}$ \\
\hline 1386 & $13 \mathrm{Cab}$ & $33 \mathrm{Ba}$ & $44 \mathrm{ABa}$ & $50 \mathrm{Aa}$ & $35 a$ \\
\hline 1941 & $7 \mathrm{Bb}$ & $14 \mathrm{ABa}$ & $24 \mathrm{Ab}$ & $23 \mathrm{Aa}$ & $17 \mathrm{~b}$ \\
\hline 2772 & $17 \mathrm{Bab}$ & $30 \mathrm{ABa}$ & $33 \mathrm{ABab}$ & $42 \mathrm{Aa}$ & $31 \mathrm{ab}$ \\
\hline 5544 & $32 \mathrm{Aa}$ & $33 \mathrm{Aa}$ & $27 \mathrm{Ab}$ & $27 \mathrm{Aa}$ & $30 \mathrm{ab}$ \\
\hline 8316 & $25 \mathrm{Aa}$ & $28 \mathrm{Aa}$ & $30 \mathrm{Aab}$ & $35 \mathrm{Aa}$ & $30 \mathrm{ab}$ \\
\hline Média & $18 \mathrm{C}$ & $26 \mathrm{~B}$ & $32 \mathrm{~A}$ & $37 \mathrm{~A}$ & 28 \\
\hline \multicolumn{2}{|c|}{$\mathrm{F}($ dose $)=3,73 *$} & $\operatorname{mada})=?$ & \multicolumn{3}{|c|}{$\mathrm{F}($ dose $\mathrm{x}$ camada $)=3,01 * *$} \\
\hline
\end{tabular}

\section{Após dezoito meses da aplicação ${ }^{(2)}$}

$\begin{array}{lrrlll}\mathbf{0} & 12 & 29 & 46 & 53 & 35 \\ \mathbf{8 3 2} & 8 & 35 & 43 & 52 & 35 \\ \mathbf{1 3 8 6} & 11 & 40 & 47 & 46 & 36 \\ \mathbf{1 9 4 1} & 12 & 33 & 42 & 48 & 34 \\ \mathbf{2 7 7 2} & 7 & 31 & 32 & 55 & 31 \\ \mathbf{5 5 4 4} & 24 & 24 & 30 & 45 & 31 \\ \mathbf{8 3 1 6} & 0 & 8 & 26 & 48 & 20 \\ \text { Média } & 11 \mathrm{D} & 29 \mathrm{C} & 38 \mathrm{~B} & 50 \mathrm{~A} & 32\end{array}$

$\mathrm{F}($ dose $)=1,09 \mathrm{NS} \quad \mathrm{F}($ camada $)=73,05 * * \quad \mathrm{~F}($ dose $\mathrm{x}$ camada $)=1,66 \mathrm{NS}$

Nas duas épocas de amostragem

$$
\mathrm{F}(\text { dose })=1,58 \mathrm{NS} \quad \mathrm{F}(\text { camada })=113,25 * * \quad \mathrm{~F} \text { (época })=4,70 *
$$

$\mathrm{F}($ dose $\mathrm{x}$ camada $)=3,15 * * \quad \mathrm{~F}($ dose $\mathrm{x}$ época $)=3,72 * * \quad \mathrm{~F}($ camada $\mathrm{x}$ época $)=6,59 * *$ $\mathrm{F}($ dose $\mathrm{x}$ camada $\mathrm{x}$ época $)=0,73 \mathrm{NS}$

(1) Após cultivo de sorgo, em maio de 1996. ${ }^{(2)}$ Após cultivo de crotalária, em maio de 1997.

Números seguidos pela mesma letra, maiúscula na linha e minúscula na coluna, não diferem entre si ao nível de $5 \%$ de probabilidade pelo teste de Tukey.

$* *, *$ significativo pelo teste $\mathrm{F}$ ao nível de $1 \%$ e $5 \%$ de probabilidade, respectivamente. NS não significativo. 


\subsubsection{Produção de matéria seca e nutrição de sorgo e crotalária}

\subsubsection{Sorgo}

A aplicação de doses crescentes de $\mathrm{NaF}$ não alterou significativamente as concentrações de macro e micronutrientes nas folhas de sorgo, com exceção do Mn, que foi aumentado (Tabela 20). A concentração de Al nas folhas também não foi influenciada pela aplicação de $\mathrm{NaF}$ (Tabela 21). A análise da variância mostrou que houve efeito de doses de $\mathrm{NaF}$ na produção de matéria seca de grãos e na concentração de $\mathrm{Mg}$ nas folhas, mas as diferenças entre os tratamentos não foram significativas pelo teste de Tukey ao nível de $5 \%$ de probabilidade (Tabela 20 ). A produção relativa de grãos de sorgo foi reduzida em aproximadamente $50 \%$ nos tratamentos com as duas doses mais altas de $\mathrm{NaF}$ (5544 e $8316 \mathrm{~kg} \mathrm{ha}^{-1}$ ), enquanto nos outros tratamentos, variou entre $83 \%$ e $100 \%$.

$\mathrm{O}$ aumento da concentração de $\mathrm{Mn}$ nas folhas de sorgo é contraditório ao esperado em situações normais em que ocorre aumento de $\mathrm{pH}$ do solo. No geral, o aumento do $\mathrm{pH}$ em função da aplicação de condicionadores do solo, entre estes o calcário, diminui a disponibilidade de $\mathrm{Mn}$, e assim sendo, diminui a concentração de $\mathrm{Mn}$ na solução do solo e conseqüentemente, ocorre menor absorção desse elemento pelas plantas. (Malavolta, 1980; Moraghan \& Mascagni, 1991). A explicação do aumento da concentração de $\mathrm{Mn}$ nas folhas em função do aumento da dose de $\mathrm{NaF}$ deveu-se, possivelmente, ao aumento da disponibilidade do $\mathrm{Mn}$ devido à destruição de minerais amorfos contendo este elemento (Perrott et al, 1976; Hsu, 1989) e também da solubilização de complexos entre $\mathrm{Mn}$ e compostos orgânicos resultantes da mineralização da matéria orgânica do solo, já que esses complexos possuem uma limitada estabilidade (Moraghan \& Mascagni, 1991).

Embora tenha ocorrido ligeiro aumento das concentrações de $\mathrm{Na}$ e $\mathrm{F}$ nas folhas com o aumento das doses de $\mathrm{NaF}$, esse efeito não foi significativo (Tabela 21). Esse resultado pode estar relacionado com mecanismos de adaptação das plantas: pouca absorção, capacidade de exclusão ou falta de redistribuição de elementos dentro da planta. Em relação à testemunha, verificou-se que no tratamento com maior dose de $\mathrm{NaF}$ ocorreu aumento de aproximadamente quinze vezes na concentração de Na no solo, 

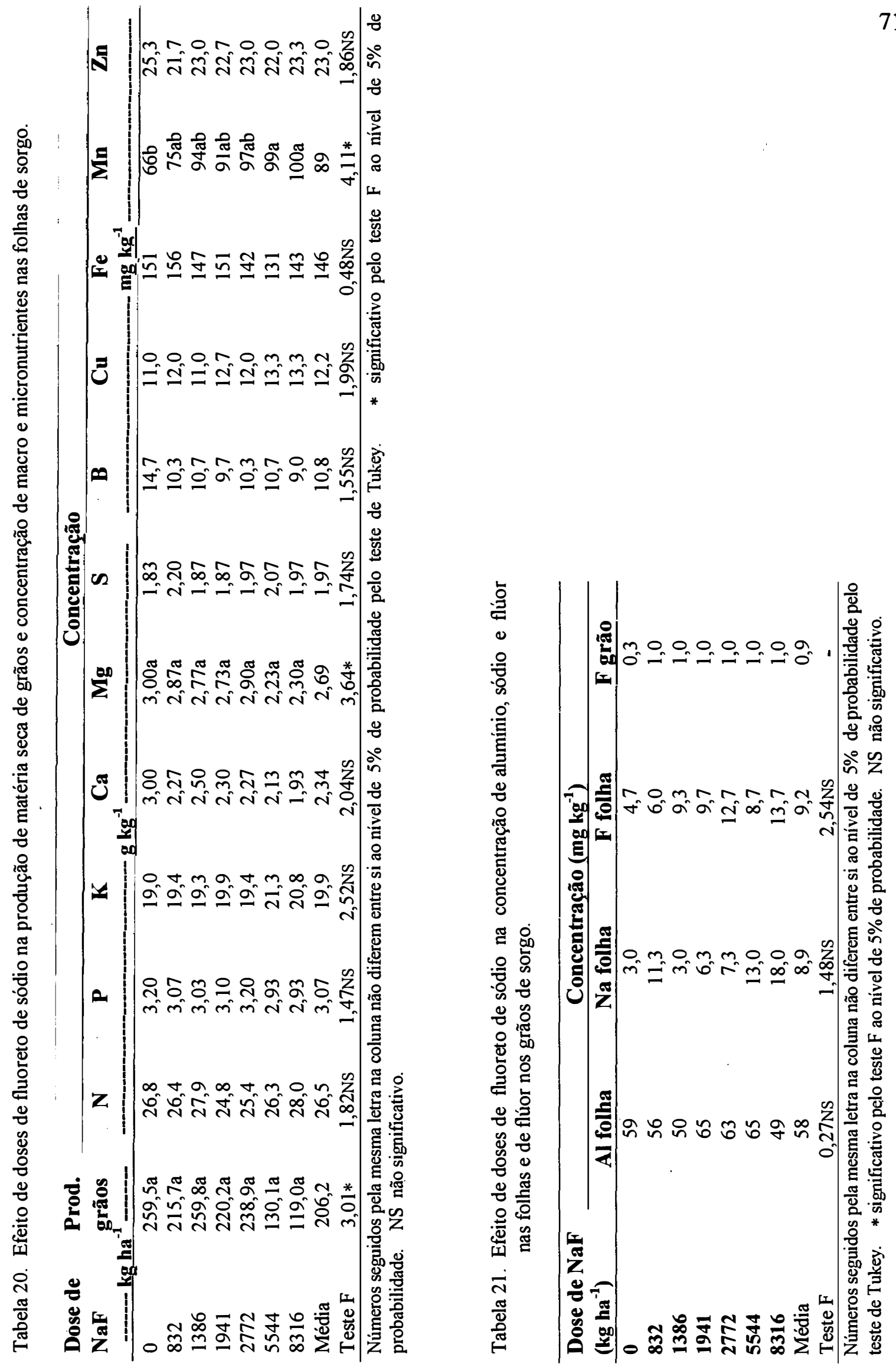
após seis meses (Tabela 13), enquanto nas folhas, esse aumento foi de seis vezes (Tabela 21). As altas concentrações de Na no solo (camada $0-5 \mathrm{~cm} \geq 34 \mathrm{mg} \mathrm{kg}^{-1}$; Tabela 13) encontradas nos dois tratamentos com as maiores doses de NaF (5544 e $8316 \mathrm{~kg} \mathrm{ha}^{-1}$ ) possivelmente diminuíram a porosidade e a aeração do solo (Tan, 1993) e restringiram o crescimento de raízes pelo aumento da pressão osmótica do solo, e concomitantemente pode ter afetado a absorção de nutrientes e também retardado o crescimento da parte aérea (Maas \& Nieman, 1978). A concentração de Na nas folhas foi diretamente proporcional à concentração de $\mathrm{Na}$ no solo $(0-30 \mathrm{~cm})$ e inversamente proporcional à produção de matéria seca de grãos de sorgo (Tabela 22).

Tabela 22. Coeficientes de correlação (r) de Pearson entre produção de matéria seca de grãos (Prod) e concentrações de elementos no sorgo e de Na e F no solo.

\begin{tabular}{lccccccccc}
\hline Variáveis & Prod & \multicolumn{7}{c}{ Concentração nas folhas } \\
\cline { 2 - 9 } & & $\mathbf{P}$ & $\mathbf{K}$ & $\mathbf{C a}$ & $\mathbf{M g}$ & $\mathbf{M n}$ & $\mathbf{A l}$ & $\mathbf{N a}$ & $\mathbf{F}$ \\
\hline Prod & - & $0,55 * *$ & $-0,67 * *$ & $0,43 \mathrm{NS}$ & $0,70 * *$ & $-0,06 \mathrm{NS}$ & $0,00 \mathrm{NS}$ & $-0,68 * *$ & $-0,11 \mathrm{NS}$ \\
Na solo & $-0,71 * *$ & $-0,50 *$ & $0,65 * *$ & $-0,54 *$ & $-0,54 *$ & $0,34 \mathrm{NS}$ & $-0,05 \mathrm{NS}$ & $0,73 * *$ & $0,49 *$ \\
Na folha & $-0,68 * *$ & $-0,56 * *$ & $0,55 * *$ & $-0,35 \mathrm{NS}$ & $-0,38 \mathrm{NS}$ & $0,06 \mathrm{NS}$ & $-0,04 \mathrm{NS}$ & - & $0,19 \mathrm{NS}$ \\
F solo & $-0,71 * *$ & $-0,48 *$ & $0,70 * *$ & $-0,50 *$ & $-0,53 *$ & $0,30 \mathrm{NS}$ & $-0,06 \mathrm{NS}$ & $0,65 * *$ & $0,36 \mathrm{NS}$ \\
F folha & $-0,11 \mathrm{NS}$ & $0,02 \mathrm{NS}$ & $0,13 \mathrm{NS}$ & $-0,50 *$ & $-0,12 \mathrm{NS}$ & $0,56 * *$ & $-0,08 \mathrm{NS}$ & $0,19 \mathrm{NS}$ & - \\
F grão & $-0,19 \mathrm{NS}$ & $-0,17 \mathrm{NS}$ & $0,24 \mathrm{NS}$ & $-0,65 * *$ & $-0,21 \mathrm{NS}$ & $0,41 \mathrm{NS}$ & $-0,07 \mathrm{NS}$ & $0,22 \mathrm{NS}$ & $0,34 \mathrm{NS}$ \\
\hline
\end{tabular}

**,* significativo ao nível de $1 \%$ e $5 \%$ de probabilidade pelo teste $\mathrm{t}$ de Student, respectivamente. NS não significativo.

A concentração de $\mathrm{F}$ nas folhas de sorgo do tratamento com maior dose de $\mathrm{NaF}\left(8316 \mathrm{~kg} \mathrm{ha}^{-1}\right)$ foi aproximadamente três vezes superior à da testemunha, podendose constatar que a absorção desse elemento pelas plantas foi muito pequena em relação à concentração de $\mathrm{F}$ no solo. No tratamento com maior dose de $\mathrm{NaF}$, a concentração média de $\mathrm{F}$ no solo $\left(0-30 \mathrm{~cm}\right.$ ) foi de $170,6 \mathrm{mg} \mathrm{dm}^{-3}$ (Tabela 15), enquanto nas folhas de sorgo, a concentração média de $\mathrm{F}$ foi de $13,7 \mathrm{mg} \mathrm{kg}^{-1}$. Ainda assim, esse valor é inferior ao limite máximo aceitável de $\mathrm{F}$ na dieta animal (bovinos, ovinos, caprinos), composta geralmente de plantas forrageiras, que é de $30 \mathrm{mg} \mathrm{kg}^{-1}$ de dieta seca na Inglaterra (Arnesen, 1997) e de $40 \mathrm{mg} \mathrm{kg}^{-1}$ de dieta seca na Nova Zelândia (Keerthisinghe et al., 
1991b). Nos grãos de sorgo, a concentração de $\mathrm{F}$ aumentou de 0,3 para $1,0 \mathrm{mg} \mathrm{kg}^{-1} \mathrm{com}$ a aplicação de doses de $\mathrm{NaF}$ (Tabela 21), revelando que a acumulação de $\mathrm{F}$ nos grãos pode ser considerada desprezível. Segundo Chaney (1983), há fatores ambientais e/ou fisiológicos nas plantas que previnem o aumento excessivo (prejudicial) do $\mathrm{F}$ na parte aérea das plantas, cujo mecanismo é descrito como "soil-plant barrier", sendo sua concentração normal, geralmente, inferior a $10 \mathrm{mg} \mathrm{kg}^{-1}$, e ainda não foi definido um valor que seja considerado fitotóxico. Com base nos resultados obtidos no presente trabalho, pode-se concluir que a acumulação de $\mathrm{F}$ pelas plantas foi muito pequena, em relação às altas concentrações de $\mathrm{F}$ no solo nos dois tratamentos com as doses mais altas de $\mathrm{NaF}$ (principalmente nos primeiros $10 \mathrm{~cm}$ de profundidade; Tabela 13), sendo aquele com maior dose $\left(8316 \mathrm{~kg} \mathrm{ha}^{-1}\right)$ correspondente à uma adição de $3762 \mathrm{~kg} \mathrm{ha}^{-1}$ de $\mathrm{F}$ no solo. Como geralmente a concentração média de $\mathrm{F}$ no adubo fosfatado super simples bem como no fosfogesso é de aproximadamente $1 \%$, seria necessário uma aplicação desses insumos de $376 \mathrm{t} \mathrm{ha}^{-1}$ para uma profundidade de $30 \mathrm{~cm}$ de solo para corresponder aos $3762 \mathrm{~kg} \mathrm{ha}^{-1}$ de $\mathrm{F}$ aplicados na maior dose de $\mathrm{NaF}$.

É importante ressaltar que ocorreu marcante diminuição das concentrações de F entre folhas e grãos de sorgo. Esses resultados concordam com os obtidos por diversos autores (Takmaz-Nisancioglu \& Davison, 1988; Beresin, 1991; Amesen, 1997; McLaughlin et al., 1996), que sugeriram que a concentração de $F$ nas plantas seja encontrada na seguinte ordem: raiz $>$ folha $>$ fruto.

A concentração de $\mathrm{F}$ nas folhas de sorgo mostrou-se diretamente proporcional à concentração de $\mathrm{Mn}$ nas folhas e inversamente proporcional à concentração de Ca nas folhas, e não associou-se significativamente com a concentração de F nos grãos (Tabela 22). Não houve associação significativa entre as concentrações de $F$ nas folhas e $F$ no solo $(0-30 \mathrm{~cm})$ e $\mathrm{Na}$ nas folhas (Tabela 22). Além disso, não foi encontrada associação significativa entre as concentrações de F e Al nas folhas de sorgo. Por outro lado, a concentração de $\mathrm{F}$ nas folhas de sorgo mostrou-se diretamente proporcional à concentração de $\mathrm{Mn}$ nas folhas. Esse resultado pode indicar que o $\mathrm{F}$ esteja sendo absorvido na forma de complexo Mn-F, discordando de Takmaz-Nisancioglu \& Davison (1988), que mostrou que os complexos Al-F são mais facilmente absorvidos pelas raízes. 
Nos tratamentos com as duas maiores doses de $\mathrm{NaF}\left(5544\right.$ e $\left.8316 \mathrm{~kg} \mathrm{ha}^{-1}\right)$, observou-se os seguintes sintomas visuais nas plantas de sorgo: clorose generalizada (coloração acinzentada) nas plantas; folhas estreitas e deformadas, com necrose apical e marginal; panículas deformadas; diminuição da taxa de sobrevivência, crescimento da parte aérea e produção das plantas. De acordo com diversos trabalhos (Treshow, 1971; Marshner, 1986), esses sintomas podem estar relacionadas com toxicidade de $\mathrm{Na}$ em plantas, mas também pode ser devido à problemas de deficiências de nutrientes. McNulty \& Newman (1961) verificaram que altas doses de NaF (em solução) podem afetar a síntese de pigmentos (clorofilas a e b e caroteno) ou induzir a degradação da estrutura do cloroplasto, reduzindo a taxa fotossintética de plântulas de feijão e soja. Segundo Marshner (1986), o sorgo, juntamente com milho, feijão e soja são consideradas espécies natrofóbicas, ou seja, são sensíveis à elevadas concentrações de $\mathrm{Na}$ no meio de crescimento, seja solo ou solução nutritiva. Nas folhas de sorgo dos tratamentos com maiores doses de $\mathrm{NaF}$, a necrose não foi acompanhada pela coloração vermelha descrita por Weinstein (1977).

As baixas produções de grãos de sorgo relacionaram-se principalmente com as altas concentrações de $\mathrm{Na}$ no solo e nas folhas (devido ao aumento das doses de $\mathrm{NaF}$ ) e as baixas concentrações de macronutrientes, exceto $\mathrm{N}$, com base nos níveis considerados adequados para o crescimento normal dessa cultura apresentados por Malavolta et al. (1989). A concentração de Mn nas folhas não foi relacionada com a produção de grãos de sorgo (Tabela 22). Alguns trabalhos (Sanchez \& Salinas, 1981; Seré \& Estrada, 1987; Tan \& Keltjens, 1995) têm constatado que o aumento do pH em função da calagem, pode melhorar a produção de sorgo em solos fortemente ácidos, desde que não sejam deficientes em $\mathrm{Mg}$.

\subsubsection{Crotalária}

A aplicação no solo de doses crescentes de $\mathrm{NaF}$ não afetou significativamente a concentração de macro e micronutrientes nas folhas, exceto o Fe, mas diminuiu significativamente a produção de matéria seca de vagens de crotalária (Tabela 23). Os tratamentos com as duas doses mais altas de $\mathrm{NaF}$ apresentaram produções de vagens 
significativamente inferiores àquela da testemunha, sendo reduzidas para $24 \%$ e $13 \%$, respectivamente com a aplicação de 5544 e $8316 \mathrm{~kg} \mathrm{ha}^{-1}$ (Tabela 23). A concentração média de $\mathrm{Zn}$ no tratamento com dose mais alta de $\mathrm{NaF}$ foi quase metade daquela da testemunha, mas os tratamentos não diferiram entre si pelo teste de Tukey ao nível de $5 \%$ de probabilidade (Tabela 24 ).

A concentração de $\mathrm{Al}$ nas folhas de crotalária não foi significativamente influenciada pela aplicação de $\mathrm{NaF}$ (Tabela 24). Ressalta-se que a concentração média de $\mathrm{Al}$ nas folhas de sorgo $\left(58 \mathrm{mg} \mathrm{kg}^{-1}\right.$; Tabela 21) foi superior àquela da crotalária (33 $\mathrm{mg} \mathrm{kg}^{-1}$; Tabela 24), para uma concentração semelhante de Al no solo (camada 0-30 $\mathrm{cm}=11 \mathrm{mmol}_{\mathrm{c}} \mathrm{dm}^{-3}$; Tabela 9). Esse resultado pode ser atribuído à diferenças genéticas na absorção e/ou transporte de $\mathrm{Al}$ para a parte aérea da planta.

A concentração de $\mathrm{Fe}$ nas folhas de crotalária aumentou significativamente com a aplicação de doses crescentes de $\mathrm{NaF}$ (Tabela 23). Comparando-se a testemunha com o tratamento com dose mais alta $\left(8316 \mathrm{~kg} \mathrm{ha}^{-1}\right)$, encontrou-se aumento de $93 \%$ na concentração de $\mathrm{Fe}$ nas folhas e redução de $87 \%$ na produção de vagens de crotalária. Diversos trabalhos (Foy et al, 1978; Kabata-Pendias \& Pendias, 1984) têm relatado que altas concentrações de Fe podem estar associadas com baixas concentrações de $\mathrm{Ca}$ e $\mathrm{Mg}$, concordando em parte com os resultados encontrados no presente trabalho, já que houve tendência de diminuição da concentração de $\mathrm{Ca}$ e aumento significativo do $\mathrm{Fe}$ nas folhas de crotalária com o aumento da dose de $\mathrm{NaF}$ aplicada no solo.

Os resultados mostraram que as aplicações de doses crescentes de $\mathrm{NaF}$ no solo aumentaram significativamente as concentrações de $\mathrm{Na}$ e F no solo (Tabelas 13 e 15 , respectivamente) e conseqüentemente aumentaram significativamente as concentrações de $\mathrm{Na}$ e $\mathrm{F}$ nas folhas (Tabela 24). A Tabela 25 revela a existência de altos graus de associação entre as concentrações de Na no solo e Na nas folhas e entre $\mathrm{F}$ no solo e F nas folhas. Resultados discordantes foram obtidos por Beresin et al. (1991), que não encontraram associação significativa entre as concentrações de $F$ no solo e $F$ nas plantas de aveia e cevada.

Nos tratamentos com as duas doses mais altas de $\mathrm{NaF}\left(5544\right.$ e $\left.8316 \mathrm{~kg} \mathrm{ha}^{-1}\right)$, as concentrações médias de $\mathrm{Na}$ e $\mathrm{F}$ nas folhas nas plantas de crotalária (Tabela 24) 


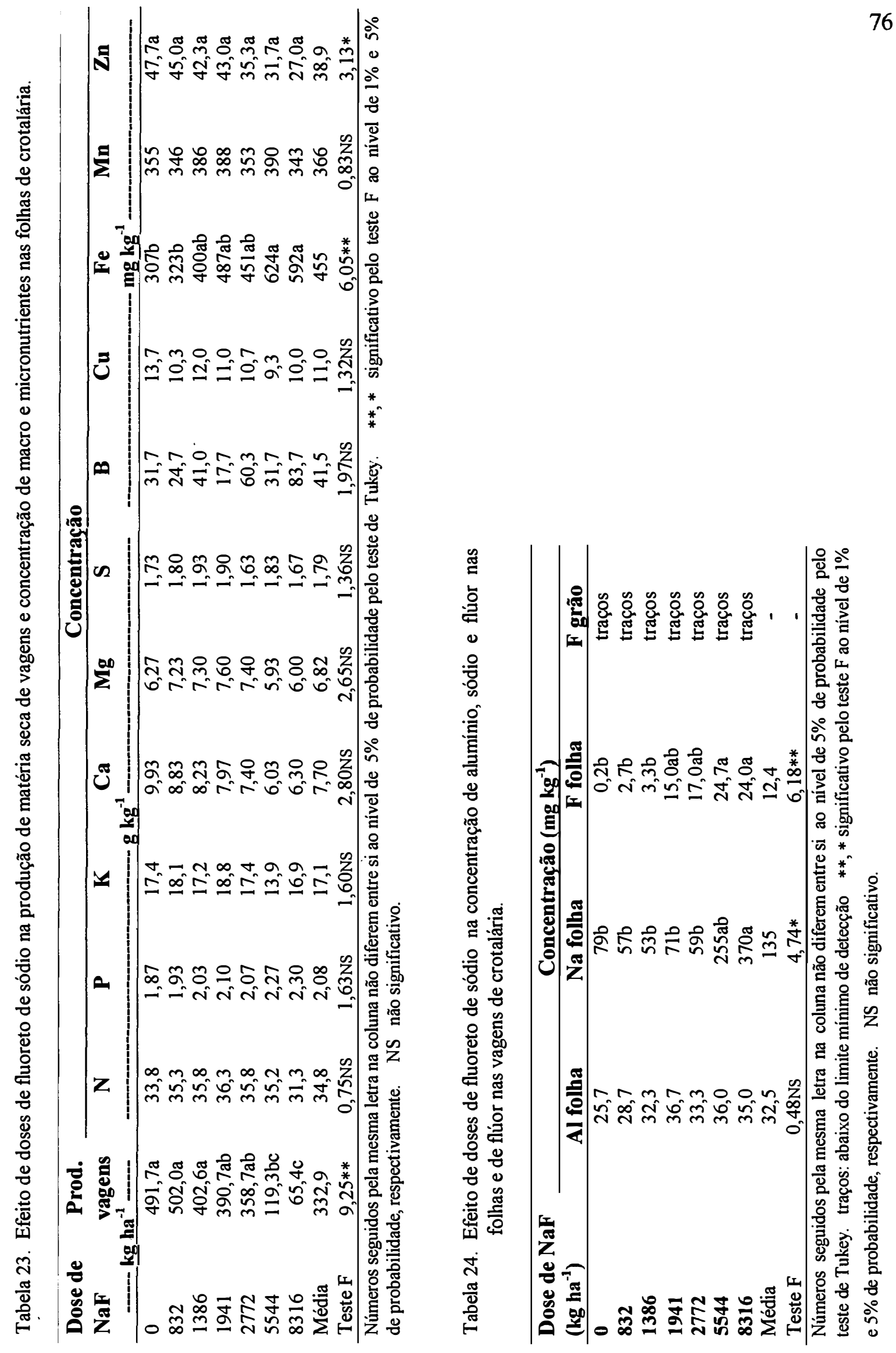


foram marcantemente superiores às encontradas nas plantas de sorgo (Tabela 21). Esses resultados mostram que a acumulação de $\mathrm{Na}$ e $\mathrm{F}$ varia com o tipo de planta, e deve ser controlada geneticamente. A elevada concentração de $\mathrm{Na}$ no solo $\left(\geq 10 \mathrm{mmol}_{\mathrm{c}} \mathrm{dm}^{-3}\right.$ nos tratamentos com as duas maiores doses de NaF; Tabela 13) após dezoito meses da aplicação, além de afetar as propriedades físicas do solo, afetou marcantemente o crescimento de raízes e da parte aérea da crotalária, semelhantemente ao relatado para o sorgo. Esse resultado é corroborado por Asher (1991), evidenciando que culturas com capacidade de fixação simbiótica de $\mathrm{N}$, como é o caso da crotalária, têm baixa exigência em $\mathrm{Na}$, e quando este elemento está presente em elevadas concentrações pode ocorrer diminuição na atividade da nitrogenase e no crescimento das plantas.

Tabela 25. Coeficientes de correlação ( $r$ ) de Pearson entre produção de matéria seca de vagens (Prod) e concentrações de elementos na crotalária e de $\mathrm{Na}$ e $\mathrm{F}$ no solo

\begin{tabular}{lccccccccc}
\hline Variáveis & Prod & \multicolumn{8}{c}{ Concentração nas folhas } \\
\cline { 2 - 10 } & & $\mathbf{P}$ & $\mathbf{C a}$ & $\mathbf{M g}$ & $\mathbf{F e}$ & $\mathbf{Z n}$ & $\mathbf{A l}$ & $\mathbf{N a}$ & $\mathbf{F}$ \\
\hline Prod & - & $-0,51 *$ & $0,63 * *$ & $0,65 * *$ & $-0,82 * *$ & $0,65 * *$ & $-0,26 \mathrm{NS}$ & $-0,71 * *$ & $-0,60 * *$ \\
Fe folha & $-0,82 * *$ & $0,59 * *$ & $-0,52 * *$ & $-0,45 *$ & - & $-0,57 * *$ & $0,45 *$ & $0,57 * *$ & $0,58 * *$ \\
Na solo & $-0,73 * *$ & $0,70 * *$ & $-0,56 * *$ & $-0,35 \mathrm{NS}$ & $0,72 * *$ & $-0,57 * *$ & $0,30 \mathrm{NS}$ & $0,59 * *$ & $0,77 * *$ \\
Na folha & $-0,71 * *$ & $0,44 *$ & $-0,54 *$ & $-0,61 * *$ & $0,57 * *$ & $-0,50 *$ & $0,11 \mathrm{NS}$ & - & $0,58 * *$ \\
F solo & $-0,67 * *$ & $0,63 * *$ & $-0,56 * *$ & $-0,42 \mathrm{NS}$ & $0,60 * *$ & $-0,51 *$ & $0,23 \mathrm{NS}$ & $0,63 * *$ & $0,73 * *$ \\
F folha & $-0,60 * *$ & $0,49 *$ & $-0,48 *$ & $-0,19 \mathrm{NS}$ & $0,58 * *$ & $-0,52 *$ & $0,56 * *$ & $0,58 * *$ & - \\
\hline
\end{tabular}

**,* significativo ao nível de $1 \%$ e $5 \%$ de probabilidade pelo teste $\mathrm{t}$ de Student, respectivamente. NS não significativo.

A concentração de $\mathrm{F}$ nas folhas mostrou-se diretamente proporcional às concentrações de $\mathrm{Fe}, \mathrm{Na}$ e $\mathrm{Al}$ nas folhas (Tabela 25). Associações significativas entre as concentrações de $\mathrm{F}$ e $\mathrm{Al}$ na parte aérea também foram relatadas em feijoeiro por Takmaz-Nisancioglu \& Davison (1988) e em forrageiras por Amesen (1997). Nas plantas de crotalária, o $\mathrm{F}$ foi preferencialmente absorvido na forma de complexos Al-F, Fe-F e Na-F (Tabela 25), enquanto nas plantas de sorgo, sua absorção foi preferencialmente na forma de complexo Mn-F (Tabela 22).

Nas vagens, a concentração de $\mathrm{F}$ não foi influenciada pelo aumento das doses 
de $\mathrm{NaF}$ (Tabela 24), demonstrando que, mesmo na presença de concentrações elevadas de $\mathrm{F}$ no solo (na camada 0-30, o F variou de 9 a $193 \mathrm{mg} \mathrm{dm}^{-3}$; Tabela 15), a acumulação foi pequena nas folhas ( $\mathrm{F}$ nas folhas variou de 2,7 a $24,7 \mathrm{mg} \mathrm{kg}^{-1}$ ) e nas vagens, foi insignificante, assim praticamente não houve transferência de $\mathrm{F}$ das folhas para as vagens, semelhantemente ao relatado por Beresin (1991) e Amesen (1997), que mostraram que a concentração de $\mathrm{F}$ é decrescente da folha para os frutos. Ainda, as concentrações de $\mathrm{F}$ nas folhas de crotalária em todos os tratamentos (Tabela 24) foram inferiores ao limite máximo aceitável de $\mathrm{F}$ na dieta animal $\left(30-40 \mathrm{mg} \mathrm{kg}^{-1}\right.$ de dieta seca) e ainda, foram inferiores aos encontrados nas plantas de sorgo, corroborando com Armesen (1997), que encontrou concentrações de F mais altas nas leguminosas do que nas gramíneas. Diversos autores (MacIntire, 1949; Weinstein, 1977; Chaney, 1983; Allaway, 1986; Miller et al., 1991) também não têm encontrado acumulação de F nas plantas, exceto para o gênero Camellia, quando este elemento é absorvido via solo.

De modo geral, com a elevação do $\mathrm{pH}$ em solos ácidos, ocorre aumento na disponibilidade de $\mathrm{N}, \mathrm{P}, \mathrm{K}, \mathrm{Ca}, \mathrm{Mg}, \mathrm{S}$ e $\mathrm{B}$, e diminuição de $\mathrm{Fe}, \mathrm{Cu}, \mathrm{Mn}, \mathrm{Zn}$ e $\mathrm{Al}$ (Malavolta, 1980). Entretanto, neste trabalho, com a elevação do $\mathrm{pH}$ em função da aplicação de $\mathrm{NaF}$ constatou-se comportamento distinto para alguns desses elementos, particulamente o Mn (após seis meses da aplicação e para a cultura de sorgo) e Fe (após dezoito meses da aplicação e para a cultura de crotalária). Para esses dois elementos, o aumento das disponibilidades não podem ser explicados pelo $\mathrm{pH}$ do solo, mas podem ser atribuídos à destruição de minerais amorfos e de complexos entre $\mathrm{Mn}$ ou $\mathrm{Fe}$ e os materiais orgânicos pela aplicação de NaF (Perrot et al., 1976; Hua, 1989). Segundo Moraghan \& Mascagni (1991), a estabilidade dos complexos entre micronutrientes e materiais orgânicos segue a seguinte ordem: $\mathrm{Mn}<\mathrm{Zn}<\mathrm{Cu}<\mathrm{Fe}$.

As baixas produções de vagens de crotalária podem ser atribuídas à elevadas concentrações de $\mathrm{Na}$ no solo e $\mathrm{Na}$ e Fe nas folhas e ainda, à problemas de defíciências de macronutrientes, entre estes $\mathrm{P}$ e $\mathrm{Ca}$. O efeito do $\mathrm{F}$ sobre a produção da crotalária foi indireto, já que foi significativamente associado com a concentração de Fe nas folhas, mas foi inferior ao limite aceitável de $\mathrm{F}$ na parte aérea das plantas (Keerthisinghe et al., 1991b; Arnesen, 1997). 
4.2 Efeito da aplicação de carbonato de cálcio e fluoreto de cálcio no solo e nas plantas, em casa de vegetação

\subsubsection{Alterações químicas na solução percolada do solo}

\subsubsection{1 pH da solução}

Os valores médios de $\mathrm{pH}$ nas soluções percoladas elevaram-se significativamente com a aplicação no solo de $\mathrm{CaF}_{2}$ e $\mathrm{CaCO}_{3}$, sendo que os aumentos variaram entre as épocas de amostragem das soluções e entre as doses, mas mantiveramse superiores à testemunha até o final do experimento (Tabela 26).

Tabela 26. Efeito de doses de carbonato de cálcio e fluoreto de cálcio no $\mathrm{pH}$ da solução percolada, em seis épocas de amostragem.

\begin{tabular}{|c|c|c|c|c|c|c|c|}
\hline \multirow{2}{*}{$\begin{array}{l}\text { Trata- } \\
\text { mento }\end{array}$} & \multicolumn{7}{|c|}{ Época de amostragem da solução percolada } \\
\hline & $0,1 \mathrm{VP}$ & 0,5 VP & $1,0 \mathrm{VP}$ & $2,0 \mathrm{VP}$ & 3,0 VP & $4,0 \mathrm{VP}$ & Média \\
\hline Testemunha & $4,38 \mathrm{ABCb}$ & $4,34 \mathrm{BCb}$ & $4,27 \mathrm{Cb}$ & $4,41 \mathrm{ABCd}$ & $4,54 \mathrm{ABc}$ & $4,63 \mathrm{Ab}$ & $4,43 c$ \\
\hline $\mathrm{CaCO}_{3}(1)$ & $4,66 \mathrm{Bab}$ & $5,06 \mathrm{Bab}$ & $5,06 \mathrm{Bb}$ & 6,21Aab & $6,28 \mathrm{Ab}$ & $5,76 \mathrm{ABab}$ & $5,51 \mathrm{~b}$ \\
\hline $\mathrm{CaCO}_{3}(2)$ & $4,75 \mathrm{Da}$ & $6,54 \mathrm{BCa}$ & $6,17 \mathrm{Ca}$ & $7,17 \mathrm{ABa}$ & $7,82 \mathrm{Aa}$ & $6,79 \mathrm{BCa}$ & $6,54 a$ \\
\hline $\mathrm{CaF}_{2}(1)$ & $4,75 \mathrm{Aa}$ & $5,60 \mathrm{Aab}$ & $4,73 \mathrm{Ab}$ & 5,12 Acd & $4,85 \mathrm{Ac}$ & $4,99 \mathrm{Ab}$ & $5,00 \mathrm{bc}$ \\
\hline $\mathrm{CaF}_{2}(2)$ & $4,67 \mathrm{Ba}$ & $6,01 \mathrm{Aab}$ & $5,09 \mathrm{ABb}$ & $5,59 \mathrm{ABbc}$ & $5,61 \mathrm{ABbc}$ & $5,43 \mathrm{ABab}$ & $5,40 \mathrm{~b}$ \\
\hline Média & $4,64 \mathrm{C}$ & $5,51 \mathrm{~A}$ & $5,06 \mathrm{~B}$ & $5,70 \mathrm{~A}$ & $5,82 \mathrm{~A}$ & $5,52 \mathrm{~A}$ & 5,37 \\
\hline \multicolumn{3}{|c|}{$\mathrm{F}($ trat $)=18,56 * *$} & \multicolumn{2}{|c|}{$F($ época $)=20,88 *$} & \multicolumn{3}{|c|}{$F($ trat $x$ época $)=4,83 * *$} \\
\hline
\end{tabular}

$1,0 \mathrm{VP}=1600 \mathrm{ml} . \mathrm{CaCO}_{3}(1)$ e $(2)=1400$ e $2800 \mathrm{mg} \mathrm{dm}^{-3}$, respectivamente. $\mathrm{CaF}_{2}(1)$ e (2) = $1092 \mathrm{e}$ $2185 \mathrm{mg} \mathrm{dm}^{-3}$, respectivamente. Números seguidos pela mesma letra, maiúscula dentro da linha e minúscula dentro da coluna, não diferem entre si ao nível de $5 \%$ de probabilidade pelo teste de Tukey. **, * significativo pelo teste $\mathrm{F}$ ao nível de $1 \%$ e $5 \%$ de probabilidade, respectivamente.

Comparando-se os valores médios de $\mathrm{pH}$ entre os tratamentos com dose (1) em todas as seis soluções percoladas, verificou-se que o tratamento com $\mathrm{CaCO}_{3}$ não diferiu significativamente daquele com $\mathrm{CaF}_{2}$, enquanto que na dose (2), o tratamento com $\mathrm{CaCO}_{3}$ aumentou significativamente o $\mathrm{pH}$ da solução percolada em relação ao $\mathrm{CaF}_{2}$.

Nos tratamentos com $\mathrm{CaCO}_{3}$, houve aumento significativo no valor de $\mathrm{pH}$ até a solução 3,0 VP, com posterior diminuição na solução 4,0 VP. Por outro lado, nos tratamentos com $\mathrm{CaF}_{2}$ ocorreu aumento significativo no $\mathrm{pH}$ da solução $0,5 \mathrm{VP}$, com 
posterior diminuição e estabilização. De modo geral, a aplicação de $\mathrm{CaCO}_{3}$ foi mais eficiente que de $\mathrm{CaF}_{2}$ na elevação do valor de $\mathrm{pH}$ da solução percolada do solo, mas o período de incubação foi comparativamente maior para o primeiro. Diversos trabalhos (Parfitt, 1978; Moore \& Ritchie, 1988; Wenzel \& Blum, 1992b) têm mostrado que a adição de fluoreto no solo, aumenta os valores de $\mathrm{pH}$ do solo e da solução do solo. $\mathrm{O}$ aumento do $\mathrm{pH}$ deveu-se possivelmente, ao deslocamento de $\mathrm{OH}^{-}$dos sítios de adsorção de argilominerais ou de espécies Al-OH pelo fluoreto.

\subsubsection{Alumínio em solução}

As perdas de $\mathrm{Al}$ por lixiviação (solução percolada) foram bastante elucidativas da dinâmica envolvendo este elemento e o F no sistema solo. A Tabela 27 mostra que a maior retirada de $\mathrm{Al}$ do sistema ocorreu nos tratamentos com $\mathrm{CaF}_{2}$, sendo que as perdas na dose (2) foram significativamente superiores às da dose (1). Este fato relacionou-se com a formação de complexos Al-F, de alta estabilidade, que por estarem em excesso no complexo sortivo do solo são, em parte, eliminados buscando o equilíbrio entre as espécies. Por outro lado, a menor perda de $\mathrm{Al}$ ocorreu na testemunha, que não diferiu estatisticamente dos tratamentos com $\mathrm{CaCO}_{3}$. Isto significa que o $\mathrm{Al}$ permaneceu em ambos sistemas, sendo que nos tratamentọs com $\mathrm{CaCO}_{3}$, a maior parte encontrava-se precipitada formando gibbsita. No entanto, o Al ora precipitado, pode ser potencialmente tóxico quando o efeito do carbonato se dissipar e o $\mathrm{pH}$ voltar a condição anterior (Figura 3).

\subsubsection{Cálcio, magnésio, potássio e sódio em solução}

No início do experimento, como o solo foi coletado sob floresta, houve grande decomposição do material orgânico proveniente das raizes finas (material reconhecidamente rico em $\mathrm{Ca}$ ), propiciando uma perda contínua de $\mathrm{Ca}, \mathrm{Mg}$ e $\mathrm{K}$ que atingiram o seu máximo na solução 1,0VP (Tabela 28). Este período também coincidiu com a fase de incubação dos insumos no solo. $\mathrm{O} \mathrm{Na}$ e $\mathrm{K}$, que são cátions de relativamente baixa retenção no solo (série liotrópica), apresentaram as maiores perdas na solução $0,1 \mathrm{VP}$ (Tabela 28). Por outro lado, $\mathrm{Ca}$ e $\mathrm{Mg}$, que são cátions de 
Tabela 27. Efeito de doses de carbonato de cálcio e fluoreto de cálcio na concentração média de alumínio $\left(\mathrm{mg} \mathrm{L}^{-1}\right)$ na solução percolada, em cinco épocas de amostragem.

\begin{tabular}{|c|c|c|c|c|c|c|}
\hline \multirow[t]{2}{*}{ Tratamento } & \multicolumn{6}{|c|}{ Época de amostragem da solução percolada } \\
\hline & $0,1 \mathrm{VP}$ & $0,5 \mathrm{VP}$ & $1,0 \mathrm{VP}$ & $2,0 \mathrm{VP}$ & $3,0 \mathrm{VP}$ & Média \\
\hline Testemunha & $0,53 \mathrm{Bb}$ & $0,73 \mathrm{Bb}$ & $2,38 \mathrm{Ac}$ & $0,55 \mathrm{Bb}$ & $1,25 \mathrm{Bc}$ & $1,09 \mathrm{c}$ \\
\hline $\mathrm{CaCO}_{3}(1)$ & $0,30 \mathrm{Bb}$ & $0,78 \mathrm{Bb}$ & $2,55 \mathrm{ABc}$ & $3,10 \mathrm{ABb}$ & $6,25 \mathrm{Abc}$ & $2,60 \mathrm{c}$ \\
\hline $\mathrm{CaCO}_{3}(2)$ & $0,53 \mathrm{Ab}$ & $0,50 \mathrm{Ab}$ & $3,65 \mathrm{Ac}$ & $1,85 \mathrm{Ab}$ & $6,00 \mathrm{Abc}$ & $2,51 \mathrm{c}$ \\
\hline $\mathrm{CaF}_{2}(1)$ & $2,03 \mathrm{Cb}$ & $7,63 \mathrm{BCab}$ & $10,05 \mathrm{ABb}$ & $6,78 \mathrm{BCb}$ & $14,50 \mathrm{Aab}$ & $8,20 \mathrm{~b}$ \\
\hline $\mathrm{CaF}_{2}(2)$ & $8,38 \mathrm{Ba}$ & $9,58 \mathrm{Ba}$ & $19,35 \mathrm{ABa}$ & $23,80 \mathrm{Aa}$ & $19,75 \mathrm{ABa}$ & $16,17 \mathrm{a}$ \\
\hline Média & $2,35 \mathrm{~B}$ & $3,84 \mathrm{~B}$ & $7,60 \mathrm{~A}$ & $7,22 \mathrm{~A}$ & $9,55 \mathrm{~A}$ & 6,11 \\
\hline \multicolumn{2}{|c|}{$\mathrm{F}(\operatorname{trat})=41,93 * *$} & \multicolumn{2}{|c|}{$\mathrm{F}($ época $)=12,88 * *$} & \multicolumn{3}{|c|}{$F($ trat $x$ época $)=2,66 * *$} \\
\hline
\end{tabular}

$1,0 \mathrm{VP}=1600 \mathrm{ml} . \mathrm{CaCO}_{3}(1)$ e $(2)=1400$ e $2800 \mathrm{mg} \mathrm{dm}^{-3}$, respectivamente. $\mathrm{CaF}_{2}(1)$ e (2) = 1092 e $2185 \mathrm{mg} \mathrm{dm}^{-3}$, respectivamente. Números seguidos pela mesma letra, maiúscula dentro da linha e minúscula dentro da coluna, não diferem entre si ao nível de $5 \%$ de probabilidade pelo teste de Tukey. **, * significativo pelo teste $\mathrm{F}$ ao nível de $1 \%$ e $5 \%$ de probabilidade, respectivamente.

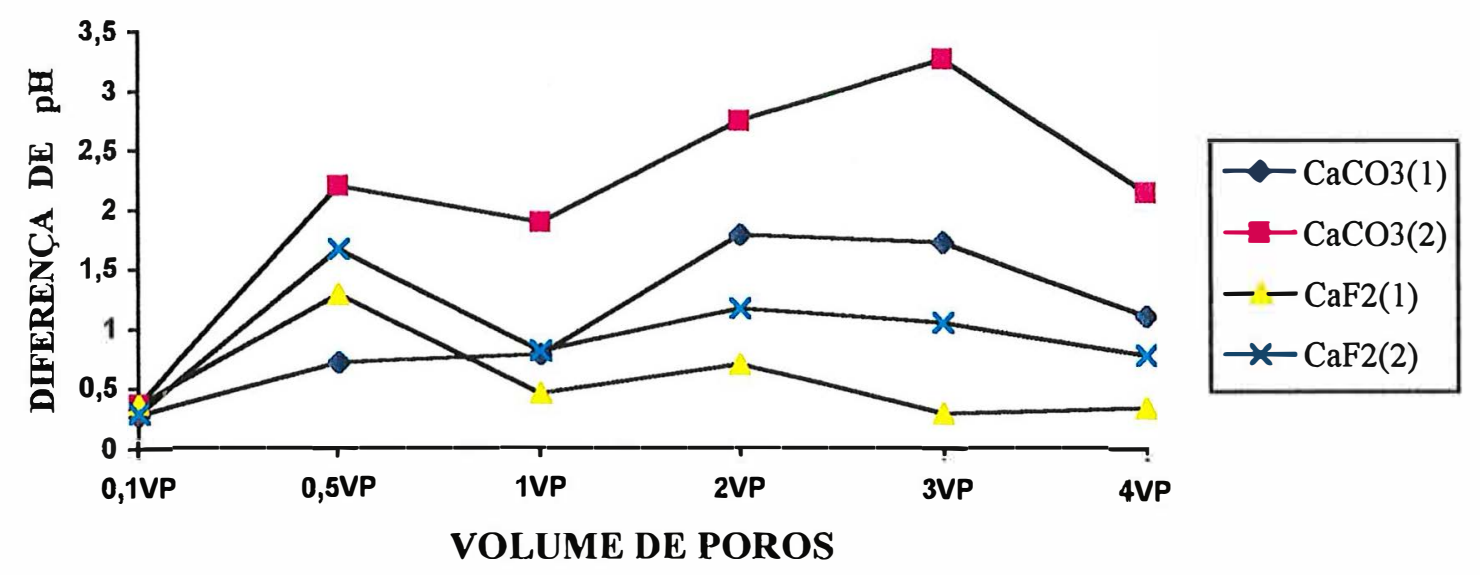

Figura 3. Diferença de $\mathrm{pH}$ ( $\mathrm{pH}$ do tratamento - $\mathrm{pH}$ da testemunha) em função do volume de solução percolada $(1 \mathrm{VP}=1600 \mathrm{~mL})$ 
relativamente maior retenção (série liotrópica), tiveram suas maiores perdas na solução 1,0 VP. Nas soluções seguintes, houve diminuições nas concentrações de $\mathrm{Ca}, \mathrm{Mg}$ e $\mathrm{K}$ por lixiviação devido, possivelmente, à intensificação do processo de incubação do solo.

A Tabela 28 mostra que a maior perda de $\mathrm{Ca}$ ocorreu no tratamento com $\mathrm{CaCO}_{3}$ (2), seguida daquela do tratamento com $\mathrm{CaF}_{2}$ (2), sendo que ambos não diferiram entre si. Isto é contraditório, já que o tratamento com $\mathrm{CaCO}_{3}(2)$ apresentou pH significativamente mais elevado, tanto na solução percolada (Tabela 26) como no solo (Tabela 38, p.99), sendo esperado portanto, uma CTC potencialmente mais elevada (sítios de carga variável) neste tratamento. Entretanto, como a CTC do solo do tratamento com $\mathrm{CaCO}_{3}$ (2) foi significativamente inferior àquela do tratamento com $\mathrm{CaF}_{2}$ (2) (Tabela 38, p.99), é provável que o $\mathrm{F}^{-}$, por ser um ligante mais forte que o bicarbonato $\left(\mathrm{HCO}_{3}{ }^{-}\right)$, possa estar gerando mais cargas nos sítios de carga variável e compensando a geração extra de cargas do tratamento com $\mathrm{CaCO}_{3}(2)$ por conta deste diferencial de $\mathrm{pH}$.

A perda de $\mathrm{K}$ por lixiviação na testemunha foi significativamente superior àquela dos outros tratamentos, enquanto que a perda de $\mathrm{Mg}$ também foi maior na testemunha, mas não diferiu dos tratamentos com $\mathrm{CaF}_{2}$ e $\mathrm{CaCO}_{3}$ (2) (Tabela 28). Para o $\mathrm{Na}$, não houve efeito significativo dos tratamentos na sua concentração média na solução percolada pelo teste de Tukey ao nível de $5 \%$ de probabilidade, mas ocorreu efeito da época de amostragem da solução, como já comentado (Tabela 28).

A Figura 4 mostra que a perda de bases $(\mathrm{SB}=\mathrm{Ca}+\mathrm{Mg}+\mathrm{K}+\mathrm{Na}$ ) foi menor no tratamento com $\mathrm{CaCO}_{3}$ (1) em relação aos outros tratamentos, enquanto a maior perda foi no tratamento com $\mathrm{CaCO}_{3}$ (2). Por outro lado, a perda de $\mathrm{Al}$ foi maior nos tratamentos com $\mathrm{CaF}_{2}$, já comentado anteriormente. Esses resultados revelaram que os tratamentos com $\mathrm{CaF}_{2}$ propiciaram uma maior diminuição da quantidade $\mathrm{Al}$ do sistema comparado aos tratamentos com $\mathrm{CaCO}_{3}$, e além disso, apresentaram menores perdas de bases em relação ao $\mathrm{CaCO}_{3}$ (2). Assim sendo, mesmo apresentando $\mathrm{pH}$ mais baixo, deve-se esperar uma significativa melhoria no ambiente radicular nos solos dos tratamentos com $\mathrm{CaF}_{2}$, tanto no tocante à menor perda de nutrientes quanto pela maior retirada de $\mathrm{Al}$ trocável. 
Tabela 28. Efeito de doses de carbonato de cálcio e fluoreto de cálcio nas concentrações médias de cálcio, magnésio, potássio e sódio $\left(\mathrm{mg} \mathrm{L}^{-1}\right)$ na solução percolada, em cinco épocas de amostragem.

\begin{tabular}{|c|c|c|c|c|c|c|}
\hline \multirow[t]{2}{*}{ Tratamento } & \multicolumn{6}{|c|}{ Época de amostragem da solução percolada } \\
\hline & 0,1 VP & 0,5 VP & 1,0 VP & 2,0 VP & $3,0 \mathrm{VP}$ & Média \\
\hline \multicolumn{7}{|c|}{ Cálcio } \\
\hline Testemunha & $3,03 \mathrm{Cb}$ & $2,97 \mathrm{Cb}$ & $23,78 \mathrm{Aa}$ & $19,48 \mathrm{ABa}$ & $11,43 \mathrm{BCa}$ & $12,14 b$ \\
\hline $\mathrm{CaCO}_{3}(1)$ & $3,98 \mathrm{Cb}$ & $3,49 \mathrm{Cb}$ & $34,48 \mathrm{Aa}$ & $14,80 \mathrm{Ba}$ & $7,20 \mathrm{BCa}$ & $12,79 b$ \\
\hline $\mathrm{CaCO}_{3}(2)$ & $8,80 \mathrm{Ba}$ & $9,19 \mathrm{Ba}$ & $83,63 \mathrm{Aa}$ & $25,55 \mathrm{Ba}$ & $23,18 \mathrm{Ba}$ & $30,07 a$ \\
\hline $\mathrm{CaF}_{2}(1)$ & $2,53 \mathrm{Bb}$ & $3,82 \mathrm{Bb}$ & $57,28 \mathrm{Aa}$ & $20,40 \mathrm{Ba}$ & $15,85 \mathrm{Ba}$ & $19,98 \mathrm{ab}$ \\
\hline $\mathrm{CaF}_{2}(2)$ & $2,90 \mathrm{Bb}$ & $4,76 \mathrm{Bb}$ & $78,08 \mathrm{Aa}$ & $18,55 \mathrm{Ba}$ & $17,28 \mathrm{Ba}$ & $24,32 a$ \\
\hline Média & $4,25 \mathrm{C}$ & $4,85 \mathrm{C}$ & $55,45 \mathrm{~A}$ & $19,76 \mathrm{~B}$ & $14,99 \mathrm{BC}$ & 19,90 \\
\hline \multicolumn{2}{|c|}{$\mathrm{F}($ trat $)=9,16 * *$} & \multicolumn{2}{|c|}{$\mathrm{F}($ época $)=54,00 * *$} & \multicolumn{2}{|c|}{$F($ trat $x$ época $)=2,83 * *$} & \\
\hline \multicolumn{7}{|c|}{ Magnésio } \\
\hline Testemunha & $2,30 \mathrm{Ba}$ & $1,88 \mathrm{Ba}$ & $15,10 \mathrm{Aa}$ & $15,60 \mathrm{Aa}$ & $9,25 \mathrm{ABa}$ & $8,83 a$ \\
\hline $\mathrm{CaCO}_{3}(1)$ & $2,20 \mathrm{BCa}$ & $0,88 \mathrm{Cb}$ & 7,95Aa & $4,03 \mathrm{Bb}$ & $1,75 \mathrm{BCa}$ & $3,36 b$ \\
\hline $\mathrm{CaCO}_{3}(2)$ & $2,38 \mathrm{Ba}$ & $1,33 \mathrm{Bab}$ & $11,70 \mathrm{Aa}$ & $4,35 \mathrm{ABb}$ & $3,23 \mathrm{Ba}$ & $4,60 \mathrm{ab}$ \\
\hline $\mathrm{CaF}_{2}(1)$ & $1,53 \mathrm{Bab}$ & $0,98 \mathrm{Bb}$ & $12,80 \mathrm{Aa}$ & $9,23 \mathrm{ABab}$ & $5,50 \mathrm{ABa}$ & $6,00 \mathrm{ab}$ \\
\hline $\mathrm{CaF}_{2}(2)$ & $1,23 \mathrm{Bb}$ & $1,05 \mathrm{Bb}$ & $18,15 \mathrm{Aa}$ & $3,85 \mathrm{Bb}$ & $3,20 \mathrm{Ba}$ & $5,50 \mathrm{ab}$ \\
\hline \multirow[t]{2}{*}{ Média } & $1,93 \mathrm{C}$ & $1,22 \mathrm{C}$ & $13,14 \mathrm{~A}$ & $7,41 \mathrm{~B}$ & $4,59 \mathrm{BC}$ & 5,66 \\
\hline & $\mathrm{F}(\mathrm{trat})=4,32 * *$ & \multicolumn{2}{|c|}{$F($ época $)=29,61 * *$} & \multicolumn{2}{|c|}{$F($ trat $x$ época $)=1,82 *$} & \\
\hline \multicolumn{7}{|c|}{ Potássio } \\
\hline Testemunha & $11,85 \mathrm{Aa}$ & $8,90 \mathrm{Ba}$ & $10,15 \mathrm{ABa}$ & $4,78 \mathrm{Ca}$ & $3,13 \mathrm{Ca}$ & $7,76 \mathrm{a}$ \\
\hline $\mathrm{CaCO}_{3}(1)$ & $8,60 \mathrm{Ab}$ & $4,03 \mathrm{BCb}$ & $4,65 \mathrm{Bb}$ & $2,23 \mathrm{CDb}$ & $0,73 \mathrm{Db}$ & $4,05 b$ \\
\hline $\mathrm{CaCO}_{3}(2)$ & $6,80 \mathrm{Abc}$ & $3,65 \mathrm{BCb}$ & $4,73 \mathrm{ABb}$ & $1,70 \mathrm{CDb}$ & $0,75 \mathrm{Db}$ & $3,53 b$ \\
\hline $\mathrm{CaF}_{2}(1)$ & $6,48 \mathrm{Abc}$ & $5,28 \mathrm{Ab}$ & $6,25 \mathrm{Ab}$ & $2,13 \mathrm{Bb}$ & $1,85 \mathrm{Bab}$ & $4,40 \mathrm{~b}$ \\
\hline $\mathrm{CaF}_{2}(2)$ & $5,30 \mathrm{Ac}$ & $5,40 \mathrm{Ab}$ & 6,93 Aab & $1,48 \mathrm{Bb}$ & $1,60 \mathrm{Bab}$ & $4,14 b$ \\
\hline \multirow[t]{2}{*}{ Média } & $7,81 \mathrm{~A}$ & $5,45 \mathrm{C}$ & $6,54 \mathrm{~B}$ & $2,46 \mathrm{D}$ & $1,61 \mathrm{D}$ & 4,77 \\
\hline & $F($ trat $)=44,26 * *$ & \multicolumn{2}{|c|}{$\mathrm{F}($ época $)=126,01 * *$} & \multicolumn{2}{|c|}{$F($ trat $x$ época $)=3,71 * *$} & \\
\hline \multicolumn{7}{|c|}{ Sódio } \\
\hline Testemunha & $3,10 \mathrm{Aa}$ & $1,70 \mathrm{Ba}$ & $1,18 \mathrm{Ca}$ & $0,65 \mathrm{Da}$ & $0,43 \mathrm{Da}$ & $1,41 \mathrm{a}$ \\
\hline $\mathrm{CaCO}_{3}(1)$ & $2,73 \mathrm{Aa}$ & $1,28 \mathrm{Ba}$ & $0,90 \mathrm{Ba}$ & $0,53 \mathrm{BCa}$ & $0,10 \mathrm{Ca}$ & $1,11 \mathrm{a}$ \\
\hline $\mathrm{CaCO}_{3}(2)$ & $1,95 \mathrm{Ab}$ & $1,08 \mathrm{Ba}$ & $1,13 \mathrm{Ba}$ & $0,40 \mathrm{Ca}$ & $0,10 \mathrm{Ca}$ & $0,93 a$ \\
\hline $\mathrm{CaF}_{2}(1)$ & $1,95 \mathrm{ABb}$ & 3,93Aa & $1,05 \mathrm{ABa}$ & $0,43 \mathrm{Ba}$ & $0,33 \mathrm{Ba}$ & $1,54 \mathrm{a}$ \\
\hline $\mathrm{CaF}_{2}(2)$ & $1,43 \mathrm{Ab}$ & $1,23 \mathrm{Aa}$ & $1,20 \mathrm{Aa}$ & $0,35 \mathrm{Ba}$ & $0,30 \mathrm{Ba}$ & $0,90 \mathrm{a}$ \\
\hline \multirow[t]{2}{*}{ Média } & $2,23 \mathrm{~A}$ & $1,84 \mathrm{~A}$ & $1,09 \mathrm{~B}$ & $0,47 \mathrm{BC}$ & $0,25 \mathrm{C}$ & 1,18 \\
\hline & $F($ trat $)=3,27 *$ & \multicolumn{2}{|c|}{$\mathrm{F}($ época $)=29,35 * *$} & \multicolumn{2}{|c|}{$\mathrm{F}($ trat $\mathrm{x}$ época $)=3,04 * *$} & \\
\hline
\end{tabular}

$1,0 \mathrm{VP}=1600 \mathrm{ml} . \mathrm{CaCO}_{3}(1)$ e $(2)=1400$ e $2800 \mathrm{mg} \mathrm{dm}^{-3}$, respectivamente. $\mathrm{CaF}_{2}(1)$ e (2) $=1092 \mathrm{e}$ $2185 \mathrm{mg} \mathrm{dm}^{-3}$, respectivamente. Números seguidos pela mesma letra, maiúscula dentro da linha e minúscula dentro da coluna, não diferem entre si ao nível de $5 \%$ de probabilidade pelo teste de Tukey. $* *$, * significativo pelo teste $\mathrm{F}$ ao nivel de $1 \%$ e $5 \%$ de probabilidade, respectivamente. 


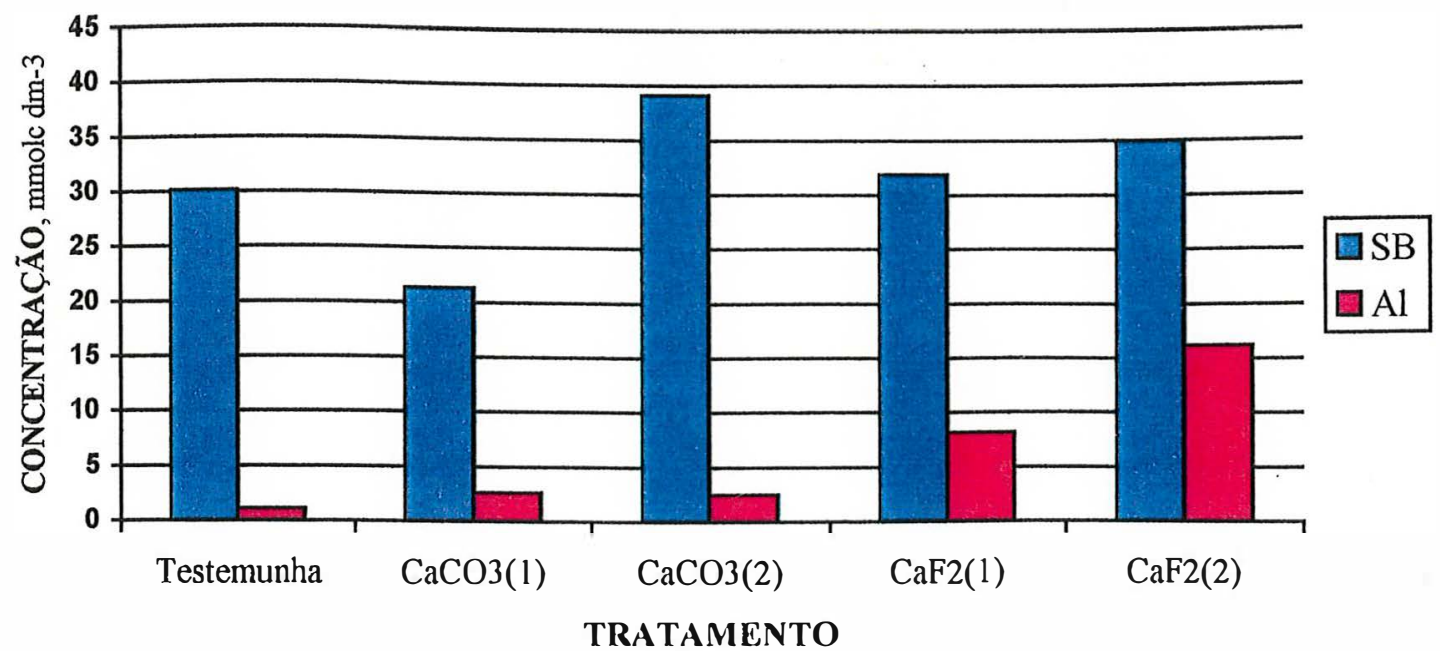

Figura 4. Concentração média de bases $(\mathrm{SB}=\mathrm{Ca}+\mathrm{Mg}+\mathrm{K}+\mathrm{Na})$ e alumínio nas soluções percoladas por tratamento.

\subsubsection{Nitrogênio}

De modo geral, o nitrogênio lixiviado apresentou tendência declinante ao longo do período experimental (Tabela 29). Provavelmente, a maior perda inicial deste ligante $\left(\mathrm{NO}_{3}{ }^{-}\right)$facilmente lixiviável, possa ser creditada à maior reserva orgânica do solo no início do experimento, cujo conteúdo foi de aproximado $4000 \mathrm{mg}$ por vaso.

A testemunha apresentou até a solução $3,0 \mathrm{VP}$, a maior perda de $\mathrm{NO}_{3}{ }^{-}$que, estatisticamente, não diferiu daquela do tratamento com $\mathrm{CaCO}_{3}$ (2) (Tabela 29). Certamente, esse $\mathrm{NO}_{3}{ }^{-}$lixiviou-se pareando a maior parte dos cátions lixiviados nestes tratamentos, já que não havia outro ligante de elevada mobilidade em elevada quantidade passível de pareamento. Nos tratamentos com $\mathrm{CaF}_{2}$, além do $\mathrm{NO}_{3}{ }^{-}$, havia o próprio $\mathrm{F}^{-}$, como já assinalado, pareando o $\mathrm{Al}$ (Tabela 27), enquanto nos tratamentos com $\mathrm{CaCO}_{3}$ havia entre outros ligantes, o $\mathrm{OH}^{-}$. 
Tabela 29. Efeito de doses de carbonato de cálcio e fluoreto de cálcio na concentração média de nitrogênio $\left(\mathrm{mg} \mathrm{L}^{-1}\right)$ na solução percolada em cinco épocas de amostragem.

\begin{tabular}{|c|c|c|c|c|c|c|}
\hline \multirow[t]{2}{*}{ Tratamento } & \multicolumn{6}{|c|}{ Época de amostragem da solução percolada } \\
\hline & $0,1 \mathrm{VP}$ & $0,5 \mathrm{VP}$ & $1,0 \mathrm{VP}$ & 2,0 VP & $\mathbf{3 , 0}$ VP & Média \\
\hline Testemunha & $70,0 \mathrm{Aa}$ & $37,7 \mathrm{Ba}$ & $36,3 \mathrm{Bb}$ & $18,8 \mathrm{Ca}$ & $14.5 \mathrm{Ca}$ & $35,5 \mathrm{a}$ \\
\hline $\mathrm{CaCO}_{3}(1)$ & $51,2 \mathrm{Ab}$ & $24,2 \mathrm{Bc}$ & $28,3 \mathrm{Bb}$ & $5,4 \mathrm{Cb}$ & $5,2 \mathrm{Cb}$ & $22,9 \mathrm{c}$ \\
\hline $\mathrm{CaCO}_{3}(2)$ & $51,2 \mathrm{Bb}$ & $39,0 \mathrm{Ca}$ & $70,0 \mathrm{Aa}$ & $5,4 \mathrm{Db}$ & $7,5 \mathrm{Db}$ & $34,6 \mathrm{a}$ \\
\hline $\mathrm{CaF}_{2}(\mathbf{1})$ & $35,5 \mathrm{Ac}$ & $30,9 \mathrm{Ab}$ & $36,4 \mathrm{Ab}$ & $9,4 \mathrm{Bb}$ & $8,9 \mathrm{Bb}$ & $24,2 \mathrm{c}$ \\
\hline $\mathrm{CaF}_{2}(\mathbf{2})$ & $50,1 \mathrm{Ab}$ & $25,6 \mathrm{Cc}$ & $35,0 \mathrm{Bb}$ & $20,2 \mathrm{Ca}$ & $19,2 \mathrm{Ca}$ & $30,0 \mathrm{~b}$ \\
\hline Média & $51,6 \mathrm{~A}$ & $31,5 \mathrm{~B}$ & $41,2 \mathrm{C}$ & $11,8 \mathrm{D}$ & $11,1 \mathrm{D}$ & 22,4 \\
\hline \multicolumn{2}{|c|}{$F($ trat $)=63,28 * *$} & \multicolumn{2}{|c|}{$\mathrm{F}($ época $)=414,52 * *$} & \multicolumn{3}{|c|}{$F($ trat $x$ época $)=32,40 * *$} \\
\hline
\end{tabular}

$1,0 \mathrm{VP}=1600 \mathrm{ml} . \mathrm{CaCO}_{3}(1)$ e (2) $=1400$ e $2800 \mathrm{mg} \mathrm{dm}^{-3}$, respectivamente. $\mathrm{CaF}_{2}(1)$ e (2) $=1092 \mathrm{e}$ $2185 \mathrm{mg} \mathrm{dm}^{-3}$, respectivamente. Números seguidos pela mesma letra, maiúscula dentro da linha $\mathrm{e}$ minúscula dentro da coluna, não diferem entre si ao nível de $5 \%$ de probabilidade pelo teste de Tukey. $* *, *$ significativo pelo teste $\mathrm{F}$ ao nivel de $1 \%$ e $5 \%$ de probabilidade, respectivamente.

\subsubsection{Fósforo e flúor em solução}

A concentração média de $\mathrm{P}$ na solução percolada foi significativamente aumentada com a aplicação de $\mathrm{CaF}_{2}$ (2), enquanto que os outros tratamentos não diferiram entre si (Tabela 30). Esse resultado deveu-se ao marcante aumento da concentração de P na solução percolada 2,0 VP, pois nas outras soluções percoladas não houve diferença entre os tratamentos.

Quanto ao F, evidentemente suas perdas manifestaram-se nos tratamentos com $\mathrm{CaF}_{2}$ e nestes, a dose (2) teve perdas maiores que a (1), como mostra a Tabela 31. No tratamento com $\mathrm{CaF}_{2}$ (2), a perda do $\mathrm{F}$ aplicado no solo foi de aproximadamente $1,7 \%$ enquanto que, no tratamento com $\mathrm{CaF}_{2}$ (1) a perda total alcançou $1,3 \%$. É provável que houvesse $\mathrm{F}$ ( $\mathrm{F}$ total) nos outros tratamentos (testemunha e $\mathrm{CaCO}_{3}$ ) e conseqüentemente quantidades muito pequenas nas soluções percoladas, já que o $\mathrm{F}$ é um elemento de ocorrência praticamente generalizada. No entanto, em solos intemperizados, o F solúvel e o chamado $\mathrm{F}$ lábil estão, muitas vezes, incomensuráveis ou seja, abaixo do limite mínimo de detecção do eletrodo $\left(10^{-6} \mathrm{M}\right)$. 
Tabela 30. Efeito de doses de carbonato de cálcio e fluoreto de cálcio na concentração média de fósforo $\left(\mu \mathrm{g} \mathrm{L}^{-1}\right)$ na solução percolada, em quatro épocas de amostragem.

\begin{tabular}{|c|c|c|c|c|c|}
\hline \multirow[t]{2}{*}{ Tratamento } & \multicolumn{5}{|c|}{ Época de amostragem da solução percolada } \\
\hline & 0,1 VP & $0,5 \mathrm{VP}$ & $1,0 \mathrm{VP}$ & $2,0 \mathrm{VP}$ & Média \\
\hline Testemunha & $3,50 \mathrm{Aa}$ & $0,75 \mathrm{Aa}$ & $1,50 \mathrm{Aa}$ & traços $\mathrm{A}$ & $1,44 b$ \\
\hline $\mathrm{CaCO}_{3}(1)$ & $1,25 \mathrm{Aa}$ & $2,00 \mathrm{Aa}$ & $3,00 \mathrm{Aa}$ & $0,50 \mathrm{~A}$ & $1,69 b$ \\
\hline $\mathrm{CaCO}_{3}(2)$ & $3,75 \mathrm{Aa}$ & $1,75 \mathrm{Aa}$ & $3,75 \mathrm{Aa}$ & traços A & $2,32 b$ \\
\hline $\mathrm{CaF}_{2}(\mathbf{1})$ & $0,50 \mathrm{Aa}$ & $3,25 \mathrm{Aa}$ & $6,00 \mathrm{Aa}$ & traços A & $2,44 b$ \\
\hline $\mathrm{CaF}_{2}(2)$ & $3,25 \mathrm{Ba}$ & $1,50 \mathrm{Ba}$ & $3,25 \mathrm{Ba}$ & $30,00 \mathrm{~A}$ & $9,50 \mathrm{a}$ \\
\hline Média & $2,45 B$ & $1,86 \mathrm{~B}$ & $3,51 \mathrm{AB}$ & $6,11 \mathrm{~A}$ & 3,50 \\
\hline \multicolumn{2}{|c|}{$\mathrm{F}($ trat $)=21,42 * *$} & \multicolumn{2}{|c|}{$\mathrm{F}$ (época) $=6,85 * *$} & época & $6 * *$ \\
\hline
\end{tabular}

$1,0 \mathrm{VP}=1600 \mathrm{ml} . \mathrm{CaCO}_{3}(1)$ e $(2)=1400$ e $2800 \mathrm{mg} \mathrm{dm}^{-3}$, respectivamente. $\mathrm{CaF}_{2}(1)$ e (2) $=1092 \mathrm{e}$ $2185 \mathrm{mg} \mathrm{dm}^{-3}$, respectivamente. traços = valor abaixo do limite mínimo de detecção. Números seguidos pela mesma letra, maiúscula dentro da linha e minúscula dentro da coluna, não diferem entre si ao nível de $5 \%$ de probabilidade pelo teste de Tukey. ${ }^{*}, *$ significativo pelo teste $\mathrm{F}$ ao nivel de $1 \%$ e $5 \%$ de probabilidade, respectivamente.

Tabela 31. Efeito de doses de carbonato de cálcio e fluoreto de cálcio na concentração média de flúor $\left(\mathrm{mg} \mathrm{L}^{-1}\right)$ na solução percolada, em cinco épocas de amostragem.

\begin{tabular}{|c|c|c|c|c|c|c|}
\hline \multirow[t]{2}{*}{ Tratamento } & \multicolumn{6}{|c|}{ Época de amostragem da solução percolada } \\
\hline & $0,1 \mathrm{VP}$ & $0,5 \mathrm{VP}$ & $1,0 \mathrm{VP}$ & $2,0 \mathrm{VP}$ & $3,0 \mathrm{VP}$ & Média \\
\hline Testemunha & traços & traços & traços & traços & traços & traços c \\
\hline $\mathrm{CaCO}_{3}(1)$ & traços & traços & traços & traços & traços & traços c \\
\hline $\mathrm{CaCO}_{3}(2)$ & traços & traços & traços & traços & traços & traços c \\
\hline $\mathrm{CaF}_{2}(1)$ & $2,4 \mathrm{C}$ & $11,3 \mathrm{~B}$ & $14,0 \mathrm{AB}$ & $11,3 \mathrm{~B}$ & $20,4 \mathrm{~A}$ & $11,9 b$ \\
\hline $\mathrm{CaF}_{2}(2)$ & $24,3 \mathrm{AB}$ & $22,4 \mathrm{~B}$ & $30,6 \mathrm{AB}$ & $40,4 \mathrm{~A}$ & $35,7 \mathrm{AB}$ & $30,7 a$ \\
\hline Média & $5,3 \mathrm{C}$ & $6,7 \mathrm{BC}$ & $8,9 \mathrm{AB}$ & $10,3 \mathrm{~A}$ & $11,2 \mathrm{~A}$ & 8,5 \\
\hline \multicolumn{2}{|c|}{$\mathrm{F}$ (trat) $=82,54 * *$} & \multicolumn{2}{|c|}{$\mathrm{F}($ época $)=8,76 * *$} & \multicolumn{3}{|c|}{$F($ trat $x$ época $)=5,04 * *$} \\
\hline
\end{tabular}

$1,0 \mathrm{VP}=1600 \mathrm{ml} . \mathrm{CaCO}_{3}(1)$ e $(2)=1400$ e $2800 \mathrm{mg} \mathrm{dm}^{-3}$, respectivamente. $\mathrm{CaF}_{2}(1)$ e (2) $=1092 \mathrm{e}$ $2185 \mathrm{mg} \mathrm{dm}^{-3}$, respectivamente. traços = valor abaixo do limite mínimo de detecção. Números seguidos pela mesma letra, maiúscula dentro da linha e minúscula dentro da coluna, não diferem entre si ao nível de $5 \%$ de probabilidade pelo teste de Tukey. **, * significativo pelo teste $\mathrm{F}$ ao nivel de $1 \%$ e $5 \%$ de probabilidade, respectivamente. 
Segundo Adriano (1986), em condições naturais, as concentrações de F nas soluções dos solos são geralmente abaixo de $1 \mathrm{mg} \mathrm{L}^{-1}$, enquanto em áreas com solos poluídos com $\mathrm{F}$, podem alcançar valores próximos a $10 \mathrm{mg} \mathrm{L}^{-1}$. Assim sendo, os valores de $\mathrm{F}$ nos tratamento com $\mathrm{CaF}_{2}$ em todas as soluções percoladas foram similares ou superiores àqueles encontrados na solução do solo de áreas poluídas com $\mathrm{F}$ (Tabela 31).

Comprovando a troca de ligantes entre $\mathrm{P}$ e $\mathrm{F}$, observou-se que no tratamento com $\mathrm{CaF}_{2}$ (1) a maior quantidade de $\mathrm{P}$ na solução percolada 1,0 VP (Tabela 30), coincidiu com uma forte elevação dos pares iônicos Al-F (Tabela 35, p.92). Esta constatação ficou ainda mais evidenciada quando se analisou a solução percolada 2,0 VP do tratamento com $\mathrm{CaF}_{2}$ (2), uma vez que nela ocorreram as perdas máximas de $\mathrm{F}, \mathrm{Al}$ e $\mathrm{P}$, comprovando então o forte inter-relacionamento destes três componentes (Tabela 36, p.93).

\subsubsection{Ferro em solução}

A concentração de Fe foi determinada na solução percolada $3,0 \mathrm{VP}$, objetivando-se inferir a possível influência do $F$, principalmente, na destruição de minerais recém-precipitados (amorfos), já que foi observado aumento da intensidade de coloração avermelhada nas soluções percoladas dos tratamentos com $\mathrm{CaF}_{2}$, à medida que o processo de incubação se intensificava. Como pode ser observado na Tabela 32, esse fato se confirmou, ou seja, à semelhança do $\mathrm{Al}$, as perdas de $\mathrm{Fe}$ nos tratamentos com $\mathrm{CaF}_{2}$ foram superiores às ocorridas nos outros tratamentos, entretanto não houve diferença significativa entre os tratamentos pelo teste de Tukey ao nível de $5 \%$ de probabilidade. Por outro lado, o tratamento com $\mathrm{CaCO}_{3}$ (1) apresentou uma perda relativamente maior de $\mathrm{Fe}$ em relação à testemunha e ao tratamento com $\mathrm{CaCO}_{3}$ (2). No tratamento com $\mathrm{CaCO}_{3}(2)$, devido ao elevado $\mathrm{pH}$, o Fe na solução percolada 3,0 VP apresentou forte tendência para reprecipitar-se com hidroxila (Tabela 37, p.94).

$\mathrm{Na}$ testemunha, as soluções percoladas apresentaram-se sempre incolores (cristalinas). Isto pode estar relacionado com o baixo $\mathrm{pH}$, maior proximidade do ponto de carga zero (PCZ) e presença de $\mathrm{Al}$ (cátion com elevada capacidade de floculação) no complexo sortivo, conduzindo o solo à uma forte agregação e, conseqüentemente, 
ausência de partículas em suspensão, confirmando observações descritas por Sumner (1993).

Tabela 32. Efeito de doses de carbonato de cálcio e fluoreto de cálcio na concentração média de ferro $\left(\mathrm{mg} \mathrm{L}^{-1}\right)$ na solução percolada 3,0 VP.

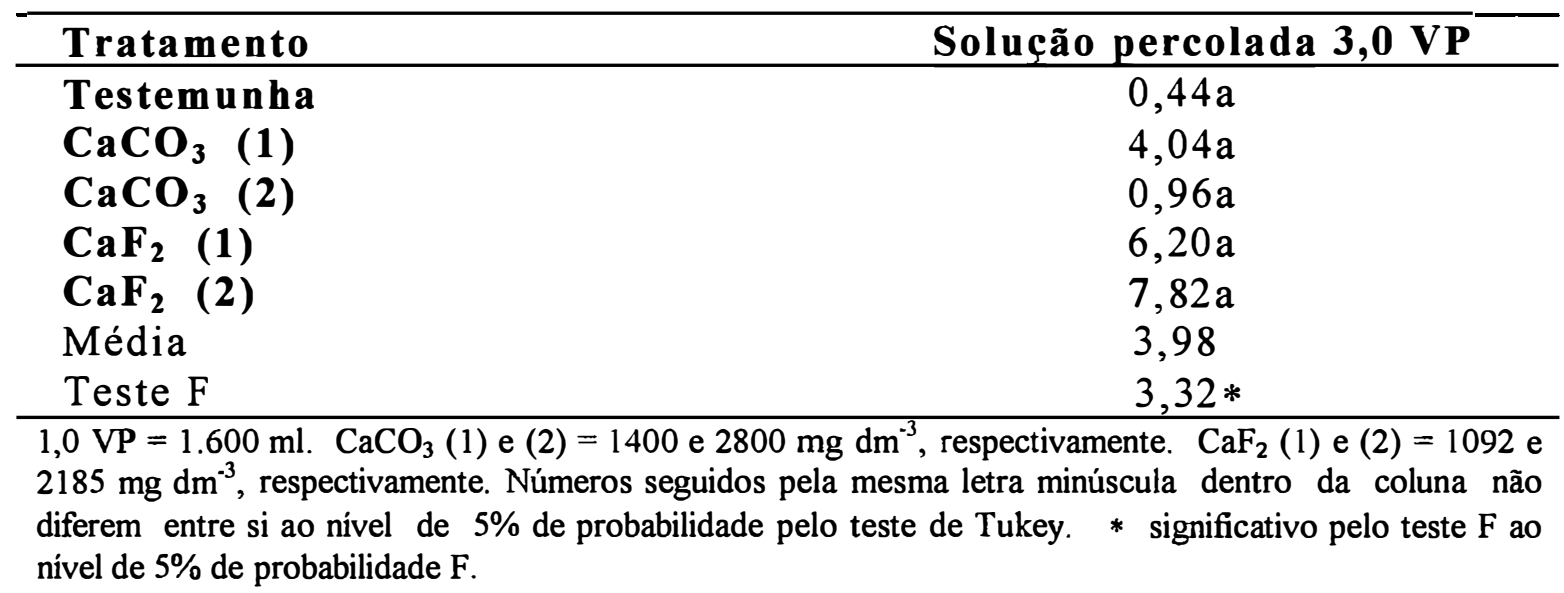

\subsubsection{Especiação iônica e atividades das espécies químicas na solução percolada}

\subsubsection{Especiação iônica na solução percolada}

A distribuição primária dos cátions e ânions em cinco soluções percoladas, amostradas no decorrer do experimento, é apresentada nas Tabelas 33 a 37. A força iônica (I) foi descrita em milimol por litro, sendo calculada pelo programa Geochem-PC (Parker et al., 1995). Não se dispondo de todos os íons presentes na solução, mas apenas dos principais, o programa tendeu a precipitar erroneamente aquelas espécies em maior concentração. Portanto, pode-se esperar que uma parte dos chamados recémprecipitados, principalmente $\mathrm{Fe}$ e $\mathrm{Al}$, estejam na verdade complexados com ligantes que não foram determinados.

Como podemos constatar pelas Tabelas 33 a 37, tanto no tratamento com $\mathrm{CaF}_{2}$ (1) quanto no tratamento com $\mathrm{CaF}_{2}$ (2), mais de $99,8 \%$ do $\mathrm{Al}$ ficou complexado com $\mathrm{F}$, confirmando a alta afinidade entre estes dois elementos. As concentrações dos íons presentes na solução são baixas, principalmente as do P. Portanto, quando apresentados em percentuais, estas muitas vezes perdem sentido. Por exemplo, na Tabela 33, a 
quantidade de $\mathrm{Ca}$ que complexa os $0,12 \%$ de $\mathrm{P}$, representa uma valor infinitesimal de todo o $\mathrm{Ca}$, muito abaixo da segunda casa decimal, estando o $\mathrm{Ca}$ portanto, praticamente $100 \%$ na forma "livre".

A apresentação de $\mathrm{PO}_{4}$ ligado a $\mathrm{H}^{+}$não significou necessariamente formação de $\mathrm{H}_{3} \mathrm{PO}_{4}$, pois para que isto ocorresse, seria necessário uma condição de elevada acidez ( $\mathrm{pH}<2,1)$ (Lindsay, 1979). Um cenário provável seria a formação de ligação

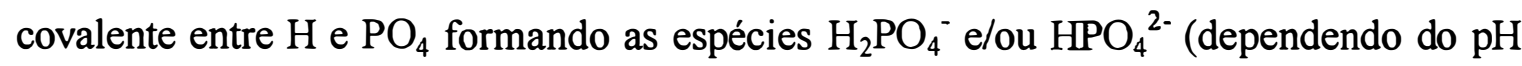
na solução), com posterior ligação iônica com $\mathrm{Al}, \mathrm{Ca}, \mathrm{Fe}, \mathrm{Mg}$ entre outros, como exemplo, a formação do par iônico $\mathrm{AlHPO}_{4}{ }^{+}$, pois estes são os principais cátions presentes na solução de um solo ácido, e que no caso deste experimento, ainda foi adicionado cálcio.

\subsubsection{Atividades das espécies químicas na solução percolada}

Algumas interações e as atividades de algumas espécies químicas $\left(\mathrm{em} \mathrm{mol} \mathrm{L} \mathrm{L}^{-1}\right)$ que ocorreram nas soluções percoladas 3,0 VP de cada tratamento (Tabela 37, p.94) foram descritas a seguir, visando a comparação das diferentes afinidades entre os ligantes e $\mathrm{Al} \mathrm{e} \mathrm{Fe.}$

\subsection{Tratamento com fluoreto de cálcio}

No tratamento com $\mathrm{CaF}_{2}$ (dose 1), as atividades de Fe em solução foram:

$\begin{array}{lccccc}{\left[\mathrm{Fe}(\mathrm{OH})_{2}\right]^{+}>} & {[\mathrm{Fe}(\mathrm{OH})]^{2+}>\left[\mathrm{Fe}(\mathrm{OH})_{3}\right]^{0}>} & (\mathrm{FeF})^{2+}> & \left(\mathrm{FeF}_{2}\right)^{+}> & {\left[\mathrm{Fe}_{2}(\mathrm{OH})_{2}\right]^{4+}>} \\ 9,96 \mathrm{e}-5 & 4,40 \mathrm{e}-6 & 2,81 \mathrm{e}-7 & 1,28 \mathrm{e}-7 & 6,56 \mathrm{e}-8 & 6,16 \mathrm{e}-10 \\ & & & \\ & & \\ \left.(\mathrm{FeNO})_{3}\right)^{2+}> & \left(\mathrm{FeF}_{3}\right)^{\circ}> & {\left[\mathrm{Fe}(\mathrm{OH})_{4}\right]^{-}} \\ 2,96 \mathrm{e}-10 & 1,67 \mathrm{e}-10 & 6,22 \mathrm{e}-11\end{array}$

O Fe pareou-se, preferencialmente, com $\mathrm{OH}^{-}(99,9 \%$ ) e muito pouco com $\mathrm{F}$, apresentando forte tendência para precipitar (Tabela 37). Provavelmente, antes da aplicação do tratamento (baixa atividade de $\mathrm{OH}^{-}$e praticamente ausência de $\mathrm{F}$ ), a maior parte deste Fe estava precipitado com baixo grau de cristalização (amorfo). As espécies ligadas a $\mathrm{NO}_{3}^{-}$(ligante fraco), assim como às com carga negativa, apresentaram atividade muito baixa. 
Tabela 33. Distribuição primána (\%) dos metais e ligantes na solução percolada 0,1VP.

\begin{tabular}{|c|c|c|}
\hline \multirow[t]{2}{*}{ Tratamento } & \multicolumn{2}{|c|}{ Porcentagem de especiação } \\
\hline & Cátions & Ânions \\
\hline $\begin{array}{l}\text { Testemunha } \\
\mathrm{pH}=4,38 \\
\mathrm{I}=3,164\end{array}$ & $\begin{array}{ll}\text { Ca } & 100 \text { como metal livre } \\
\mathrm{Mg} & 100 \text { como metal livre } \\
\mathrm{K} & 100 \text { como metal livre } \\
\mathrm{Na} & 100 \text { como metal livre } \\
\text { Al } & 82,97 \text { como metal livre } \\
& 0,17 \text { complexado com } \mathrm{PO}_{4} \\
& 16,86 \text { complexado com } \mathrm{OH}^{-}\end{array}$ & $\begin{array}{cc}\mathrm{PO}_{4} & 0,12 \text { complexado com } \mathrm{Ca} \\
& 28,24 \text { complexado com } \mathrm{Al} \\
& 71,63 \text { complexado com } \mathrm{H}^{+} \\
\mathrm{NO}_{3} & 100 \text { como ligante livre }\end{array}$ \\
\hline $\begin{array}{l}\mathrm{CaCO}_{3}(\mathbf{1}) \\
\mathrm{pH}=4,66 \\
\mathrm{l}=2,418\end{array}$ & $\begin{array}{l}\text { Ca } 100 \text { como metal livre } \\
\text { Mg } 100 \text { como metal livre } \\
\mathrm{K} \quad 100 \text { como metal livre } \\
\mathrm{Na} 100 \text { como metal livre } \\
\text { Al } 68,39 \text { como metal livre } \\
\quad 0,10 \text { complexado com } \mathrm{PO}_{4} \\
\quad 31,51 \text { complexado com } \mathrm{OH}^{-}\end{array}$ & $\begin{array}{cl}\mathrm{PO}_{4} & 0,17 \text { complexado com } \mathrm{Ca} \\
& 0,01 \text { complexado com } \mathrm{Mg} \\
& 28,29 \text { comlexado com } \mathrm{Al} \\
& 71,52 \text { complexado com } \mathrm{H}^{+} \\
\mathrm{NO}_{3} & 100 \text { como ligante livre }\end{array}$ \\
\hline $\begin{array}{l}\mathrm{CaCO}_{3} \text { (2) } \\
\mathrm{pH}=4,75 \\
\mathrm{I}=2,652\end{array}$ & $\begin{array}{l}\text { Ca } 100 \text { como metal livre } \\
\text { Mg } 100 \text { como metal livre } \\
\mathrm{K} 100 \text { como metal livre } \\
\mathrm{Na} 100 \text { como metal livre } \\
\mathrm{Al} 63,02 \text { como metal livre } \\
\quad 0,27 \text { complexado com } \mathrm{PO}_{4} \\
36,71 \text { complexado com } \mathrm{OH}^{-}\end{array}$ & $\begin{array}{ll}\mathrm{PO}_{4} & 0,30 \text { complexado com } \mathrm{Ca} \\
& 0,01 \text { complexado com } \mathrm{Mg} \\
& 41,83 \text { complexado com } \mathrm{Al} \\
& 57,86 \text { complexado com } \mathrm{H}^{+} \\
\mathrm{NO}_{3} & 100 \text { como ligante livre }\end{array}$ \\
\hline $\begin{array}{l}\mathrm{CaF}_{\mathbf{2}}(\mathbf{1}) \\
\mathrm{pH}=4,75 \\
\mathrm{I}=1,695\end{array}$ & $\begin{array}{c}\text { Ca } 99,99 \text { como metal livre } \\
0,01 \text { complexado com } \mathrm{F} \\
\mathrm{Mg} 99,93 \text { como metal livre } \\
0,07 \text { complexado com } \mathrm{F} \\
\mathrm{K} \quad 100 \text { como metal livre } \\
\mathrm{Na} 100 \text { como metal livre } \\
\mathrm{Al} 0,12 \text { como metal livre } \\
99,81 \text { complexado com } \mathrm{F} \\
0,07 \text { complexado com } \mathrm{OH}^{-}\end{array}$ & $\begin{array}{c}\mathrm{F} \quad 8,74 \text { como ligante livre } \\
0,03 \text { complexado com } \mathrm{Mg} \\
91,08 \text { complexado com } \mathrm{Al} \\
0,15 \text { complexado com } \mathrm{H}^{+} \\
\mathrm{PO}_{4} \quad 0,16 \text { complexado com } \mathrm{Ca} \\
0,02 \text { complexado com } \mathrm{Mg} \\
0,58 \text { complexado com } \mathrm{Al} \\
99,25 \text { complexado com } \mathrm{H}^{+} \\
\mathrm{NO}_{3} 100 \text { como ligante livre }\end{array}$ \\
\hline $\begin{array}{l}\mathrm{CaF}_{2}(\mathbf{2}) \\
\mathrm{pH}=4,67 \\
\mathrm{I}=2,355\end{array}$ & $\begin{array}{c}\text { Ca } 99,70 \text { como metal livre } \\
0,30 \text { complexado com } \mathrm{F} \\
\mathrm{Mg} 98,12 \text { como metal livre } \\
1,88 \text { complexado com } \mathrm{F} \\
\mathrm{K} 100 \text { como metal livre } \\
\mathrm{Na} 100 \text { como metal livre } \\
\text { Al } 100 \text { complexado com } \mathrm{F}\end{array}$ & $\begin{array}{c}\mathrm{F} \quad 28,95 \text { como ligante livre } \\
0,02 \text { complexado com } \mathrm{Ca} \\
0,07 \text { complexado com } \mathrm{Mg} \\
70,38 \text { complexado com } \mathrm{Al} \\
0,58 \text { complexado com } \mathrm{H}^{+} \\
\mathrm{PO}_{4} 0,17 \text { complexado com Ca } \\
99,82 \text { complexado com } \mathrm{H}^{+} \\
\mathrm{NO}_{3} 100 \text { como ligante livre }\end{array}$ \\
\hline
\end{tabular}


Tabela 34. Distribuição prinánia (\%) dos metais e ligantes na solução percolada 0,5VP.

\begin{tabular}{|c|c|c|}
\hline \multirow[t]{2}{*}{ Tratamento } & \multicolumn{2}{|c|}{ Porcentagem de especiacão } \\
\hline & Cátions & Anions \\
\hline $\begin{array}{l}\text { Testemunha } \\
\mathrm{pH}=4,34 \\
\mathrm{I}=1,913\end{array}$ & $\begin{array}{ll}\text { Ca } & 100 \text { como metal livre } \\
\mathrm{Mg} & 100 \text { como metal livre } \\
\mathrm{K} & 100 \text { como metal livre } \\
\mathrm{Na} & 100 \text { como metal livre } \\
\mathrm{Al} & 83,38 \text { como metal livre } \\
& 0,03 \text { complexado com } \mathrm{PO}_{4} \\
& 16,59 \text { complexado com } \mathrm{OH}^{-}\end{array}$ & $\begin{array}{cc}\mathrm{PO}_{4} & 0,11 \text { complexado com } \mathrm{Ca} \\
& 35,65 \text { complexado com } \mathrm{Al} \\
& 64,23 \text { complexado com } \mathrm{H}^{+} \\
\mathrm{NO}_{3} & 100 \text { como ligante livre }\end{array}$ \\
\hline $\begin{array}{l}\mathrm{CaCO}_{3}(\mathbf{1}) \\
\mathrm{pH}=5,06 \\
\mathrm{I}=1,265\end{array}$ & $\begin{array}{l}\text { Ca } 100 \text { como metal livre } \\
\mathrm{Mg} 100 \text { como metal livre } \\
\mathrm{K} \quad 100 \text { como metal livre } \\
\mathrm{Na} 100 \text { como metal livre } \\
\text { Al } 36,63 \text { como metal livre } \\
\\
\quad 0,14 \text { complexado com } \mathrm{PO}_{4} \\
\quad 63,23 \text { complexado com } \mathrm{OH}^{-}\end{array}$ & $\begin{array}{c}\mathrm{PO}_{4} \quad 0,10 \text { complexado com } \mathrm{Ca} \\
57,13 \text { comlexado com } \mathrm{Al} \\
42,76 \text { complexado com } \mathrm{H}^{+} \\
\mathrm{NO}_{3} 100 \text { como ligante livre }\end{array}$ \\
\hline $\begin{array}{l}\mathrm{CaCO}_{3}(2) \\
\mathrm{pH}=6,54 \\
\mathrm{I}=2,015\end{array}$ & $\begin{array}{l}\text { Ca } 100 \text { como metal livre } \\
\text { Mg } 100 \text { como metal livre } \\
\mathrm{K} \quad 100 \text { como metal livre } \\
\mathrm{Na} 100 \text { como metal livre } \\
\text { Al } 0,03 \text { como metal livre } \\
\quad 99,96 \text { complexado com } \mathrm{OH}^{-}\end{array}$ & $\begin{array}{cl}\mathrm{PO}_{4} & 2,12 \text { complexado com } \mathrm{Ca} \\
& 0,63 \text { complexado com } \mathrm{Mg} \\
& 1,86 \text { complexado com } \mathrm{Al} \\
& 95,39 \text { complexado com } \mathrm{H}^{+} \\
\mathrm{NO}_{3} & 100 \text { como ligante livre }\end{array}$ \\
\hline $\begin{array}{l}\mathbf{C a F}_{\mathbf{2}}(\mathbf{1}) \\
\mathrm{pH}=5,60 \\
\mathrm{I}=1,694\end{array}$ & $\begin{array}{c}\text { Ca 99,99 como metal livre } \\
0,01 \text { complexado com } \mathrm{F} \\
\text { Mg 99,91 como metal livre } \\
0,09 \text { complexado com } \mathrm{F} \\
\mathrm{K} \quad 100 \text { como metal livre } \\
\mathrm{Na} 100 \text { como metal livre } \\
\text { Al } 0,08 \text { como metal livre } \\
98,93 \text { complexado com } \mathrm{F} \\
0,99 \text { complexado com } \mathrm{OH}^{-}\end{array}$ & 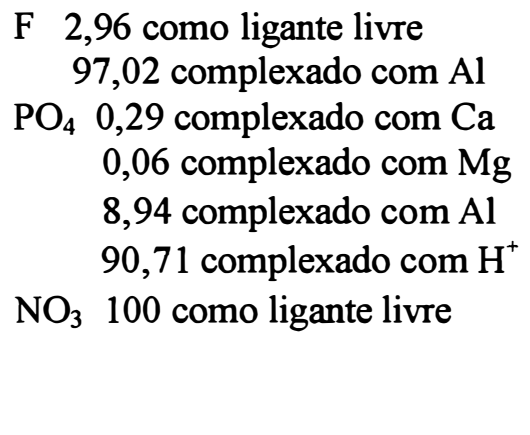 \\
\hline $\begin{array}{l}\mathrm{CaF}_{2}(\mathbf{2}) \\
\mathrm{pH}=6,01 \\
\mathrm{I}=1,529\end{array}$ & $\begin{array}{c}\text { Ca } 99,84 \text { como metal livre } \\
0,16 \text { complexado com } \mathrm{F} \\
\mathrm{Mg} 98,98 \text { como metal livre } \\
1,02 \text { complexado com } \mathrm{F} \\
\mathrm{K} 100 \text { como metal livre } \\
\mathrm{Na} 100 \text { como metal livre } \\
\text { Al } 99,98 \text { complexado com } \mathrm{F} \\
0,02 \text { complexado com } \mathrm{OH}^{-}\end{array}$ & $\begin{array}{c}\mathrm{F} \quad 16,76 \text { como ligante livre } \\
0,02 \text { complexado com } \mathrm{Ca} \\
0,04 \text { complexado com } \mathrm{Mg} \\
83,18 \text { complexado com } \mathrm{Al} \\
0,02 \text { complexado com } \mathrm{H}^{+} \\
\mathrm{PO}_{4} 0,59 \text { complexado com } \mathrm{Ca} \\
0,17 \text { complexado com } \mathrm{Mg} \\
0,09 \text { complexado com } \mathrm{Al} \\
99,14 \text { complexado com } \mathrm{H}^{+} \\
\mathrm{NO}_{3} 100 \text { como ligante livre } \\
\end{array}$ \\
\hline
\end{tabular}


Tabela 35. Distribuição primánia (\%) dos metais e ligantes na solução percolada 1,0VP.

\begin{tabular}{|c|c|c|}
\hline \multirow[t]{2}{*}{ Tratamento } & \multicolumn{2}{|c|}{ Porcentagem de especiação } \\
\hline & Cátions & Anions \\
\hline $\begin{array}{l}\text { Testemunha } \\
\mathrm{pH}=4,27 \\
\mathrm{I}=4,056\end{array}$ & $\begin{array}{ll}\text { Ca } & 100 \text { como metal livre } \\
\mathrm{Mg} & 100 \text { como metal livre } \\
\mathrm{K} & 100 \text { como metal livre } \\
\mathrm{Na} & 100 \text { como metal livre } \\
\mathrm{Al} & 87,12 \text { como metal livre } \\
& 0,03 \text { complexado com } \mathrm{PO}_{4} \\
& 12,85 \text { complexado com } \mathrm{OH}^{-}\end{array}$ & $\begin{array}{cc}\mathrm{PO}_{4} & 0,52 \text { complexado com } \mathrm{Ca} \\
& 0,02 \text { complexado com } \mathrm{Mg} \\
58,68 \text { complexado com } \mathrm{Al} \\
\\
40,78 \text { complexado com } \mathrm{H}^{+} \\
\mathrm{NO}_{3} 100 \text { como ligante livre }\end{array}$ \\
\hline $\begin{array}{l}\mathrm{CaCO}_{3}(\mathbf{1}) \\
\mathrm{pH}=5,03 \\
\mathrm{I}=3,472\end{array}$ & $\begin{array}{l}\text { Ca } 100 \text { como metal livre } \\
\text { Mg } 100 \text { como metal livre } \\
\text { K } 100 \text { como metal livre } \\
\text { Na } 100 \text { como metal livre } \\
\text { Al } 43,20 \text { como metal livre } \\
\\
\quad 0,08 \text { complexado com } \mathrm{PO}_{4} \\
\quad 56,71 \text { complexado com } \mathrm{OH}^{-}\end{array}$ & $\begin{array}{cc}\mathrm{PO}_{4} & 0,39 \text { complexado com } \mathrm{Ca} \\
0,03 \text { complexado com } \mathrm{Mg} \\
80,90 \text { comlexado com } \mathrm{Al} \\
18,69 \text { complexado com } \mathrm{H}^{+} \\
\mathrm{NO}_{3} 100 \text { como ligante livre }\end{array}$ \\
\hline $\begin{array}{l}\mathrm{CaCO}_{3}(2) \\
\mathrm{pH}=6,17 \\
\mathrm{I}=7,726\end{array}$ & $\begin{array}{l}\text { Ca } 100 \text { como metal livre } \\
\text { Mg } 100 \text { como metal livre } \\
\mathrm{K} \quad 100 \text { como metal livre } \\
\mathrm{Na} 100 \text { como metal livre } \\
\text { Al } 0,62 \text { como metal livre } \\
\quad 0,04 \text { complexado com } \mathrm{PO}_{4} \\
99,34 \text { complexado com } \mathrm{OH}^{-}\end{array}$ & $\begin{array}{cl}\mathrm{PO}_{4} & 4,90 \text { complexado com } \mathrm{Ca} \\
& 1,11 \text { complexado com } \mathrm{Mg} \\
& 43,32 \text { complexado com } \mathrm{Al} \\
& 50,68 \text { complexado com } \mathrm{H}^{+} \\
\mathrm{NO}_{3} & 100 \text { como ligante livre }\end{array}$ \\
\hline $\begin{array}{l}\mathrm{CaF}_{\mathbf{2}}(\mathbf{1}) \\
\mathrm{pH}=4,73 \\
\mathrm{I}=5,628\end{array}$ & $\begin{array}{c}\text { Ca 99,99 como metal livre } \\
0,01 \text { complexado com } \mathrm{F} \\
\mathrm{Mg} 99,94 \text { como metal livre } \\
0,06 \text { complexado com } \mathrm{F} \\
\mathrm{K} \quad 100 \text { como metal livre } \\
\mathrm{Na} 100 \text { como metal livre } \\
\mathrm{Al} \quad 0,18 \text { como metal livre } \\
99,74 \text { complexado com } \mathrm{F} \\
0,08 \text { complexado com } \mathrm{OH}^{-}\end{array}$ & $\begin{array}{c}\mathrm{F} \quad 1,85 \text { como ligante livre } \\
0,02 \text { complexado com } \mathrm{Ca} \\
0,04 \text { complexado com } \mathrm{Mg} \\
98,05 \text { complexado com } \mathrm{Al} \\
0,03 \text { complexado com } \mathrm{H}^{+} \\
\mathrm{PO}_{4} 2,93 \text { complexado com } \mathrm{Ca} \\
0,10 \text { complexado com } \mathrm{Mg} \\
2.87 \text { complexado com } \mathrm{Al} \\
94,10 \text { complexado com } \mathrm{H}^{+} \\
\mathrm{NO}_{3} 100 \text { como ligante livre }\end{array}$ \\
\hline $\begin{array}{l}\mathrm{CaF}_{\mathbf{2}} \text { (2) } \\
\mathrm{pH}=5,09 \\
\mathrm{I}=7,082\end{array}$ & $\begin{array}{c}\text { Ca } 99,88 \text { como metal livre } \\
0,02 \text { complexado com } \mathrm{F} \\
\mathrm{Mg} 99,85 \text { como metal livre } \\
0,15 \text { complexado com } \mathrm{F} \\
\mathrm{K} \quad 100 \text { como metal livre } \\
\mathrm{Na} 100 \text { como metal livre } \\
\text { Al } 0,03 \text { como metal livre } \\
99,93 \text { complexado com } \mathrm{F} \\
0,04 \text { complexado com } \mathrm{OH}^{-}\end{array}$ & $\begin{array}{c}\text { F } 2,05 \text { como ligante livre } \\
0,03 \text { complexado com } \mathrm{Ca} \\
0,07 \text { complexado com } \mathrm{Mg} \\
97,84 \text { complexado com } \mathrm{Al} \\
0,02 \text { complexado com } \mathrm{H}^{+} \\
\mathrm{PO}_{4} 4,11 \text { complexado com } \mathrm{Ca} \\
0,31 \text { complexado com } \mathrm{Mg} \\
2,04 \text { complexado com } \mathrm{Al} \\
93,55 \text { complexado com } \mathrm{H}^{+} \\
\mathrm{NO}_{3} 100 \text { como ligante livre }\end{array}$ \\
\hline
\end{tabular}


Tabela 36. Distribuição primánia (\%) dos metais e ligantes na solução percolada 2,0VP.

\begin{tabular}{|c|c|c|}
\hline \multirow[t]{2}{*}{ Tratamento } & \multicolumn{2}{|c|}{ Porcentagem de especiação } \\
\hline & Cátions & Ânions \\
\hline $\begin{array}{l}\text { Testemunha } \\
\mathrm{pH}=4,41 \\
\mathrm{I}=3,106\end{array}$ & $\begin{array}{ll}\mathrm{Ca} & 100 \text { como metal livre } \\
\mathrm{Mg} & 100 \text { como metal livre } \\
\mathrm{K} & 100 \text { como metal livre } \\
\mathrm{Na} & 100 \text { como metal livre } \\
\mathrm{Al} & 81,97 \text { como metal livre } \\
& 18,03 \text { complexado com } \mathrm{OH}^{-}\end{array}$ & $\mathrm{NO}_{3} 100$ como ligante livre \\
\hline $\begin{array}{l}\mathrm{CaCO}_{3}(\mathbf{1}) \\
\mathrm{pH}=6,21 \\
\mathrm{I}=1,306\end{array}$ & 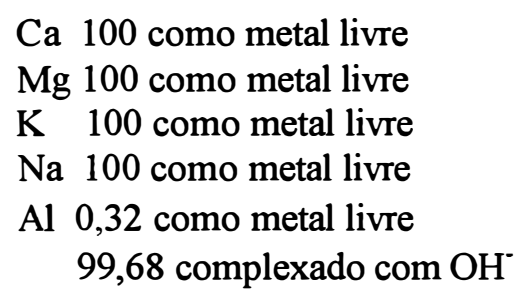 & $\mathrm{NO}_{3} 100$ como ligante livre \\
\hline $\begin{array}{l}\mathrm{CaCO}_{3} \text { (2) } \\
\mathrm{pH}=7,17 \\
\mathrm{I}=1,838\end{array}$ & $\begin{array}{l}\text { Ca } 100 \text { como metal livre } \\
\text { Mg } 100 \text { como metal livre } \\
\mathrm{K} 100 \text { como metal livre } \\
\mathrm{Na} 100 \text { como metal livre } \\
\mathrm{Al} 100 \text { complexado com } \mathrm{OH}^{-}\end{array}$ & $\mathrm{NO}_{3} 100$ como ligante livre \\
\hline $\begin{array}{l}\mathrm{CaF}_{\mathbf{2}}(\mathbf{1}) \\
\mathrm{pH}=5,12 \\
\mathrm{I}=2,293\end{array}$ & $\begin{array}{c}\text { Ca 99,97 como metal livre } \\
0,03 \text { complexado com } \mathrm{F} \\
\text { Mg 99,83 como metal livre } \\
0,17 \text { complexado com } \mathrm{F} \\
\mathrm{K} \quad 100 \text { como metal livre } \\
\mathrm{Na} 100 \text { como metal livre } \\
\text { Al } 0,02 \text { como metal livre } \\
99,94 \text { complexado com } \mathrm{F} \\
0,04 \text { complexado com } \mathrm{OH}^{-}\end{array}$ & $\begin{array}{c}\text { F } 5,60 \text { como ligante livre } \\
0,02 \text { complexado com } \mathrm{Ca} \\
0,11 \text { complexado com } \mathrm{Mg} \\
94,23 \text { complexado com } \mathrm{Al} \\
0,04 \text { complexado com } \mathrm{H}^{+} \\
\mathrm{NO}_{3} 100 \text { como ligante livre }\end{array}$ \\
\hline $\begin{array}{l}\mathrm{CaF}_{\mathbf{2}} \text { (2) } \\
\mathrm{pH}=5,59 \\
\mathrm{I}=2,232\end{array}$ & $\begin{array}{c}\text { Ca } 99,93 \text { como metal livre } \\
0,04 \text { complexado com } \mathrm{F} \\
0,03 \text { complexado com } \mathrm{PO}_{4} \\
\mathrm{Mg} 99,72 \text { como metal livre } \\
0,27 \text { complexado com } \mathrm{F} \\
0,01 \text { complexado com } \mathrm{PO}_{4} \\
\mathrm{~K} 100 \text { como metal livre } \\
\mathrm{Na} 100 \text { como metal livre } \\
\text { Al } 99,88 \text { complexado com } \mathrm{F} \\
0,03 \text { complexado com } \mathrm{PO}_{4} \\
0,09 \text { complexado com } \mathrm{OH}^{-}\end{array}$ & $\begin{array}{c}\mathrm{F} \quad 2,44 \text { como ligante livre } \\
0,02 \text { complexado com } \mathrm{Mg} \\
97,52 \text { complexado com } \mathrm{Al} \\
\mathrm{PO}_{4} 1,43 \text { complexado com } \mathrm{Ca} \\
0,24 \text { complexado com } \mathrm{Mg} \\
2,65 \text { complexado com } \mathrm{Al} \\
95,68 \text { complexado com } \mathrm{H}^{+} \\
\mathrm{NO}_{3} 100 \text { como ligante livre }\end{array}$ \\
\hline
\end{tabular}


Tabela 37. Distribuição pnimánia (\%) dos metais e ligantes na solução percolada 3,0VP.

\begin{tabular}{|c|c|c|}
\hline \multirow{2}{*}{ Tratamento } & \multicolumn{2}{|c|}{ Porcentagem de especiacão } \\
\hline & Cátions & Anions \\
\hline $\begin{array}{l}\text { Testemunha } \\
\mathrm{pH}=4,54 \\
\mathrm{I}=3,167\end{array}$ & $\begin{array}{ll}\text { Ca } & 100 \text { como metal livre } \\
\mathrm{Mg} & 100 \text { como metal livre } \\
\mathrm{K} & 100 \text { como metal livre } \\
\mathrm{Na} & 100 \text { como metal livre } \\
\mathrm{Fe} & 0,06 \text { como metal livre } \\
& 99,94 \text { complexado com } \mathrm{OH}^{-} \\
\text {Al } & 76,23 \text { como metal livre } \\
& 23,77 \text { complexado com } \mathrm{OH}^{-}\end{array}$ & $\mathrm{NO}_{3} 100$ como ligante livre \\
\hline $\begin{array}{l}\mathrm{CaCO}_{3}(1) \\
\mathrm{pH}=6,28 \\
\mathrm{I}=2,238\end{array}$ & 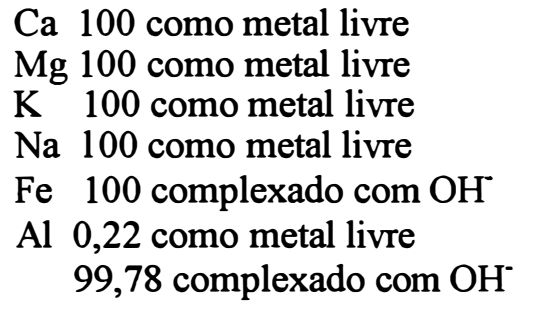 & $\mathrm{NO}_{3} 100$ como ligante livre \\
\hline $\begin{array}{l}\mathrm{CaCO}_{3}(2) \\
\mathrm{pH}=7,82 \\
\mathrm{I}=3,156\end{array}$ & 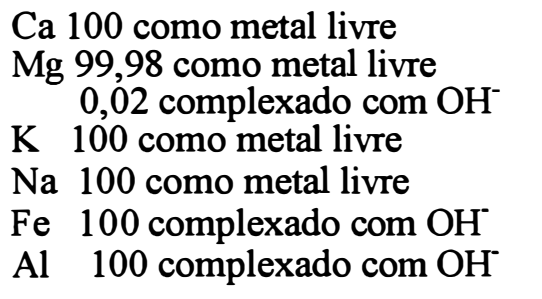 & $\mathrm{NO}_{3} 100$ como ligante livre \\
\hline $\begin{array}{l}\mathrm{CaF}_{\mathbf{2}}(\mathbf{1}) \\
\mathrm{pH}=4,85 \\
\mathrm{I}=3,289\end{array}$ & $\begin{array}{c}\text { Ca 99,99 como metal livre } \\
0,01 \text { complexado com } \mathrm{F} \\
\mathrm{Mg} 99,93 \text { como metal livre } \\
0,07 \text { complexado com } \mathrm{F} \\
\mathrm{K} \quad 100 \text { como metal livre } \\
\mathrm{Na} 100 \text { como metal livre } \\
\mathrm{Fe} \quad 0,02 \text { como metal livre } \\
0,21 \text { complexado com } \mathrm{F} \\
99,97 \text { complexado com } \mathrm{OH}^{-} \\
\text {Al } 0,15 \text { como metal livre } \\
99,72 \text { complexado com } \mathrm{F} \\
0,11 \text { complexado com } \mathrm{OH}^{-}\end{array}$ & $\begin{array}{c}\mathrm{F} \quad 1,28 \text { como ligante livre } \\
0,01 \text { complexado com } \mathrm{Mg} \\
0,03 \text { complexado com } \mathrm{Fe} \\
98,63 \text { complexado com } \mathrm{Al} \\
0,02 \text { complexado com } \mathrm{H}^{+} \\
\mathrm{NO}_{3} 100 \text { como ligante livre }\end{array}$ \\
\hline $\begin{array}{l}\mathrm{CaF}_{2}(2) \\
\mathrm{pH}=5,61 \\
\mathrm{I}=2,932\end{array}$ & $\begin{array}{c}\text { Ca } 99,95 \text { como metal livre } \\
0,05 \text { complexado com } \mathrm{F} \\
0,03 \text { complexado com } \mathrm{PO}_{4} \\
\mathrm{Mg} 99,66 \text { como metal livre } \\
0,34 \text { complexado com } \mathrm{F} \\
\mathrm{K} 100 \text { como metal livre } \\
\mathrm{Na} 100 \text { como metal livre } \\
\mathrm{Fe} \quad 0,07 \text { complexado com } \mathrm{F} \\
99,93 \text { complexado com } \mathrm{OH}^{-} \\
\mathrm{Al} 99,94 \text { complexado com } \mathrm{F} \\
0,05 \text { complexado com } \mathrm{OH}^{-} \\
\end{array}$ & $\begin{array}{c}\text { F 3,69 como ligante livre } \\
\text { 0,01 complexado com } \mathrm{Ca} \\
0,02 \text { complexado com } \mathrm{Mg} \\
\text { 96,25 complexado com } \mathrm{Al} \\
\mathrm{NO}_{3} 100 \text { como ligante livre }\end{array}$ \\
\hline
\end{tabular}


No tratamento com $\mathrm{CaF}_{2}$ (dose 2), foram obtidas as seguintes atividades das espécies químicas do Fe na solução percolada 3,0 VP (Tabela 37):

$$
\begin{aligned}
& {\left[\mathrm{Fe}(\mathrm{OH})_{2}\right]^{+}>\left[\mathrm{Fe}(\mathrm{OH})_{3}\right]^{\circ}>[\mathrm{Fe}(\mathrm{OH})]^{2+}>>\left(\mathrm{FeF}_{2}\right)^{+}>(\mathrm{FeF})^{2+}>\left[\mathrm{Fe}(\mathrm{OH})_{4}\right]^{-}>} \\
& \text {1,30e-4 2,10e-6 } \quad 1,00 \mathrm{e}-6 \quad 6,62 \mathrm{e}-8 \quad 2,53 \mathrm{e}-8 \quad 2,69 \mathrm{e}-9 \\
& \left(\mathrm{FeF}_{3}\right)^{\mathrm{o}}>\left[\mathrm{Fe}_{2}(\mathrm{OH})_{2}\right]^{4+}>\left[\mathrm{FeNO}_{3}\right]^{2+} \\
& \text { 8,41e-10 3,23e-11 } 1,17 \mathrm{e}-11
\end{aligned}
$$

Nesse tratamento, cuja dose foi o dobro daquela do tratamento com $\mathrm{CaF}_{2}(1) \mathrm{e}$ também com $\mathrm{pH}$ mais elevado que este último, verificou-se um grande aumento na atividade do primeiro par iônico (Fe ligado a hidroxila) em relação ao tratamento anterior. A segunda espécie química foi o hidróxido férrico, mostrando tendência à precipitação. $\mathrm{O}$ Fe pareou-se com o F somente na quarta espécie em ordem decrescente de atividade, mesmo assim, com atividade relativamente baixa.

Com relação ao $\mathrm{Al}$, suas atividades químicas no tratamento com $\mathrm{CaF}_{2}$ (1) foram as seguintes:

$$
\begin{aligned}
& \left(\mathrm{AlF}_{2}\right)^{+}>\left(\mathrm{AlF}_{3}\right)^{\mathrm{o}}>(\mathrm{AlF})^{2+}>[\mathrm{Al}(\mathrm{OH})]^{2+}>\left(\mathrm{AlF}_{4}\right)^{-}>\left[\mathrm{Al}(\mathrm{OH})_{2}\right]^{+}> \\
& \text {3,76e-4 6,02e-5 5,83e-5 3,17e-7 3,09e-7 } \quad 1,80 \mathrm{e}-7 \\
& {\left[\mathrm{Al}(\mathrm{OH})_{3}\right]^{0}>\left[\mathrm{Al}(\mathrm{OH})_{4}\right]^{-}>\left(\mathrm{AlF}_{5}\right)^{2-}>>\left(\mathrm{AlNO}_{3}\right)^{2+}>>\left(\mathrm{AlF}_{6}\right)^{3-}} \\
& 2,55 \mathrm{e}-9 \quad 2,25 \mathrm{e}-10 \quad 6,38 \mathrm{e}-11 \quad 1,47 \mathrm{e}-14 \quad 8,24 \mathrm{e}-16
\end{aligned}
$$

Os resultados da especiação do $\mathrm{Al}$ na solução $3,0 \mathrm{VP}$ do tratamento com $\mathrm{CaF}_{2}$ (1) revelaram que a maior parte deste metal (99,9\%) complexou-se com o $\mathrm{F}$ em $\mathrm{pH}<5,6$ (Tabela 37). Resultados obtidos para a especiação do Al nas outras soluções percoladas, cujos valores de $\mathrm{pH}$ variaram entre 4,7 e 5,6 (Tabelas 33 a 36), corroboram esses resultados. Ressalta-se a alta afinidade do $\mathrm{Al}$ pelo $\mathrm{F}$, sendo as atividades dos dois primeiros pares $(3,76 \mathrm{e}-4$ e $6,02 \mathrm{e}-5)$ fortemente superiores àquelas dos dois primeiros pares Fe-F (1,28e-7 e 6,56e-8).

Para o $\mathrm{Al}$ na solução percolada do tratamento com $\mathrm{CaF}_{2}(2)$, tem-se:

$$
\begin{aligned}
& \left(\mathrm{AlF}_{2}\right)^{+}>\left(\mathrm{AlF}_{3}\right)^{\mathrm{o}}>(\mathrm{AlF})^{2+}>\left(\mathrm{AlF}_{4}\right)^{-}>\left[\mathrm{Al}(\mathrm{OH})_{2}\right]^{+}>[\mathrm{Al}(\mathrm{OH})]^{2+}> \\
& \text { 3,85e-4 3,09e-4 1,17e-5 7,95e-6 2,39e-7 7,32e-8 }
\end{aligned}
$$

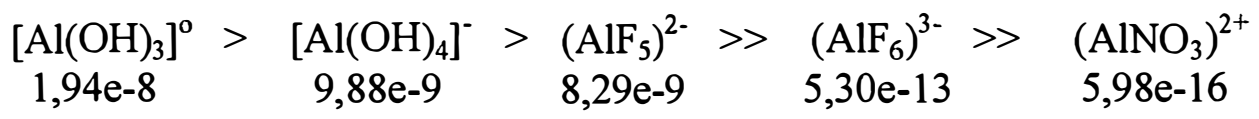


A ordem dos três primeiros pares mostrou a proporção $\mathrm{Al} / \mathrm{F}$ esperada, já que a dose estabelecida no tratamento com $\mathrm{CaF}_{2}(1)$, objetivou a equivalência $\left(\mathrm{AlF}_{3}\right)^{\circ}$. A elevada atividade desse par foi, provavelmente, um dos motivos da grande retirada de $\mathrm{Al}$ do sistema tratado com $\mathrm{F}$, em relação aos outros tratamentos.

$\mathrm{O} F$ que não pareou com o $\mathrm{Al}$ na solução percolada do tratamento com $\mathrm{CaF}_{2}$ (1) ficou assim distribuído:

$$
\underset{1,84 \mathrm{e}-7}{(\mathrm{HF})^{\circ}}>{ }_{1,41 \mathrm{e}-7}^{(\mathrm{MgF})^{+}} \rightarrow \underset{3,98 \mathrm{e}-8}{(\mathrm{CaF})^{+}} \rightarrow \underset{3,69 \mathrm{e}-12}{(\mathrm{KF})^{\mathrm{o}}}>\underset{3,53 \mathrm{e}-12}{(\mathrm{NaF})}
$$

Como a primeira e as duas últimas espécies são consideradas potencialmente tóxicas, essas devem ser evitadas. Isto pode ser feito evitando-se que a quantidade de $\mathrm{F}$ presente no meio supere as quantidades de $\mathrm{Al}$ e $\mathrm{Si}$, que em ambiente ácido, tenderia a formar, em parte, $\mathrm{HF}$.

Apesar do aumento do $\mathrm{pH}$ no tratamento com $\mathrm{CaF}_{2}$ (2), o $\mathrm{F}$ continuou apresentando maior afinidade com $\mathrm{Al}$, com os pares e atividades semelhantes ao tratamento com $\mathrm{CaF}_{2}$ (1). Entretanto, os pares Al-F com carga negativa (excesso de $\mathrm{F}$ ) apresentaram atividade bem maior que no tratamento anterior. Nesse tratamento, mesmo com $\mathrm{pH}$ mais alto, a espécie química entre $\mathrm{Al}$ e $\mathrm{OH}$ com maior atividade continuou sendo da ordem de $10^{-7}$, semelhante ao tratamento com $\mathrm{CaF}_{2}$ (1). Portanto, mesmo a maior concentração de hidroxilas (ligante forte com elevada afinidade pelo $\mathrm{Al}$ ) não foi capaz de romper as ligações Al-F, mostrando mais uma vez que a afinidade entre Al-F foi de tal magnitude, que houve forte resistência ao rompimento, mesmo com a elevação do $\mathrm{pH}$.

A seguir, pode-se notar que o $\mathrm{F}$ em excesso, que não reagiu com $\mathrm{Al}$, não diferiu acentuadamente, tendo o próprio $\mathrm{HF}$ atividade ligeiramente inferior, pois o aumento do $\mathrm{pH}$ consumiu proporcionalmente $\mathrm{o} \mathrm{H}$.

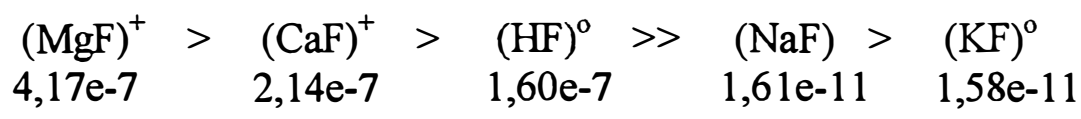




\subsection{Tratamento com carbonato de cálcio}

As espécies químicas de $\mathrm{Fe}$ e suas respectivas atividades encontradas na solução percolada 3,0 VP do tratamento com $\mathrm{CaCO}_{3}$ (1) (Tabela 37) foram as seguintes: $\left[\mathrm{Fe}(\mathrm{OH})_{2}\right]^{+}>\left[\mathrm{Fe}(\mathrm{OH})_{3}\right]^{0}>[\mathrm{Fe}(\mathrm{OH})]^{2+}>\left[\mathrm{Fe}(\mathrm{OH})_{4}\right]^{-}>>\left[\mathrm{Fe}_{2}(\mathrm{OH})_{2}\right]^{4+}>\left[\mathrm{FeNO}_{3}\right]^{2+}$ $6,40 \mathrm{e}-5 \quad 4,86 \mathrm{e}-6 \quad 1,07 \mathrm{e}-7 \quad 2,95 \mathrm{e}-8 \quad 3,62 \mathrm{e}-13 \quad 2,65 \mathrm{e}-13$

Nesse tratamento, apesar da dose de $\mathrm{CaCO}_{3}$ (1) ser metade da dose equivalente de $\mathrm{CaF}_{2}$ (2), o valor do $\mathrm{pH}$ da solução percolada foi superior. Além disso, com a ausência de ligantes fortes, como por exemplo o $\mathrm{F}^{-}$, o Fe ficou complexado em sua quase totalidade pela hidroxila.

No tratamento com $\mathrm{CaCO}_{3}(2)$, o $\mathrm{Fe}$ apresentou-se nas seguintes espécies e atividades:

$$
\begin{aligned}
& {\left[\mathrm{Fe}(\mathrm{OH})_{3}\right]^{0}>\left[\mathrm{Fe}(\mathrm{OH})_{2}\right]^{+}>\left[\mathrm{Fe}(\mathrm{OH})_{4}\right]^{-}>[\mathrm{Fe}(\mathrm{OH})]^{2+}>>\left[\mathrm{FeNO}_{3}\right]^{2+}>\left[\mathrm{Fe}_{2}(\mathrm{OH})_{2}\right]^{4+}} \\
& 1,07 \mathrm{e}-5 \quad 4,07 \mathrm{e}-6 \quad 2,22 \mathrm{e}-6 \quad 1,93 \mathrm{e}-10 \quad 1,39 \mathrm{e}-17 \quad 1,20 \mathrm{e}-18
\end{aligned}
$$

Nesse tratamento, o valor do $\mathrm{pH}$ final foi nitidamente superior ao do tratamento com $\mathrm{CaCO}_{3}$ (1). Portanto, houve uma inversão da espécie dominante na solução, mostrando a forte tendência de precipitação do Fe. A espécie negativa dominante teve sua atividade bastante acentuada e, novamente, o $\mathrm{NO}_{3}{ }^{-}$praticamente não existiu como par, encontrando-se na forma "livre", ou seja com fraca ligação (Tabela 37).

No caso do $\mathrm{Al}$ na solução percolada do tratamento com $\mathrm{CaCO}_{3}(1)$, tem-se:

$$
\begin{aligned}
& \left.\mathrm{Al}(\mathrm{OH})_{2}\right]^{+}>\left[\mathrm{Al}(\mathrm{OH})_{4}\right]^{-}>\left[\mathrm{Al}(\mathrm{OH})_{3}\right]^{0}>[\mathrm{Al}(\mathrm{OH})]^{2+}>\left(\mathrm{AlNO}_{3}\right)^{2+} \\
& \text { 9,19e-5 } \quad 8,47 \mathrm{e}-5 \quad 3,50 \mathrm{e}-5 \quad 6,13 \mathrm{e}-6 \quad 1,10 \mathrm{e}-14
\end{aligned}
$$

$\mathrm{Na}$ ausência de $\mathrm{F}$ e ligantes orgânicos no tratamento com $\mathrm{CaCO}_{3}$ (1), com este último não sendo determinado pois interessava apenas a comparação entre $\mathrm{F}$ e $\mathrm{CO}_{3}$ (o que no entanto, não descarta a sua ação sobre o $\mathrm{Al}$ ), o primeiro par iônico entre $\mathrm{Al}$ e $\mathrm{OH}$ apresentou-se na ordem de $10^{-5}$. Novamente, o ligante fraco $\mathrm{NO}_{3}^{-}$apresentou pareamento muito baixo.

No caso do $\mathrm{Al}$ na solução percolada do tratamento com $\mathrm{CaCO}_{3}(2)$, tem-se:

$$
\begin{aligned}
& \left.\mathrm{Al}(\mathrm{OH})_{4}\right]^{-}>\left[\mathrm{Al}(\mathrm{OH})_{3}\right]^{0}>\left[\mathrm{Al}(\mathrm{OH})_{2}\right]^{+}>[\mathrm{Al}(\mathrm{OH})]^{2+}>\left(\mathrm{AlNO}_{3}\right)^{2+} \\
& \text { 2,08e-4 2,52e-6 } \quad 1,91 \mathrm{e}-7 \quad 3,61 \mathrm{e}-10 \quad 1,83 \mathrm{e}-20
\end{aligned}
$$


Pode-se constatar nessa distribuição que, apesar de concentrações semelhantes entre $\mathrm{Fe}$ e Al, na ausência de F, novamente o $\mathrm{Al}$ (ácido duro de Pearson) complexouse com $\mathrm{OH}^{-}$(base dura de Pearson) com mais intensidade, de tal modo, que a espécie dominante apresentou-se na forma negativa com elevada atividade (ordem de $10^{-4}$ ), seguindo-se a espécie neutra. Evidentemente, nessa concentração $(\mathrm{pH} 7,82)$ e na ausência de F, a formação de gibbsita poderia ocorrer em alto grau.

\subsection{Testemunha}

Com relação à testemunha, o Fe na solução percolada 3,0 VP da testemunha (Tabela 37) distribuiu-se como:

$\left[\mathrm{Fe}(\mathrm{OH})_{2}\right]^{+}>[\mathrm{Fe}(\mathrm{OH})]^{2+}>>\left[\mathrm{Fe}(\mathrm{OH})_{3}\right]^{\circ}>>\left[\mathrm{FeNO}_{3}\right]^{2+}>\left[\mathrm{Fe}_{2}(\mathrm{OH})_{2}\right]^{4+}>\left[\mathrm{Fe}(\mathrm{OH})_{4}\right]^{-}$ 6,72e-6 6,08e-7 9,29e-9 $8,33 \mathrm{e}-11 \quad 1,19 \mathrm{e}-11 \quad 1,01 \mathrm{e}-12$

$\mathrm{Na}$ solução percolada da testemunha, verificou-se que o $\mathrm{Fe}$ continuou interagindo fortemente com $\mathrm{OH}$, no entanto, com tendências de formar complexos solúveis em maior escala e apenas uma menor parte tendendo a precipitar. Devido ao $\mathrm{pH}$ baixo $(4,5)$, a espécie negativa teve atividade tão baixa (ordem de $10^{-12}$ ) que chegou a ser superada pela atividade do par iônico $\left(\mathrm{FeNO}_{3}\right)^{2+}$.

No caso do Al:

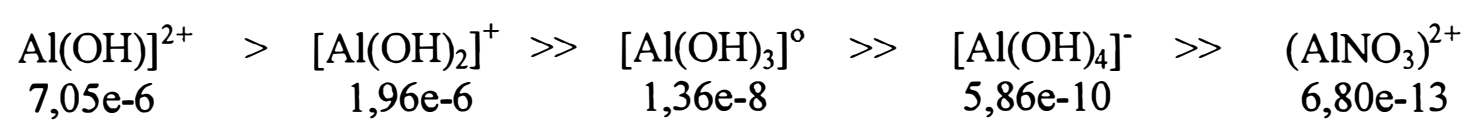

Devido ao pH baixo e ausência de $\mathrm{F}$, o $\mathrm{Al}$ na solução percolada 3,0 VP da testemunha permaneceu, predominantemente, em sua forma mais fitotóxica ( $76 \%$ como metal livre) e em menor proporção (24\%) ligado à $\mathrm{OH}^{\circ}$ só que na forma positiva (Tabela 37). Segundo Hodges (1987), tanto o Al trivalente como os pares iônicos $\mathrm{Al}-\mathrm{OH}$ são considerados fitotóxicos. As espécies neutras ou negativas, assim como o $\mathrm{NO}_{3}^{-}$, apresentaram baixa atividade no meio. 


\subsubsection{Alterações químicas do solo}

Os resultados das análises químicas do solo no final do experimento, após o cultivo do milho, são mostrados na Tabela 38. No solo do tratamento com $\mathrm{CaCO}_{3}$ (2), verificou-se o valor de $\mathrm{pH}$ significativamente mais alto e ausência de Al trocável, enquanto o oposto para ambos ocorreu na testemunha. É importante destacar que os tratamentos com $\mathrm{CaF}_{2}$ até o final do experimento, apresentaram valores de $\mathrm{pH}$ do solo significativamente superiores ao da testemunha, não diferindo do tratamento com $\mathrm{CaCO}_{3}$ (1). $\mathrm{O}$ valor de $\mathrm{pH}$ do solo mostrou-se diretamente proporcional à dose de $\mathrm{CaF}_{2}$ ou $\mathrm{CaCO}_{3}$ e ao valor de $\mathrm{pH}$ da solução percolada (Tabelas 39 e 40). Esse resultado concorda com diversos trabalhos (Parfitt, 1978; Gilpin \& Johnson, 1980; Peek \& Volk, 1986), que verificaram aumento de $\mathrm{pH}$ com a adição no solo de fluoreto.

Tabela 38. Efeito da aplicação de carbonato de cálcio e fluoreto de cálcio nos atributos químicos do solo, em casa de vegetação.

\begin{tabular}{|c|c|c|c|c|c|c|c|}
\hline \multirow{2}{*}{$\begin{array}{l}\text { Atributo } \\
\text { do solo }\end{array}$} & \multicolumn{6}{|c|}{ Tratamento } & \multirow{2}{*}{$\begin{array}{c}\text { Teste } \\
\text { F }\end{array}$} \\
\hline & Testemunha & $\mathrm{CaCO}_{3}(1)$ & $\mathrm{CaCO}_{3}(2)$ & $\mathrm{CaF}_{2}(1)$ & $\mathrm{CaF}_{2}(2)$ & Média & \\
\hline $\mathrm{pH}$ em $\mathrm{CaCl}_{2}$ & $3,88 \mathrm{~d}$ & $4,45 b c$ & $4,98 \mathrm{a}$ & $4,33 \mathrm{c}$ & $4,55 b$ & 4,44 & $110 * *$ \\
\hline $\mathrm{MO}\left(\mathrm{g} \mathrm{dm}^{-3}\right)$ & $17,0 \mathrm{a}$ & $20,0 \mathrm{a}$ & $18,0 \mathrm{a}$ & $18,0 \mathrm{a}$ & $20,3 a$ & 18,7 & $3,43 *$ \\
\hline $\mathrm{Al}\left(\mathrm{mmol}_{\mathrm{c}} \mathrm{dm}^{-3}\right)$ & $44,8 \mathrm{a}$ & $11,0 \mathrm{c}$ & $0,0 \mathrm{~d}$ & $25,5 b$ & $24,0 \mathrm{~b}$ & 21,1 & $139 * *$ \\
\hline $\mathrm{Ca}\left(\mathrm{mmol}_{\mathrm{c}} \mathrm{dm}^{-3}\right)$ & $8,5 \mathrm{c}$ & $31,5 b$ & $55,0 \mathrm{a}$ & $32,5 b$ & $44,5 \mathrm{a}$ & 34,4 & $53,9 * *$ \\
\hline $\mathrm{Mg}\left(\mathrm{mmol}_{c} \mathrm{dm}^{-3}\right)$ & 6,25 & 8,00 & 7,25 & 7,50 & 7,25 & 7,25 & $2,91 \mathrm{NS}$ \\
\hline $\mathrm{K}\left(\mathrm{mmol}_{\mathrm{c}} \mathrm{dm}^{-3}\right)$ & $1,30 \mathrm{a}$ & $0,90 \mathrm{~b}$ & $0,98 \mathrm{~b}$ & $1,08 \mathrm{ab}$ & $1,13 \mathrm{ab}$ & 1,08 & $5,00 * *$ \\
\hline $\mathrm{Na}\left(\mathrm{mmol}_{\mathrm{c}} \mathrm{dm}^{-3}\right)$ & $0,33 \mathrm{c}$ & $0,48 \mathrm{c}$ & $4,80 \mathrm{~b}$ & $0,43 \mathrm{c}$ & $7,00 \mathrm{a}$ & 2,61 & $3383 * *$ \\
\hline$P\left(m g d m^{-3}\right)$ & 3,75 & 3,50 & 3,25 & 3,50 & 3,75 & 3,55 & $0,47 \mathrm{NS}$ \\
\hline $\mathrm{F}\left(\mathrm{mg} \mathrm{dm}^{-3}\right)$ & $0,5 \mathrm{c}$ & $0,4 c$ & $0,3 \mathrm{c}$ & $26,0 \mathrm{~b}$ & $62,6 a$ & 17,9 & $406 * *$ \\
\hline $\mathrm{H}+\mathrm{Al}\left(\mathrm{mmol}_{\mathrm{c}} \mathrm{dm}^{-3}\right)$ & $100,8 \mathrm{a}$ & $56,5 b$ & $37,0 \mathrm{c}$ & $67,0 \mathrm{~b}$ & $59,5 b$ & 64,2 & $99,5 * *$ \\
\hline $\mathrm{CTC}\left(\mathrm{mmol}_{\mathrm{c}} \mathrm{dm}^{-3}\right)$ & $116,8 \mathrm{a}$ & $96,9 c$ & $100,2 b c$ & $108,1 \mathrm{ab}$ & $112,4 \mathrm{a}$ & 106,9 & $11,2 * *$ \\
\hline V (\%) & $14 \mathrm{c}$ & $42 b$ & $63 a$ & $39 b$ & $47 \mathrm{~b}$ & 41 & $85,9 * *$ \\
\hline $\mathrm{m}(\%)$ & $74 a$ & $22 \mathrm{c}$ & od & $39 \mathrm{~b}$ & $32 b$ & 33 & $178 * *$ \\
\hline
\end{tabular}

Números seguidos pela mesma letra na linha não diferem entre si ao nível de $5 \%$ pelo teste de Tukey.

As aplicações de doses crescentes de $\mathrm{CaCO}_{3}$ e $\mathrm{CaF}_{2}$ não influenciaram significativamente o conteúdo de MO e as concentrações de Mg e P no solo (Tabela 38). 
Tabela 39. Coeficientes de correlação ( $r$ ) de Pearson entre alguns atributos químicos do solo no final do experimento e $\mathrm{pH}$ na solução percolada $3,0 \mathrm{VP}$ e produção de matéria seca da parte aérea do milho, em função de doses crescentes de carbonato de cálcio.

\begin{tabular}{lcccc}
\hline Variável & \multicolumn{4}{c}{ Atributos químicos do solo } \\
\cline { 2 - 5 } & pH & Al & Ca & Na \\
\hline Dose & $0,99 * *$ & $-0,96 * *$ & $0,99 * *$ & $0,88 * *$ \\
pH solo & - & $-0,96 * *$ & $0,98 * *$ & $0,86 * *$ \\
pH sol. perc. & $0,91 * *$ & $-0,58 *$ & $0,76 * *$ & $0,87 * *$ \\
Produção milho & $0,83 * *$ & $-0,93 * *$ & $0,82 * *$ & $0,61 *$ \\
\hline
\end{tabular}

**,* significativo ao nivel de $1 \%$ e $5 \%$ de probabilidade pelo teste $\mathrm{t}$ de Student, respectivamente. NS: não significativo.

Tabela 40. Coeficientes de correlação ( $r$ ) de Pearson entre alguns atributos químicos do solo no final do experimento e na solução percolada 3,0VP e produção de matéria seca e concentração de $\mathrm{F}$ na parte aérea do milho, em função de doses crescentes de fluoreto de cálcio.

\begin{tabular}{lccccc}
\hline Variável & \multicolumn{5}{c}{ Atributos químicos do solo } \\
\cline { 2 - 5 } & $\mathbf{p H}$ & $\mathbf{A l}$ & $\mathbf{C a}$ & $\mathbf{N a}$ & $\mathbf{F}$ \\
\hline Dose & $0,95 * *$ & $-0,92 * *$ & $0,96 * *$ & $0,68 * *$ & $0,92 * *$ \\
pH solo & - & $-0,94 * *$ & $0,98 * *$ & $0,73 * *$ & $0,90 * *$ \\
pH sol. perc. & $0,72 * *$ & $-0,58 *$ & $0,76 * *$ & $0,87 * *$ & $0,89 * *$ \\
Al sol. perc. & $0,92 * *$ & $-0,87 * *$ & $0,93 * *$ & $0,68 *$ & $0,88 * *$ \\
F solo & $0,90 * *$ & $-0,76 * *$ & $0,90 * *$ & $0,91 * *$ & - \\
F sol. perc. & $0,92 * *$ & $0,87 * *$ & $0,93 * *$ & $0,82 * *$ & $0,95 * *$ \\
Prod. milho & $0,03 \mathrm{NS}$ & $-0,18 \mathrm{NS}$ & $0,08 \mathrm{NS}$ & $-0,33 \mathrm{NS}$ & $-0,02 \mathrm{NS}$ \\
\hline
\end{tabular}

**,* significativo ao nível de $1 \%$ e $5 \%$ de probabilidade pelo teste $\mathrm{t}$ de Student, respectivamente. NS: não significativo

As concentrações médias de $\mathrm{Al}$ trocável no solo dos tratamentos com $\mathrm{CaF}_{2}$ foram significativamente menores que da testemunha, sendo os tratamentos com $\mathrm{CaCO}_{3}$ significativamente mais eficientes na redução desse elemento tóxico para as plantas (Tabela 38). A concentração de $\mathrm{Al}$ mostrou-se inversamente proporcional às doses aplicadas de $\mathrm{CaCO}_{3}$ e $\mathrm{CaF}_{2}$ e ao $\mathrm{pH}$ do solo e da solução percolada (Tabelas 39 e 40). Nos tratamentos com $\mathrm{CaF}_{2}$, a concentração de $\mathrm{Al}$ no solo mostrou-se inversamente proporcional às concentrações de $\mathrm{Al}$ na solução percolada e de $\mathrm{F}$ no solo e diretamente proporcional à concentração de $\mathrm{F}$ na solução percolada ( $\mathrm{T}$ deela 40). 
Não houve diferença significativa na concentração de Ca trocável do solo entre as mesmas doses dos tratamentos com $\mathrm{CaCO}_{3}$ e $\mathrm{CaF}_{2}$ (Tabela 38). A concentração de $\mathrm{Ca}$ do solo mostrou-se diretamente proporcional às doses de $\mathrm{CaCO}_{3} \mathrm{e} \mathrm{CaF}_{2}$ aplicadas, ao $\mathrm{pH}$ do solo e da solução percolada (Tabelas 39 e 40).

A concentração de $\mathrm{K}$ trocável do solo foi significativamente diminuída com a aplicação de doses crescentes de $\mathrm{CaCO}_{3}$, mas não foi afetada pela aplicação de $\mathrm{CaF}_{2}$ (Tabela 38).

Para o $\mathrm{Na}$ do solo, verificou-se que sua concentração no tratamento com $\mathrm{CaF}_{2}$ (2) foi significativamente mais elevada do que no $\mathrm{CaCO}_{3}$ (2), que por sua vez, foi significativamente superior aos outros tratamentos (Tabela 38). A concentração de $\mathrm{Na}$ no solo mostrou-se diretamente proporcional às doses de $\mathrm{CaCO}_{3}$ e $\mathrm{CaF}_{2}$ aplicadas, ao $\mathrm{pH}$ do solo e da solução percolada (Tabelas 39 e 40). Ainda, nos tratamentos com $\mathrm{CaF}_{2}$, a concentração de Na no solo mostrou-se diretamente proporcional às concentrações de $\mathrm{F}$ no solo e de F e Al na solução percolada (Tabela 40).

\subsubsection{Produção de matéria seca e concentração de flúor em diferentes culturas}

Os resultados da aplicação de doses de $\mathrm{CaCO}_{3}$ e de $\mathrm{CaF}_{2}$ sobre a produção de matéria seca média das culturas de feijão, soja, crotalária e milho, plantadas seqüencialmente em condições de casa de vegetação, são apresentados na Tabela 41.

A cultura de feijão apresentou baixa produção de matéria seca de vagens em todos os tratamentos (Tabela 41), devendo-se à elevada acidez e baixa fertilidade do solo (ítem 3.2.1, p.37) no início do processo de incubação, pois essa cultura é muito sensivel à acidez e ao $\mathrm{Al}$ tóxico. A produção de vagens de feijão foi significativamente superior no tratamento com $\mathrm{CaCO}_{3}$ (1), em relação aos outros tratamentos (Tabela 41). Esse resultado não pode ser atribuído ao $\mathrm{pH}$ e à concentração de $\mathrm{Al}$ na solução percolada 0,1 VP (Tabela 27, p.81). A concentração de $F$ nas vagens de feijão não foi determinada devido à pequena quantidade de matéria seca produzida. 
Tabela 41. Efeito da aplicação no solo de carbonato de cálcio e fluoreto de cálcio na produção e concentração de $\mathrm{F}$ na matéria seca em quatro culturas.

\begin{tabular}{|c|c|c|c|c|c|c|c|}
\hline \multirow[t]{2}{*}{ Tratamento } & \multirow{2}{*}{$\frac{\text { Feijão }^{1}}{\text { Prod }}$} & \multicolumn{2}{|c|}{ Soja ${ }^{1}$} & \multicolumn{2}{|c|}{ Crota lár ${ }^{2}$} & \multicolumn{2}{|c|}{ Milho $^{2}$} \\
\hline & & Prod & $\mathbf{F}$ & Prod & $\mathbf{F}$ & Prod & $\mathbf{F}$ \\
\hline & g/vaso & g/vaso & $\mathrm{mg} \mathrm{kg}^{-1}$ & g/vaso & $\mathrm{mg} \mathrm{kg}^{-1}$ & g/vaso & $\mathrm{mg} \mathrm{kg}^{-1}$ \\
\hline Testemunha & $0,00 \mathrm{~b}$ & $0,08 \mathrm{~b}$ & traços & $0,19 b$ & traços c & $7,80 \mathrm{~b}$ & $3,0 \mathrm{c}$ \\
\hline $\mathrm{CaCO}_{3}(1)$ & $0,38 \mathrm{a}$ & $0,89 \mathrm{ab}$ & traços & $2,19 a$ & traços c & $12,12 \mathrm{a}$ & $2,8 \mathrm{c}$ \\
\hline $\mathrm{CaCO}_{3}(2)$ & $0,10 \mathrm{~b}$ & $1,29 a$ & traços & $2,55 \mathrm{a}$ & traços c & $12,99 a$ & $2,5 \mathrm{c}$ \\
\hline $\mathrm{CaF}_{2}(1)$ & $0,02 b$ & $0,93 \mathrm{ab}$ & 0,3 & $1,82 \mathrm{a}$ & $1,0 \mathrm{~b}$ & $10,36 \mathrm{ab}$ & $8,5 b$ \\
\hline $\mathrm{CaF}_{2}(2)$ & $0,06 \mathrm{~b}$ & $0,93 \mathrm{ab}$ & 0,5 & $2,80 \mathrm{a}$ & $2,0 \mathrm{a}$ & $7,83 \mathrm{~b}$ & $11,8 a$ \\
\hline Média & 0,11 & 0,82 & 0,2 & 1,91 & 0,6 & 10,22 & 5,7 \\
\hline Teste F & $12,7 * *$ & $4,08 *$ & - & $12,2 * *$ & $148,3 * *$ & $12,3 * *$ & $148,8 * *$ \\
\hline
\end{tabular}

A cultura de soja, em sucessão ao feijão, foi significativamente influenciada pelos tratamentos, mas também foi afetada pela baixa fertilidade do solo e ao $\mathrm{Al}$ tóxico. A produção de vagens no tratamento $\operatorname{com} \mathrm{CaCO}_{3}(2)$ foi significativamente superior à da testemunha, enquanto os outros tratamentos não diferiram entre si (Tabela 41). Esse resultado pode ser explicado pelo $\mathrm{pH}$ mais elevado na solução percolada $0,5 \mathrm{VP}$ do tratamento com $\mathrm{CaCO}_{3}$ (2) (Tabela 26, p.79). A concentração média de $\mathrm{F}$ nas vagens de soja dos tratamentos com $\mathrm{CaF}_{2}$ foi muito baixa, não ocorrendo diferenças entre os tratamentos (Tabela 41).

Com relação a crotalária, verificou-se efeito significativo de doses de $\mathrm{CaCO}_{3} \mathrm{e}$ de $\mathrm{CaF}_{2}$ na produção de matéria seca da parte aérea, mas não houve diferença significativa entre esses tratamentos (Tabela 41). Estes resultados mostraram que o $\mathrm{CaF}_{2}$ foi tão eficiente quanto o $\mathrm{CaCO}_{3}$ na melhoria do ambiente radicular, devido ao aumento do $\mathrm{pH}$ e possível formação de pares iônicos Al-F. A concentração de $\mathrm{F}$ na parte aérea da crotalária foi significativamente aumentada com a aplicação de doses crescentes de $\mathrm{CaF}_{2}$ (Tabela 41), mas na prática esses valores foram muito baixos em relação a quantidade de $\mathrm{F}$ aplicada ao solo, indicando que a acumulação foi muito 
pequena nas plantas de crotalária. No experimento de campo, a acumulação nas folhas de crotalária em função da aplicação de doses crescentes de $\mathrm{NaF}$ (Tabela 24, p.76) foi superior à encontrada no experimento em casa de vegetação com aplicação de $\mathrm{CaF}_{2}$, podendo ser atribuído à menor solubilidade desse último, conforme relatado por KabataPendias \& Pendias (1984).

As produções de matéria seca da parte aérea do milho nos tratamentos com $\mathrm{CaCO}_{3}$ foram significativamente superiores às da testemunha e do tratamento com $\mathrm{CaF}_{2}$ (2), mas não diferiram do tratamento com $\mathrm{CaF}_{2}$ (1) (Tabela 41). Nos tratamentos com $\mathrm{CaCO}_{3}$, a produção de matéria seca da parte aérea do milho mostrou-se diretamente proporcional ao $\mathrm{pH}$ e às concentrações de $\mathrm{Ca}$ e $\mathrm{Na}$ no solo, e ainda, inversamente proporcional à concentração de $\mathrm{Al}$ no solo (Tabela 39). Por outro lado, nos tratamentos com $\mathrm{CaF}_{2}$, a produção de matéria seca da parte aérea do milho não foi associada com nenhum dos atributos químicos do solo (Tabela 40) e da solução percolada 3,0 VP avaliados.

A concentração média de $\mathrm{F}$ na parte aérea do milho aumentou significativamente com a aplicação de doses crescentes de $\mathrm{CaF}_{2}$ (Tabela 41). No solo, a concentração de $\mathrm{F}$ no tratamento com $\mathrm{CaF}_{2}$ (2) foi cerca de $140 \%$ superior à do tratamento com $\mathrm{CaF}_{2}$ (1) (Tabela 38), enquanto que na parte aérea do milho, a concentração de $\mathrm{F}$ no tratamento com $\mathrm{CaF}_{2}$ (2) foi somente cerca de $40 \%$ superior à do tratamento com dose (1) (Tabela 41). A concentração de $F$ na parte aérea do milho mostrou-se diretamente proporcional às doses de $\mathrm{CaF}_{2}$ aplicadas $(\mathrm{r}=0,97 * *)$, às concentrações de $\mathrm{F}$ no solo $(\mathrm{r}=0,95 * *)$, F na solução percolada $(\mathrm{r}=0,98 * *)$, Al na solução percolada $(r=0,89 * *)$ e Fe na solução percolada $(r=0,65 *)$ e também mostrouse inversamente proporcional à concentração de $\mathrm{Al}$ no solo $(\mathrm{r}=0,88 * *)$. Esses resultados evidenciam que o $\mathrm{F}$ deve estar sendo, preferencialmente, absorvido na forma de complexo Al-F e em parte como Fe-F, confirmando os resultados obtidos em condições de campo para a crotalária (p.77). Takmaz-Nisancioglu \& Davison (1988) e Amesen (1997) também encontraram associações significativas entre F e Al na parte aérea de feijoeiro e forrageiras, respectivamente. 
A Figura 5 apresenta uma avaliação geral das produções de matéria seca das diferentes culturas no decorrer do experimento em casa de vegetação, empregando-se a produção relativa, tomando-se como base 100 àquela obtida no tratamento com $\mathrm{CaCO}_{3}$ (1). As produções de feijão, soja, crotalária e milho nos tratamentos com $\mathrm{CaF}_{2}$ foram sempre superiores à da testemunha. As plantas de crotalaria foram menos sensíveis à altas concentrações de $\mathrm{F}$ no solo do que as plantas de milho, assim sendo para a crotalária, o tratamento com $\mathrm{CaF}_{2}$ (2) apresentou a maior produção de matéria seca da parte aérea.

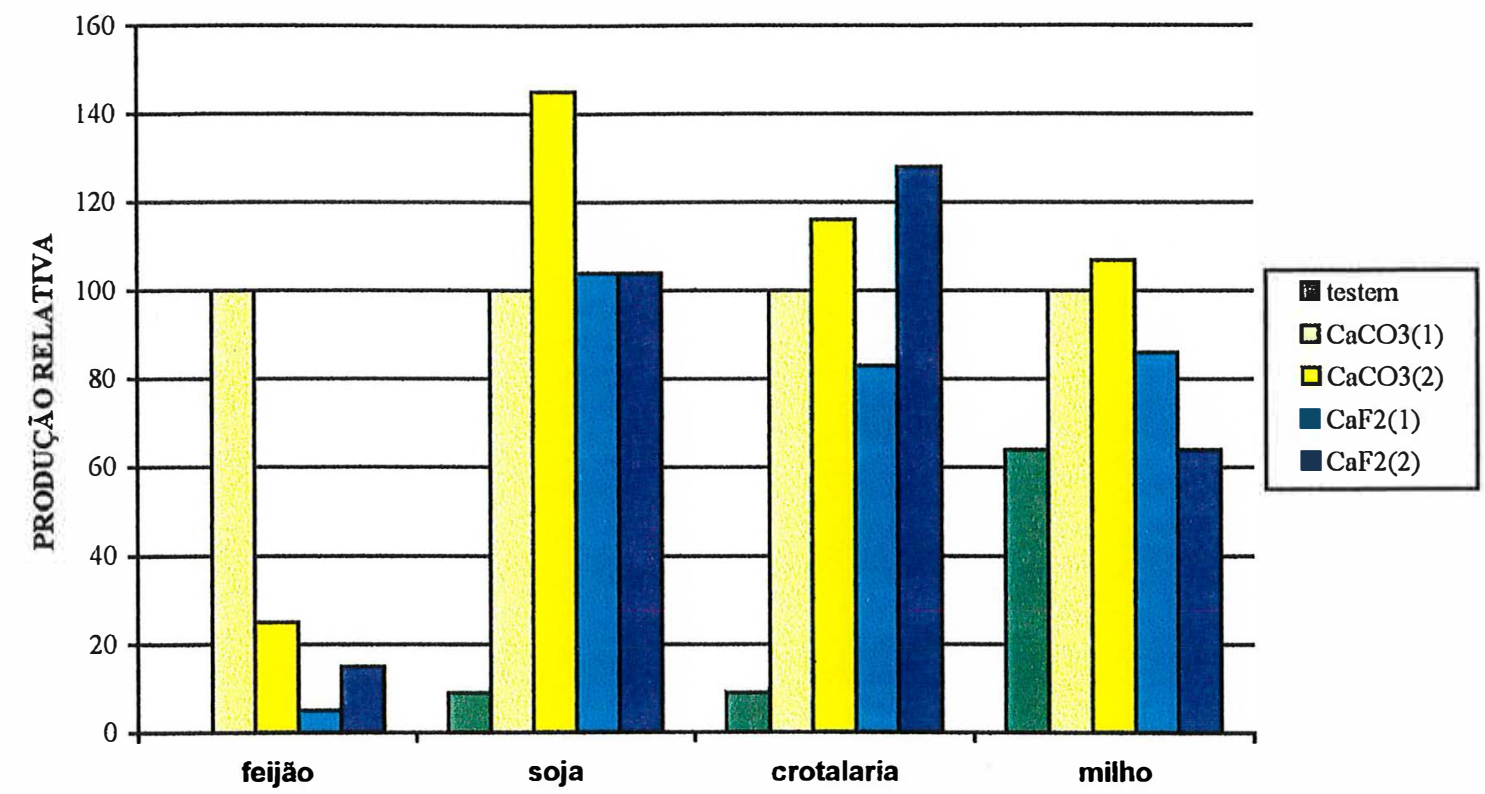

CULTURA

Figura 5. Produção relativa $\left(\mathrm{CaCO}_{3}(1)=100 \%\right)$ de matéria seca nos vasos, em função de doses crescentes de $\mathrm{CaCO}_{3}$ e $\mathrm{CaF}_{2}$.

De modo geral, não houve fitotoxicidade do $\mathrm{F}$ neste experimento. A concentração máxima de $\mathrm{F}$ encontrada na parte aérea do milho $\left(11,8 \mathrm{mg} \mathrm{kg}^{-1}\right.$; Tabela 41), que foi semelhante à encontrada em plantas crescidas em áreas não poluídas com $\mathrm{F}$ (Davison et al., 1983), foi obtida com à aplicação no solo de $2129 \mathrm{~kg} \mathrm{ha}^{-1}$ de $\mathrm{F}$ (4370 $\mathrm{kg} \mathrm{ha}^{-1}$ de $\mathrm{CaF}_{2}$ ). É importante ressaltar que para atingir essa quantidade de $\mathrm{F}$ no solo seria necessário à aplicação de $213 \mathrm{tha}^{-1}$ de superfosfato simples ou gesso agrícola. 


\section{CONCLUSÕES}

1. A aplicação no solo de doses crescentes de fluoreto (na forma de $\mathrm{NaF}$ ou $\mathrm{CaF}_{2}$ ) aumentou significativamente o valor de $\mathrm{pH}$ e diminuiu a concentração de $\mathrm{Al}$ trocável no solo, que foi lixiviado na forma de complexo Al-F.

2. $\mathrm{O} F$ ligado ao $\mathrm{Na}$ apresentou maior solubilidade que àquele ligado ao $\mathrm{Ca}$.

3. Em condições de campo, aumentando-se as doses de NaF ocorreu tendência de aumento da concentração de $\mathrm{P}$ no solo, sendo explicado pelo aumento de $\mathrm{pH}$ do solo.

4. A concentração de F na parte aérea (folha, grãos ou vagens) nas plantas estudadas (crotalária, milho, soja e sorgo), mesmo com a aplicação de doses elevadas de $\mathrm{NaF}$ ou $\mathrm{CaF}_{2}$, foi inferior ao nível considerado crítico de toxicidade na dieta animal, sendo decrescente das folhas para os grãos ou vagens.

5. Em condições de campo, as produções de sorgo e crotalária não foram significativamente afetadas com a aplicação de até $2772 \mathrm{~kg} \mathrm{ha}^{-1}$ de $\mathrm{NaF}$, enquanto em casa de vegetação, as produções de feijão, soja, crotalária e milho dos tratamentos com $\mathrm{CaF}_{2}$ foram sempre superiores à testemunha. 


\section{REFERÊNCIAS BIBLIOGRÁFICAS}

ADRIANO, D.C. Trace elements in the terrestrial environment. New York: Springer-Verlag, 1986. 533p.

ADRIANO, D.C.; DONER, H.E. Bromine, chlorine, and fluorine. In: PAGE, A.L.; MILLER, R.H.; KEENEY, D.R. (Ed.) Methods of soil analysis: Part 2 - Chemical and microbiological properties. Madison: Soil Science Society of America, 1982. p.449-483.

ALCARDE, J. C.; CHITOLINA, J.C. Determinação do nitrogênio total em solos pelo método da liga de Raney. Revista de Agricultura, v.66, n.1, p.97-106, 1991.

ALLAWAY, W.H. Food chain aspects of the use of organic residues. In: ELLIOTT, L.F.; STEVENSON, F.J. (Ed.) Soils for management of organic wastes and wastes waters. 2.imp. Madison: American Society of Agronomy, Crop Science Society of America, Soil Science Society of America, 1986. p.283-298.

ALVA, A.K.; GASCHO, G.J.; GUANG, Y. Gypsum material effects on peanut and soil calcium. Communications in Soil Science and Plant Analysis, v.20, p.1727-1744, 1989.

ALVA, A.K.; SUMNER, M.E. Effects of phosphogypsum or calcium sulphate on aluminon reactive aluminum in solutions at varying $\mathrm{pH}$. Communications in Soil Science and Plant Analysis, v.19, n.15, p.1715-1730, 1988.

ALVA, A.K.; SUMNER, M.E.; NOBLE, A.D. Effects of fluoride on colorimetric measurement of solution aluminum. Soil Science Society American Journal, v.52, p.374-378, 1988.

ALVAREZ, E.; GARCIA-RODEJA, E; CALVO, R. Parent soil materials and toxic species of $\mathrm{Al}$ in acid soils of Galicia (Spain). Fresenius Environmental Bulletin, v.1, n.9, p.553-558, 1992.

ANDERSON, M.A.; BERTSCH, P.M. Dynamics of aluminum complexation in multiple ligand systems. Soil Science Society of America Journal, v.52, n.6, p.1597-1602, 1988.

ANUÁRIO ESTATÍSTICO DO BRASIL - 1996, v.56, 1997. 
ARNESEN, A.K.M. Availability of fluoride to plants grown in contamined soils. Plant and Soil, v.191, n.1, p.13-25, 1997.

ASHER, C.J. Beneficial elements, functional nutrients, and possible new essential elements. In: MORTVEDT, J.J.; COX, F.R.; SHUMAN, L.M.; WELCH, R.M. (Ed.) Micronutrients in Agriculture. 2.ed. Madison: Soil Science Society of America, 1991. cap.18, p.703-723.

BARANOVSKII, A.Z;; PANKRUTSKAYA, L.I. Accumulation of fluorine in biological objects with long-term application of phosphorus fertilizers on peat-bog soils. Agrokhimiya, n.12, p.27-34, 1992.

BARRACO, P.; CHIARO, G.; BARBERA, A. Infuence of impurities on stainless steels corrosion in wet process phosphoric acid. Fertilizer Research, v.26, p.281-289, 1990.

BARROW, N.J. Testing a mechanistic model. I. The effects of time and temperature on the reaction of fluoride and molybdate with a soil. Journal of Soil Science, v.37, n.2, p.267-275, 1986.

BARROW, N.J.; ELLIS, A.S. Testing a mechanistic model. III. The effects of fluoride retention by a soil. Journal of Soil Science, v.37, p.287-293, 1986.

BERESIN, L.V.; TOKAREVA, T.M.; SABAEVA, O.V. Investigation of fluorine accumulation and standard strotium in plants in relation to melioration of sodic soils. Izvestiya Sibirskogo Otdeleniya Akademii Nauk SSSR. Sibirski i Biologicheskii Zhurnal, n.3, p.52-59, 1991. /Resumo em CAB Abstracts on CD-ROM, 1992/

BISSANI, C.; GIONGO, V.; MIELNICZUK, J.; SALET, R.L. Correção da acidez pela aplicação superficial de calcário e gesso em sistema plantio direto. In: CONGRESSO BRASILEIRO DE CIÊNCIA DO SOLO, 26., Rio de Janeiro, 1997. Anais. Rio de Janeiro: SBCS, 1997.

BOND, W.J.; SMITH, C.J.; GIBSON, A.E.; WILLETT, I.R. The effect of sulfate and fluoride on the mobility of aluminium in soil. Australian Journal of Soil Research, v.33, p.883-97, 1995.

BÖSZÖRMÉNYI, Z.; CSEH, E. The uptake of halide ions and their relationships in absorption. Physiologia Plantarum, v.14, p.242-252, 1961.

BOWER, C.A.; HATCHER, J.J. Adsortion of fluoride by soils and minerals. Soil Science, v.103, p. 151-154, 1967.

BRAY, R.H.; KURTZ, L.T. Determination of total, organic, and available forms of phosphorus in soils. Soil Science, v.59, p.39-55, 1945.

BREWER, R.F. In: CHAPMAN, H.D. (Ed.) Diagnostic criteria for plants and soils. Abilene,TX: Quality Printing Co. Inc., 1965. p.180-196. 
BREWER, R.F.; CHAPMAN, H.P.; SUTHERLANDS, F.H.; McCULLOGH, R.B. Effect of fluoride additions to substrate on naval orange trees grown in solution cultures. Soil Science, v.87, p.183-188, 1958.

CAMERON, R.S.; RITCHIE, G.S.P.; ROBSON, A.D. Relative toxicities of inorganic aluminum complexes to barley. Soil Science Society of America Journal, v.50, n.5, p.1231-1236, 1986.

CAMPEN, D.R. van. Trace elements in human nutrition. In: MORTVEDT, J.J.; COX, F.R.; SHUMAN, L.M.; WELCH, R.M. (Eds.) Micronutrients in Agriculture. 2.ed. Madison: Soil Science Society of America, 1991. cap.17, p.663-701.

CARVALHO, M.C.S. Sulfato de cálcio, fosfogesso e carbonato de cálcio na melhoria do ambiente radicular de subsolos ácidos. Piracicaba, 1994. 84p. Dissertação (Mestrado) Escola Superior de Agricultura "Luiz de Queiroz", Universidade de São Paulo.

CHANEY, R.L. Potencial effects of waste constituents on the food chain. In: PARR, J.F. et al. (Eds.) Land Treatment of Hazardous Wastes. Park Ridge: Noyes Data Corporation, 1983. p.152-240.

CHANG, S.C.; JACKSON, M.L. Fractionation of soil phosphorus. Soil Science, v.84, p.133-144, 1957.

COOKE, J.A.; JOHNSON, M.S.; DAVISON, A.W. Determination of fluoride in vegetation: a review of modern techniques. Environmental Pollution, v.11, p.257$268,1976$.

CUNNIFF, P. (Ed.) Official Methods of Analysis of AOAC International. v.1. 16.ed. Arlington: AOAC International, 1995.

DABEKA, R.W.; McKENZIE, A.D: Survey of lead, cadmium, fluoride, nickel, and cobalt in food composites and estimation of dietary intakes of these elements by canadians in 1986-1988. Journal of AOAC International, v.78, n.4, p.897-909, 1995.

DAINES, R.H.; LEONE, I.; BRENNAN, E. The effects of fluoride on plants as determined by soil nutrition and fumigation studies. In: MACABE, L. (Ed.) Air pollution. New York: Springer-Verlag, 1952. p.97-105.

DAVID, M.B.; DRISCOLL, C.T. Aluminum speciation and equilibria in soil solutions of a haplorthod in the Adirondack Mountains (New York, USA). Geoderma, v.33, p.297-318, 1984.

DAVISON, A.W.; TAKMAZ-NISANCIOGLU, S; BAILEY, I.F. The dynamics of fluoride accumulation by vegetation. In: CONFERENCE OF THE INTERNATIONAL SOCIETY FOR FLUORIDE RESEARCH, 13., Nova Deli, 1983. Proceedings. Nova Deli: ISFR, 1983. p.30-46. 
DICKMAN, S.R.; BRAY, R.H. Replacement of adsorbed phosphate from kaolinitic by fluoride. Soil Science, v.52, p.263-273, 1941.

DOLEY, D. Fluoride-induced enhancement and inhibition of shoot growth in four taxa of Pinus. New Pytologist, v.112, p.543-552, 1989.

ELRASHIDI, M.A.; LINDSAY, W.L. Solubility relationships of fluorine minerals in soils. Soil Science Society of America Journal, v.49, n.5, p.1133-1136, 1985.

ELRASHIDI, M.A.; LINDSAY, W.L. Solubility of aluminum fluoride, fluorite, and fluorophlogopite minerals. Soil Science Society of America Journal, v.50, n.3, p.594-598, 1986a.

ELRASHIDI, M.A.; LINDSAY, W.L. Chemical equilibria of fluorine in soils: a theoretical development. Soil Science, v.141, n.4, p.274-280, 1986 b.

FARRAH, H.; PICKERING, W.F. Interaction of dilute fluoride solutions with hydrous iron oxides. Australian Journal of Soil Research, v.24, n.2, p.201-208, 1986.

FARRAH, H.; SLAVEK, J.; PICKERING, W.F. Fluoride sorption by soil components: calcium carbonate, humic acid, manganese dioxide and silica. Australian Journal of Soil Research, v.23, n.3, p.429-439, 1985.

FLÜHLER, H.; POLOMSKI, J.; BLASER, P. Retention and movement of fluoride in soils. Journal of Environment Quality, v.11, n.3, p.414-468, 1982.

FOOD AND NUTRIIION BOARD. National Research Council. Recommended dietary allowances. 10.ed. Washington: National Academy Press, 1989.

FOY, C.D. Soil chemical factors limiting plant root growth. Advances in Soil Science, v.19, p.97-149, 1992.

FOY, C.D.; CHANEY, R.L.; WHITE, M.C. The physiology of metal toxicity in plants. Annual Review of Plant Physiology, v.29, p.511-566, 1978.

GAPONYUK, E.I.; REUT, G.M. Effect of sodium fluoride on the organomineral components of a sod-podzolic soil. Soviet Soil Science, v.15, n.6, p.44-51, 1983.

GARDINER, P.E.; SCHIERL, R.; KREUTZER, K. Aluminum speciation in soil solutions as studied by size exclusion chromatografy. Plant and Soil, v.103, p.151-154, 1987.

GAROTTI, F.V.; MASSARO, S.; SERRANO, S.H.P. Determination of aluminium in soils with fluoride ion selective eletrode. Analusis, v.20, n.5, p.287-290, 1992.

GEOGHEGAN, I.E. ; SPRENT, J..I. Aluminum and nutrient concentrations in species native to Central Brazil. Communications in Soil Science and Plant Analysis, v.27, n.18-20, p.2925-2934, 1996. 
GIBSON, J.A.E.; WILLETT, I.R.; BOND, W.J. The effects of sulphate and fluoride on the sorption of aluminium by an oxisol. Journal of Soil Science, v.43, n.3, p.429439, 1992.

GILKES, R.J.; HUGHES, J.C. Sodium fluoride $\mathrm{pH}$ of Southwestem Australian soils as an indicator of P-sorption. Australian Journal of Soil Research, v.32, n.4, p.755766, 1994.

GLPIN, L.; JOHNSON, A.H. Fluorine in agricultural soils of Southeastem Pennsylvania. Soil Science Society of America Journal, v.44, p.255-258, 1980.

GIONGO, V.; BISSANI, C.; SALET, R.L.; MIELNICZUK, J. Complexação de alumínio, em sistemas de culturas no sistema plantio direto. In: CONGRESSO BRASILEIRO DE CIÊNCIA DO SOLO, 26., Rio de Janeiro, 1997. Anais. Rio de Janeiro: SBCS, 1997.

GREWAL, M.S.; DAHIYA, I.S. Evaluation on spatial variation in water soluble fluorine content of the soils of different agro-climatic zones of Haryana, India. Fluoride, v.25, n.3, p.135-142, 1992.

HAAG, H.P. Chuvas Ácidas. Campinas: Fundação Cargill, 1985. 77p.

HANSEN, E.D.; WIEBE, H.H.; THORNE, W. Air pollution with relation to agronomic crops: VII. Fluoride uptake from soils. Agronomy Journal, v.50, p.565-568, 1958.

HEEDE, M.A. van den; HEYNDRICKY, A.M.; PETEGHEM, C.H. van; ZELE, W.A. van Determination of fluoride in vegetation: a comparative study of four sample preparation methods. Journal of AOAC, v.58, n.6, p.1135-1137, 1975.

HIIL, A.C.; TRANSTRUM, L.G.; PACK, M.R.; WINTERS, W.S. Air pollution with relation to agronomic crops: VI. An investigation of the "hidden injury" theory of fluoride damage to plants. Agronomy Journal, v.50, p.562-565, 1958.

HINGSTON, F.J.; POSNER, A.M.; QUIRK, J.P. Anion adsorption by goethite and gibbsite: II. Desorption of anions from hydrous oxide surfaces. Journal of Soil Science, v.25, p.16-26, 1974.

HODGES, S.C. Aluminum speciation: a comparison of five methods. Soil Science Society America Journal, v.51, p.57-64, 1987.

HSU, P.H. Aluminum oxides and oxyhydroxides. In: DIXON, J.B. \& WEED, S.B. (Eds.) Minerals in soil environments. Madison: Soil Science Society of America, 1989. p.331-378. (SSSA Book Series, 1).

HUA, L. Buffer capacities and affecting factors in six types of soils in China and Russia. Acta Agriculturae Universitatis Pekinensis, v.17, n.2, p.55-62, 1991. / Resumo em CAB Abstracts on CD-ROM, 1993/ 
ILKUN, G.M.; MOTRUK, U.V. Accumulation and transport of fluorine compounds in soils. In: ILKUN, G.M. (Ed.) Plants and industrial environment. Kiev: Nankova Dumka, 1976. p.82-85.

KABATA-PENDIAS, A.; PENDIAS, $\mathrm{H}$. Trace elements in soils and plants. Boca Raton, CRC Press, 1984. 315p.

KEERTHISINGHE, G.; McLAUGHLIN, M.J.; FRENEY, J.R. Use of gypsum, phosphogypsum and fluoride to ameliorate subsuperface acidity in a pasture soil. In: WRIGHT, R.J.; BALIGAR, V.C.; MURRMANN, R.P. (Ed.) Plant-soil interactions at low pH. Dordrecht: Kluwer Academic Publ., 1991a. p.509-517. (Developments in Plant and Soil Sciences, 45).

KEERTHISINGHE, G.; McLAUGHLIN, M.J.; RANDALL, P.J. Improved recovery of fluoride in plant material using a low temperature sealed chamber digestion technique in conjunction with a fluoride ion-specific electrode. Communications in Soil Science and Plant Analysis, v.22, n. 17-18, p.1831-1846, 1991b.

KERVEN, G.L.; LARSEN, P.L.; BELL, L.C.; EDWARDS, D.G. Quantitative ${ }^{27} \mathrm{Al}$ NMR spectroscopic studies of $\mathrm{Al}$ (III) complexes with organic acid ligands and their comparison with GEOCHEM predicted values. Plant and Soil, v.171, n.1, p.35-39, 1995.

KIEHL, E.J. Manual de Edafologia: Relações Solo-Planta. São Paulo: Ed. Agronômica Ceres, 1979. 264p.

KINRAIDE, T.B.; PARKER, D.R. Non-phytotoxicity of the aluminum sulfate ion, $\mathrm{AlSO}_{4}{ }^{+}$. Physiologia Plantarum, v.71, p.207-212, 1987.

KLUMPP, A.; MODESTO, I.; DOMINGOS, M.; KLUMPP, G. Susceptibility of various gladiolus cultivars to fluoride pollution and their suitability for bioindication. Pesquisa Agropecuária Brasileira, v.32, n.3, p.239-247, 1997.

KREMLENKOVA, N.P.; GAPONYUK, E.I. Change in humus composition and enzyme activity of soils produced by sodium fluorine. Soviet Soil Science, v.16, n.6, p.26-30, 1984.

LARSEN, S.; WIDDOWSON, A.E. Soil fluorine. Journal of Soil Science, v.22, n.2, p.210-221, 1971.

LEONE, I.; BRENNAN, E.; DAINES, R.H.; ROBBINS, W.R. Some effects of fluoride on peach, tomato and buckwheat when absorbed through the roots. Soil Science, v.66, p.259-66, 1948.

LINDSAY, W.L. Chemical equilibria in soils. New York: John Wiley \& Sons, 1979. 449 p. 
$\mathrm{LO}, \mathrm{K}$.; LO, H. Buffering in soils to $\mathrm{Cu}, \mathrm{Pb}, \mathrm{Cd}$ and $\mathrm{F}$ in some soils of the Chinese People's Republic. Izvestiya Timiryazevskoi Sel'skokhozyaistvennoi Akademii, n. 1, p.202-206, 1991. /Resumo em CAB Abstracts on CD-ROM, 1994/

LU, J.G.; ZHAO, X.M. Effects of soil development on the fluorine contents in soils and tea leaves. Journal of Tea Science, v.12, n.1, p.33-38, 1992. /Resumo em CAB Abstracts on CD-ROM, 1994/

LUTHER, S.M.; POULSEN, L.; DUDAS, M.J.; RUTHERFORD, P.M. Fluoride sorption and mineral stability in an Alberta soil interacting with phosphogypsum leachate. Canadian Journal of Soil Science, v.76, p.83-91, 1996.

MAAS, E.V.; NIEMAN, R.H. Physiology of plant tolerance to salinity. In: JUNG, G.A; STELLY, M.; KRAL, D.M.; NAUSEEF, J.H. (Eds.) Crop tolerance to suboptimal land conditions. Madison: American Society of Agronomy, Crop Science Society of America, Soil Science Society of America, 1978. cap.13, p.277-299 (ASA. Special Publication, 32)

MacINTIRE, W.H. Effects of fluorine in Tennessee soils and crops. Industrial and Engineering Chemistry, v.41, p.2466-2475, 1949.

MacINTIRE, W.H., SHAW, W.M.; ROBINSON, B. Behavior of incorporations of potassium and calcium fluorides in a 6-year lysimeter study. Journal of Agricultural and Food Chemistry, v.3, p.772-777, 1955.

MacLEAN, D.C.; HANSEN, K.S.; SCHNEIDER, R.E. Amelioration of aluminium toxicity in wheat by fluoride. New Phytologist, v.121, p.81-88, 1992.

MAFTOUN, M; SHEIBANY, B. Effect of fluorine content of irrigation water on the growth of four plant species in relation to soil salinity. Tropical Agriculture, v.56, n.3, p.213-218, 1979.

MALAVOLTA, E. Elementos de nutrição mineral de plantas. São Paulo: Editora Agronômica Ceres, 1980. 251p.

MALAVOLTA, E.; NOGUEIRA, F.D.; OLIVEIRA, I.P.; NAKAYAMA, L.; EIMORI, I. Aluminum tolerance in sorghum and bean-methods and results. Journal of Plant Nutrition, v.3, n.1-4, p.687-694, 1981.

MALAVOLTA, E.; VITTI, G.C; OLIVEIRA, S.D. de. Avaliação do estado nutricional das plantas: princípios e aplicações. Piracicaba, POTAFOS, 1989. 201p.

MARSHNER, H. Mineral nutrition of higher plants. New York: Academic Press, 1986. 674p.

MASON, J.W. Accumulation of fluoride by the soybean (Glycine max L. Merrill var Dare). Part I: Visible injury and related effects on seed yield. Journal of Plant Nutrition, v.3, n.1-4, p.429-440, 1981. 
McLAUGHLIN, M.J.; TILLER, K.G.; NAIDU, R.; STEVENS, D.P. Review : the behaviour and environmental impact of contaminants in fertilizers. Australian Journal of Soil Research, v.34, p.1-54, 1996.

McNULTY, I.B.; NEWMAN, D.W. Mechanism(s) of fluoride induced chlorosis. Plant Physiology, v.36, n.4, p.385-388, 1961.

McQUAKER, N.R.; GURNEY, M. Determination of total fluoride in soil and vegetation using an alkali fusion-selective ion electrode technique. Analytical Chemistry, v.49, n.1, p.53-56, 1977.

MENDONÇA, E.S. Oxidação da matéria orgânica e sua relação com diferentes formas de alumínio de latossolos. Revista Brasileira de Ciência do Solo, v.19, n.1, p.25-30, 1995.

MENGEL, K.; KIRKBY, E.A. Principles of plant nutrition. 3.ed. Bern: International Potash Institute, 1982. 655p.

MEYER, M.; O' HAGAN, D. Rare fluorinated natural products. Chemistry in Britain, v.28, n.9, p.785-788, 1992.

MISHRA, U.N. Use of phosphogypsum in reclamation of sodic soils in India. In: INTERNATIONAL SYMPOSIUM ON PHOSPHOGYPSUM, Battow, 1980. Proceedings. Battow: Institute of Phosphate Research, 1980. p.223-241.

MILLER, E.R.; LEI, X.; ULLREY, D.E. Trace elements in animal nutrition. In: MORTVEDT, J.J.; COX, F.R.; SHUMAN, L.M.; WELCH, R.M. (Ed.) Micronutrients in Agriculture. 2.ed. Madison: Soil Science Society of America, 1991. cap.16, p.593-662.

MIYAZAWA, M.; CHIERICE, G.D.; PAVAN, M.A. Determinação indireta de alumínio no solo com eletrodo seletivo de fluoreto. Revista Brasileira de Ciência do Solo, v.16, n.1, p.133-138, 1992a.

MIYAZAWA, M.; CHIERICE, G.D.; PAVAN, M.A. Amenização da toxicidade de alumínio às raízes do trigo pela complexação com ácidos orgânicos. Revista Brasileira de Ciência do Solo, v.16, n.2, p.209-215, 1992 b.

MIYAZAWA, M.; PAVAN, M.A.; CALEGARI, A. Efeito de material vegetal na acidez do solo. Revista Brasileira de Ciência do Solo, v.17, n.3, p.411-416, 1993.

MOORE, C.S.; RITCHIE, G.S.P. Aluminum speciation and $\mathrm{pH}$ of an acid soil in the presence of fluoride. Journal of Soil Science, v.39, p.1-8, 1988.

MORAGHAN, J.T.; MASCAGNI Jr., H.J. Environmental and soil factors affecting micronutrient deficiencies and toxicities. In: MORTVEDT, J.J.; COX, F.R.; SHUMAN, L.M.; WELCH, R.M. (Ed.) Micronutrients in Agriculture. 2.ed. Madison: Soil Science Society of America, 1991. cap.11, p.371-425. 
MORSHINA, T.N.; FANASKOVA, T.P. Changes in soil properties caused by fluorine. Soviet Soil Science, v.17, n.1, p.74-79, 1985.

MUNNS, D.N.; HELYAR, K.R.; CONYERS, M. Determination of aluminium activity from measurements of fluoride in acid soil solutions. Journal of Soil Science, v.43, p.441-446, 1992.

MURRAY, F. Fluoride retention by sand soils. Water, Air and Soil Pollution, v.20, n.4, p.361-367, 1983.

NEEDHAM, P. The occurrence and treatment of mineral disorders in the field. In: ROBNSON, J.B.D. (Ed.) Diagnosis of mineral disorders in plants: Principles. v.1. London: Her Majesty's Stationery Office, 1983. cap.4, p.137-166.

NOEMMIK, H. Fluorine in Swedish agricultural products, soils and drinking water. Acta Polytechnica, v.127, p.1-121, 1953.

OATES, K.M.; CALDWELL, A.G. Use of by-product gypsum to alleviate soil acidity. Soil Science Society of America Journal, v.49, p.915-918, 1985.

O'BRIEN, L.O.; SUMNER, M.E. Effects of phosphogypsum on leachate and soil chemical composition. Communications in Soil Science and Plant Analysis, v.19, p.1319-1329, 1988.

OLSEN, S.R.; SOMMERS, L.E. Phosphorus. In: PAGE, A.L.; MILLER, R.H; KEENEY, D.R. (Ed.) Methods of soil analysis: Part 2 - Chemical and microbiological properties. Madison: Soil Science Society America, 1982. p.403-430, 1982.

OMUETTI, J.A.I.; JONES, R.L. Fluoride adsorption by Illinois soils. Journal of Soil Science, v.28, p.564-572,1977.

ORVEDAL, A.C.; ACKERSON, K.T. Agricultural soil resources of the world. Washington: USDA, Soil Conservation Service, 1972.

PAOLINELLI, M.T.; OLIVEIRA, P.M. de; SANTOS, P.R.R.S.; LEANDRO, V. de P.; MORAIS, W.W. de. Aplicação direta do fosfogesso. In: SEMINÁRIO SOBRE O USO DO FOSFOGESSO NA AGRICULTURA, 1., Brasília, 1986. Anais. Brasília: EMBRAPA-DDT, 1986. p.177-204.

PARFITT, R.L. Anion adsorption by soils and soils materials. Advances in Agronomy, v.30, p.1-50, 1978.

PARFITT, R.L. Chemical properties of variable charge soils. In: THENG, B.K.G. (Ed.) Soils with variable charge. New Zeland Society of Soil Science, 1980. p.167-194.

PARKER, D.R.; KINRAIDE, T.B.; ZELAZNY, L.W. Aluminum speciation and phytotoxicity in dilute hydroxy-aluminum solutions. Soil Science Society America Journal, v.52, p.438-444, 1988. 
PARKER, D.R.; NORVELL, W.A.; CHANEY, R.L. GEOCHEM-PC: a chemical speciation program for IBM and compatible personal computers. In: LOEPPERT, R.H.; SCHWAB, A.P.; GOLDBERG, S. (Eds.) Chemical equilibrum and reactions models. Madison: Soil Science Society of America, 1995. p.253-269. (Special Publication, 42).

PAVAN, M.A.; BINGHAM, F.T. Toxicity of aluminum to coffee seedlings grown in nutrient solution. Soil Science Society of America Journal, v. 46, p.993-997, 1982.

PEEK, D.C.; VOLK, V.V. Composition and speciation of sodium fluoride extracted soil solutions. Communications in Soil Science and Plant Analysis, v.17, n.7, p.741-756, 1986.

PERROTT, K.W.; SMITH, B.F.L.; INKSON, H.E. The reaction of fluoride with soils and soil minerals. Journal of Soil Science, v.27, p.58-67, 1976.

PETERS, R.; SHORTHOUSE, M. Fluoride metabolism in plants. Nature, v.202, n.4927, p.21-22, 1964.

PICKERING, W.F. The mobility of soluble fluoride in soils. Environmental Pollution, v.9, n.4, p.282-308, 1985.

RAIJ, B. van. Gesso agrícola na melhoria do ambiente radicular no subsolo. São Paulo: Associação Nacional para Difusão de Adubos e Corretivos, 1988. 88p.

RAIJ, B. van. Fertlidade do solo e adubação. Piracicaba: Ceres, Potafos, 1991. 343p.

RAIJ, B. van; QUAGGIO, J.A.; CANTARELLA, H.; FERREIRA, M.E.; LOPES, A.S.; BATAGLIA, O.C. Análise química do solo para fins de fertilidade. Campinas, Fundação Cargill, 1987. 170p.

RITCHIE, G.S.P. Soluble aluminium in acidic soils: Principles and practicalities. Plant and Soil, v.171, n.1, p.17-27, 1995.

RITCHIE, G.S.P.; NELSON, M.P.; WHITTEN, M.G. The estimation of free aluminium and the competition between fluoride and humate anions for aluminium. Communications in Soil Science and Plant Analysis, v.19, n.7-12, p.857-871, 1988.

RUTHERFORD, P.M.; DUDAS, M.J.; SAMEK, R.A. Environmental impacts of phosphogypsum. Science of the Total Environment, v.149, n.1-2, p.1-38, 1994.

SAEKI, K.; MATSUMOTO, S. Proton consumption and release of organic-carbon, silicate and sulfate by anion sorption on andosols. Communications in Soil Science and Plant Analysis, v.24, n.17-18, p.2375-2387, 1993.

SAHA, S.K.; SHANKER, J.; DE, S.K. Effect of salts of fluoride on the decomposition of organic matter (wheat straw) in soil. Journal of Environmental Biology, v.2, n.2, p.87-89, 1981. 
SANCHEZ, P.A.; SALINAS, J.G. Low-input technology for managing Oxisols and Ultisols in tropical America. Advances in Agronomy, v.34, p.280-406, 1981.

SCHUPPLI, P.A. Total fluorine in CSSC reference soil samples. Canadian Journal of Soil Science, v.65, n.3, p.605-607, 1985.

SERÉ, C.; ESTRADA, R.D. Potencial role of grain sorghum in the agricultural systems of regions with acid soils in tropical Latin America. In: GOURLEY, L.M.; SALINAS, J.G. (Eds) Sorghum for acid soils. Cali: INTSORMI, ICRISAT, CIAT, 1987. p. 145-169.

SHEPPARD, S.C.; EVENDEN, W.G. Response of some vegetable crops to soil-applied halides. Canadian Journal of Soil Science, v.72, n.4, p.555-567, 1992.

SHORTLAND, J.W. Fluorine. In: McKENZIE, H.A.; SMYTHE, L.E. (Eds) Quantitative trace analysis of biological materials: principles and methods for determination of trace elements and trace amounts of some macroelements. Amsterdan: Elsevier Science Publishers, 1988. Cap.29, p.503-517.

SIKORA, F.J.; COPELAND, J.P.; DILLARD, E.F.; BURNELL, J.R. Corn growth as affected by suspension fertilizers containing fluorosilic acid. Soil Science Society of America Journal, v.56, n.3, p.961-966, 1992.

SIMARD, R.R.; LAFRANCE, P. Fluoride sorption and desorption indices in Quebec soils. Communications in Soil Science and Plant Analysis, v.27, n.3-4, p.853-866, 1996.

SILVA FILHO, N.L. Recomposição da cobertura vegetal de um trecho degradado da Serra do Mar, Cubatão, SP. Campinas: Fundação Cargill, 1988. 53p.

SINGH, A.; CHHABRA, R; ABROL, I.P. Effect of fluorine and phosphorus on the yield and chemical composition of rice (Oryza sativa) grown in soils of two sodicities. Soil Science, v.127, n.2, p.86-93, 1979a.

SINGH, A.; CHHABRA, R.; ABROL, I.P. Effect of fluorine and phosphorus applied to a sodic soil on their availability and on yield and chemical composition of wheat. Soil Science, v. 128, n.2, p.90-97, 1979 b.

SINGH, S. Effect of chloride and sulfate anions on the chemical characteristics of some acid soils. Canadian Journal of Soil Science, v.62, n.4, p.549-557, 1982.

SIZOV, A.P.; TYUNYAEVA, G.N.; LUNEV, M.I. Effect of increasing doses of fertilizers on the accumulation of nitrates and fluorine in the green matter of maize. Agrokhimiya, n.5, p.63-68, 1992.

SOUZA, D.M.G.; RITCHEY, E.D. Uso do gesso no solo de cerrado. In: SEMINÁRIO SOBRE O USO DO FOSFOGESSO NA AGRICULTURA, 1., Brasília, 1986. Anais. EMBRAPA-DDT, Brasilia, 1986. p.119-144. 
SPENCER, H.; KRAMER, L. Calcium, phosphorus and fluoride. In: SMITH, K.T. (Ed.) Trace minerals in foods. New York: Marcel Decker, 1988. p.95-115.

SPOSITO, G. The Chemistry of Soils. New York: Oxford University Press, 1989. $277 \mathrm{p}$.

STATISTICAL ANALYSIS SYSTEM INSTITUTE. SAS / STAT User's Guide. Release 6.11. Cary: SAS Institute, 1996.

SUMNER, M. Gypsum and acid soils: the world scene. Advances in Agronomy, v.51, p.1-32, 1993.

TAKMAZ-NISANCIOGLU, S.; DAVISON, A.W. Effects of aluminium on fluoride uptake by plants. New Phytologist, v.109, n.2, p.149-155, 1988.

TAN, K.; KELTJENS, W.G. Analysis of acid-soil stress in sorghum genotypes with emphasis on aluminium and magnesium interactions. Plant and Soil, v.171, n.1, p.147150, 1995.

TAN, K.H. Principles of soil chemistry. 2.ed. New York: Marcel Decker, 1993. 362p.

TANDON, H.L.S. Fluoride-extractable aluminum in soils: I. its relation to fluorideextractable phosphorus. Soil Science, v.108, p.397-401, 1969.

TRESHOW, M. Fluorides as air pollutants affeting plants. Annual Review of Phytopatology, v.9, p.21-44, 1971.

TRESHOW, M.; HARNER, F.M. Growth responses of Pinto bean and alfafa to sublethal fluoride concentrations. Canadian Journal of Botany, v.46, p.1207-1210, 1968.

VENKATESWARLU, P.; ARMSTRONG, W.P.; SINGER, L. Absortion on fluoride and chloride by barley roots. Plant Physiology, v.40, p.255-261, 1965.

VETTORI, L. Métodos de Análise de Solo. Rio de Janeiro: EPE - Ministério da Agricultura, 1969. 24p. (Boletim Técnico, 7).

WEINSTEIN, L.H. Fluoride and plant life. Journal of Occupational Medicine, v.19, n.1, p.49-78, 1977.

WENZEL, W.W.; BLUM, W.E.H. Fluorine speciation and mobility in Fcontaminated soils. Soil Science, v.153, n.5, p.357-364, 1992a.

WENZEL, W.W.; BLUM, W.E.H. Effects of fluorine deposition on the chemistry of acid luvisols. International Journal of Environmental Analytical Chemistry, v.46, n. 1-3, p.223-231, $1992 \mathrm{~b}$. 
WHITTEN, M.G.; RTTCHIE, G.S.P. Soil tests for aluminium toxicity in the presence of organic matter: laboratory development and assessment. Communications in Soil Science and Plant Analysis, v.22, n.3-4, p.343-368, 1991.

WRIGHT, D.A.; THOMPSON, A. Retention of fluoride from diets containing minerals produced during aluminium smelting. British Journal of Nutrition, v.40, p.139-146, 1978.

WRIGHT, R.J. Soil aluminum toxicity and plant growth. Communications in Soil Science and Plant Analysis, v.20, n.15-16, p.1479-1497, 1989.

YUAN, T.L.; FISKELL, J.G.A. II. The extraction of aluminum from some Florida soils. Soil Science Society America Proceedings, v.23, p.202-205, 1959. 